\title{
ELECTRON DRIVEN CHEMISTRY IN MICROREACTORS
}

Anıl Ağıral 
Promotion committee

Prof. dr. ing. M. Wessling, chairman

Prof. dr. ir. J. G. E. (Han) Gardeniers, promoter

Prof. dr. ir. L. Lefferts

Prof. dr. ir. J. A. M. Kuipers

Prof. dr. ir. M. C. M. van de Sanden

Dr. K. Seshan

Dr. T. Nozaki
University of Twente, The Netherlands

University of Twente, The Netherlands

University of Twente, The Netherlands

University of Twente, The Netherlands

Eindhoven University of Technology, The Netherlands

University of Twente, The Netherlands

Tokyo Institute of Technology, Japan

Title: Electron driven chemistry in microreactors

Author: Anıl Ağıral

ISBN: 978-90-365-2916-7

This research is supported by the Technology Foundation STW, applied science division of NWO and the technology program of the Ministry of Economic Affairs, The Netherlands, project number 06626.

Cover picture: EIELSON AIR FORCE BASE, Alaska -- The Aurora Borealis, or Northern Lights, shines above beautifully Bear Lake here Jan. 18. The lights are the result of solar plasma particles colliding with oxygen in Earth's atmosphere. Early Eskimos and Indians believed different legends about the Northern Lights, such as they were the souls of animals dancing in the sky or the souls of fallen enemies trying to rise again. (U.S. Air Force photo by Senior Airman Joshua Strang)

Publisher: Gildeprint, Enschede, The Netherlands.

Portions of this work, such as excerpted text and images from journal publications, are copyrighted by the American Chemical Society, Wiley Interscience, IEEE Nuclear and Plasma Sciences Society, Elsevier and Wiley $\mathrm{VCH}$, and are used with permission.

For the remainder of this work, I the copyright holder of this work, hereby release it into the public domain. For jurisdictions where this is not legally possible, I grant anyone the right to use this work for any purpose, without any conditions, unless such conditions are required by law. 


\title{
ELECTRON DRIVEN CHEMISTRY IN MICROREACTORS
}

\author{
DISSERTATION
}

to obtain

the degree of doctor at the University of Twente, on the authority of the rector magnificus, prof. dr. H. Brinksma,

on account of the decision of the graduation committee, to be publicly defended

on Friday the 6th of November 2009 at 16:45

by

\author{
Anıl Ağıral \\ born on the $8^{\text {th }}$ of December 1980 \\ in Ordu, Turkey
}


This dissertation has been approved by the promoter Prof. dr. ir. J. G. E. (Han) Gardeniers 


\section{CONTENTS}

\section{CHAPTER 1}

Electron driven chemistry in microreactors: Microplasma reactors

$\begin{array}{ll}\text { ABSTRACT } & \mathbf{1} \\ \text { Microplasma reactors } & \mathbf{2} \\ \text { Atmospheric pressure microplasma } & \mathbf{2} \\ \text { DC glow discharges } & \mathbf{3} \\ \text { Dielectric barrier discharges } & \mathbf{4} \\ \text { Microhollow cathode discharges } & \mathbf{5} \\ \text { Microcavity discharges } & \mathbf{6} \\ \text { Applications of microplasma reaction technology } & \mathbf{7} \\ \text { Nanostructure synthesis in microplasma reactors } & \mathbf{7} \\ \text { Environmental applications with microplasma reactors } & \mathbf{1 2} \\ \text { Chemical synthesis in microplasma reactors } & \mathbf{1 5} \\ \text { References } & \mathbf{2 2}\end{array}$

\section{CHAPTER 2}

Propane conversion at ambient temperatures $\mathrm{C}-\mathrm{C}$ and $\mathrm{C}-\mathrm{H}$ bond activation using cold plasma in a microreactor

ABSTRACT 27

Introduction 28

Experimental 29

Plasma microreactor 29

Propane activation/conversion in plasma microreactors 31

Kinetic modeling 31

Results 32

Propane conversion in the presence of plasma in the microreactor 32

Discussion 39

Conlusion 42

References 44 


\section{CHAPTER 3}

Oxidative conversion of propane in a microreactor in the presence of plasma over $\mathrm{MgO}$ based catalysts - An experimental study

\begin{tabular}{ll} 
ABSTRACT & 47 \\
\hline Introduction & 48 \\
Experimental & $\mathbf{5 0}$ \\
Microplasma reactor & $\mathbf{5 0}$ \\
Catalyst deposition in the microchannels & $\mathbf{5 1}$ \\
Catalyst characterization & $\mathbf{5 2}$ \\
Catalytic tests & $\mathbf{5 2}$ \\
Results & $\mathbf{5 3}$ \\
$\quad$ Catalyst characterization & $\mathbf{5 3}$ \\
$\quad$ Propane conversion in the presence of plasma & $\mathbf{5 4}$ \\
$\quad$ Microreactor without catalyst & $\mathbf{5 4}$ \\
Discussion & $\mathbf{5 7}$ \\
Conclusion & $\mathbf{5 9}$ \\
References & $\mathbf{6 4}$
\end{tabular}

\section{CHAPTER 4}

Plasma catalytic oxi-cracking of hexane for olefin synthesis at atmospheric pressure

\section{ABSTRACT}

Experimental

Results and discussion

Plasma conversion of hexane without catalyst

Effect of temperature

Effect of $\mathrm{O}_{2} / \mathrm{C}_{6}$ on hexane and oxygen conversion 75

Effect of helium flow rate on hexane conversion 77

Plasma enhanced catalytic process 


\section{CHAPTER 5}

Direct methane conversion to liquid oxygenates using a multi-phase flow, non-thermal plasma microreactor

\begin{tabular}{ll} 
ABSTRACT & 87 \\
\hline Introduction & 88 \\
Experimental & 88 \\
Results and discussion & 91 \\
\multicolumn{1}{c}{ Effect of pulsed injection of liquid water } & 91 \\
\multicolumn{1}{|}{$\mathrm{H}_{2} \mathrm{O}_{2}$ as a reaction promoter: synergy between $\mathrm{H}_{2} \mathrm{O}_{2}$ and $\mathrm{O}_{2}$} & 93 \\
Conclusion & 96 \\
References & 98
\end{tabular}

\section{CHAPTER 6}

Microplasma activation of catalyst for CNF synthesis in a microreactor

\begin{tabular}{lc} 
ABSTRACT & $\mathbf{9 9}$ \\
\hline Introduction & $\mathbf{1 0 0}$ \\
Experimental & $\mathbf{1 0 1}$ \\
$\quad$ In-situ CVD of CNFs synthesis & $\mathbf{1 0 1}$ \\
$\quad$ Catalyst activation with microplasma & $\mathbf{1 0 3}$ \\
Results and discussion & $\mathbf{1 0 5}$ \\
$\quad$ In-situ CVD of carbon nanofibers in a microreactor & $\mathbf{1 0 5}$ \\
$\quad$ Carbon nanofiber synthesis on a catalyst activated by a microplasma & \\
$\quad$ in a microreactor & $\mathbf{1 1 1}$ \\
$\quad$ Discharge characteristics & $\mathbf{1 1 1}$ \\
$\quad$ Catalyst characterization and CNFs synthesis & $\mathbf{1 1 4}$ \\
Conlusion & $\mathbf{1 1 9}$ \\
References & $\mathbf{1 2 0}$
\end{tabular}

\section{CHAPTER 7}

Charge injection from nanostructures at atmospheric pressure and on-chip microplasma reactors with integrated nanoelectrodes 
$\begin{array}{ll}\text { Experimental } & 125\end{array}$

Synthesis of tungsten oxide nanorods and field emission measurements $\quad \mathbf{1 2 5}$

Incorporation of nanostructures into microplasma reactor $\quad \mathbf{1 2 6}$

$\begin{array}{ll}\text { Results and discussion } & 128\end{array}$

Synthesis and atmospheric pressure field emission operation of $\mathrm{W}_{18} \mathrm{O}_{49}$ nanorods 128

Synthesis and characterization of $\mathrm{W}_{18} \mathrm{O}_{49}$ nanorods $\quad \mathbf{1 2 8}$

$\begin{array}{ll}\text { Atmospheric pressure field emission measurements } & \mathbf{1 3 3}\end{array}$

On-chip microplasma reactors using carbon nanofibers and tungsten oxide nanorods as electrodes

Tungsten oxide nanorods as microplasma electrodes at atmospheric pressure in air

$\mathrm{CO}_{2}$ consumption in the microplasma reactor with CNFs as electrodes at $\begin{array}{ll}\text { atmospheric pressure } & \mathbf{1 4 1}\end{array}$

$\begin{array}{ll}\text { Conclusions } & 144\end{array}$

$\begin{array}{lr}\text { References } & 145\end{array}$

\section{CHAPTER 8}

Outlook and general recommendations

\section{List of publications}

\section{Acknowledgments}

\section{Curriculum Vitae}




\section{Summary}

This thesis describes the development of novel process windows by the combination of atmospheric pressure plasmas with microreaction technology. In the first chapter, recent literature on microreactor technology and non-equilibirum microplasma chemistry is discussed. The focus is on microplasmas in confined microchannels for the purpose of chemical synthesis and environmental applications.

In the second chapter, study of oxidative conversion of propane using dielectric barrier discharge in a microreactor is described. This generates a cold microplasma at atmospheric pressure and ambient temperature. Surprisingly, large amounts of products with molecular weight higher than propane, such as, $\mathrm{C}_{4}$ and $\mathrm{C}_{4}+$ were mainly observed due to $\mathrm{C}-\mathrm{C}$ bond formation, in contrast to what is usually observed for this reaction when it is carried out under thermal activation, which leads to cracking products. A chemical kinetic model was developed to better understand the radical reaction network. The results suggest that (i) at lower level of propane conversion the model can nicely predict the experimental results, and (ii) depending on the radical density the product selectivity can be tailored. In particular at higher radical density enhanced C-C bond formation was observed.

In the third chapter, oxidative cracking of propane is described in a plasma catalytic microreactor. A dielectric barrier discharge allows one to generate cold microplasma, which activates the formation of radicals from propane, at room temperature and atmospheric pressure. Homogeneous and crystalline $25 \mu \mathrm{m}$ thick layers of $\mathrm{MgO}$ and $\mathrm{Li} / \mathrm{MgO}$ catalysts were deposited in the microchannel using a sol-gel method and by micropipette. The $\mathrm{Li} / \mathrm{MgO}$ catalyst showed higher propane conversion and olefin selectivity than $\mathrm{MgO}$, which suggests that (i) radicals formed by $\mathrm{DBD}$ are differently terminated depending on the catalyst surface; (ii) the surface of $\mathrm{Li} / \mathrm{MgO}$ catalyst presents more selective sites than $\mathrm{MgO}$, such as $\left[\mathrm{Li}^{+} \mathrm{O}^{-}\right]$centers and F-type defects which are generated and able to react at RT. Large amounts of products like $\mathrm{C} 4, \mathrm{C} 4+$, with a higher molecular weight than the starting gas propane, were observed due to $\mathrm{C}-\mathrm{C}$ bond formation.

In the fourth chapter, development of a plasma catalytic reactor based on a dielectric barrier discharge for oxidative cracking of hexane with $\mathrm{Li} / \mathrm{MgO}$ based catalysts is reported. The effect of temperature, oxygen concentration, helium flow, and $\mathrm{MgO}$ support, and the role of $\mathrm{Li} / \mathrm{MgO}$ catalysts on the conversion of hexane, and on the selectivity and yield of olefin formation are described. 
In the fifth chapter, direct synthesis of liquid oxygenates from partial oxidation of methane is demonstrated in a multi-phase flow, non-equilibrium plasma microreactor near $0^{\circ} \mathrm{C}$ at atmospheric pressure. A method for liquid-water injection into the microreactor was introduced in order to remove incomplete oxidation products such as methanol, which prevents further oxidation with excited species originating from the microplasma. Unlike in the conventional methane oxidation at high-temperature, in the microplasma reactor at low-temperature a significant amount of hydrogen peroxide $\left(\mathrm{H}_{2} \mathrm{O}_{2}\right)$ was produced, which accelerates the rate-determining step in methane partial oxidation: hydroxyl radicals $(\mathrm{OH})$ derived from $\mathrm{H}_{2} \mathrm{O}_{2}$ efficiently abstract hydrogen from methane. As a result of the synergistic oxidizing effects of $\mathrm{H}_{2} \mathrm{O}_{2}$ and $\mathrm{O}_{2}$, a one-pass yield of liquid oxygenates of $10 \%$ was demonstrated.

In the sixth chapter, development of an in-situ CVD method for the growth of CNFs on $\mathrm{Ni} /$ alumina and nickel thin film catalyst coated inside a closed channel fused silica microreactor is described. By directly flowing reactant gases over a catalytic coating inside the capillaries, a mechanically stable and porous CNF-alumina composite was formed with high surface area $\left(160 \mathrm{~m}^{2} / \mathrm{g}\right)$. Effects of growth time, growth temperature and $\mathrm{H}_{2}$ addition during pretreatment and deposition steps on the composite thickness and nanofibers diameter were investigated. Hydrogen addition increases the deposition rate and helps in producing a mechanically stable support in the capillary. In the second part of this chapter, a method for microplasma activation of catalyst for CNFs synthesis in the microreactor will be described. A dielectric barrier discharge is generated by flowing helium and hydrogen through a microreactor capillary which contains the coating of Ni-alumina catalyst to activate carbon nanofiber (CNF) synthesis. Cold plasma operation for $15 \mathrm{~min}$ is simple and audio-visual and increases the CNF yield significantly compared to non-activated samples and can compete with a high temperature treatment at $973 \mathrm{~K}$ for $2 \mathrm{~h}$.

In the seventh chapter, synthesis, characterization and atmospheric pressure field emission operation of tungsten oxide $\mathrm{W}_{18} \mathrm{O}_{49}$ nanorods is discussed. Nanorods with diameters of 15-20 nm were grown on tungsten thin films exposed to ethene and nitrogen at $700^{\circ} \mathrm{C}$ at atmospheric pressure. Atmospheric pressure field emission measurements in air showed a turn-on field of $3.3 \mathrm{~V} / \mu \mathrm{m}$, and a stable and reproducible emission current density of $28 \mathrm{~mA} / \mathrm{cm}^{2}$. Carbon nanofibers (CNFs) and tungsten oxide nanorods have been incorporated in a continuous flow microplasma reactor to increase the reactivity and efficiency of the barrier discharge at atmospheric 
pressure. Field emission of electrons from the nanostructures supplies free electrons and ions during microplasma production. In comparison with planar electrodes in air at the same applied voltage, for the nanostructured electrodes a reduction in breakdown voltage, a higher number of microdischarges and a higher energy deposition were observed. It was also shown that compared to planar electrodes, $\mathrm{CO}_{2}$ consumption increased with CNFs in the microplasma reactor.

In the last chapter, outlook and general recommendations are given for future strategies. 


\section{Chapter 1}

\section{Electron driven chemistry in microreactors: Microplasma reactors}

Novel applications have been developed from the combination of microreactor technology and non-equilibrium microplasma chemistry. Here we discuss a selection from the recent literature on this topic to illustrate several main trends. We will focus on microplasmas in confined microchannels for the purpose of chemical synthesis and environmental applications.

This chapter will be published as book chapter in:

Microreactors with electrical fields, ANIL AGIRAL, J. G. E. (HAN) GARDENIERS, will appear in "Micro Systems and Devices for (Bio)chemical Processes" in the Elsevier series of Advances in Chemical Engineering, July 2009. 


\section{Microplasma reactors:}

\section{Atmospheric pressure microplasmas:}

The plasma state is referred to as the fourth state of matter. It is used to describe a partially or completely ionized gas consisting of positive and negative ions, electrons, excited and neutral species. The ionization degree of plasma can vary from partially ionized to fully ionized. Plasma exhibits quasi-neutrality which is referred to as a balance of positive and negative charges. Local charges can be balanced by electrostatic forces which restore the quasi-neutrality. Plasmas are classified by the number density [particles $/ \mathrm{cm}^{3}$ ] and average kinetic energy $[\mathrm{eV}]$, mostly expressed in terms of temperature $[\mathrm{K}]$, of the different charged species. The average kinetic energy of electrons, ions, excited and neutral species depends on the plasma conditions. In equilibrium or thermal plasmas, all constituents (ions, electrons and neutrals) have the same average temperature, which can vary from a few thousand Kelvin (e.g. in plasma torches) to a few million Kelvin (in fusion plasmas). In a non-thermal low-temperature plasma, the temperature of the ions and neutral species can be close to ambient temperature, while in that same plasma the temperature of the electrons can exceed several thousand Kelvin. The temperature of plasma components (e.g. electrons and species in an excited state) can exceed the temperatures applied in conventional thermal chemical processes and these exceptional conditions of the plasma can generate a thermodynamic non-equilibrium state with a high concentration of energetic and reactive species [1-3].

Atmospheric-pressure non-thermal discharges may become of great importance for chemical industry because they create a highly reactive environment at cold temperatures and therewith open up alternative, highly flexible, environmentally friendly and energy saving processing routes. Characteristics and properties of non-equilibrium atmospheric pressure plasmas can be found in many review articles and books for further details [1-8].

Atmospheric pressure plasmas, just like most other plasmas, are generated by a high electric field in a gas volume. The few free electrons which are always present in the gas, due to e.g. cosmic radiation or radioactive decay of certain isotopes, will, after a critical electric field strength has been exceeded, develop an avalanche with ionization and excitation of species. Energy gained by the hot electrons is efficiently transferred and used in the excitation and dissociation of gas molecules. In a non-equilibrium atmospheric pressure plasma, collisions and radiative processes are dominated by energy transfer by 
step-wise processes and three-body collisions. The dominance of these processes has allowed many novel applications, e.g. in medical sterilization, biological decontamination, remediation of pollutants, excimer lamps and light sources [6]. However, high pressure plasmas have a tendency to become unstable due to the rapid transition to arcs and filamentation. To avoid instability problems and maintain a self-sustaining discharge for practical applications, a solution was found in the confinement of the high pressure plasma to dimensions below about $1 \mathrm{~mm}$. Such a plasma is often referred to as a "microplasma". The current and energy densities in this type of plasma is found to be high and results in effective gas heating and momentum transfer from electrons to gas molecules.

Chemistry in reactors with dimensions below $1 \mathrm{~mm}$ leads us into the field of microreactor technology. Implementation of microplasmas in microreactors offers the potential to exploit the advantages of atmospheric pressure non-equilibrium chemical processes for efficient synthesis of valuable chemicals and nanostructures as well as the decomposition of hazardous compounds. As mentioned before, microplasmas can be generated at low gas temperatures and possess an electron energy distribution containing large fractions of high-energy electrons, and reactive species deriving from these electrons. In addition, the increased surface area-to-volume ratio in microreactor channels leads to enhanced plasma-surface interactions, which is very useful in cases where active coatings are present on the channel walls. The combination of the reactive species and the additional plasma activation of the surface may be exploited to produce chemical products in an energy efficient manner.

A number of configurations of microplasma reactors will be described here. Classification will be based on the power sources, the electric field switching frequency ranging from $\mathrm{DC}$ to $\mathrm{GHz}$, and electrode geometries and materials, extending from dielectric barrier discharges to micro hollow cathodes and microcavity discharges.

\section{DC glow discharges}

Atmospheric pressure DC glow discharges can be generated between two electrodes when the current through the discharge is limited to low values by a large resistor [9]. The microplasma can be stabilized when the electrode separation is kept below $1 \mathrm{~mm}$ and the transition to an unstable arc discharge can be avoided when the spatial dimensions of the discharge are kept small enough [10]. Fig. 1 shows a picture of such a discharge in air. Spectroscopic temperature measurements show that the 
discharge is non-thermal with a gas temperature above room temperature. The nonequilibrium nature of glow discharges for small dimensions may find applications in microreactors for gas reforming, material deposition and the destruction of environmentally harmful substances.
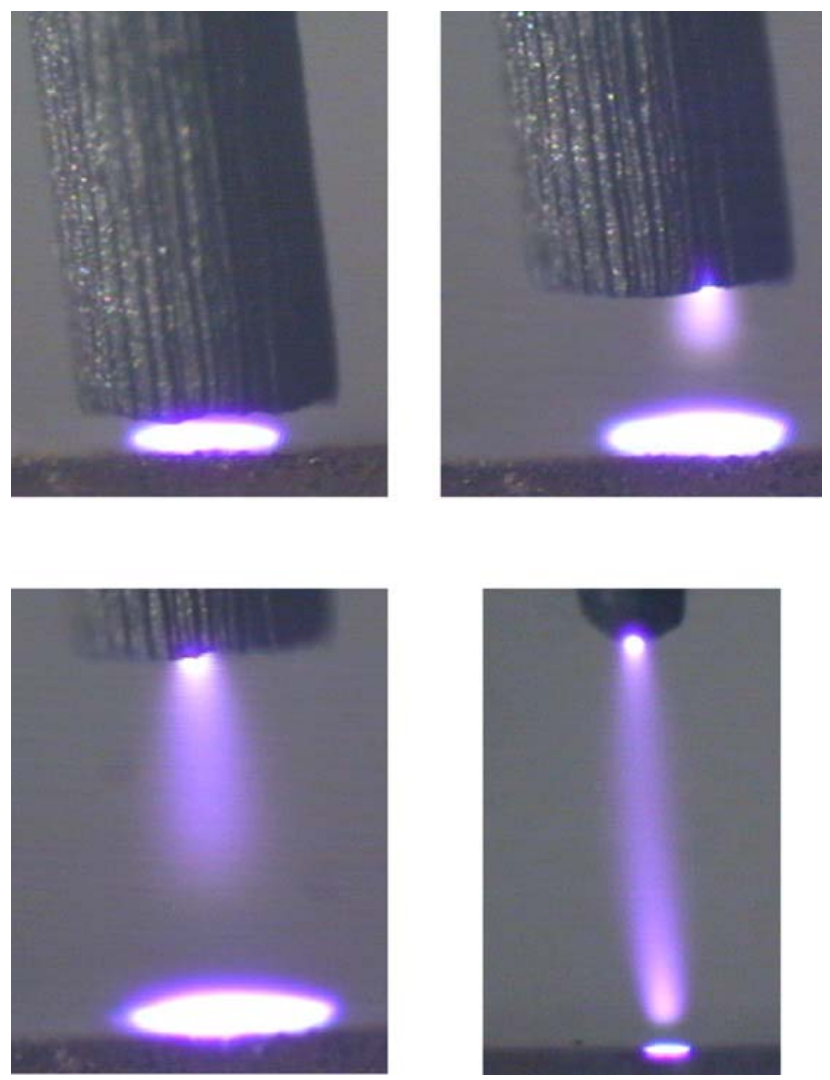

Figure 1. Glow discharges at atmospheric pressure in air at (a) $0.1 \mathrm{~mm}$, (b) $0.5 \mathrm{~mm}$, (c) 1 $\mathrm{mm}$ and (d) $3 \mathrm{~mm}$ electrode spacing [10].

\section{Dielectric barrier discharges}

Dielectric barrier discharges (DBDs) are non-equilibrium plasmas at atmospheric pressure with applications in ozone generation, surface modification, pollution control, excimer lamps, and recently also in flat plasma display panels [11]. Typical planar DBD configurations are shown in Fig. 2. They have at least one dielectric layer, being an insulator, between electrode and plasma, to prevent arc formation. Dielectric barriers can be glass, ceramic or polymer coatings. In a DBD configuration, the plasma has a capacitive nature and consists of a large number of microdischarges in the gap between the insulator and the opposite (often uncovered) electrode, where the duration of the 
filamentary microdischarges is limited to a few nanoseconds. In this way, excess gas heating is minimized, although activation of molecules and atoms in the gas volume is ensured by high-energy electrons created in the microdischarges. The incorporation of a DBD in a microreactor as a miniature source of ions, excited species and radicals can generate a highly reactive and quenching environment which is difficult to obtain in thermochemical processes.
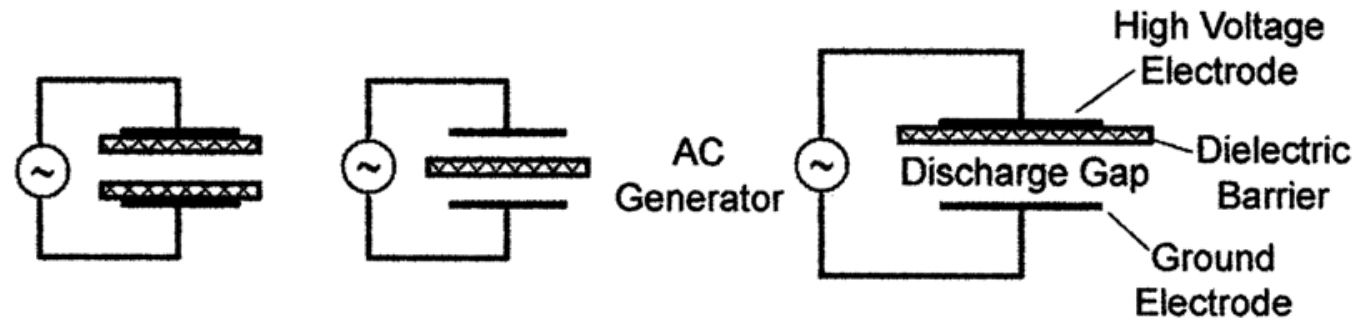

Figure 2. Dielectric barrier discharge configurations [11].

\section{Micro hollow Cathode Discharges}

Micro hollow cathode discharges (MHCDs) were first reported as stable atmospheric pressure microdischarges in cylindrical hollow cathode geometry [12]. In a typical hollow cathode structure, there is a cylindrical hole in the cathode, with a ringshaped anode separated by an insulator (Fig. 3a), or a cylindrical opening in a thin solid cathode layer (Fig. 3b) [13]. Because of the relatively simple fabrication process of these electrode configurations, manufacturing of large area arrays of microplasma devices with parallel operation becomes feasible. Flowing gas through the plasma volume inside the hollow part allows the use of these discharges as microreactors. It is also possible to apply a third electrode placed at the anode side to achieve a stable glow discharge with dimensions of up to centimeters in atmospheric pressure [14]. Micro hollow cathode discharges can be operated at atmospheric pressure in direct current or pulsed mode with electron densities exceeding those in other non-equilibrium high-pressure glow discharges. Extreme power densities (on the order of $10^{5} \mathrm{~W} / \mathrm{cm}^{3}$ ) make these microdischarges very attractive in microreactors for the efficient decomposition of molecules such as hydrocarbons and ammonia. 


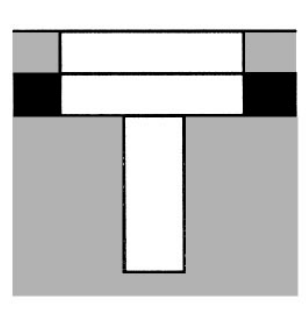

(a)

\section{Anode Dielectric} Cathode

(b)

Figure 3. Electrode geometries for micro hollow cathode discharges [12].

\section{Microcavity discharges}

Microcavity plasma devices have cavities with precisely controlled cross-sections. Large arrays of these devices have been fabricated in different materials such as ceramics [15], photodefinable glass [16], alumina structures [17] and plastic substrates [18]. An example with inverted square pyramid microcavities fabricated in silicon is represented in Fig. 4. Physical and chemical isolation between the electrodes and the discharge is
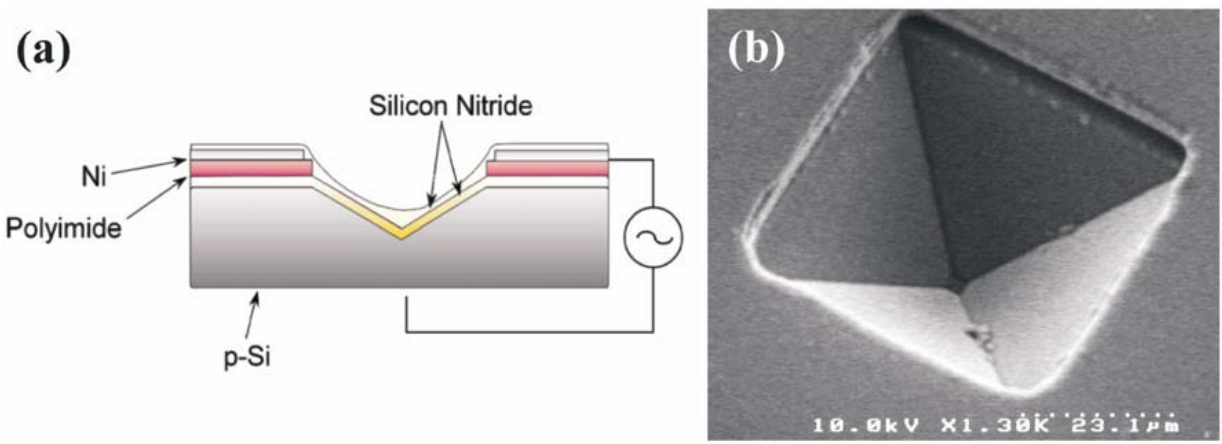

Figure 4. (a) Cross-sectional diagram of a silicon based microcavity discharge device with an inverted square pyramid microcavity and (b) An SEM (Scanning Electron Microscopy) image of a single microplasma device with $50 \times 50 \mu \mathrm{m}^{2}$ emitting aperture [8].

maintained by the dielectric. The advantage of using silicon as the host material in these microplasma devices is the wide range of microfabrication techniques which are available for this material, which allows production of large arrays of microcavity discharge devices at reasonable expense. As an application example, parallel linear arrays of 
interconnected cylindrical microcavity plasma elements integrated in microreactors, based on disposable plastic substrates, have been demonstrated [18].

\section{Applications of microplasma reaction technology}

In this part, we will focus on microplasma reaction technology in confined microchannels for the purpose of chemical synthesis and environmental applications in recent literature including our publications from this thesis to give the reader overview about the new developments.

\section{Nanostructure synthesis in microplasma reactors:}

Synthesis of nanostructures using microplasma reactors is an attractive method since decomposition of the source material and subsequent crystal nucleation can be performed in the high density non-equilibrium plasma within time intervals on the order of milliseconds. For example, Giapis et al. [19] synthesized silicon nanoparticles, 1-3 nm in diameter, from a mixture of argon/silane in a continuous flow atmospheric pressure microplasma reactor. Their technique is based on high pressure microdischarges with very short operation time ( $\mu$ s-ms). Microdischarges were created in a hollow cathode, which consists of a stainless steel capillary tube with $180 \mu \mathrm{m}$ ID (Inner Diameter) and extended towards an anode, a metal tube with $1 \mathrm{~mm}$ ID, as shown in Fig. 5.

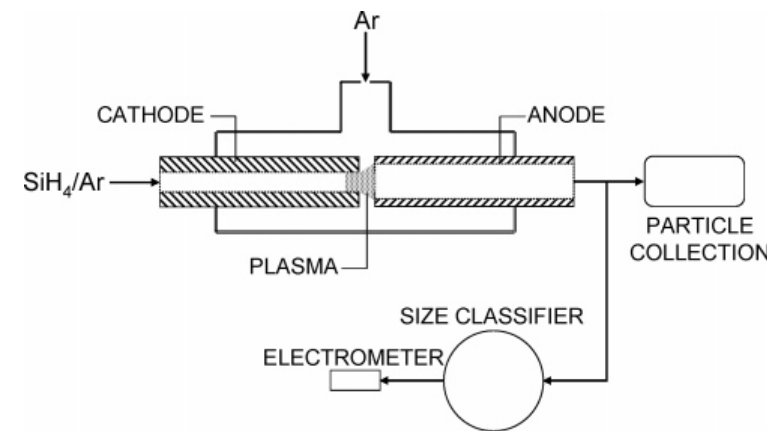

Figure 5. Schematic diagram of microplasma reactor for the synthesis of silicon nanoparticles. A microdischarge forms at the cathode tip and extends a short distance towards the anode [19].

Using a direct current microplasma which was sustained at $300-500 \mathrm{~V}$ and 3-10 $\mathrm{mA}$, silicon nanoparticles were produced as an aerosol around atmospheric pressure. Since this microreactor operates at low powers $(5-10 \mathrm{~W})$ in plasma volumes less than 1 
$\mu \mathrm{L}$, resulting power densities were as high as $10 \mathrm{~kW} / \mathrm{cm}^{3}$. Such a high density plasma allows fast plasma processing for the synthesis of blue luminescent silicon nanoparticles. The high density of energetic electrons in the microdischarges efficiently decomposed the gaseous precursor to produce radicals in the reaction zone. At a radical concentration high enough for nucleation, nanoparticles can start to grow in the microplasma. When the particles are removed by the gas flow from the discharge zone to a zone with a low concentration of radicals, particle growth will stop. An additional feature of the system is that particle charging in the microplasma reduces coagulation downstream of the reaction zone. Using the same direct current microplasma technique, $\mathrm{Fe}$ and $\mathrm{Ni}$ catalyst particles were synthesized in a controlled way at atmospheric pressure and used for gas-phase growth of carbon nanotubes (CNTs) $[20,21]$. The catalyst particles were prepared from ferrocene and nickelocene, respectively. In summary, this simple and inexpensive microreaction technique can be used to synthesize nanoparticles in a continuous flow from the decomposition of gaseous precursors.

Nozaki et al. [22, 23] developed an atmospheric pressure microplasma reactor for the fabrication of tunable photoluminescent silicon nanocrystals $(3-15 \mathrm{~nm})$. They generated a capacitively coupled non-equilibrium plasma in a capillary glass tube with a volume of less than $1 \mu \mathrm{L}$ and a residence time around $100 \mu$ s and used it to decompose silicon tetrachloride

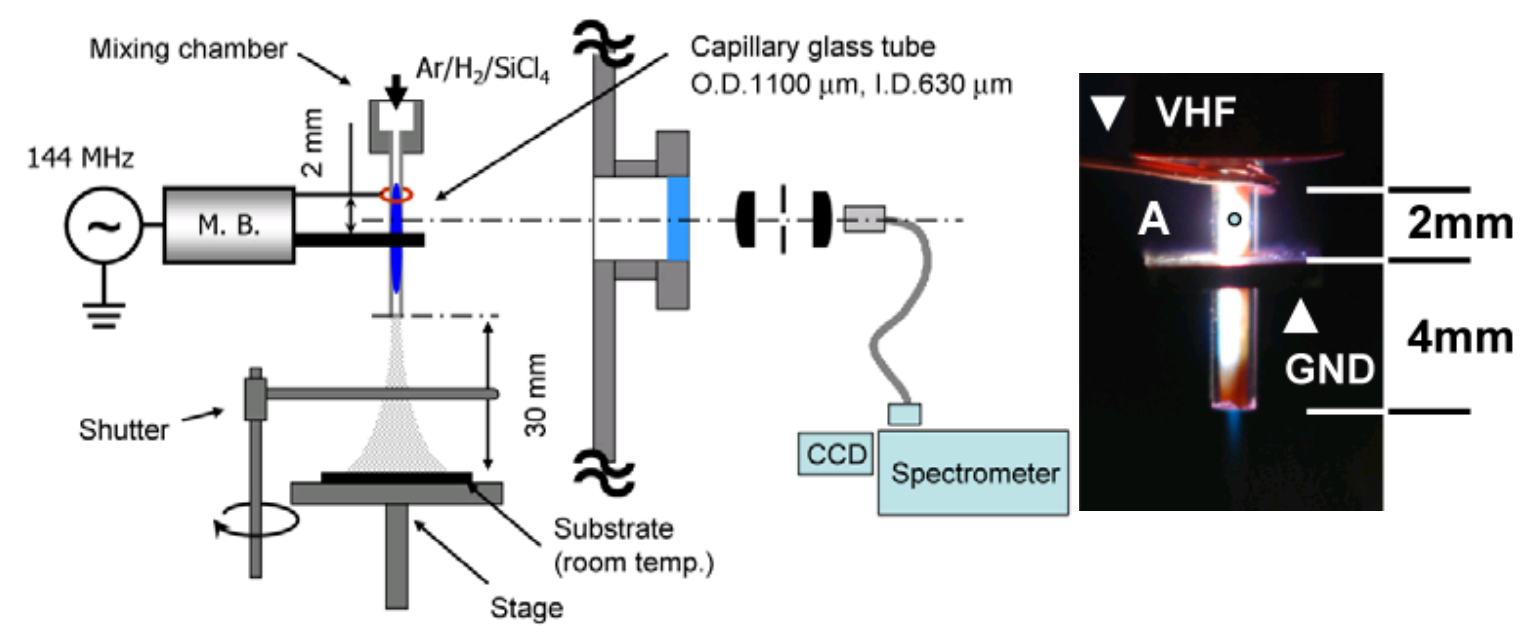

Figure 6. Schematic diagram of experimental setup and image of microplasma reactor with VHF source developed for the synthesis of photoluminescent silicon nanocrystals at room temperature [22].

into atomic silicon. In the reactor a mixture of argon, hydrogen and silicon tetrachloride was activated using a very-high-frequency power source (VHF, $144 \mathrm{MHz}$ ). A schematic 
diagram of the experimental setup and an image of the microplasma reactor are shown in Fig. 6. The upper electrode is connected to the VHF source (35 W discharge power) through a matching circuit and metallic electrodes with a $2 \mathrm{~mm}$ gap between them are around the outside of the capillary tube (borosilicate glass: ID $630 \mu \mathrm{m}$, OD $1100 \mu \mathrm{m}$ ).

Optical emission spectroscopic characterization of the microplasma indicated an electron density of $10^{15} \mathrm{~cm}^{-3}$, an argon excitation temperature of $5000 \mathrm{~K}$, and a rotational temperature of $1500 \mathrm{~K}$. Under these high-density reactive conditions, efficient decomposition of the silicon source gas and formation of a supersaturated silicon vapor lead to nucleation of gas phase crystals via three-body collisions and subsequent rapid termination of crystal growth due to the very short residence time in the microreactor.

An inductively coupled microplasma reactor was developed by applying ultra high frequency (UHF) to deposit a material on different substrates [24-26]. An atmospheric pressure $\mathrm{O}_{2}$-Ar microplasma reactor was used to prepare molybdenum oxide nanoparticles using molybdenum wire as the source material. The molybdenum metal wire with a diameter of $100 \mu \mathrm{m}$ was inserted $6 \mathrm{~mm}$ from the exit of a pinched nozzle with an exit opening with an ID of 60-70 $\mu \mathrm{m}$. A 20-turn copper coil was used to connect the reactor to the UHF source via a matching circuit. A drawing of the capillary microreactor is shown in Fig. 7.

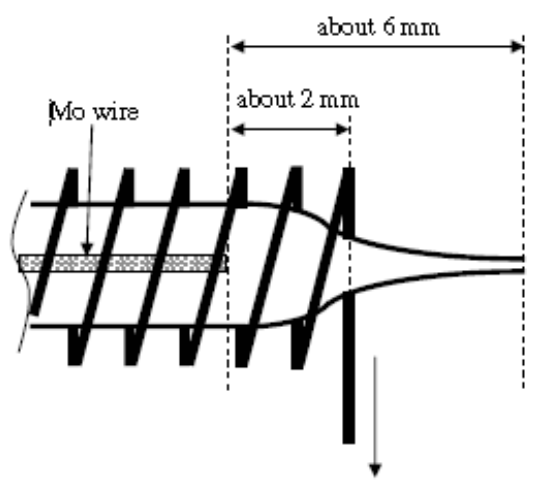

To UHF source via matching circuit

Figure 7. Capillary head of UHF microplasma reactor developed for the synthesis of molybdenum oxide nanoparticles [24].

A high density microplasma oxidized the molybdenum, and $\mathrm{MoO}_{\mathrm{x}}$ nanoparticle seeds were supplied from the wire. The flow rate of the $\mathrm{O}_{2}$-Ar mixture affected the process mechanism and therewith controlled shape, size and oxidation state of the 
nanoparticles. It was found that $\mathrm{MoO}_{2}$ oxidized to $\mathrm{MoO}_{3}$ and that nanoparticle size decreased with an increase in flow rate. Using the same UHF microplasma technique, a tungsten wire was coated with multi-walled carbon nanotubes (MWCNTs)s by flowing methane and vaporized ferrocene gases through a microchannel [25]. This new microreaction method is unique as it gives a higher growth rate of MWCNTs with low power consumption (a few tens of Watts) than conventional plasma enhanced chemical vapor deposition processes.

Atmospheric pressure microplasma technology has the advantage of creating high density reactive media in small spaces which can be used for surface modification and material deposition inside microchannels. We have recently developed a dielectric barrier discharge technique to activate a coating of nickel/alumina catalyst in a capillary microreactor to enhance carbon nanofiber (CNF) growth on this coating [27]. CNFs are promising nanostructured catalytic supports for liquid phase reactions due to their high porosity and tortuosity [28]. Although thermal activation is an important way to significantly increase nanofiber yield, an atmospheric pressure microplasma may form an alternative route by using discharge activated species which react at the catalyst surface at ambient temperatures. In our work, the fused silica capillary microreactor (500 $\mu \mathrm{m}$ ID, $550 \mu \mathrm{m}$ OD) with an internal nickel/alumina catalyst coating was connected to a gas supply through a graphite ferrule high voltage electrode. A dielectric barrier discharge was generated to activate the catalyst at $300 \mathrm{~K}$ under a flow of hydrogen $(5 \mathrm{ml} / \mathrm{min})$ and helium $(150 \mathrm{ml} / \mathrm{min})$ for $15 \mathrm{~min}$. The microreactor, catalyst coating and microplasma treatment are shown in Fig. 8. The catalyst color changed from light gray to dark gray after activation for $15 \mathrm{~min}$ showing that reduction of nickel took place during the discharge operation. Optical emission spectroscopic characterization showed that low temperature activation of the catalyst occurs via active plasma species in the microreactor at atmospheric pressure. The discharge generated in the microchannel was characterized as uniform and stable with a high power density $\left(680 \mathrm{~W} / \mathrm{cm}^{3}\right)$ at ambient gas temperature. The discharge treatment increased the CNF yield significantly compared to a nonactivated sample and the process can compete with a high temperature treatment at $973 \mathrm{~K}$ for 2 hrs. Additionally, a comparison of the low temperature microplasma treatment with a thermal treatment showed that the diameter of nanofibers is much more uniform in the former case. The method demonstrates the feasibility of cold catalyst activation on microreactor walls. 

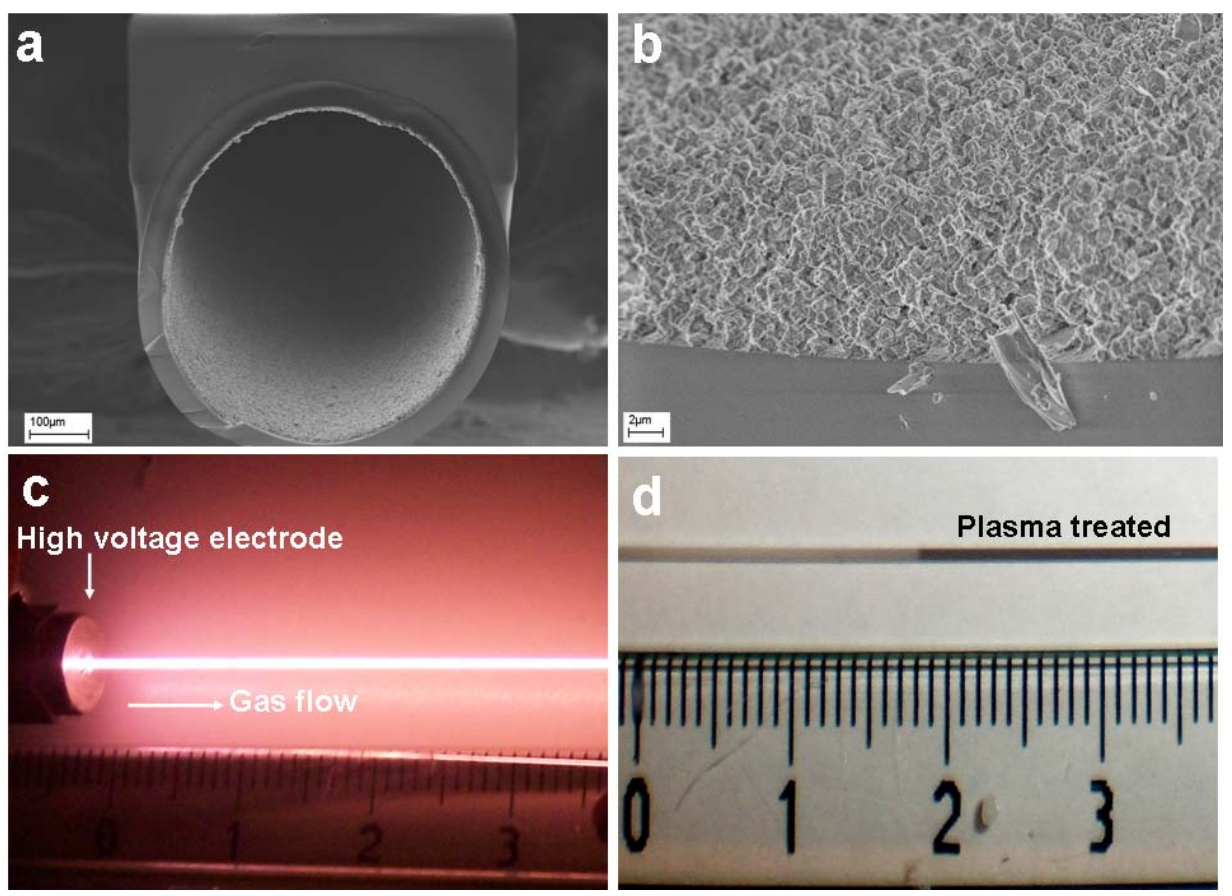

Figure 8. (a) SEM images of fused silica capillary microreactor coated with Ni/alumina catalyst, (b) catalyst layer after calcinations, (c) photo taken during microplasma treatment to increase catalyst activity for CNF synthesis and (d) change in color of catalyst from light gray to dark gray after activation for $15 \mathrm{~min}$ [27].

Another example of inner wall modification of microchannels with a microplasma is the deposition of uniform platinum films in microchannels [29]. This was done by generating a dielectric barrier discharge at a low-pressure (a few Torr) in a capillary and in a microchannel in a glass chip, with electrodes attached to the outer surface along the channel axis. Photographs of the microplasma in the capillary and in the Pyrex chip are shown in Fig. 9. Cylindrical graphite and metal foil electrodes were used for the capillary and the Pyrex chip, respectively. By introducing vaporized platinum bisacetylacetonate, plasma deposition led to a platinum film with a thickness of more than $100 \mathrm{~nm}$. By controlling the voltage and frequency parameters, it was possible to achieve uniform deposition between the electrodes in the microchannel. This technique is a good example of the possibility of using microplasma technology to deposit a thin film catalyst or other coatings in a controlled way in microreactors. 


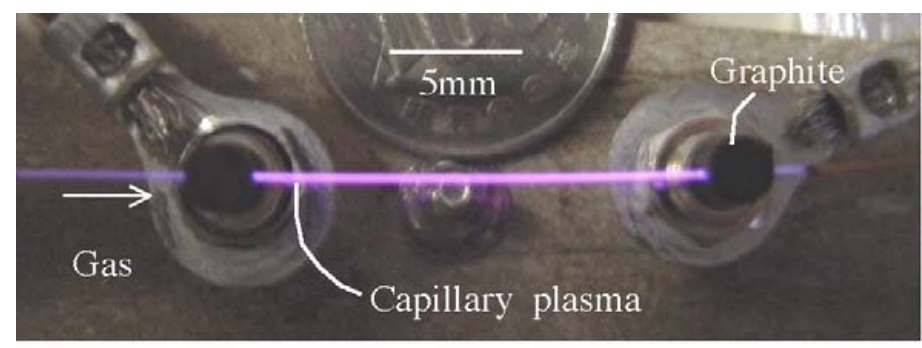

(a) $\mathrm{Ar}, 2 \mathrm{Torr}$

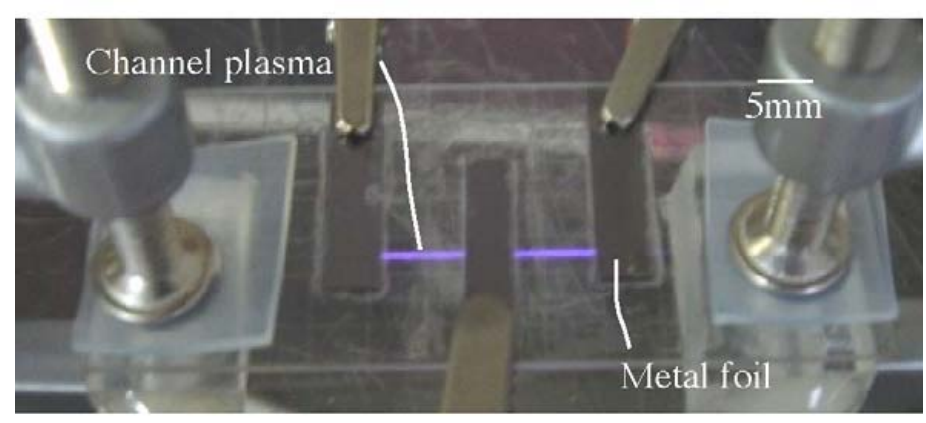

(b) He, 5Torr

Figure 9. Photos of a microplasma in (a) a capillary and (b) a microchannel in a Pyrex chip, developed for plasma chemical vapor deposition of platinum films [29].

\section{Environmental applications with microplasma reactors:}

Through the generation of highly reactive species such as energetic electrons and active radicals, microplasma reactors create novel process windows for $\mathrm{C}-\mathrm{C}$ and $\mathrm{C}-\mathrm{H}$ bond cleavage involved in the decomposition of harmful gaseous pollutants at atmospheric pressure. As an example of this, a miniature dielectric barrier discharge device was developed for the decomposition of volatile organic compounds (VOCs) [30]. The device works with a surface discharge microplasma and contains microelectrodes manufactured by photoetching of stainless steel foil and a dielectric substrate, acting as a barrier, made from a rectangular sheet of mica (Fig. 10). By applying a high voltage (3.5 $\mathrm{kV}) \mathrm{AC}$ field $(67 \mathrm{kHz})$ to the discharge electrode, a microplasma was formed on the surface of the mica sheet and high energy electrons were generated which dissociated molecules, formed negative and positive ions, and excited molecular and elemental species. Ion counting measurements showed that most of the byproducts were negatively charged. The efficiency of toluene decomposition 


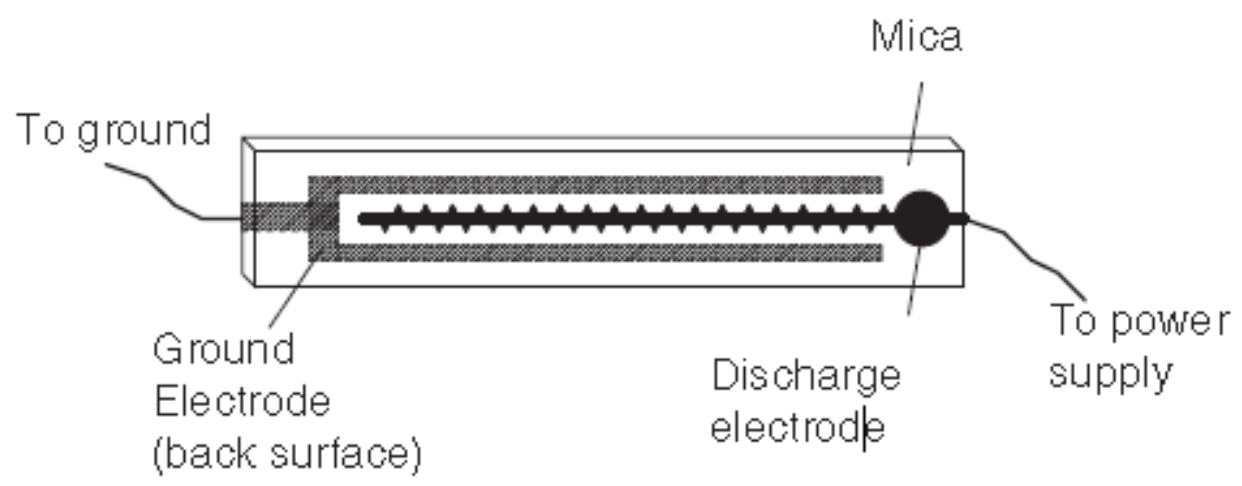

Figure 10. Illustration of a surface-discharge microplasma reactor developed for the decomposition of volatile organic compounds in the gas phase [30].

was found to be more than $99 \%$ in batch and 30-80\% in continuous flow, and it was shown that toluene was completely converted into carbon dioxide by the atomic oxygen generated in the microplasma reactor.

Decomposition of tetrafluoromethane at atmospheric pressure was achieved with a microreactor which has very small electrode gaps $(70 \mu \mathrm{m})$ between micro-structured electrodes with an interdigitated arrangement (Fig. 11) [31]. The merits of this reactor are

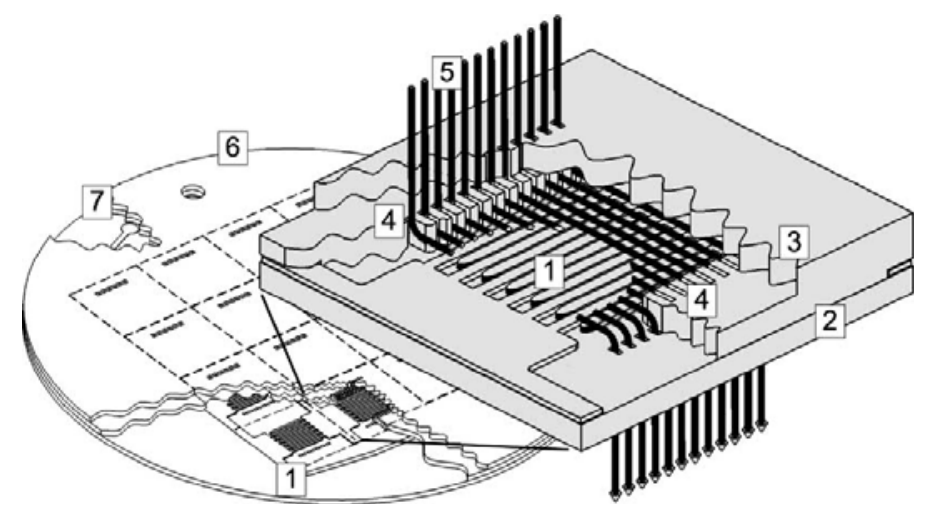

Figure 11. Illustration of a single microplasma reactor and its integration in a multireactor. Numbered features are (1) plasma source, (2) glass structure, (3) reaction chamber, (4) inlet and outlet of the reactor, (5) gas flow, (6) 4 x 4 array in a multireactor, (7) contact pads for RF power [31].

low ignition voltages and a homogeneous plasma at high pressure. Alumina substrates, nickel electrodes and Foturan $^{\circledR}$ glass with an alumina coating were used as the microreactor materials. It was shown that micromachined flow structures provide 
effective flow control and have a large effect on decomposition efficiency. Additionally, scale-up to larger exhaust gas flows was achieved by "numbering up", i.e. by constructing a multireactor with 16 microplasma reactors in parallel. Besides the larger throughput, the transition to a multireactor concept reduced the power strain on single microreactors and prolonged their lifetime. It was suggested that 25 of such multireactors are needed to treat $20 \mathrm{l} / \mathrm{min}$ of fluorinated waste gas for a small semiconductor plant, at an energy consumption of only $50 \%$ of that of a conventional combustion system.

Mori et al. used capillary discharge tubes with an ID of $0.5 \mathrm{~mm}$ or $3 \mathrm{~mm}$ to decompose carbon dioxide. The set-up is shown in Fig. 12 [32]. The capillary plasma

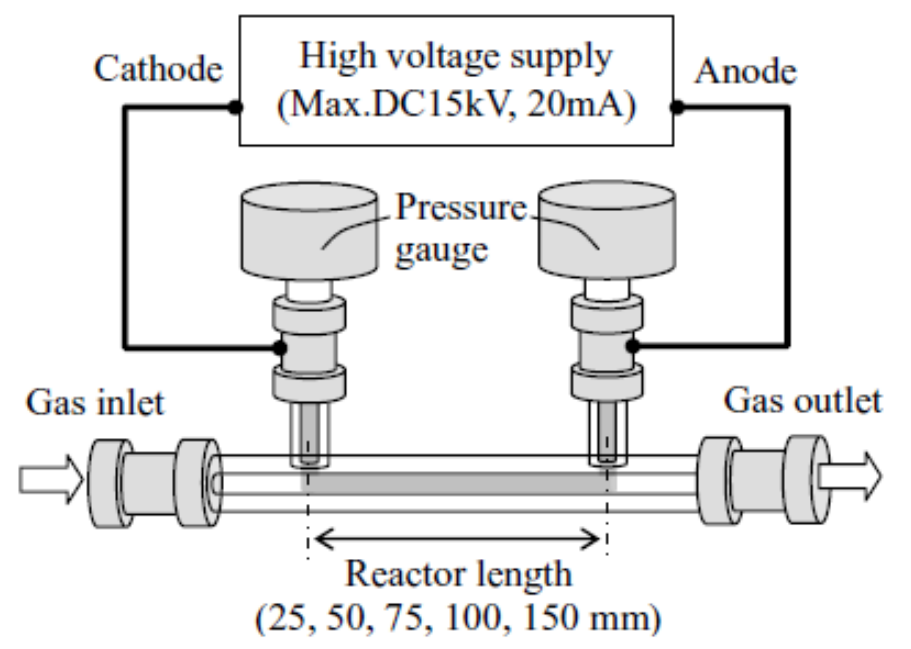

Figure 12. Schematic diagram of the capillary plasma reactor developed for the decomposition of carbon dioxide [32].

reactor consists of a Pyrex glass body and mounted electrodes which are not in direct contact with the gas flow in order to eliminate the influence of the cathode and anode region on $\mathrm{CO}_{2}$ decomposition. Analysis of downscaling effects on the plasma chemistry and discharge characteristics showed that the carbon dioxide conversion rate is mainly determined by electron impact dissociation and gas phase reverse reactions in the capillary microreactor. The extremely high $\mathrm{CO}_{2}$ conversion rate was attributed to an increased current density rather than to surface reactions or an increased electric field.

The application of nanostructures as electrodes in a microplasma reactor was used to increase the reactivity and efficiency of barrier discharge processes at atmospheric pressure [33]. Carbon nanofibers $(\mathrm{CNFs})$ and tungsten oxide $\left(\mathrm{W}_{18} \mathrm{O}_{49}\right)$ nanowires were integrated into a continuous flow microplasma reactor so that charge injection from the nanostructures by field emission supplied free electrons and ions after discharge. 
Incorporation of the nanostructures was performed by growing nanowires and nanofibers on the silicon chip which was used as a high voltage electrode in a glass microreactor system, as shown in Figure 13. Atmospheric pressure field electron emission tests showed that field enhancement
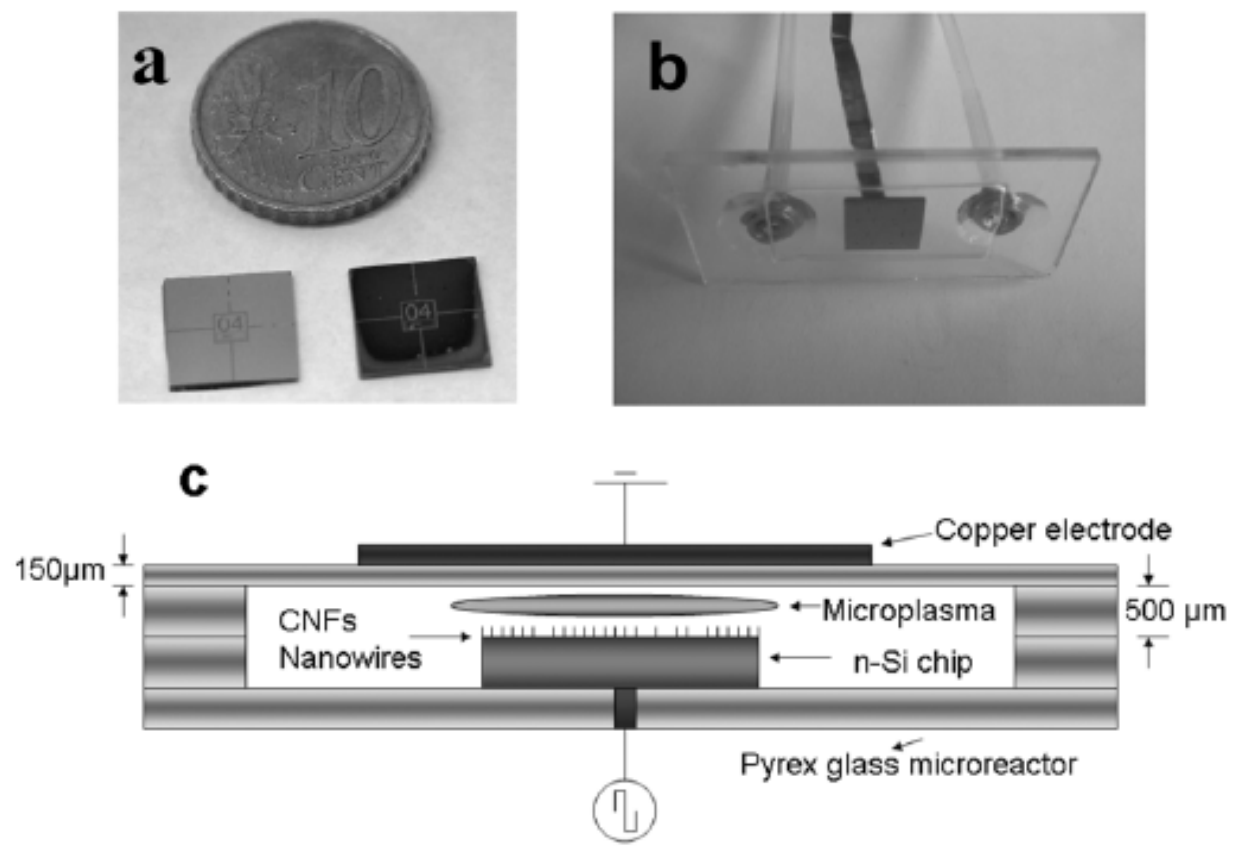

Figure 13. On-chip microplasma reactor using nanostructured electrodes, (a) silicon chip before and after a CVD process for nanostructure growth, (b) microplasma reactor and (c) general diagram of the device [33].

at the tip apex of the nanostructures results in electron emission in air. Injection of charged species during discharge generation results in a decrease in breakdown voltage and a higher power deposition, at the same measured potentials as applied on electrodes without nanostructures. As a model reaction, $\mathrm{CO}_{2}$ cracking was tested and it was found that the chemical reactivity of the discharge is increased by application of the nanofibers.

\section{Chemical synthesis in microplasma reactors:}

Performing plasma processes in a continuous-flow microreactor leads to precise control of residence time and to extreme quenching conditions, therewith enabling control over the composition of the reaction mixture and product selectivity. In a non-equilibrium microplasma reactor, low temperature activation of hydrocarbons and fuels, which is 
difficult to obtain in conventional thermochemical processes, can be achieved at ambient conditions.

Nozaki et al. [34] described the application of a microplasma reactor in partial oxidation of methane. The plasma generation principle in this case is similar to a dielectric barrier discharge and gives high energy electrons which activate methaneoxygen mixtures for direct production of methanol. The microreactor consists of a Pyrex thin glass tube (ID $1.0 \mathrm{~mm}$, length $60 \mathrm{~mm}$ ) with a twisted metallic wire (ID $0.2 \mathrm{~mm}$, length $100 \mathrm{~mm}$ ) inside, as shown in Fig. 14. Power consumption was calculated to be between 3 and $10 \mathrm{~W}$. Excess heat
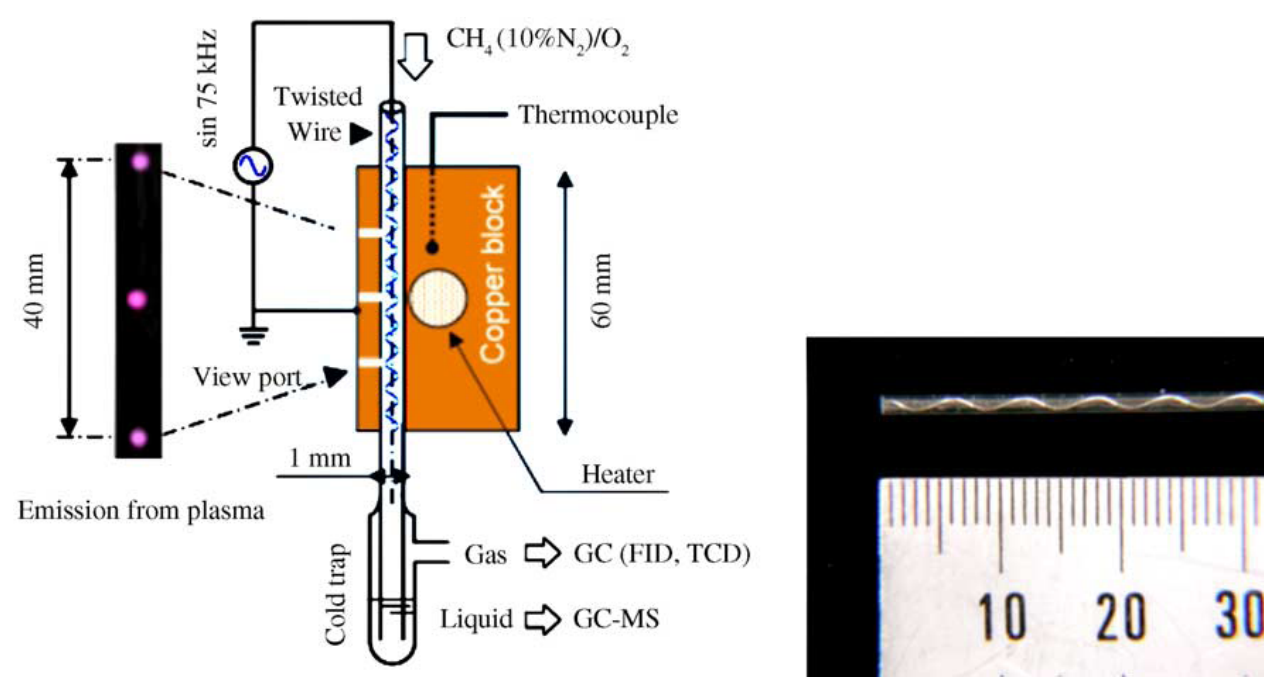

Figure 14. Microplasma reactor set-up for partial oxidation of methane (left) and photo of thin glass tube equipped with a twisted metal wire (right) [34].

generated by partial oxidation was efficiently removed from the microreactor, and successive destruction of formed oxygenates was minimized in the highly quenching environment. It was possible to produce methanol reproducibly in a one-pass process, with $10 \%$ maximum yield at room temperature, and at $100 \mathrm{kPa}$ within $280 \mathrm{~ms}$ without explosion of the methane/oxygen mixture. The advantage of using a plasma microreactor for fuel processing is that methane can be activated by high energy electrons to achieve $40 \%$ conversion, independent of temperature and pressure. Additionally, unlike in thermochemical reactions, product selectivity is independent of methane conversion. However, the present microplasma reactor has not yet been made compatible with existing methanol manufacturing processes, the reactor dimensions and power 
consumption need to be optimized in terms of a balance between excitation and quenching processes.

Graves et al. [35] have used a micro hollow cathode as a microreactor to decompose ammonia and carbon dioxide. A micro hollow cathode discharge can provide a highly reactive environment with a high electron temperature, power density and ion density which would be ideal for endothermic cracking reactions. Decomposition of ammonia into nitrogen and hydrogen can be used as a source of pure hydrogen, while cracking of carbon dioxide can be used to dispose of radioactive carbon dioxide, or for the production of oxygen. In this case, the micro hollow cathode discharge was constructed from two molybdenum electrodes (100 $\mu \mathrm{m}$ thick) sandwiching a mica dielectric $(260 \mu \mathrm{m}$ thick). The three layers were glued together and a $200 \mu \mathrm{m}$ hole was drilled to construct a continuous flow microreactor. Significant decomposition of ammonia and carbon dioxide with effective reaction temperatures exceeding $2000 \mathrm{~K}$ was shown. As a demonstration of the numbering-up principle, it was shown that with two or more microreactors in series the conversion could be increased significantly. This work demonstrated that microplasma-induced generation of hydrogen from ammonia in a flowthrough micro hollow cathode discharge is feasible, however, to become of economic relevance, the overall power efficiency should be increased. This may be done by pulsing the plasma, or operating many microplasma reactors in parallel and/or in series. It was proposed to pulse the discharge with short microsecond pulses to minimize electrical power input and stabilize the plasma.

Direct hydroxylation of benzene to phenol and of toluene to cresol in a microplasma reactor was carried out using a dielectric barrier discharge at atmospheric pressure [36]. This type of discharge provides hot electrons which dissociate molecules and therewith initiate hydroxylation reactions at ambient gas temperature. The glass microreactor studied by Seki et al. has a rectangular shape $(100 \mathrm{~mm}$ in length and $70 \mathrm{~mm}$ in width) with aluminum electrodes and Teflon sheets as spacers, see Fig. 15. Energetic electrons and oxygen radicals can dissociate the aromatic ring and functional groups, which is followed by oxidation. It was proposed that the selectivity and the yield of this plasma- based direct hydroxylation process may be increased by controlling the production of oxygen radicals via changes in the reactor surface or plasma generation methods. 


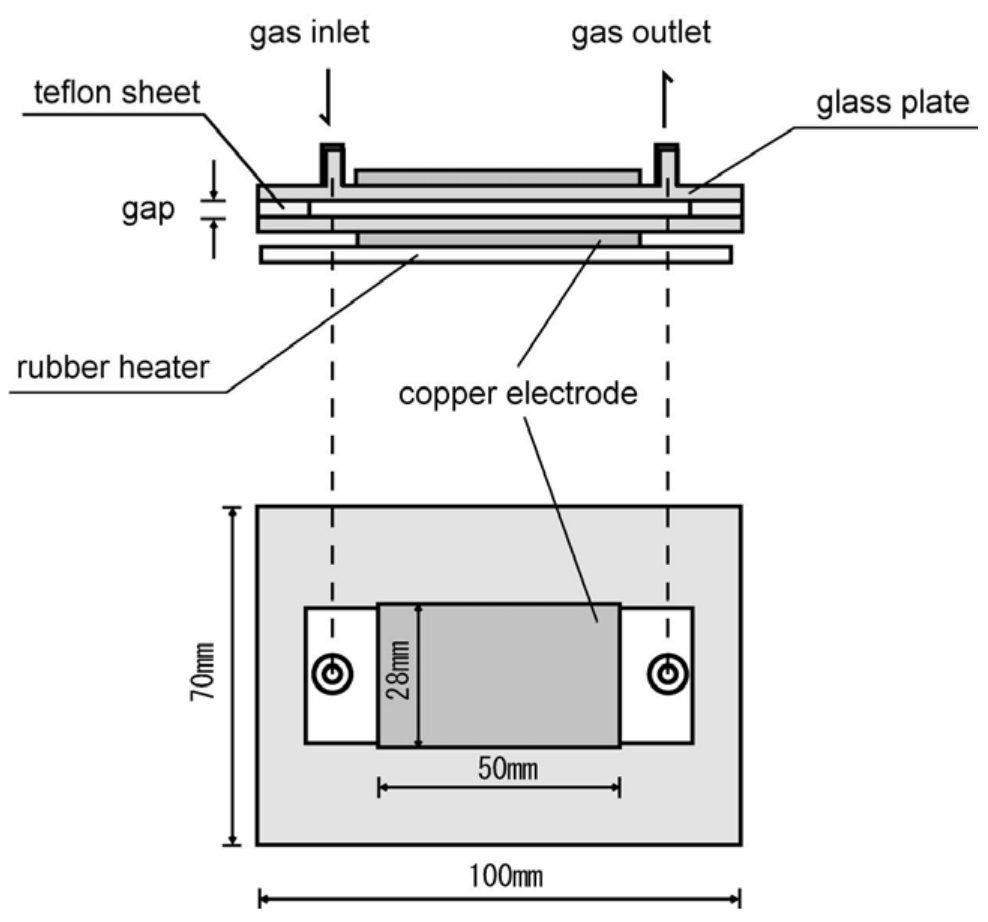

Figure 15. Schematic diagram of microplasma reactor, based on dielectric barrier discharge, for hydroxylation of benzene and toluene [36].

Oxidative conversion of light alkanes, $\mathrm{C}_{1}-\mathrm{C}_{3}$ range, was carried out in a dielectric barrier type microplasma reactor [37]. The direct conversion of alkanes is largely obstructed by the strong $\mathrm{C}-\mathrm{H}\left(415 \mathrm{~kJ} \mathrm{~mol}^{-1}\right.$, for methane) and $\mathrm{C}-\mathrm{C}$ bonds $\left(350 \mathrm{~kJ} \mathrm{~mol}^{-1}\right.$ for ethane) [38]. Cold plasma processing can be an alternative to high temperature thermochemical processes. A barrier discharge treatment in a confined reactor offers the advantages of a uniform and dense plasma with a better control of residence time. The tested microplasma reactor (30 $\mathrm{mm}$ length, $5 \mathrm{~mm}$ width, $500 \mu \mathrm{m}$ channel depth) was fabricated by thermal bonding of 3 Pyrex layers and attaching copper electrodes on top and bottom at the outside of the chip, as shown in Fig. 16. A plasma was generated by applying a high voltage $(5-10 \mathrm{kV})$ sine wave $(60 \mathrm{kHz})$ to the top electrode while the bottom electrode was grounded. Heat produced during the oxidative conversion of alkanes was easily removed due to the small volume and high surface area of the microreactor, so that it operated at ambient temperature. The feed composition was $10 \%$ alkane and $1 \%$ oxygen in helium. Activation of hydrocarbons follows two main routes. In the first one, energized electrons dissociate alkane molecules by cleaving $\mathrm{C}-\mathrm{H}$ and $\mathrm{C}-\mathrm{C}$ bonds. The direct observation of $\mathrm{CH}, \mathrm{C}_{2}$ and $\mathrm{H}$ excited species by an optical emission spectrometer is an indication of this bond cleavage at room temperature. 

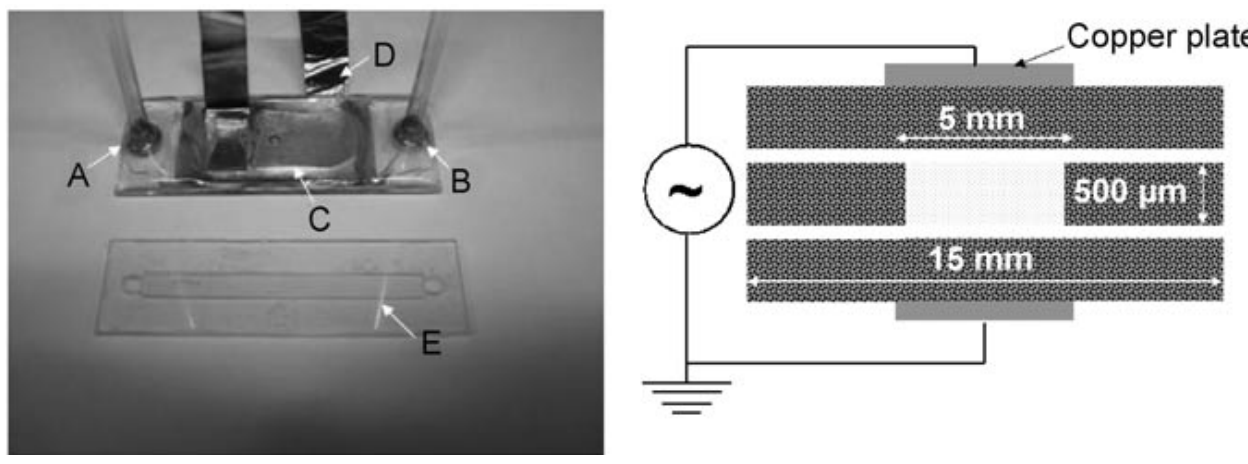

Figure 16. Microplasma reactor, based on dielectric barrier discharge, for oxidative conversion of $\mathrm{C}_{1}-\mathrm{C}_{3}$ alkanes [37].

Secondly, electron impact dissociation of oxygen molecules produces active oxygen radicals which initiate radical chain reactions. Excited helium species also may play a role in the process, by transferring energy to alkane and oxygen molecules. In the experiments with propane, a high selectivity ( $37 \%$ ) to products with a molecular weight higher than propane $\left(\mathrm{C}_{4}, \mathrm{C}_{4}^{+}\right)$was observed, indicating that under microplasma conditions $\mathrm{C}-\mathrm{C}$ bond formation occurs. Coupling reactions between radicals are favored at lower temperatures and the cold plasma process in a microreactor could be an alternative for upgrading light hydrocarbons by direct homologation of alkanes. A kinetic model of plasma propane conversion in this microplasma reactor was developed for better understanding of physical and chemical processes over a range of reactor operation conditions [39]. The model employed the well-mixed plasma reactor module of Chemkin 4.1 [40] to determine the time-averaged species composition an electron energy balance which equates the rate of change of the electron swarm internal energy to the net flow of electron enthalpy into and out of the reactor, therewith accounting for net chemical production rates, surface losses, collisional losses, and power deposition from the externally applied electromagnetic field. Reaction rate coefficients of electron impact reactions with propane were determined with the aid of BOLSIG + software [41]. This software also calculates the relation between the average electron energy and the reduced electric field inside the microreactor. The estimated average electron temperature was used to obtain a steady state solution in the Chemkin plasma reactor model. The BOLSIG+ code uses the twoterm spherical harmonic expansion of the electron energy distribution function to solve a 0 -dimensional Boltzmann equation. Cross-sections of partial dissociative excitation and ionization processes $\left(\mathrm{e}^{-}+\mathrm{C}_{\mathrm{x}} \mathrm{H}_{\mathrm{y}}, \mathrm{x}=1-3 ; \mathrm{y}=1-8\right)$ were obtained from the experimental 
data of total dissociation cross-sections and of total cross-sections for dissociative ionization [42]. It is necessary to correct the residence time since a barrier discharge consists of filaments, and this was done on the basis of a quantitative agreement with experimental data. The model includes electron impact dissociation and ionization, ionneutral reactions, neutral-neutral chemistry and surface recombination of ions at the walls. Simulated results were compared with experimental data and a good agreement was found. $\mathrm{H}, \mathrm{CH}, \mathrm{CH}_{2}, \mathrm{CH}_{3}, \mathrm{C}_{2} \mathrm{H}_{3}, \mathrm{C}_{2} \mathrm{H}_{5}, \mathrm{C}_{3} \mathrm{H}_{5}, \mathrm{C}_{3} \mathrm{H}_{7}$ and $\mathrm{C}_{4} \mathrm{H}_{9}$ radicals were found to play an important role during propane conversion in the microplasma reactor. At higher propane conversion levels, enhanced C-C bond formation was observed.

The same microplasma reactor was used to study the feasibility of oxidative dehydrogenation of propane in the presence of a $\mathrm{Li} / \mathrm{MgO}$ catalyst [43]. It was anticipated that a synergistic effect between catalytic and plasma processes may be obtained, that possibly may give a higher conversion and yield of target products. The reason for this expectation was based on the following: First of all, a catalyst supported on an insulator oxide deposited in the barrier discharge region may influence the plasma properties due to a change in surface properties and permittivity of the dielectric material, and this influence may be positive. A well-chosen catalyst will, as always, decrease the overall activation energy, but the selectivity of a catalytic reaction may be increased by selective plasma activation of specific molecular bonds between adsorbates and surface. This can be thought to occur as follows: In a non-equilibrium plasma, molecules are excited by electron impact. Among the characteristic species (electrons, ions, molecular fragments and excites species such as electronic, vibrational, rotational/translational excitations), only radicals and vibrationally excited species will be relevant for surface reactions in an atmospheric pressure non-equilibrium plasmas, due to the fact that radicals have long relaxation times compared to the time needed for chemical reactions, plus that they have a high sticking probability on surfaces. Vibrational activation in the dissociation degree of freedom can lower the activation barrier for dissociative adsorption [44].

In addition to the above, in a microplasma reactor a more intensive interaction of plasma and catalyst surface can be achieved in a confined environment. $\mathrm{Li} / \mathrm{MgO}$ catalysts in the presence of oxygen at high temperatures have $\left[\mathrm{Li}^{+} \mathrm{O}^{-}\right]$defect sites which activate $\mathrm{C}$ $\mathrm{H}$ bonds in alkanes [45]. Propane activation starts with hydrogen abstraction by oxygen ions, forming propyl radicals [46], $\mathrm{C}-\mathrm{C}$ and $\mathrm{C}-\mathrm{H}$ bond cleavage happens at high temperatures $(\mathrm{T}>823 \mathrm{~K})$ in the presence of $\left[\mathrm{Li}^{+} \mathrm{O}^{-}\right]$centers. At these temperatures, a loss of catalyst area was observed, which results in less heterogeneous formation of propene [47]. A microplasma reactor may allow initial propane activation at lower temperatures 
by enhanced radical surface interactions in the confinement of a microreactor. To test this, a $\mathrm{Li} / \mathrm{MgO}$ catalyst was deposited on the surface of a glass microchannel by micropipetting a sol-gel precursor system. The catalytic microplasma reactor showed enhanced olefin selectivity in the presence of $\mathrm{Li} / \mathrm{MgO}$, which indicates the formation of defect sites at ambient temperatures. Formation of higher hydrocarbon products $\left(\mathrm{C}_{4}+\mathrm{C}_{4}{ }^{+}\right)$showed that coupling of radicals occurs predominantly in the homogeneous phase.

Anderson et. al. [18] have fabricated plastic microreactors based on parallel linear arrays of interconnected cylindrical microcavity plasma devices, using replica molding in UV-curable polymers. Their study was aimed at on-chip plasma processing with the

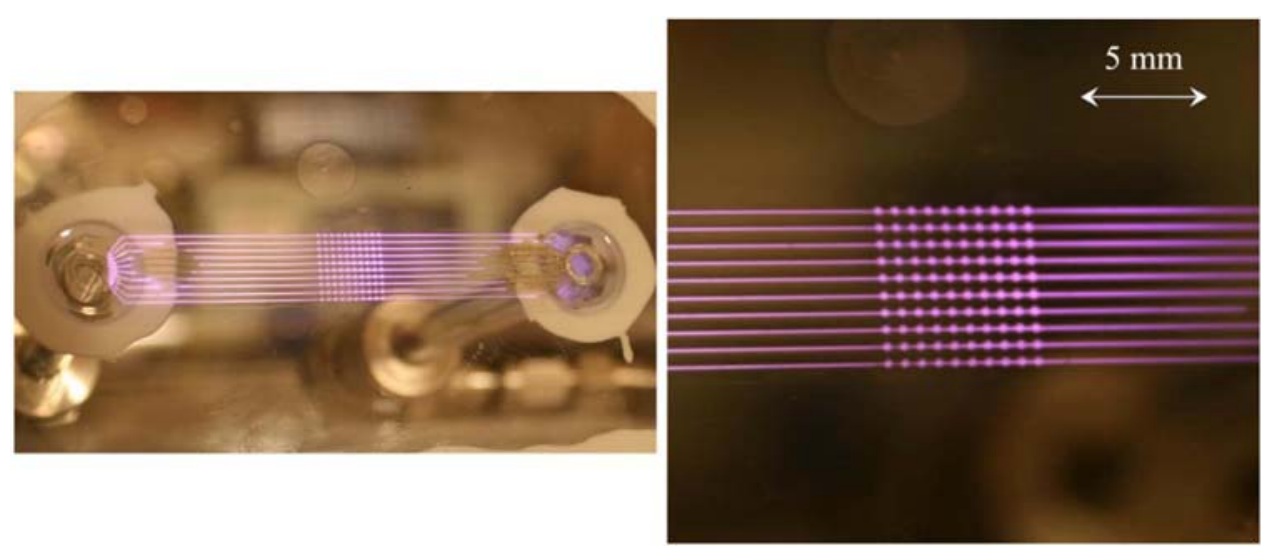

Figure 17. Photographs of microplasma reactor fabricated by replica molding on a plastic substrate (left) and magnified view of the $10 \times 10$ array of $400 \mu \mathrm{m}$ diameter microcavity plasma channels, operating in argon (right) [18].

generation of gas or solid phase from a gas feedstock. Fig. 17 shows a magnified view of the $10 \times 10$ arrays of $400 \mu \mathrm{m}$ diameter microplasma devices, operating in 600 Torr of Ar. Deposition of $(\mathrm{C}-\mathrm{S})_{\mathrm{n}}$ microstructured polymer was done in $\mathrm{Ar} / \mathrm{CS}_{2}$ plasma. This study showed the feasibility of using low cost and disposable polymer microplasma reactors for potential chemical synthesis applications. 


\section{References}

[1] A. von Engel, Ionized Gases, Clarendon Press, Oxford, 1955.

[2] Y. Raizer, Gas Discharge Physics, Springer Verlag, Heidelberg, 1991.

[3] M.A. Lieberman, A.J. Lichtenberg, Principles of Plasma Discharges and Materials Processing, John Wiley, New York, 1994.

[4] K.H. Becker, U. Kogelschatz, K.H. Schoenbach, R. Barker (Eds.), Non Equilibrium Air Plasmas at Atmospheric Pressure. Chapter 9 Applications of Atmospheric-Pressure Air Plasmas, IOP Publ., Bristol, UK, 2004.

[5] K. Tachibana, Current status of microplasma research, IEEJ Trans. Electrical and Electronic Eng., 1 (2006) 145-155.

[6] R. Foest, M. Schmidt and K. Becker, Microplasmas an emerging field of lowtemperature plasma science and technology, Int. J. Mass Spect., 248 (2006) 87-102.

[7] K. Becker, A. Koutsospyros, S. -M. Yin, C. Christodoulatos, N. Abramzon, J. C. Joaquin and G. B.- Marino, Environmental and biological applications of microplasmas, Plasma Phys. Control. Fusion, 47 (2005) B513-B523.

[8] K. H. Becker, K. H. Schoenbach and J. G. Eden, Microplasmas and applications, J. Phys. D: Appl. Phys., 39 (2006) R55-R70.

[9] W. Grotrian, Ann. Physik, (4) 4710 (1915) 141.

[10] D. Staack, B. Farouk, A. Gutsol and A. Fridman, Characterization of a DC atmospheric pressure normal glow discharge, Plasma Sources Sci. Technol., 14 (2005) 700-711.

[11] U. Kogelschatz, Dielectric-barrier discharges: Their history, discharge physics, and industrial applications, Plasma Chem. Plasma Proc., 23 (2003) 1 1-46.

[12] K.H. Schoenbach, R. Verhappen, T. Tessnow, P.F. Peterkin and W. Byszewski, Micro hollow cathode discharges, Appl. Phys. Lett., 68 (1996) 13.

[13] K. H. Schoenbach, M. Moselhy, W. Shi and R. Bentley, Micro hollow cathode discharges, J. Vac. Sci. Technol. A, 21 (2003) 41260.

[14] R. H. Stark and K. H. Schoenbach, Direct current high-pressure glow discharges, J. Appl. Phys., 85 (1999) 2075.

[15] P. V. Allmen, S. T. Mccain, N. P. Ostrom, B. A. Vojak, J. G. Eden, F. Zenhausern, C. Jensen and M. Oliver, Ceramic microdischarge arrays with individually ballasted pixels, Appl. Phys Lett., 82 (2003) 162562. 
[16] S. -O. Kim and J. G. Eden, Arrays of microplasma devices fabricated in photodefinable glass and excited AC or DC by interdigitated electrodes, IEEE Phot. Tech Lett., 17 (2005) 7 1543-1545.

[17] S. -J. Park, K. S. Kim and G. J. Eden, Nanoporous alumina as a dielectric for microcavity plasma devices: Multilayer $\mathrm{Al} / \mathrm{Al}_{2} \mathrm{O}_{3}$ structures, Appl. Phys. Lett., 86 (2005) 221501.

[18] T. S. Anderson, J. H. Ma, S. -J. Park and J. G. Eden, Multichannel microchemical reactor comprising replica-molded microplasma devices: Chemiluminescence and sulfur deposition in $\mathrm{Ar} / \mathrm{CS}_{2}$ flows, IEEE Trans. Plasma Sci., 36 (2008) 4 1250-1251.

[19] R. M. Sankaran, D. Holunga, R. C. Flagan and K. P. Giapis, Synthesis of blue luminescent Si nanoparticles using atmospheric-pressure microdischarges, Nanoletters, 5 (2005) 3 537-541.

[20] W. -H. Chiang and R. M. Sankaran, Microplasma synthesis of metal nanoparticles for gas-phase studies of catalyzed carbon nanotube growth, Appl. Phys. Lett., 91 (2007) 121503.

[21] W. -H. Chiang and R. M. Sankaran, In-flight dimensional tuning of metal nanoparticles by microplasma synthesis for selective production of diameter-controlled carbon nanotubes, J. Phys. Chem. C, 112 (2008) 17920-17925.

[22] T. Nozaki, K. Sasaki, T. Ogino, D. Asahi and K. Okazaki, Microplasma synthesis of tunable photoluminescent silicon nanocrystals, Nanotechnology, 18 (2007)235 603.

[23] T. Nozaki, K. Sasaki, T. Ogino, D. Asahi and K. Okazaki, Silicon nanocrystal synthesis in microplasma reactor, Journal of Thermal Science and Technology, 2 (2007) 2 192-199.

[24] A. C. Bose, Y. Shimizu, D. Mariotti, T. Sasaki, K. Terashima and N. Koshizaki, Flow rate effect on the structure and morphology of molybdenum oxide nanoparticles deposited by atmospheric-pressure microplasma processing, Nanotechnology, 17 (2006) 5976-5982.

[25] Y. Shimizu, T. Sasaki, C. Liang, A. C. Bose, T. Ito, K. Terashima and N. Koshizaki, Cylindrical metal wire surface coating with multiwalled carbon nanotubes by an atmospheric-pressure microplasma CVD technique, Chem. Vap. Deposition, 11 (2005) 244-249.

[26] Y. Shimizu, T. Sasaki, T. Ito, K. Terashima and N. Koshizaki, Fabrication of spherical carbon via UHF inductively coupled microplasma CVD, J. Phys. D: Appl. Phys. 36 (2003) 2940-2944. 
[27] A. Agiral, L. Lefferts and J. G. E. (Han) Gardeniers, Catalyst activation by microplasma for carbon nanofibers synthesis in a microreactor, IEEE Trans. Plasma Sci., accepted for future publication First Published: 2009-05-15 ISSN: 0093-3813 doi:10.1109/TPS.2009.2019981.

[28] K. De Jong, and J. Geus, Carbon nanofibers: Catalytic synthesis and applications, Catal. Rev. Sci. Eng., 42 (2000) 4 481-510.

[29] M. Kadowaki, H. Yoshizawa, S. Mori and M. Suzuki, Plasma CVD on the inner surface of microchannel, Thin Solid Films, 506 (2006) 123-127.

[30] T. Seto, S.- B. Kwon, M. Hirasawa and A. Yabe, Decomposition of toluene with surface-discharge microplasma device, Jpn. J. Appl. Phys., 44 (2005) 7A 5206-5210.

[31] P. Sichler, S. Buttgenbach, L. B.- Hibbe, C. Shrader and K. -H. Gericke, A micro plasma reactor for fluorinated waste gas treatment, Chem. Eng. J., 101 (2004) 465-468.

[32] S. Mori, A. Yamamoto and M. Suzuki, Characterization of a capillary plasma reactor for carbon dioxide decomposition, Plasma Sour. Sci. Technol., 15 (2006) 609-613.

[33] A. Agiral, A. W. Groenland, J. K. Chinthaginjala, K. Seshan, L. Lefferts and J. G. E. (Han) Gardeniers, On-chip microplasma reactors using carbon nanofibres and tungsten oxide nanowires as electrodes, J. Phys. D: Appl. Phys., 41 (2008) 194009.

[34] T. Nozaki, A. Hattori and K. Okazaki, Partial oxidation of methane using a microscale non-equilibrium plasma reactor, Cat. Tod., 98 (2004) 607-616.

[35] D. D. Hsu and D. B. Graves, Micro hollow cathode discharge reactor chemistry, Plasma Chem. Plasma Proc., 21 (2005) 1.

[36] H. Sekiguchi, M. Ando and H. Kojima, Study of hydroxylation of benzene and toluene using a micro-DBD plasma reactor, J. Phys. D: Appl. Phys. 38 (2005) 1722-1727.

[37] C. Trionfetti, A. Agiral, Han J. G. E. Gardeniers, L. Lefferts and K. Seshan, Alkane activation at ambient temperatures: Unusual selectivities, C-C, C-H bond scission versus C-C bond coupling, ChemPhysChem, 9 (2008) 533-537.

[38] T. V. Choudhary, E. Aksoylu and D. W. Goodman, Non-oxidative activation of methane, Catal. Rev., 45 (2003) 151-203.

[39] A. Agiral, C. Trionfetti, L. Lefferts, K. Seshan, J. G. E. (Han) Gardeniers, Propane conversion at ambient temperatures $\mathrm{C}-\mathrm{C}$ and $\mathrm{C}-\mathrm{H}$ bond activation using cold plasma in a microreactor, Chem. Eng. Tech. 31 (2008) 1116-1123.

[40] R. J. Kee et al., CHEMKIN Release 4.0, Reaction Design, San Diego, CA 2004.

[41] G. J. M. Hagelaar and L. C. Pitchford, Solving the Boltzmann equation to obtain electron transport coefficients and rate coefficients for fluid models, Plasma Sources Sci. Technol., 14 (2005) 722-733. 
[42] R. K. Janev and D. Reiter, Collision processes of $\mathrm{C}_{2,3} \mathrm{H}_{\mathrm{y}}$ and $\mathrm{C}_{2,3} \mathrm{H}_{\mathrm{y}}{ }^{+}$hydrocarbons with electrons and protons, Physics of Plasmas, 11 (2004) 2 780-829.

[43] C. Trionfetti, A. Agiral, J. G. E. (Han) Gardeniers, L. Lefferts and K. Seshan, Oxidative conversion of propane in a microreactor in the presence of plasma over $\mathrm{MgO}-$ based catalysts: An experimental study, J. Phys. Chem. C, 112 (2008) 11 4267-4274.

[44] A. Tas, Plasma induced catalysis, Ph.D. dissertation, Technische Universiteit Eindhoven, October 1995.

[45] J. -X. Wang and J. H. Lunsford, Characterization of $\left[\mathrm{Li}^{+} \mathrm{O}^{-}\right]$centers in Lithiumdoped MgO catalysts, J. Phys. Chem., 90 (1986) 5883-5887.

[46] I. Balint and K. -I. Aika, Defect chemistry of lithium-doped magnesium oxide, J. Chem. Soc., Faraday Trans., 93 (1997) 1797-1801.

[47] C. Trionfetti, I. V. Babich, K. Seshan and L. Lefferts, Formation of high surface area $\mathrm{Li} / \mathrm{MgO}-$ Efficient catalyst for the oidative dehydrogenation/cracking of propane, Appl. Cat. A: Gen., 310 (2006) 105-113. 


\section{Chapter 2}

\section{Propane conversion at ambient temperatures $\mathrm{C}-\mathrm{C}$ and $\mathrm{C}-\mathrm{H}$ bond activation using cold plasma in a microreactor}

In this work oxidative conversion of propane was studied using a dielectric barrier discharge in a microreactor. This generates a cold microplasma at atmospheric pressure and ambient temperature. Surprisingly, large amounts of products with molecular weight higher than propane, such as, $\mathrm{C}_{4}$ and $\mathrm{C}_{4}+$ were mainly observed due to $\mathrm{C}-\mathrm{C}$ bond formation, in contrast to what is usually observed for this reaction when it is carried out under thermal activation, which leads to cracking products. A chemical kinetic model was developed to better understand the radical reaction network. The results suggest that (i) at lower level of propane conversion the model can nicely predict the experimental results, and (ii) depending on the radical density the product selectivity can be tailored. In particular at higher radical density enhanced C-C bond formation was observed.

Portions of this chapter were published in:

Alkane activation at ambient temperatures-unusual selectivities, $\mathrm{C}-\mathrm{C}, \mathrm{C}-\mathrm{H}$ bond scission vs C-C bond coupling, CRISTIANO TRIONFETTI, ANIL AGIRAL, J. G. E. (HAN) GARDENIERS, LEON LEFFERTS, K. SESHAN, ChemPhysChem, volume 9, page 533-537 (2008).

Propane conversion at ambient temperatures $\mathrm{C}-\mathrm{C}$ and $\mathrm{C}-\mathrm{H}$ bond activation using cold plasma in a microreactor (Review), ANIL AGIRAL, CRISTIANO TRIONFETTI, K. SESHAN, LEON LEFFERTS, J. G. E. (HAN) GARDENIERS, Chemical Engineering and Technology, volume 31(8), page 1116-1123 (2008). 


\section{Introduction}

In numerous catalytic reactions involving partial oxidation of light alkanes, in the range $\mathrm{C}_{1}-\mathrm{C}_{4}$, the formation and reaction of gas phase free radicals as intermediates have been proposed [1]. More specifically, in these cases, activation of hydrocarbons occurs on the catalytic site, via homolytic splitting of $\mathrm{C}-\mathrm{C}$ or $\mathrm{C}-\mathrm{H}$ bonds, resulting in the formation of radicals. The radicals thus generated are released from the catalyst surface to the gas phase and radical chain reactions lead to final products $[2,3]$. The contribution of such homogeneous gas phase routes in heterogeneous catalysis has been especially discussed in the last 20 years for the case of oxidative coupling of methane to higher hydrocarbons $[4,5]$.

Conversion of alkanes is a challenging problem due to their strong $\mathrm{C}-\mathrm{H}$ and $\mathrm{C}-\mathrm{C}$ bonds $(415 \mathrm{~kJ} / \mathrm{mol}$ for methane and $350 \mathrm{KJ} / \mathrm{mol}$ for ethane) [6]. In catalytic processes, it is common to tackle this problem with the use oxygen at high temperatures. For e.g., oxidative methane conversion is carried out at temperatures close to $850^{\circ} \mathrm{C}$, while for ethane a temperature of $750^{\circ} \mathrm{C}$, and for LPG range hydrocarbons $\left(\mathrm{C}_{3}+\mathrm{C}_{4}\right)$ temperatures above $600^{\circ} \mathrm{C}$ are required [7]. However, the use of high temperatures for alkane conversion leads to several inherent difficulties, viz. (i) extensive endothermic C-C and C$\mathrm{H}$ bond cleavage causing coke formation (ii) loss of catalyst activity due to sintering and (iii) if oxygen is present, non-selective combustion is favored. Therefore it would be of considerable value if a process could be developed by which alkane activation can be performed at lower temperatures.

Plasma processes can generate active species i.e., electrons, ions and radicals at lower temperatures than catalytic processes $[8,9]$. For example, methane conversion with plasma has been widely investigated $[10,11]$. Typically, the used glow and corona discharge technology suffered from (i) rather high gas temperatures (ii) deterioration of electrodes because of their direct contact with the plasma and (iii) constriction of the plasma volume due to the employed electrode geometry.

In order to overcome these limitations, a plasma generated between two parallel electrodes by a dielectric barrier discharge (DBD) at atmospheric pressure has a large potential [12]. By definition, DBD is an electric discharge often referred to as a silent discharge or a microdischarge. In the case of $\mathrm{DBD}$, the temperature of the gas is close to ambient [13-15]. DBD is reported to be able to activate hydrocarbons as a result of electron impact collisions [14-16]. Plasmas generated by DBD in parallel-plate geometries at atmospheric pressure are the subject of numerous investigations of both 
experimental and theoretical nature. In the latter case, attempts were made to investigate the radical reaction network which involved under plasma conditions. Pioneering work by Kogelschatz and coworkers $[17,18]$ reported the direct conversion of $\mathrm{CO}_{2}$ and $\mathrm{CH}_{4}$ to synthesis gas and/or higher hydrocarbons, i.e., $\mathrm{C}_{2}-\mathrm{C}_{6}$, in a quartz reactor using dielectric barrier discharge. They also demonstrated the feasibility of performing the reaction of methane with carbon dioxide over various zeolite catalysts, promoted by DBD at ambient conditions $[19,20]$.

In this study, we report the oxidative conversion of propane in the presence of cold plasma in a microreactor [21]. The use of a microreactor for plasma processing [22] helps to work at higher pressures than those required in conventional plasma systems which all operate at low pressures in the milliTorr range [17]. Moreover, generation of a DBD at atmospheric pressure in a small and confined reactor space may imply (i) a stronger electric field, (ii) a more uniform and dense plasma, (iii) higher concentrations of electrons and radicals and (iv) better control of the residence time. The addition of small amounts of oxygen helps to achieve higher levels of hydrocarbon conversion, because the oxygen radicals generated help hydrogen abstraction from hydrocarbons [14, 15]. C-C and $\mathrm{C}-\mathrm{H}$ bond activation at lower temperatures and its influence on product selectivity will be discussed. Data obtained using a kinetic model are presented and the resulting product selectivity is compared to that obtained experimentally.

\section{Experimental}

Plasma microreactor. Fig. 1 shows the top view of the plasma microreactor used in this study. It consists of a Pyrex rectangular chip of $50 \mathrm{~mm}$ length $\mathrm{x} 15 \mathrm{~mm}$ width. The fabrication procedure of the open micro channel (E) is as follows: A chromium/gold mask layer was deposited by DC plasma sputtering on the wafer surface. Subsequently, the microchannels were defined by photolithography and using wet etching of, respectively, (i) the metal layers, and (ii) the Pyrex wafer using hydrofluoric acid (33 vol. \%). Sandwich thermal bonding $\left(600^{\circ} \mathrm{C}\right.$ for $\left.2 \mathrm{~h}\right)$ of three Pyrex wafers (one with and, respectively, the bottom and top plate without a channel) allowed fabrication of the microreactor (see Fig. 2). Before thermal bonding, the chromium/gold mask layer was stripped and the surface of the Pyrex 


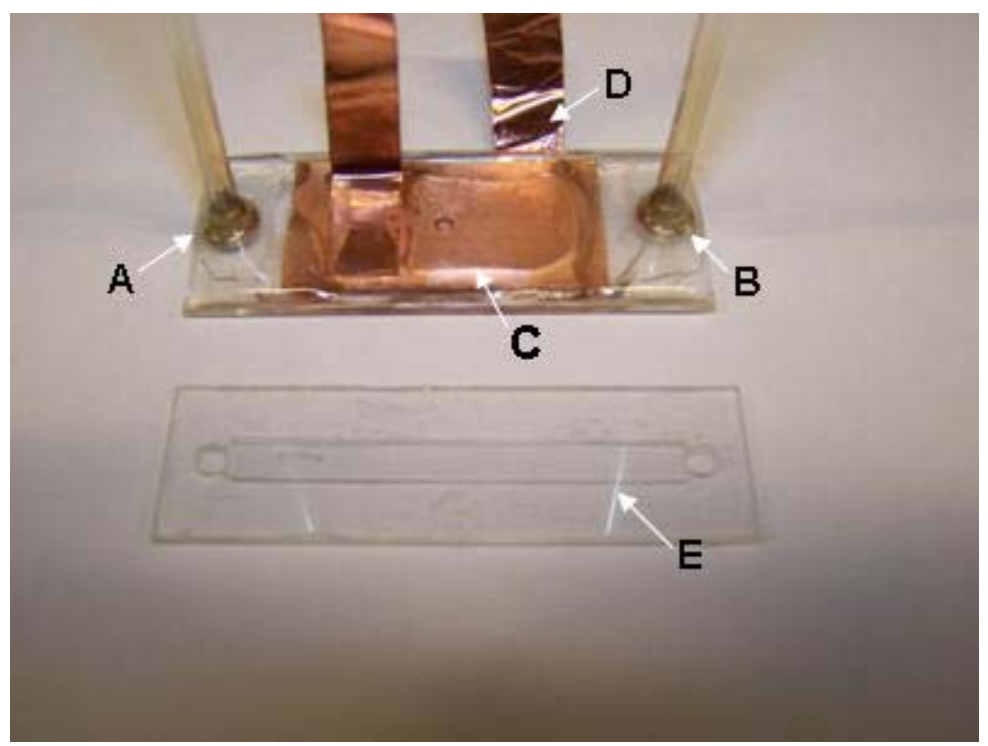

Figure 1. Employed microplasma reactor made of Pyrex. Top view. The inlet and outlet are indicated with A, B, resp. The copper plate (C) is connected to a power supply using adhesive copper foils (D). The microchannel (E) is also shown in the picture.

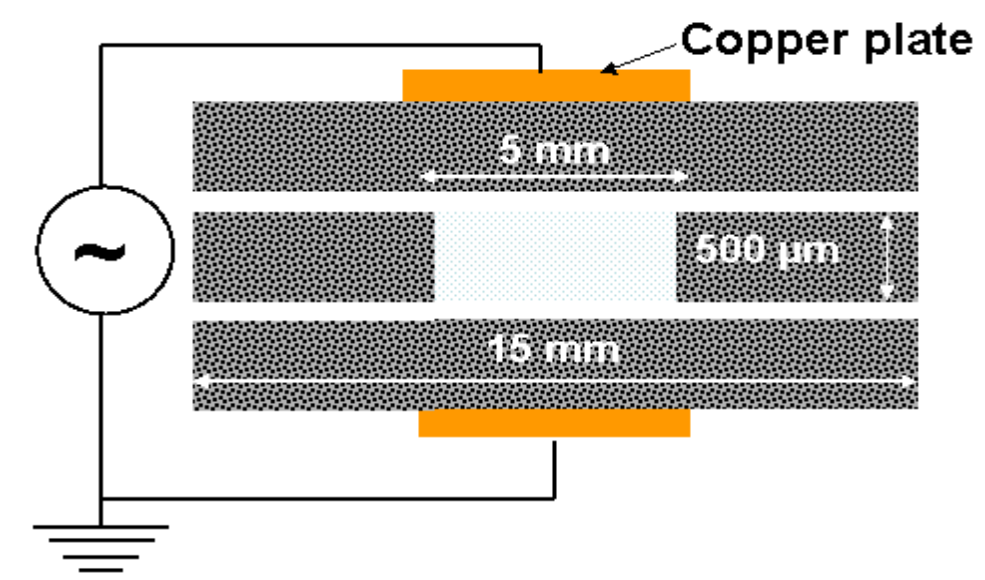

Figure 2. Schematic cross sectional view of the microplasma reactor. The 3 Pyrex plates forming the microreactor are schematically represented.

wafer was cleaned using (i) $\mathrm{HNO}_{3}(100 \%)$ and (ii) a solution of $\mathrm{KOH}(33 \%)$. Gas inlet and outlets were created by powder blasting using $\mathrm{Al}_{2} \mathrm{O}_{3}$ particles. Two copper ribbon electrodes were attached externally on the top and bottom side of the chip (see Fig. 1) and connected to a power supply in order to generate cold plasma by dielectric barrier discharge (DBD) at atmospheric pressure [23]. The power supply generates output voltages varying from 1 to $15 \mathrm{kV}$ at frequencies from 20 to $60 \mathrm{kHz}$. This corresponds to an output power between 2 and 25 watts. The power absorbed by the plasma was 
calculated from the corresponding V-Q Lissajous figures, obtained using an oscilloscope [24]. The resulting plasmas were stable and experiments were carried out at 3 Watt of absorbed power. Typically propane conversions of around $15-20 \%$ were observed under these conditions.

In order to determine the temperature of the gaseous plasma, optical emission spectra were recorded with an Ocean Optics HR 4000 spectrometer ( $0.7 \mathrm{~nm}$ spectral resolution) using an optical fiber connected to the microreactor. From the molecular emission spectra the rotational gas temperature can be calculated [25]. The temperature of the gas, outside the plasma region, was also monitored with a Type-K thermocouple. Gas flow rates were set using mass flow controllers and mixing occurred before the inlet to the microplasma reactor.

Propane activation/conversion in plasma microreactors. Propane activation was attempted in the microreactor containing a plasma at atmospheric pressure. The total gas flow rate was varied between 10 and $20 \mathrm{ml} . \mathrm{min}^{-1}$. The feed composition was varied between $10 \%$ alkane in helium and $100 \%$ alkane. A Varian $3800 \mathrm{GC}$ was used to analyze reactants and products. The GC was equipped with FID and TCD detectors. It was possible to separate all the hydrocarbons on an Alumina Plot column and the remaining components i.e., oxygen, $\mathrm{CO}$ and $\mathrm{CO}_{2}$, on a Porapak Q column in combination with a Molsieve-13X column.

Kinetic modeling. In order to understand the dominant reaction pathways in the plasma propane conversion process, a kinetic model was developed [26], in which it was assumed that the plasma process occurs at atmospheric pressure and constant temperature (298 K). Modeling was based on a "well stirred reactor model". The time averaged species composition was determined by solving balance equations for species, mass, gas and electron energy, with the use of the Chemkin 4.1 software package [27]. The Boltzmann equation solving BOLSIG+ software [28] was used for the calculation of the electron energy distribution function, which was combined with a reactor model to determine the electron energy using a power balance on the detailed electron-driven kinetics. Since the DBD is a non-homogeneous filamentary discharge, the residence time of the gas stream was corrected by the time in the filament. Assumption was made on matching the quantitative agreement of conversion of propane with the experimental result.

The reaction mechanism includes neutral-neutral chemistry, electron-induced dissociation, vibrational and electronic excitations, ionization, ion-neutral reactions and 
recombination of ions at the walls. With 38 neutral molecules in the model, more than 200 reactions were considered. Reactions of hydrocarbon radicals were assumed to play an important role in the propane plasma. The most important radicals are $\mathrm{H}, \mathrm{CH}, \mathrm{CH}_{2}$, $\mathrm{CH}_{3}, \mathrm{C}_{2} \mathrm{H}_{3}, \mathrm{C}_{2} \mathrm{H}_{5}, \mathrm{C}_{3} \mathrm{H}_{5}, \mathrm{C}_{3} \mathrm{H}_{7}$ and $\mathrm{C}_{4} \mathrm{H}_{9}$. Ionization, dissociative, vibrational and electronic excitation processes provided over 80 electron impact reactions of $\mathrm{H}_{2}, \mathrm{CH}_{4}$, $\mathrm{C}_{2} \mathrm{H}_{2}, \mathrm{C}_{2} \mathrm{H}_{4}, \mathrm{C}_{2} \mathrm{H}_{6}, \mathrm{C}_{3} \mathrm{H}_{8}$, and $\mathrm{C}_{4} \mathrm{H}_{10}$. As surface reactions we only included recombination of positive ions and electrons on the wall, where the released excitation energy deposits into the surface. All surfaces (sides, top and bottom) were assumed to have uniform conditions.

\section{Results}

Propane conversion in the presence of plasma in the microreactor. Fig. 3 shows the influence of the absorbed power, i.e., in the presence of plasma, on the propane conversion in the absence of oxygen. These experiments were performed between 0 and $6 \mathrm{~W}$ of absorbed power $(5-10 \mathrm{kV}$ applied voltage) because the non-thermal plasma was stable in this range. The dominant reaction path that occurs in such a non-thermal plasma is electron impact bond splitting [25]. In particular, as shown in Fig. 3, propane conversion increases with increasing energy input due to the increase of (i) the number of electrons and (ii) their average energy [26]. A typical propane conversion at $3 \mathrm{~W}$ power input was about $15 \mathrm{~mol} \%$.

Fig. 4 shows the optical emission spectrum recorded in the presence of $\mathrm{C}_{3} \mathrm{H}_{8}-\mathrm{He}$ and plasma at $3 \mathrm{~W}$ power input. Electronic excitation of ' $\mathrm{CH}$ ' corresponding to the $\mathrm{A}^{2} \Delta$ $\rightarrow X^{2} \Pi$ transition at $431.5 \mathrm{~nm}$ was used to determine the kinetic gas temperature in this emission region [29].

Rotational temperature, which reflects the gas temperature inside the filamentary discharge, was calculated by comparing the $\mathrm{CH}$ band (see Fig. 4) with those in spectra simulated as a function of temperature using LIFBASE software [14]. The best fit was obtained in the region of $25-75^{\circ} \mathrm{C}$. A thermocouple inserted inside the microchannel measured $75^{\circ} \mathrm{C}$ at the highest power of 24 watt supplied from the source. In the case of the $3 \mathrm{~W}$ used in our experiments the average gas temperature was close to ambient. 


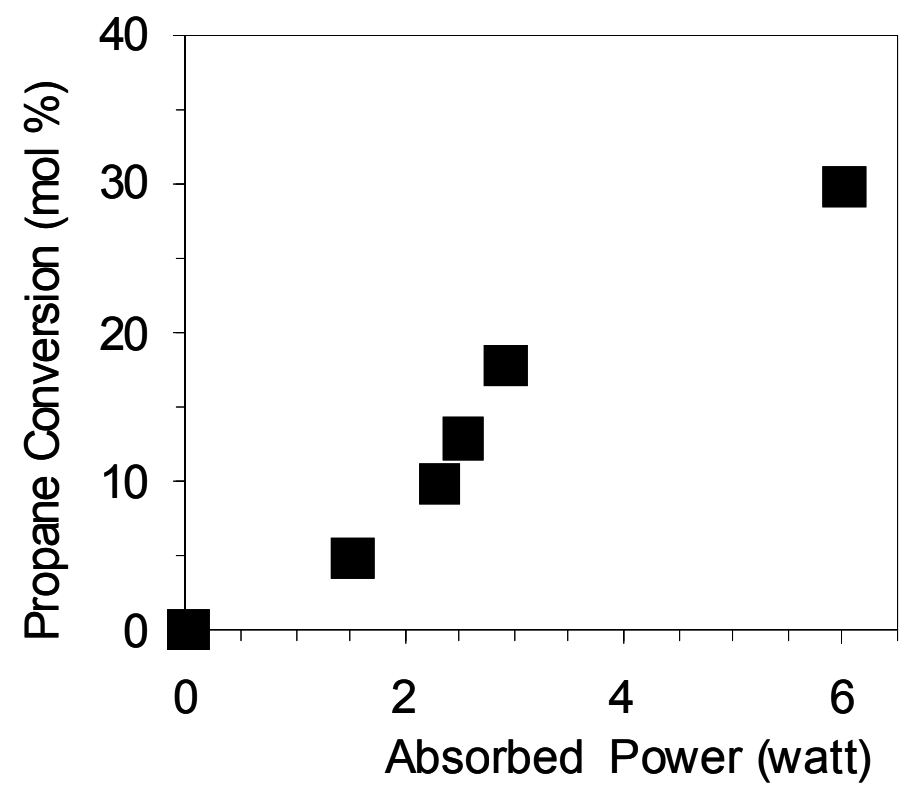

Figure 3. Influence of the power absorbed by the plasma on the conversion of propane. Conditions: $10 \%$ propane in helium, flow rate $10 \mathrm{ml} \cdot \mathrm{min}^{-1}, 1 \mathrm{~atm}$, and $25^{\circ} \mathrm{C}$.

The presence of $\mathrm{CH}$ and $\mathrm{H}$ bands in the spectra shown in Fig. 4 indicates decomposition of propane via $\mathrm{C}-\mathrm{C}$ and $\mathrm{C}-\mathrm{H}$ bond scission. This proofs that propane activation occurs close to room temperature.

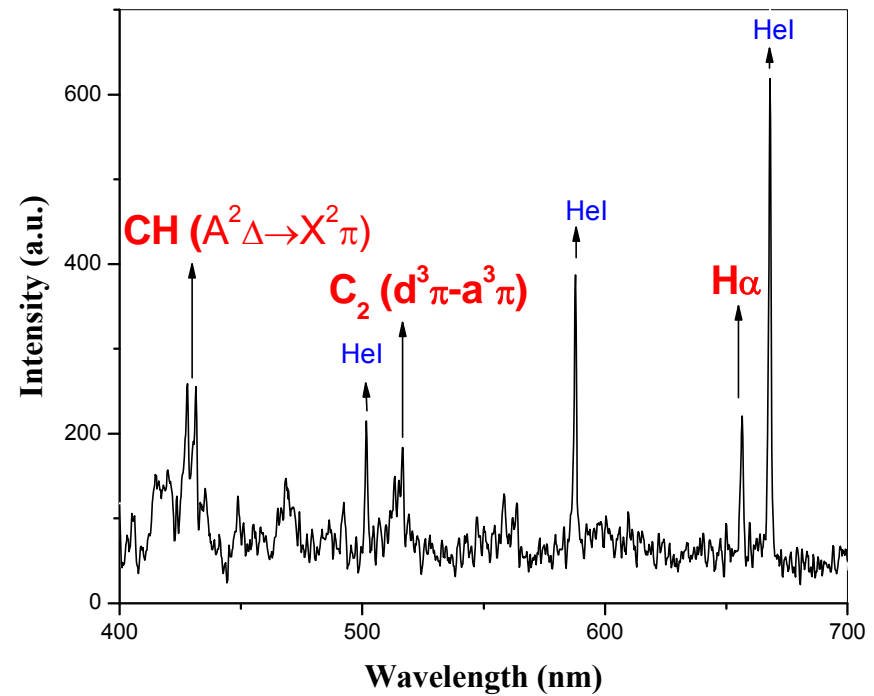

Figure 4. Optical emission spectrum for a gas mixture of $10 \%$ propane in helium in the presence of plasma in the microreactor; $3 \mathrm{~W}$ applied power.

In the presence of oxygen and under identical conditions ( $3 \mathrm{~W}$ of input power, $10 \%$ 
propane and $1 \%$ oxygen in helium), the propane conversion was higher i.e., $22 \mathrm{~mol} \%$ instead of $15 \mathrm{~mol} \%$, indicating that oxygen plays an added role in the propane conversion. Fig. 5 shows the typical product distribution obtained in the plasma microreactor at room temperature in the presence of oxygen. The carbon balance was $95 \pm 5 \%$, and no carbon deposition was observed in the reactor. It can be seen from Fig. 5 that propene is the most abundant olefin (14\%) followed by ethylene (12\%). Additionally, alkanes, methane ( $8 \%)$ and ethane $(14 \%)$ were also observed. Combustion products $\left(\mathrm{CO}+\mathrm{CO}_{2}\right)$ are present in about $10 \%$. As often reported for alkane activation by plasma [30], also ethyne (6\%) was found in the product stream. Most remarkably, a very high product selectivity to $\geq \mathrm{C}_{4}$ components was observed $\left(\mathrm{C}_{4}-13 \%, \mathrm{C}_{4}^{+}-24 \%\right)$.

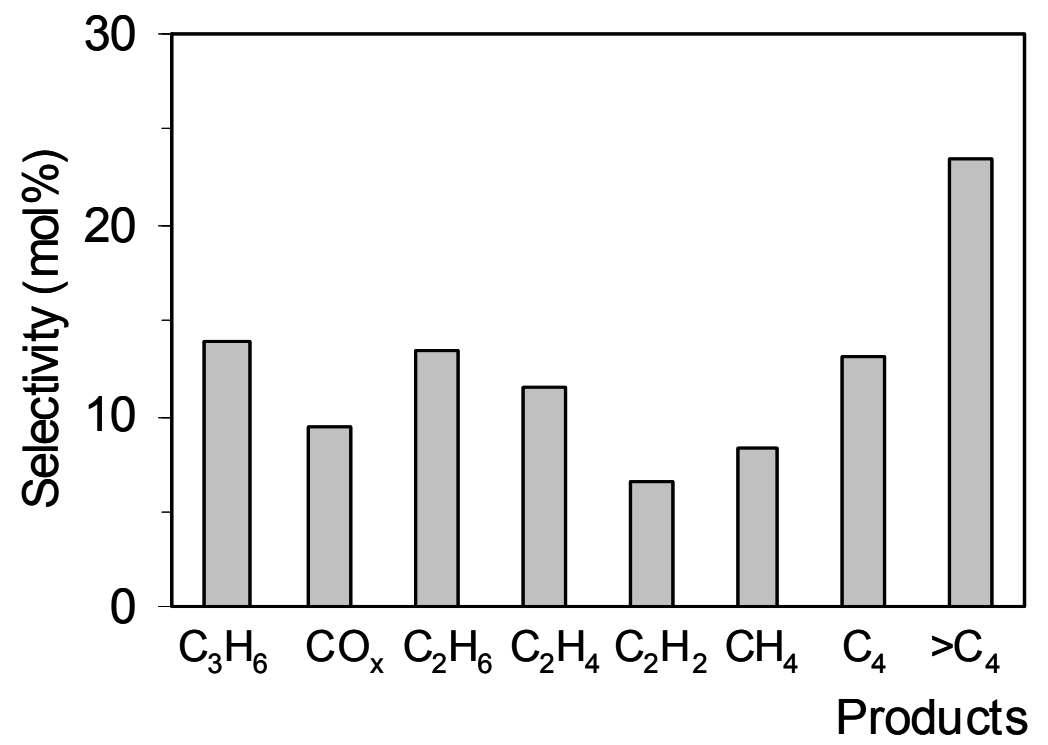

Figure 5. Selectivity to the " $C$ " containing products in the presence of plasma in the microreactor. Conditions: flow rate $15 \mathrm{ml} / \mathrm{min}$, feed composition $10 \%$ propane, $1 \%$ oxygen in helium, at ambient temperature; $22 \%$ propane conversion $\left(\mathrm{CO}_{\mathrm{x}}=\mathrm{CO}+\mathrm{CO}_{2}\right)$.

In order to highlight the product selectivity obtained in the micro plasma reactor, the product distribution obtained in an empty (i.e. no catalyst present) quartz tube reactor at $600^{\circ} \mathrm{C}$ (same feed composition) [14] is compared in Fig. 6. The selectivity presented in both cases is obtained at the same level of propane conversion, ca $20 \%$. In the case of the conventional high temperature experiments, no products containing a higher carbon number than the starting feed $\left(\mathrm{C}_{3}\right)$ were observed. It is obvious from Fig. 6 that the product selectivity shows striking differences in the two cases. In particular, in the case of the plasma microreactor large amounts $(37 \mathrm{~mol} \%)$ of products with higher molecular weights than propane, i.e., $\mathrm{C}_{4}, \mathrm{C}_{4}^{+}$, were observed. 


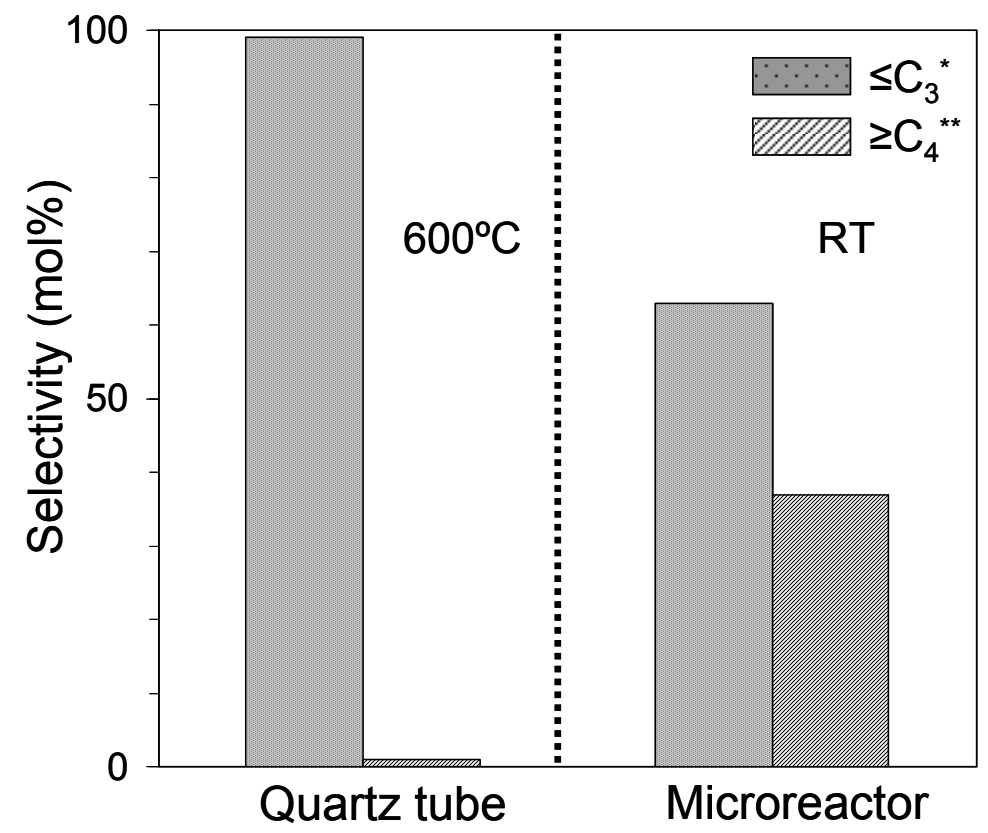

Figure 6. Product selectivity in oxidative conversion of propane, for a quartz tube reactor, without catalyst, at $600^{\circ} \mathrm{C}$ and a plasma microreactor at room temperature. Conditions: $10 \%$ propane and $1 \%$ oxygen in helium, same level of propane conversion $(20 \%)$ achieved by varying space velocity. ${ }^{*} \leq \mathrm{C}_{3}$ corresponds to $\mathrm{CO}_{\mathrm{x}}, \mathrm{C}_{2} \mathrm{H}_{4}, \mathrm{C}_{2} \mathrm{H}_{6}, \mathrm{C}_{3} \mathrm{H}_{6} ; * * \geq \mathrm{C}_{4}$ corresponds to $\mathrm{C}_{4}$ and $\mathrm{C}_{4}^{+}$(alkanes + olefins).

In order to check if the homologation observed during propane conversion in the microreactor, will also take place for ethane and methane, plasma activation of the latter compounds was tested. The results of this study, which showed that in both cases appreciable amounts of products were formed by C-C coupling, were previously reported [15]. .

Fig. 7 shows the calculated rates of the main dissociative excitation reactions as a function of the electric field in the presence of propane and plasma at atmospheric pressure. It is necessary to stress here that all the experiments of propane conversion in the presence of a plasma in the microreactor were performed in the electric field range 26$66 \mathrm{kV} / \mathrm{cm}$. In this range, as shown in Fig. 7, reaction channels which produce $\mathrm{C}_{3} \mathrm{H}_{6}, \mathrm{C}_{2} \mathrm{H}_{4}$ and $\mathrm{CH}_{4}$ present the highest reaction rates. These are the dominant electron impact reaction paths that occur during the conversion of propane. Reaction rates of plasma chemical reactions depend on the energy input. As the electric field increases in the microplasma reactor, higher energy input and larger average electron energies can be obtained. 


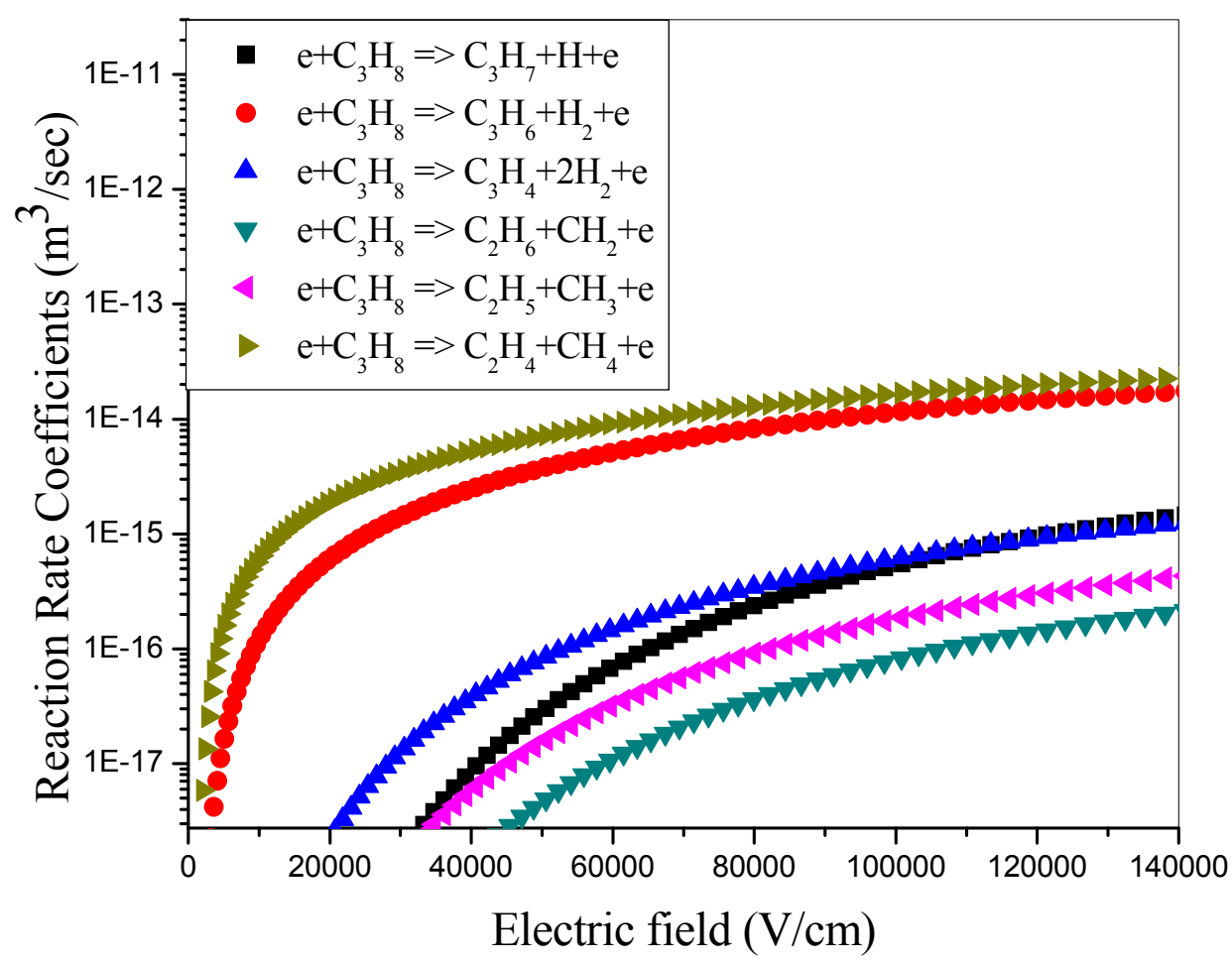

Figure 7. Calculated reaction rates as a function of electric field for the main dissociative excitation channels during propane conversion in the presence of plasma. Conditions: $100 \%$ propane at atmospheric pressure.

In Fig. 8, the selectivity to the main products observed during propane conversion under plasma conditions are compared with those obtained using the model predictions. In this particular case the experimental conditions were the following: $100 \%$ propane as feed and low conversion level of propane $(<8 \%)$ obtained by varying the space velocity. It is obvious from Fig. 8 that the product selectivity in both cases shows a close match. The plasma chemical kinetic model is able to predict the product selectivity within a few percent of the experimental results. From the results shown in Fig. 8 and with the aid of the $\mathrm{BOLSIG}+$ program [28] the estimated electron temperature was $3.6 \mathrm{eV}$, which is in good agreement with the one predicted with the CHEMKIN well-stirred plasma reactor model [27]. 


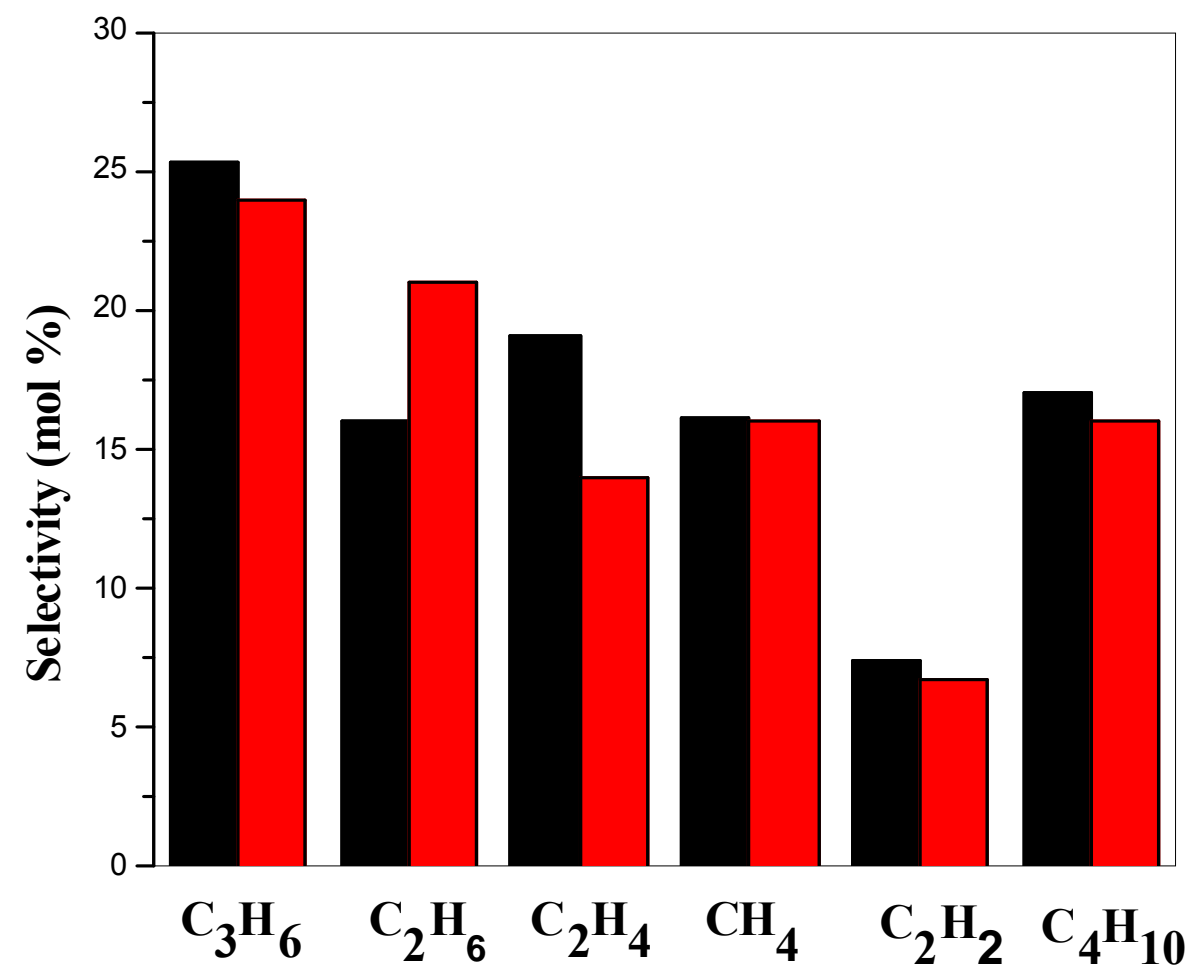

Figure 8. Selectivity for the main products of propane conversion. (1) Experimental results obtained under plasma conditions, $100 \%$ propane at ambient temperature and atmospheric pressure. ( $\square$ ) Modeling results, calculated for the same level of propane conversion (7.4\%), using Chemkin 4.1 [27].

Tab. 1 shows the most important reactions that occur during propane consumption/production under plasma conditions in the microreactor. In particular, the listed negative coefficients indicate propane consumption while the positive coefficients indicate propane production from radicals. The reactions listed in Tab. 1 involve (i) propane molecules, (ii) radicals having higher concentration, and (iii) free electrons (E). Dominant reaction paths that affect the conversion of propane are exclusively electron impact dissociation reactions.

The most important reaction that causes $\mathrm{C}_{3} \mathrm{H}_{8}$ consumption via electron impact leads to ethylene and methane by, eq. (1):

$$
\mathrm{E}+\mathrm{C}_{3} \mathrm{H}_{8}=>\mathrm{C}_{2} \mathrm{H}_{4}+\mathrm{CH}_{4}+\mathrm{E}
$$


Table 1. Most important reactions occuring during propane consumption or production under plasma conditions in the microreactor, determined by reaction rate analysis.

$\begin{array}{llr}\# & \text { Normalized Rate of Production Coefficients for } \\ & \mathrm{C}_{3} \mathrm{H}_{8} \text { Production and Consumption } \\ 1 & \mathrm{E}+\mathrm{C}_{3} \mathrm{H}_{8}=>\mathrm{C}_{3} \mathrm{H}_{6}+\mathrm{H}_{2}+\mathrm{E} & -0.107 \\ 2 & \mathrm{E}+\mathrm{C}_{3} \mathrm{H}_{8}=>\mathrm{C}_{3} \mathrm{H}_{6}+2 \mathrm{H}+\mathrm{E} & -0.027 \\ 3 & \mathrm{E}+\mathrm{C}_{3} \mathrm{H}_{8}=>\mathrm{C}_{2} \mathrm{H}_{4}+\mathrm{CH}_{4}+\mathrm{E} & -0.666 \\ 4 & \mathrm{CH}_{3}+\mathrm{C}_{2} \mathrm{H}_{5}=>\mathrm{C}_{3} \mathrm{H}_{8} & 0.738 \\ 5 & \mathrm{C}_{3} \mathrm{H}_{7}-1+\mathrm{C}_{2} \mathrm{H}_{5}=>\mathrm{C}_{2} \mathrm{H}_{4}+\mathrm{C}_{3} \mathrm{H}_{8} & 0.048 \\ 6 & \mathrm{C}_{3} \mathrm{H}_{7}-1+\mathrm{H}=>\mathrm{C}_{3} \mathrm{H}_{8} & 0.122 \\ 7 & \mathrm{C}_{3} \mathrm{H}_{7}-1+\mathrm{C}_{3} \mathrm{H}_{7}-2=>\mathrm{C}_{3} \mathrm{H}_{8}+\mathrm{C}_{3} \mathrm{H}_{6} & 0.011 \\ 8 & 2 \mathrm{C}_{3} \mathrm{H}_{7}-1=>\mathrm{C}_{3} \mathrm{H}_{8}+\mathrm{C}_{3} \mathrm{H}_{6} & 0.073 \\ 9 & \mathrm{C}_{3} \mathrm{H}_{8}+\mathrm{CH}_{2}=>\mathrm{n}-\mathrm{C}_{4} \mathrm{H}_{10} & -0.092 \\ 10 & \mathrm{C}_{3} \mathrm{H}_{8}+\mathrm{CH}_{2}=>\mathrm{i}-\mathrm{C}_{4} \mathrm{H}_{10} & -0.039 \\ 11 & \mathrm{C}_{3} \mathrm{H}_{8}+\mathrm{H}=>\mathrm{H}_{2}+\mathrm{C}_{3} \mathrm{H}_{7} & -0.047\end{array}$

Under plasma conditions the recombination of radicals such as $\mathrm{CH}_{3} \cdot$ and $\mathrm{C}_{2} \mathrm{H}_{5}$. can lead back to propane molecules (re-forming of propane) and hydrocarbons with a number of carbon atoms that is higher than 3, see eq. (2) and (3):

$$
\begin{aligned}
& \mathrm{CH}_{3} \cdot+\mathrm{C}_{2} \mathrm{H}_{5} \cdot=>\mathrm{C}_{3} \mathrm{H}_{8} \\
& \mathrm{C}_{3} \mathrm{H}_{8}+\mathrm{CH}_{2}=>\text { n, i- } \mathrm{C}_{4} \mathrm{H}_{10}
\end{aligned}
$$

Tab. 2 shows a comparison of the product selectivity observed for two different propane conversion levels obtained in the plasma microreactor at room temperature and atmospheric pressure. At a higher level of propane conversion (18.5\%), hydrocarbons with higher molecular weight than propane $\left(\mathrm{C}_{4}\right.$ and $\left.\mathrm{C}_{4}+\right)$ are the main products. This result implies an enhanced $\mathrm{C}-\mathrm{C}$ coupling mechanism at increasing conversion levels.

Table 2. Conversion of pure propane. Comparison of the product selectivity observed for two different propane conversion levels obtained in a plasma microreactor at room temperature and atmospheric pressure. 


\begin{tabular}{|c|l|l|l|l|l|l|}
\hline $\begin{array}{c}\mathrm{C}_{3} \mathrm{H}_{8} \\
\text { conversion (\%) }\end{array}$ & \multicolumn{6}{|c|}{ Product selectivity (\%) } \\
\hline & $\mathrm{C}_{3} \mathrm{H}_{6}$ & $\mathrm{C}_{2} \mathrm{H}_{6}$ & $\mathrm{C}_{2} \mathrm{H}_{4}$ & $\mathrm{CH}_{4}$ & $\mathrm{C}_{2} \mathrm{H}_{2}$ & $\geq \mathrm{C}_{4}$ \\
\hline 7.4 & 25.3 & 16 & 19 & 16 & 7.2 & $\mathbf{1 6 . 5}$ \\
\hline 18.5 & 18.6 & 16.1 & 15.2 & 15.5 & 8.6 & $\mathbf{2 6}$ \\
\hline
\end{tabular}

\section{Discussion}

It is general knowledge that the non-thermal plasma generated at atmospheric pressure by dielectric barrier discharge consists of current filaments, namely microdischarges, distributed in the space between the two electrodes (see Fig. 2). The number of microdischarges depends on (i) the voltage applied to the electrodes (ii) the distance between the electrodes (iii) the relative permittivity of the dielectric barriers and (iv) the gas ambient [31]. The relative permittivity of a dielectric barrier can strongly determine the amount of charge that can be stored for a certain value of applied electric field. This parameter plays a critical role in plasma formation [32].

In the plasma microreactor, $\mathrm{C}_{3} \mathrm{H}_{8}$ molecules are directly activated or converted via collisions with energized electrons. Activation produces radicals such as $\mathrm{C}_{3} \mathrm{H}_{7}$. due to cleavage of $\mathrm{C}-\mathrm{H}$ bonds (eq. 4). These can initiate radical chain reactions.

$$
\mathrm{C}_{3} \mathrm{H}_{8}+\mathrm{e}-\rightarrow \mathrm{C}_{3} \mathrm{H}_{7} \cdot \mathrm{H} \cdot+\mathrm{e}-
$$

Reaction (4) is strongly influenced by the number of charges transferred or accumulated on the dielectric surface [33].

Additionally, propane activation can also occur via an indirect route involving activation of gas phase oxygen by the plasma. Among the atomic processes taking place in a non-thermal plasma, electron impact dissociation of $\mathrm{O}_{2}$ to form charged and neutral oxygen has been reported in literature and is described in reaction equations (5) and (6) [34]. In equation (6), $\mathrm{O}_{2}{ }^{*}$ represents an electronically excited oxygen molecule.

$$
\begin{aligned}
\mathrm{E}+\mathrm{O}_{2} & =>2 \mathrm{O}+\mathrm{E}=>\mathrm{O}^{-}+\mathrm{O} \\
\mathrm{E} & +\mathrm{O}_{2}=>\mathrm{O}_{2} *+\mathrm{e}-\mathrm{O}+\mathrm{O}+\mathrm{E}
\end{aligned}
$$

The $\mathrm{O}^{-}$species, present in the homogeneous phase, is reported to enhance $\mathrm{C}-\mathrm{H}$ bond scission in alkanes and thus increase the concentration of radical species [35]. In the case 
of propane this will result in the formation of propyl and hydroxyl radicals as shown below:

$$
\left[\mathrm{O}^{-}\right]+\mathrm{C}_{3} \mathrm{H}_{8}=>\left[\mathrm{OH}^{-}\right]+\mathrm{C}_{3} \mathrm{H}_{7} .
$$

The increased propane conversion (22\%) observed while co-feeding oxygen (propane conversion was $15 \%$ in the absence of oxygen under identical conditions) supports the above argument. Electron impact processes which induce dissociation of oxygen molecules to radicals can enhance the conversion of propane. Additionally, we observed earlier that by adding oxygen the number and concentration of chain carrier radicals increased [36]. $\mathrm{C}_{3} \mathrm{H}_{7}$. radicals react fast with $\mathrm{O}_{2}$ forming hydro-peroxyl $\left(\mathrm{HO}_{2} \cdot\right)$ radicals, which can react with propane molecules to form $\mathrm{H}_{2} \mathrm{O}_{2}$. Decomposition of $\mathrm{H}_{2} \mathrm{O}_{2}$ results in hydroxyl radicals $(\mathrm{OH} \cdot)$ which become the main chain propagators.

In our experiments, we observe appreciable amounts of ethyne. Activation of methane is known to yield ethyne in the presence of plasma $[30,35]$. Two routes are often suggested. Firstly, ethyne can be formed by extensive dehydrogenation of $\mathrm{C}_{2}$ species present during methane conversion [37]. We have also observed $\mathrm{C}_{2}$ species in our experiments (see Fig. 5). Furthermore, $\mathrm{CH}$ species are formed in the presence of plasma (see Fig. 4). Dimerization of such species can result in ethyne. Such a possibility was also suggested by Kado et al. [38] basen on their study on methane conversion. Hydrogen redistribution during this reaction, forming dehydrogenated products like ethyne, may be the reason for the appreciable amount of methane observed.

The oligomerization argument can also be logically connected to the large amounts of $\mathrm{C}_{4}$ and $\mathrm{C}_{4}^{+}$products that we observe. The role of plasma is in the activation of propane and formation of radicals at ambient temperatures as stated previously. Formation of $\mathrm{C}_{4}$ and $\mathrm{C}_{4}{ }^{+}$products from propane essentially requires $\mathrm{C}-\mathrm{C}$ bond formation, which is an exothermic process and therefore favored at lower temperatures. Coupling reactions between radicals also imply a decrease in entropy because the number of molecules/radicals is decreasing by definition. Therefore, it is not surprising to see C-C bond formation reactions under our conditions. In conventional fixed bed reactors, propane activation occurs at higher temperatures $\left(\mathrm{T}>600^{\circ} \mathrm{C}\right)$ in the presence of catalyst. These conditions favor the rupture of $\mathrm{C}-\mathrm{C}$ bonds (causing an increase in entropy) and therefore only products of cracking i.e., with molecular weights lower than that of propane, are observed.

An understanding of the exact reaction network under the reaction conditions in this study is still a challenging task. In order to simplify the problem, simulation of propane conversion in the presence of plasma was performed in the absence of oxygen and for low 
conversion levels of propane $(<8 \%)$. The set of reactions chosen (265 steps) in the model is sufficient to describe the plasma chemical kinetics since it can predict the experimental selectivity relatively well. In the discharge region of the microreactor, energetic electrons collide with propane via inelastic collisions and form radicals, ions and excited species (rotational, vibrational and electronic) in the gas stream. Ions and excited species can transfer their energy to the neutral molecules and the walls of the microreactor. In order to understand the complex non-equilibrium processes in the propane plasma, the dominant reaction paths were determined by a sensitivity analysis and a rate of production analysis. These reaction channels, in the case of propane conversion, are most likely the electronimpact dissociation reactions. As previously discussed [12] a DBD consists of a large number of current streamers which last tens of nanoseconds. During the short life time of the current streamers, primary radicals such as $\mathrm{H}, \mathrm{CH}, \mathrm{CH}_{2}, \mathrm{CH}_{3}, \mathrm{C}_{2} \mathrm{H}_{3}, \mathrm{C}_{2} \mathrm{H}_{5}, \mathrm{C}_{3} \mathrm{H}_{5}, \mathrm{C}_{3} \mathrm{H}_{7}$ and $\mathrm{C}_{4} \mathrm{H}_{9}$ are created by electron-impact collisions and they will be rapidly consumed in recombination reactions to produce higher molecular weight hydrocarbons. The relationship between the electric field applied and electron impact dissociative excitation of propane (see Fig. 7) indicates that higher electric fields inside the microreactor result in higher rate constants. Therefore, higher conversion rates of propane could be obtained. As the energy deposition into the microplasma increases, the density of reaction products also increases and products accumulate in the gas stream.

Based on the observed product selectivity it is possible to establish a reaction network for the studied conditions. Fig. 9 proposes a scheme with the dominant reaction paths for $\mathrm{C}_{1}, \mathrm{C}_{2}, \mathrm{C}_{3}$ and $\mathrm{C}_{4}$ hydrocarbons, where species containing more than four carbon atoms were not considered. The first step is electron impact dissociation of propane, which leads to the main reaction products and radicals. Several chain reactions involving $H$ and hydrocarbon radicals may take place. As the current streamers propagate, the radicals combine quickly to form the main products. The experimental results (see Fig. 8) at low level of propane conversion $(<8 \%)$ and in absence of oxygen show that light hydrocarbons in the range $\mathrm{C}_{1}-\mathrm{C}_{3}$ are the main products. $\mathrm{C}_{4}$ species are also detected to an appreciable extent, the formation of which would require $\mathrm{C}-\mathrm{C}$ bond formation (coupling). At higher levels of propane conversion (>15\%) (see Tab. 2) and therefore with a high density of radical species, more and more of the hydrocarbons with higher molecular weight than the starting feedstock, like $\mathrm{C}_{4}$ and $\mathrm{C}_{4}+$, become the dominant features, due to enhanced coupling under cold plasma conditions. 


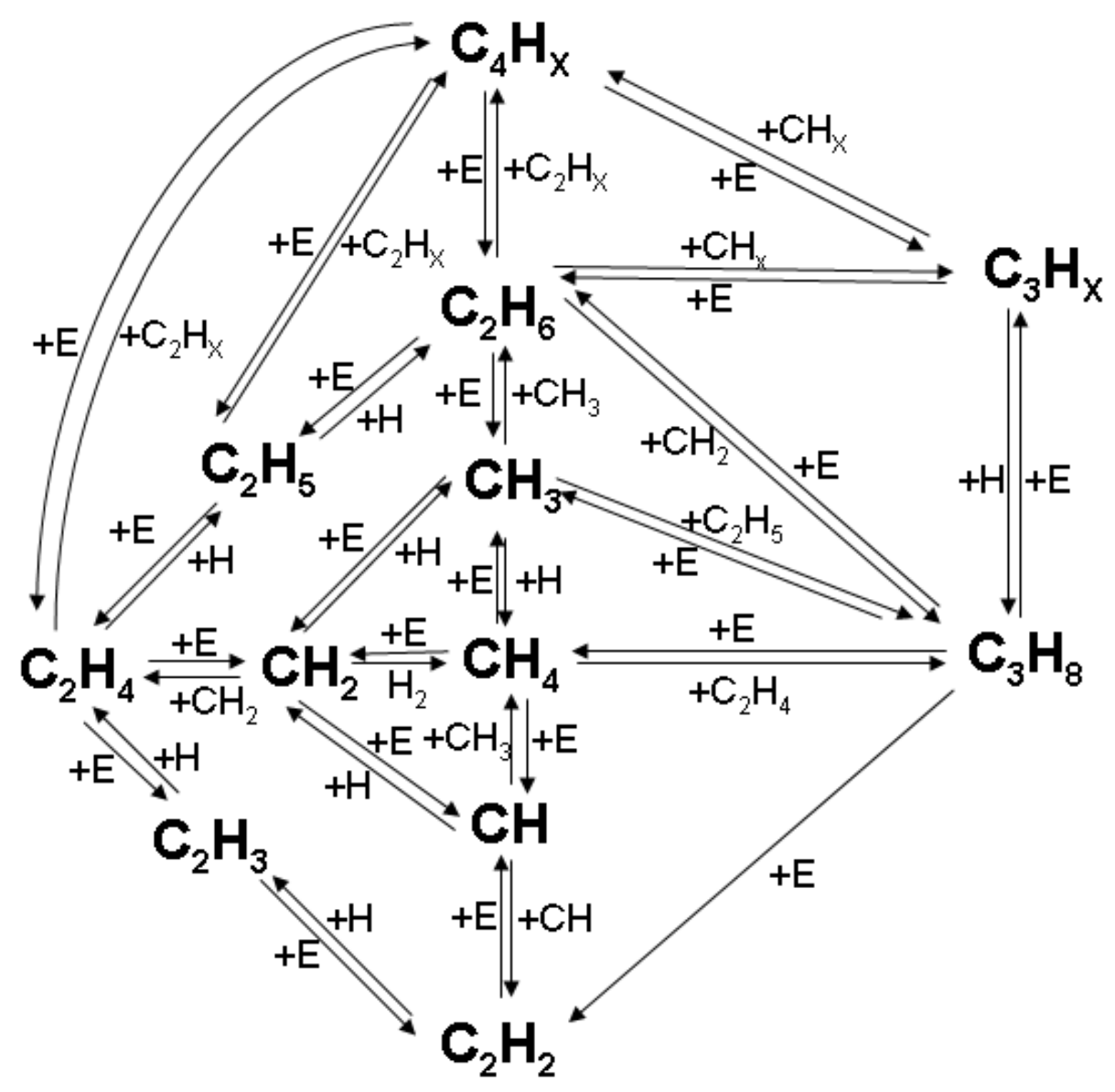

Figure 9. Propane conversion scheme showing dominant reaction paths.

Thus, during propane conversion in the presence of a plasma, in a confined small volume, the radical density plays a key role and fine-tunes the final product selectivity. In addition, the low activation temperature for propane conversion offers exciting opportunities.

Finally, it is appropriate to discuss here the additional advantage of plasmas generated by DBD. It is generally discussed that due to the non-homogenous nature of the discharge (during plasma generation) the streamers occupy exclusively a small fraction of the whole reactor volume. Primary propane activation occurs in these regions, however further interaction with species of radical chain reactions with electrons in the streamers are minimized and reduce undesired electron impact dissociation reactions with desired products.

\section{Conclusion}

The oxidative conversion of propane was carried out in a Pyrex microreactor in the presence of a plasma generated by dielectric breakdown at atmospheric pressure and 
ambient temperatures. The conditions present in the investigated microplasma reactor, in particular the low activation temperatures, favor the formation of $\mathrm{C}-\mathrm{C}$ bonds. $\mathrm{C}_{4}$ and $\mathrm{C}_{4}+$ are the major products.

A chemical kinetic model was developed to point out the dominant reaction pathways during propane conversion. At lower levels of propane conversion and in absence of oxygen the chemical kinetic model accurately predicts the final product selectivity. The results showed that in a confined reactor volume also the radical density can determine the final product selectivity. At higher level of propane conversion and therefore higher radical density an enhanced $\mathrm{C}-\mathrm{C}$ bond formation is observed.

\section{Acknowledgements}

We thank the Dutch Technology Foundation STW, applied science division of NWO and the Technology Program of the Ministry of Economic Affairs, The Netherlands, for financial support (project number 06626). Part of this research was supported by the CW/NWO, The Netherlands (project number 700.50.005). 


\section{References}

(1) D. J. Driscoll, K. Campbell, J. H. Lunsford, Advances in Catalysis 1987, 35, 139.

(2) L. Leveles, K. Seshan, J. A. Lercher, L. Lefferts, J. Catal. 2003, 218, 307.

(3) O. V. Buyevskaya, M. Baerns, Catal. Tod. 1998, 42, 315.

(4) P. M. Couwenberg, Q. Chen, G. B. Marin, Ind. \& Eng. Chem. Res. 1996, 35 (11), 3999.

(5) J. H. Lunsford, Langmuir 1989, 5, 12.

(6) T. V. Choudary, E. Aksoylu, D. Wayne Goodman, Catalysis Reviews 2003, 45 (1), 151.

(7) V. P. Vislovskiy, T. E. Suleimanov, M. Y. Sinev, Y. P. Tulenin, L. Y. Margolis, V. C. Corberan, Catal. Tod. 2000, 61, 287.

(8) F. M. Aghamir, N. S. Matin, A. H. Jalili, M. H. Esfarayeni, M. A. Khodagholi, R. Ahmadi, Plasma Sources Sci. Technol. 2004, 13, 707.

(9) A. Huang, G. Xia, J. Wang, S.L. Suib, Y. Hayashi, H. Matsumoto, J. Catal. 2000, 189, 349.

(10) A. Marafee, C. Liu, G. Xu, R. Mallinson, L. Lobban, Ind. Eng. Chem. Res. 1997, 36, 632.

(11) S. Y. Savinov, H. Lee, H. K. Song, B. K. Na, Ind. Eng. Chem. Res. 1999, 38(7), 2540.

(12) H.K. Jeong, S.C. Kim, C. Han, H. Lee, H.K. Song, K.B. Na, Korean J. Chem. Eng. 2001, 18(2), 196.

(13) H. Kim, Plasma Proc. and Polym. 2004, 1, 91.

(14) C. Trionfetti, A. Agiral, J.G.E. Gardeniers, L. Lefferts, K. Seshan, J. Phys. Chem. C 2008, 112(11), 4267.

(15) C. Trionfetti, A. Agiral, J.G.E. Gardeniers, L. Lefferts, K. Seshan, ChemPhysChem 2008, 9(4), 533.

(16) U. Kogelschatz, Plasma Chem. and Plasma Proc. 2003, 23 (1), 1.

(17) B. Eliasson, C.J. Liu, U. Kogelschatz, Ind. Eng. Chem. Res. 2000, 39, 1221.

(18) K. Zhang, U. Kogelschatz, B. Eliasson, Energy \& Fuel 2001, 15, 395.

(19) K. Zhang, B. Eliasson, U. Kogelschatz, Ind. Eng. Chem. Res. 2002, 41, 1462.

(20) M. Kraus, B. Eliasson, U. Kogelschatz, A. Wokaun, Phys. Chem. Chem. Phys. 2001, 3, 294.

(21) R.M. Tiggelaar, F. Benito-Lopez, D.C. Hermes, H. Rathgen, R.J.M. Egberink, F. Mugele, D. N. Reinhoudt, A. van den Berg, W. Verboom, H.J.G.E. Gardeniers, Chem. Eng. J. 2007, 131, 163.

(22) U. Kogelschatz, Contrib. Plasma Phys. 2007, 47 (1-2), 80. 
(23) G. Nersisyan, W. G. Graham, Plasma Sources Sci. Technol. 2004, 13, 582-587.

(24) T. Nozaki, N. Muto, S. Kadio, K. Okazaki, Catalysis Today 2004, 89, 67.

(25) U. Kogelschatz, Plasma Physics and Controlled Fusion 2004, 46, B63-B75.

(26) A. Agiral, C. Trionfetti, K. Seshan, L. Lefferts, J.G.E. Gardeniers, in Proc. of the 18th Int. Conf. on Plasma Chemistry (Eds: K. Tachibana, O. Takai, K. Ono, T. Shirafuji), 28P-137, 2007.

(27) R. J. Kee, F. M. Rupley, J. A. Miller, M. E. Coltrin, J. F. Grcar, E. Meeks, H. K. Moffat, A. E. Lutz, G. Dixon-Lewis, M. D. Smooke, J. Warnatz, G. H. Evans, R. S. Larson, R. E. Mitchell, L. R. Petzold, W. C. Reynolds, M. Caracotsios, W. E. Stewart, P. Glarborg, C. Wang, C. L. McLellan, O. Adigun, W. G. Houf, C. P. Chou, S. F. Miller, P. Ho, P. Young, D. J. Young, CHEMKIN Release 4.0, Reaction Design, San Diego, CA (2004).

(28) G. J. M. Hagelaar, L. C. Pitchford, Plasma Sources Sci. Technol. 2005, 14, 722.

(29) J. Lugue, D. R. Crosley, Lifbase: Database and Spectral Simulation Program (ver.1.6) 1999 SRI International Report MP 99-009.

(30) Y. Yang, Plasma Chemistry and Plasma Processing 2003, 23(2), 327.

(31) R. Li, Y. Yamaguchi, S. Yin, Q. Tang, T. Sato, Solid State Ionics 2004, 72, 235.

(32) X. Xu, Thin Solid Films 2001, 390, 237.

(33) J. Pons, E. Moreau, G. Touchard, J. Phys. D : Appl. Phys. 2005, 38, 3635.

(34) P. C. Cosby, J. Chem. Phys. 1993, 98(12), 9560.

(35) X. Zhang, A. Zhu, X. Li, W. Gong, Catal. Tod. 2004, 89, 97.

(36) L. Leveles, K. Seshan, J. A. Lercher, L. Lefferts, J. Catal. 2003, 218, 296.

(37) S. S. Kim, H. Lee, B. K. Na, H. K. Song, Korean J. Chem. Eng. 2003, $20(5), 869$.

(38) S. Kado, K. Urasaki, Y. Sekine, K. Fujimoto, T. Nozaki, K. Okazaki, Fuel 2003, 82, 2291. 


\section{Chapter 3}

\section{Oxidative conversion of propane in a microreactor in the presence of plasma over MgO based catalysts - An experimental study}

In this work, oxidative cracking of propane was studied in a microreactor containing a catalyst. A dielectric barrier discharge allows one to generate a cold microplasma, which activates the formation of radicals from propane, at room temperature and atmospheric pressure. Homogeneous and crystalline $25 \mu \mathrm{m}$ thick layers of $\mathrm{MgO}$ and $\mathrm{Li} / \mathrm{MgO}$ catalysts were deposited in the microchannel using a sol-gel method and by micropipette. The $\mathrm{Li} / \mathrm{MgO}$ catalyst showed higher propane conversion and olefin selectivity than $\mathrm{MgO}$, which suggests that (i) radicals formed by $\mathrm{DBD}$ are differently terminated depending on the catalyst surface; (ii) the surface of $\mathrm{Li} / \mathrm{MgO}$ catalyst presents more selective sites than $\mathrm{MgO}$, such as $\left[\mathrm{Li}^{+} \mathrm{O}^{-}\right]$centers and F-type defects which are generated and able to react at RT. Surprisingly large amounts of products like C4, C4+, with a higher molecular weight than the starting gas propane, were observed due to C-C bond formation.

This chapter was published in:

Oxidative conversion of propane in a microreactor in the presence of plasma over MgO based catalysts-an experimental study, CRISTIANO TRIONFETTI, ANIL AGIRAL, J. G. E. (HAN) GARDENIERS, LEON LEFFERTS, K. SESHAN, Journal of Physical Chemistry C, volume 112(11), page 4267-4274 (2008). 


\section{Introduction}

Formation and reaction of gas phase free radicals generated on a catalyst surface has raised increasing interest in recent years, especially in the case of reactions occurring at higher temperatures [1]. Radical species have been proposed as intermediates in numerous catalytic reactions involving partial oxidation of hydrocarbons to olefins and oxygenates. These are the so called heterogeneously initiated homogeneous processes [2]. In these processes, activation of hydrocarbons occurs on the catalytic site via homolytic splitting of C-C or C-H bonds, resulting in the formation of radicals. There is general evidence that the radicals thus generated are released from the catalyst surface to the gas phase, while subsequently radical chain reactions lead to the final products [1-2]. Alternatively, these radicals can also remain on the catalyst surface and undergo further reactions before desorption, to yield specific products [3].

Homogeneous gas phase routes in heterogeneous catalysis have been considered in the last 20 years as important steps in the coupling of methane to higher hydrocarbons [4] and in oxidative dehydrogenation of light alkanes (ODH) to olefins [5]. By varying the post-catalytic volume of the reactor in which the reaction is carried out and recording that this causes an increase in conversion [3], it was concluded that gas phase radical reactions form a major contribution to such processes. In addition, direct evidence for the presence of surface-generated gas-phase radicals has been provided by spectroscopic methods, in particular by techniques like matrix isolation electron spin resonance (MIESR) and infrared spectroscopy (MI-IR) in tandem with a catalytic reactor [6-7].

In the case of oxidative dehydrogenation of alkanes, using $\mathrm{Li} / \mathrm{MgO}$ catalysts, EPR studies showed the existence of $\left[\mathrm{Li}^{+} \mathrm{O}^{-}\right]$defect sites to be the active centers [8]. These sites are responsible for the activation of $\mathrm{C}-\mathrm{H}$ bonds of alkanes in the presence of oxygen at higher temperatures. During the hydrocarbon conversion, the initial step is the hydrogen atom abstraction by oxygen ions [9], forming hydroxyl groups and alkyl radicals (Eq.1):

$$
\left[\mathrm{Li}^{+} \mathrm{O}^{-}\right]+\mathrm{C}_{3} \mathrm{H}_{8} \rightarrow\left[\mathrm{Li}^{+} \mathrm{OH}^{-}\right]+\mathrm{C}_{3} \mathrm{H}_{7} \text {. }
$$

These propyl radicals undergo radical chain reactions in the gas phase $[5,10]$. Thus the catalyst affects the activation of propane and product selectivity is determined by the gas phase homogeneous reactions. On the other hand, Kondratengo et al. recently reported for the case of vanadium oxide systems that increasing the density of active sites 
affected olefin distribution [11]. More specifically, for a high density of oxidizing sites, heterogeneous $\mathrm{H}$-atom abstraction from $\mathrm{C}_{3} \mathrm{H}_{7}$. radicals yielding propene can be more effective than the reaction of $\mathrm{C}_{3} \mathrm{H}_{7}$. radicals in the gas phase [11].

In the case of $\mathrm{Li} / \mathrm{MgO}$ catalyst an increase of olefin selectivity could be achieved by increasing the number of active sites per volume of catalytic bed [12]. It was suggested recently, that propyl radicals undergo a second hydrogen abstraction at the active sites leading to propene (Eq. 2) [12]:

$$
\left[\mathrm{Li}^{+} \mathrm{O}^{-}\right]+\mathrm{C}_{3} \mathrm{H}_{7} \cdot \rightarrow\left[\mathrm{Li}^{+} \mathrm{OH}^{-}\right]+\mathrm{C}_{3} \mathrm{H}_{6}
$$

Generally, propane activation by $\mathrm{C}-\mathrm{C}, \mathrm{C}-\mathrm{H}$ bond scission requires higher temperatures $\left(\mathrm{T}>550^{\circ} \mathrm{C}\right)$, even in the presence of a strong $[\mathrm{H} \cdot]$ abstractor such as $\left[\mathrm{Li}^{+} \mathrm{O}^{-}\right]$. This is a drawback because substantial loss of catalyst surface area occurs due to sintering of $\mathrm{Li} / \mathrm{MgO}[13,14]$. This may result in a lower contribution from the heterogeneous formation of propene (eq. 2). This can be investigated in two ways i.e., (i) to allow initial alkane activation at lower temperatures, and (ii) to carry out the reaction in small and confined reactor space, enhancing radical surface interactions. We propose to achieve this by carrying out the oxidation of propane in the presence of plasma in a microreactor $(\mu-$ reactor). The use of a microreactor allows one to generate a non-thermal plasma at higher pressures, i.e., without the need for vacuum.

A stable and cold gaseous plasma can be generated inside a microreactor at room temperature by dielectric barrier discharge, DBD [15]. This plasma consists of energetic electrons which can activate propane as a result of inelastic collisions [16]. Ions and radicals are thus formed at room temperatures at which the catalyst surface area is not affected. Additionally, performing the reaction in a microscale system (in microchannels with dimensions 10-1000 $\mu \mathrm{m}$ ) with an intrinsic high surface-to-volume ratio provides extreme quenching potential [17-18].

A microplasma reactor containing catalyst may be used to convert hydrocarbons i.e., light alkanes, into more valuable molecules by cleavage or formation of $\mathrm{C}-\mathrm{H}$ and $\mathrm{C}-\mathrm{C}$ bonds at room temperature and atmospheric pressure [19]. Incorporation of a stable catalyst layer on the reactor wall is crucial in such a situation. Much has been reported about the deposition of catalysts on microreactors walls as a replacement for powders packed in the microchannels, which leads to a high pressure drop [20].

The objective of the present study is to (i) develop a microreactor containing 
$\mathrm{Li} / \mathrm{MgO}$ catalyst, (ii) demonstrate plasma activation of $\mathrm{C}-\mathrm{C}, \mathrm{C}-\mathrm{H}$ bonds at room temperature, (iii) allow efficient contact of radicals with the catalyst surface at low temperature and (iv) investigate the effect of this interaction on product selectivity. The target reaction is oxidative conversion of propane to olefins.

\section{Experimental}

\section{Microplasma reactor}

Figs. 1 and 2 show, respectively, a top view and a cross-section of the microplasma reactor used in this study. The reactor consists of a Pyrex rectangular chip of $50 \mathrm{~mm}$ length $\times 15 \mathrm{~mm}$ width, in which microchannels of $30 \mathrm{~mm}$ long, $5 \mathrm{~mm}$ wide and $500 \mu \mathrm{m}$ deep were realized by means of chemical etching with aqueous HF. The three Pyrex plates (one with, two without a channel) were thermally bonded. Details of the processing scheme are given elsewhere [21]. Gas in- and outlet holes were created by powder blasting with $\mathrm{Al}_{2} \mathrm{O}_{3}$ particles. The bottom surface of the reactor channels was treated by powder blasting to increase their roughness and allow better catalyst adhesion. After powder blasting, the reactor was cleaned in an ultra sonic bath to remove contamination. Two copper ribbon electrodes were attached externally on the top and bottom side of the chip and connected, via adhesive copper foil, to a power supply in order to generate plasma by DBD at atmospheric pressure. A high voltage $(5-10 \mathrm{kV})$ sine wave with a frequency around $60 \mathrm{kHz}$ was applied to one electrode while the other was grounded. This generated an output power between 2 to 25 watts. The power absorbed by the plasma was calculated from the corresponding V-Q Lissajous figures [22].

The plasma generated in the DBD configuration consists of high energy electrons and is characterized by a large number of microdischarge filaments (ionization of the medium by the electrons), each lasting nano-seconds [23]. These electrons with a high energy in the range $3-4 \mathrm{eV}$ are able to activate hydrocarbons and oxygen at room temperature and atmospheric pressure [24].

The short lifetime, nanoseconds, of the current spikes helps in minimizing local heating. Moreover, the small volume and the large surface-to-volume ratio of the microreactor allow fast removal of the heat produced during oxidation of propane. Optical emission spectra were recorded with an Ocean Optics HR 4000 spectrometer with fiber optic coupling to the microreactor. 


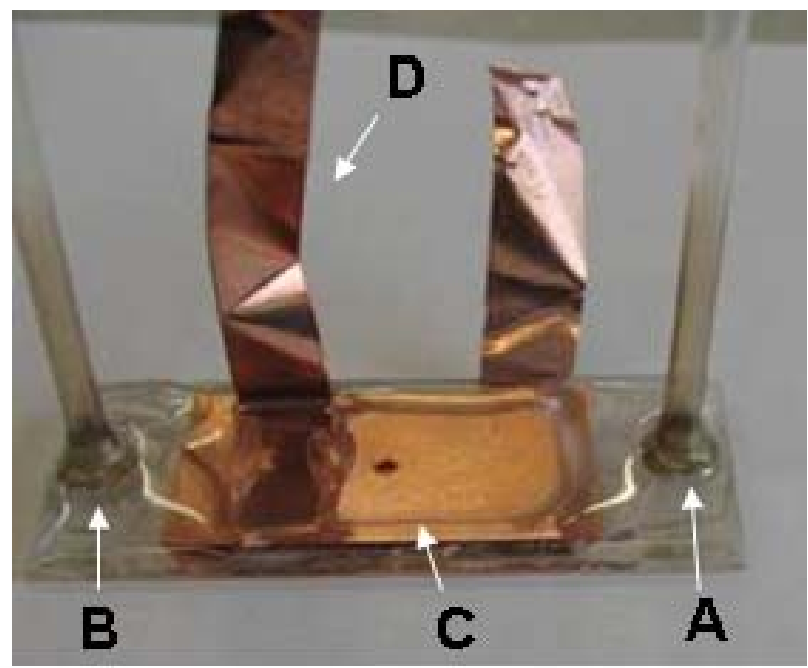

Figure 1. Top view of microplasma reactor made of Pyrex. Inlet and outlet are indicated by $\mathrm{A}$ and $\mathrm{B}$. The copper plate $(\mathrm{C})$ is connected to a power supply via adhesive copper strips (D).

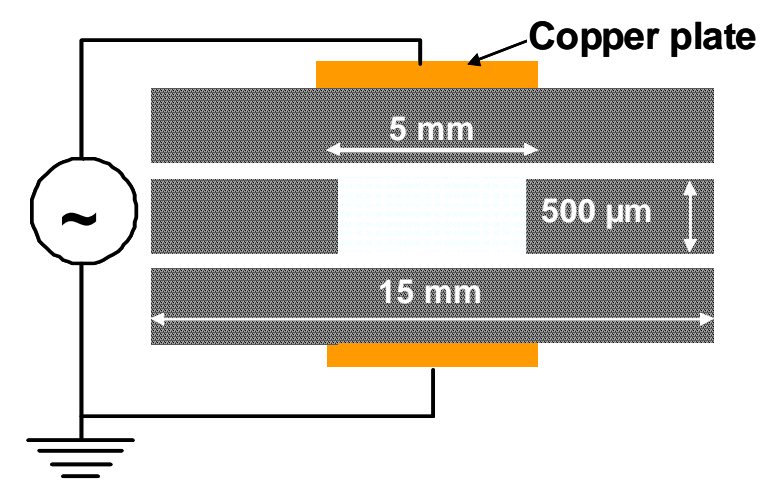

Figure 2. Schematic cross sectional view of microplasma reactor, composed of 3 thermally bonded Pyrex plates.

\section{Catalyst deposition in the microchannels}

The channels of the microreactor were coated with a catalyst layer using a sol-gel method [13]. Chemicals used were: $\mathrm{Mg}\left(\mathrm{OCH}_{3}\right)_{2}$ solution (Aldrich, $8.7 \mathrm{wt} \%$, in methanol), methanol (Merck), $\mathrm{LiNO}_{3}$ (Merck), $\mathrm{HNO}_{3}$ (Merck) and doubly-deionized water. A solution of $\mathrm{Mg}\left(\mathrm{OCH}_{3}\right)_{2}$ in $\mathrm{CH}_{3} \mathrm{OH}$ was mixed with DI water in methanol $(0.8 \mathrm{M})$ containing $\mathrm{LiNO}_{3}$ in appropriate amount $(0-5 \mathrm{wt} \%)$ and a small amount of $\mathrm{HNO}_{3}$ in order to get a stable sol [25]. This sol was used as the precursor for catalyst synthesis and introduced in the open channel by micropipette [26]. The method consists of injecting the 
precursor sol from a micro syringe until the microchannel is filled over its complete length. The sol was kept in contact with air for 45 minutes at $40^{\circ} \mathrm{C}$ and a thin film of gel was formed. The procedure was repeated till about $10 \mathrm{mg}$ of catalyst was deposited on the open microchannel. Since the area outside the channel needs to be kept clean for subsequent sealing with the top plate by thermal bonding, the catalyst precursor must be injected precisely into the channel. The gel formed was dried at $50^{\circ} \mathrm{C}$ on a hotplate for 12 hrs in air and subsequently calcined in a furnace at $500^{\circ} \mathrm{C}$ for $1 \mathrm{hr}$ after a temperature ramp of $5^{\circ} \mathrm{C} / \mathrm{min}$.

\section{Catalyst characterization}

The catalyst layer deposited in the microchannel reactor was characterized using different techniques like X-ray diffraction (XRD), optical microscopy and BET. A portion of the open microchannel where the catalyst layer is deposited as described above was used for these analyses.

The chemical composition of the catalyst was determined with XRF analysis. The following elements and compounds were detected as trace impurities: $\mathrm{Mg}, \mathrm{O}, \mathrm{Li}, \mathrm{Cl}, \mathrm{S}$, $\mathrm{BaO}$ and $\mathrm{CaO}$. X-ray patterns were recorded with a Philips PW1830 diffractometer using $\mathrm{Cu} \mathrm{K} \mathrm{K}_{\alpha}$ radiation, $\lambda=0.1544 \mathrm{~nm}$, in the $2 \theta$ range between $30^{\circ}$ and $60^{\circ}$. Surface areas were estimated using the BET method in a Micrometrics Tristar system. Prior to the analysis, the samples were out-gassed in vacuum at $200^{\circ} \mathrm{C}$ for 24 hours. For the optical microscopy a Philips microscope DB600 was used.

\section{Catalytic tests}

Steady state measurements of the oxidative conversion of propane were performed in the microreactor in the presence of plasma. Empty $\mu$-reactors as well as $\mu$ reactors containing catalyst layers $(\mathrm{MgO}$ or $5 \mathrm{wt} \% \mathrm{Li} / \mathrm{MgO})$ were used at identical conditions. The total gas flow rate was $15 \mathrm{~mL} \mathrm{~min}^{-1}$, the feed composition was $10 \%$ propane and 1 to $10 \%$ oxygen in helium. The reactor was operated at room temperature and atmospheric pressure.

A Varian $3800 \mathrm{GC}$ was used to analyze reactants and products. The GC was equipped with FID and TCD detectors. It was possible to separate all the hydrocarbons on an Alumina Plot column and the remaining components i.e. oxygen, $\mathrm{CO}$ and $\mathrm{CO}_{2}$, on a Porapak Q column in combination with a Molsieve-13X column. For the $\mu$-reactors containing catalyst, prior to each run, the sample surface was pretreated using pure 
oxygen plasma. The microreactors remained stable and rendered reproducible data even after 1 hr operation.

\section{Results}

\section{Catalyst characterization}

Optical micrographs of the cross section of the microchannel reactor with and without catalyst are shown in Fig. 3a and b, respectively. The images show that a ca. 25 $\mu \mathrm{m}$ uniform catalyst layer was deposited in the open microchannel. Similar results were obtained for all the catalysts studied. Table 1 shows the BET surface area of the microreactor chips with and without the catalyst layers. The empty microreactor has a low surface area $\left(<1 \mathrm{~m}^{2} / \mathrm{g}\right)$. The table shows that it is possible to prepare catalyst layers having high surface areas on a Pyrex microchannel, using the described sol-gel method. The fact that milder heat treatments during the sol-gel procedure can prevent sintering effects has also been observed in preparing $\mathrm{Li} / \mathrm{MgO}$ catalyst particles [13].
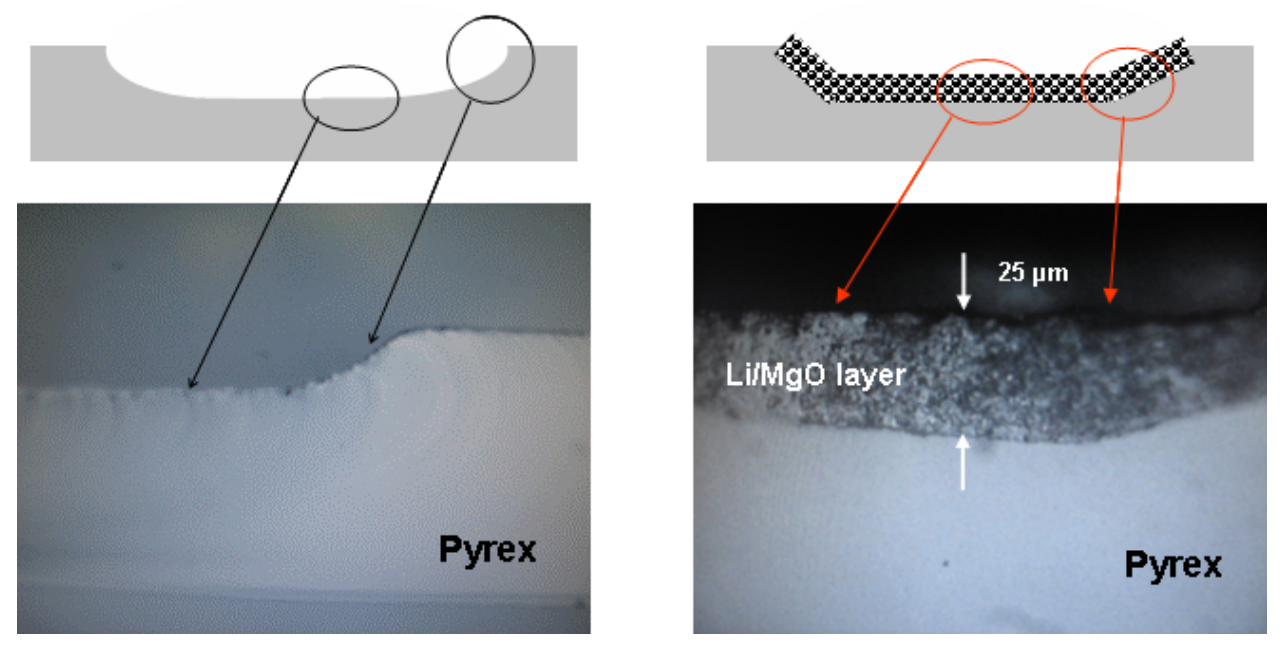

Figure 3. Optical microscopy - Cross sectional views of the base of the microchannel (a) after powder blasting and (b) after catalyst deposition ( $5 \mathrm{wt} \% \mathrm{Li} / \mathrm{MgO})$ by sol gel and micropipette.

XRD patterns of the catalyst layers deposited in the microreactor are shown in Fig. 4. The spectra typically contain lines corresponding to $\mathrm{MgO}$. No Li phases, including $\mathrm{LiNO}_{3}$, were detected, but the peaks corresponding to the $\mathrm{MgO}$ phase became narrower for the samples containing lithium. In general, results show that crystalline catalyst layers can be obtained after calcination at $500^{\circ} \mathrm{C}$ and that the crystallinity is enhanced in lithium 
containing samples [13].

Table 1. Calculated surface area per gram of catalyst deposited in the microchannels using sol gel method and calcined at $500^{\circ} \mathrm{C}$ for $1 \mathrm{~h}$.

\begin{tabular}{lc}
\hline Samples & $\begin{array}{l}\mathrm{BET}\left(\mathrm{m}^{2} / \mathrm{g}\right) \\
\text { Surface area }\end{array}$ \\
\hline Empty $\mu$-reactor & $<1 \mathrm{~m}^{2} / \mathrm{g}$ \\
$\mu$-reactor + $\mathrm{MgO}$ & $120 \mathrm{~m}^{2} / \mathrm{g}$ \\
$\mu$-reactor + $1 \mathrm{wt} \% \mathrm{Li} / \mathrm{MgO}$ & $100 \mathrm{~m}^{2} / \mathrm{g}$ \\
$\mu$-reactor + $5 \mathrm{wt} \% \mathrm{Li} / \mathrm{MgO}$ & $80 \mathrm{~m}^{2} / \mathrm{g}$ \\
\hline
\end{tabular}

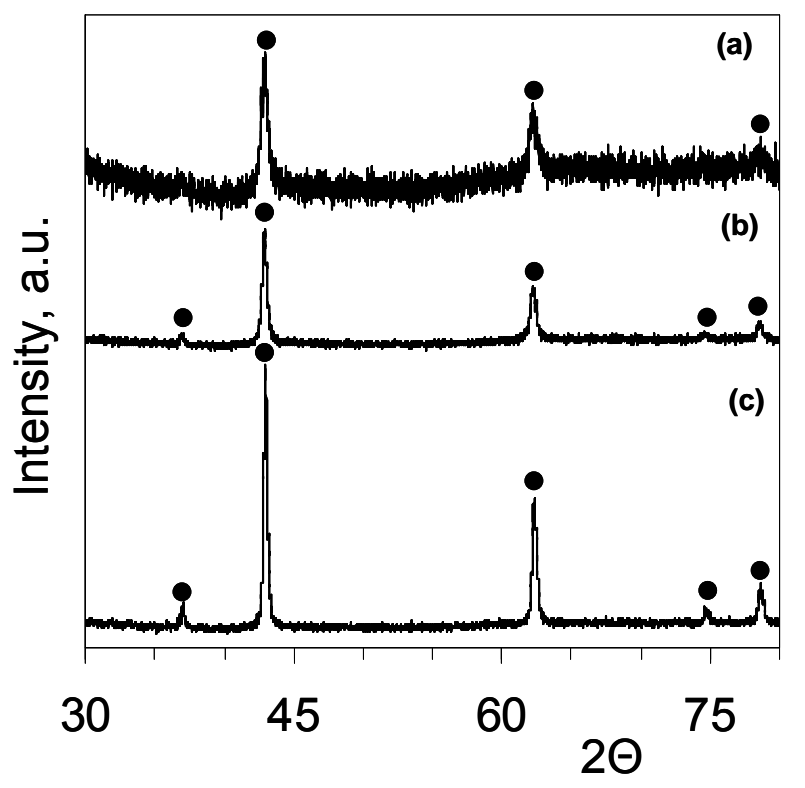

Figure 4. XRD patterns for $\mathrm{MgO}(\mathrm{a}), 1 \mathrm{wt} \% \mathrm{Li} / \mathrm{MgO}$ (b) and $5 \mathrm{wt} \% \mathrm{Li} / \mathrm{MgO}$ (c) catalyst

We will now first discuss the results for the oxidative conversion of propane in an empty $\mu$-reactor in the presence of plasma and then show results for the $\mu$-reactor containing catalyst layers.

\section{Propane conversion in the presence of plasma}

\section{$\mu$-reactor without catalyst}

Figure 5 shows the influence of the absorbed power, during plasma formation, on the propane conversion in the absence of oxygen. These experiments were performed between 0 and $6 \mathrm{~W}$ of absorbed power $(5-10 \mathrm{kV}$ applied voltage) because the non-thermal plasma was stable in this range. The dominant reaction path which occurs in the non- 
thermal plasma is electron impact homogeneous bond splitting. As shown in Fig. 5, propane conversion increases with increasing energy input due to the increase of (i) the number of electrons and (ii) their average energy [27-28]. Propane conversions up to 30 mol\% could be achieved near room temperature in the presence of plasma. Further experiments were carried out applying 3 Watt of power. Typical propane conversion in this situation was about $15 \mathrm{~mol} \%$.

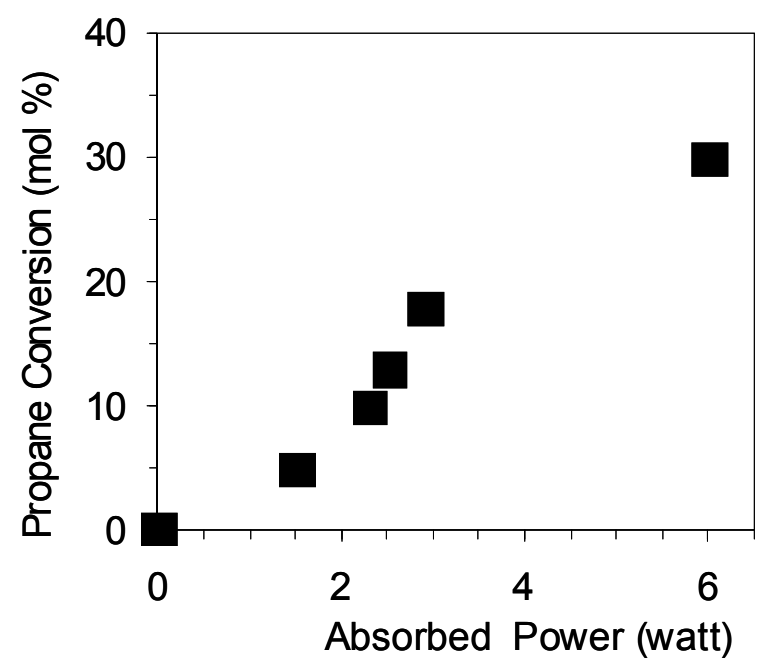

Figure 5. Influence of the power absorbed by the plasma on the conversion of propane. Conditions: $10 \%$ propane in helium, flow rate $10 \mathrm{ml} . \mathrm{min}^{-1}, 1 \mathrm{~atm}$, and $25^{\circ} \mathrm{C}$.

Fig. 6 shows the optical emission spectrum of a $\mathrm{C}_{3} \mathrm{H}_{8}$-He plasma with $3 \mathrm{~W}$ power input. Electronic excitation of ' $\mathrm{CH}$ ' corresponding to the $\mathrm{A}^{2} \Delta \rightarrow \mathrm{X}^{2} \Pi$ transition at 431.5 $\mathrm{nm}$ was used to determine the kinetic gas temperature in this emission region [22]. The resolution of the spectrometer, calibrated using a UV lamp, was determined to be $0.7 \mathrm{~nm}$ (full width at half maximum). This is not enough to resolve the individual rotational lines of the Q, R and P branches of the $\mathrm{CH}$ band. However, the rotational temperature, which reflects the gas temperature inside the filamentary discharge, was calculated by comparing the $\mathrm{CH}$ band in Fig 6 with that in spectra simulated as a function of temperature using LIFBASE software [29]. The best fit was obtained in the region of 25$75^{\circ} \mathrm{C}$. A thermocouple inserted post discharge region of the microreactor measured $75^{\circ} \mathrm{C}$ at the highest power of 24 watt supplied from the source. In the case of the $3 \mathrm{~W}$ used in our experiments the average gas temperature of $25 \pm 50^{\circ} \mathrm{C}$ was obtained by fitting experimental $\mathrm{CH}$ band with simulated spectrum. Thus propane activation occurs close to ambient temperature. 


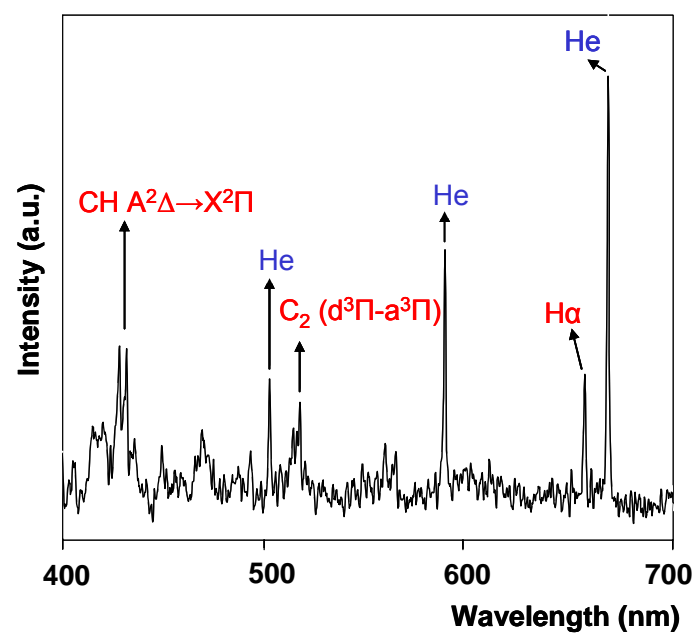

Figure 6. Optical emission spectrum for a gas mixture of 10\% propane in helium in the presence of plasma; $3 \mathrm{~W}$ power was applied.

Existence of $\mathrm{CH}$ and $\mathrm{H}$ bands in the spectra shown in Fig. 6 indicates decomposition of propane via $\mathrm{C}-\mathrm{C}$ and $\mathrm{C}-\mathrm{H}$ bond scission. Based on the propane conversion in Fig 5 and the corresponding selectivity observed (results not shown here), the kinetic data were fitted with a set of reaction equations [27-28] and the results indicated that mainly radicals, for e.g., $\mathrm{C}_{3} \mathrm{H}_{7}, \mathrm{C}_{2} \mathrm{H}_{5}, \mathrm{CH}_{3}$. and $\mathrm{H} \cdot$ were present in the gas phase as a result of inelastic electron collisions.

In the presence of oxygen, under identical conditions ( $3 \mathrm{~W}$ of input power, $10 \%$ propane and $1 \%$ oxygen in helium), propane conversion was higher i.e. $22 \mathrm{~mol} \%$ instead of $15 \mathrm{~mol} \%$, indicating that oxygen plays a role in the propane conversion. Fig. 7 shows the typical product distribution obtained in an empty plasma microchip reactor at room temperature in the presence of oxygen. Results from an empty quartz tube reactor (internal diameter $4 \mathrm{~mm}$ ) operating with the same feed composition (10\% propane and $1 \%$ oxygen in helium), and heated up to $600^{\circ} \mathrm{C}$ are also given [5]. The presented selectivity is at the same level of propane conversion, i.e. $20 \%$.

It is obvious from Fig. 7 that the product selectivity shows striking differences in the two cases. To start with, in the case of the plasma microreactor there was less $\mathrm{CO}_{\mathrm{x}}$ formation (Fig. 7a), however the total olefin selectivity unexpectedly was also lower (Fig. 7b). In the microreactor case a substantial amount of ethyne was observed (Fig. 7c). Furthermore, large amounts $(37 \mathrm{~mol} \%)$ of products with higher molecular weights than propane, i.e., $\mathrm{C}_{4}, \mathrm{C}_{4}{ }^{+}$, were also observed (Fig. 7d). A presence of products containing four or more $\mathrm{C}$ atoms requires $\mathrm{C}-\mathrm{C}$ bond formation under the conditions present in the microreactor. 
(a)

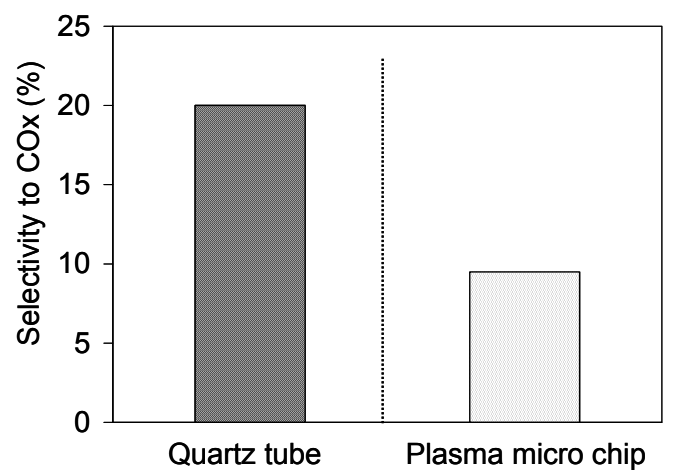

(c)

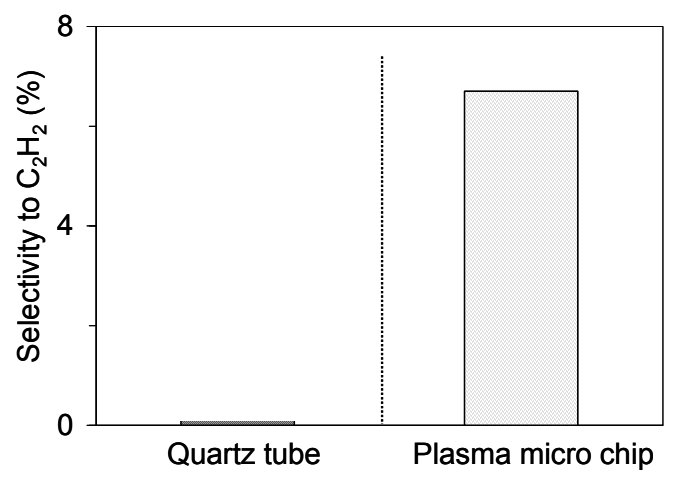

(b)

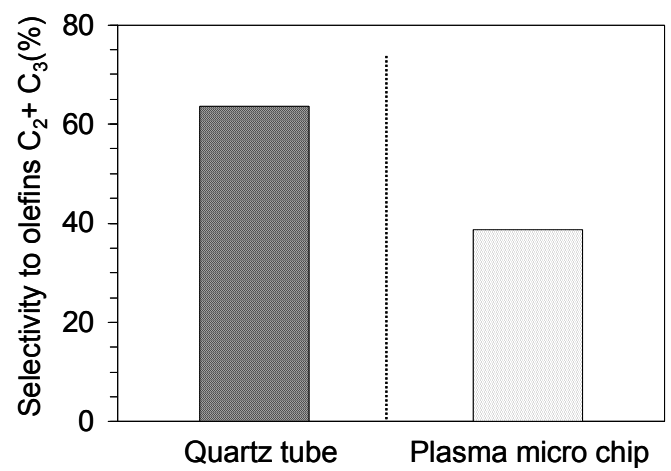

(d)

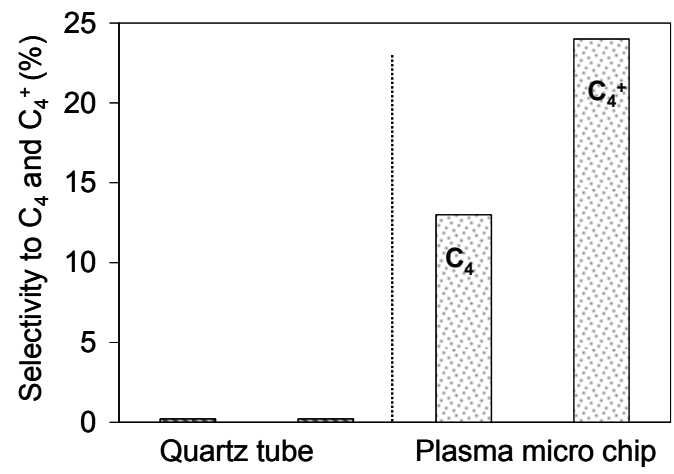

Figure 7. Results of the oxidative conversion of propane. Selectivity to the products observed, respectively, for empty, quartz tube reactor at $600^{\circ} \mathrm{C}$ [5] and plasma microreactor at room temperature and at the same level of propane conversion achieved by varying SV: (a) $\mathrm{CO}_{x}$, (b) products from $\mathrm{C}_{2}$ to $\mathrm{C}_{3}$, (c) $\mathrm{C}_{2} \mathrm{H}_{2}$, (d) $\mathrm{C}_{4}$ and $\mathrm{C}_{4}{ }^{+}$. Conditions: $10 \%$ propane, $1 \%$ oxygen in helium.

\section{$\mu$-reactor with catalyst}

Fig. 8 compares propane conversions for an empty $\mu$-reactor with those obtained for a $\mu$-reactor containing, respectively, $\mathrm{MgO}$ or $5 \mathrm{wt} \% \mathrm{Li} / \mathrm{MgO}$ catalyst. In order to make a proper comparison, all the experiments were carried out under the same conditions of flow rate, feed composition and applied power (3W). Clearly, in the presence of catalyst, the conversion of propane increases. An increase in propane conversion was also observed in the presence of lithium, the conversion increased from $24 \%$ for $\mathrm{MgO}$, to $30 \%$ in the case of $5 \mathrm{wt} \% \mathrm{Li} / \mathrm{MgO}$. Figure 9 shows the selectivity to $\mathrm{CO}_{\mathrm{x}}$ in the case of $\mu$ reactors containing $\mathrm{MgO}$ or $5 \mathrm{wt} \% \mathrm{Li} / \mathrm{MgO}$ catalysts. As can be seen from the figure, the microreactor containing $\mathrm{MgO}$ gave more combustion than the one with $\mathrm{Li} / \mathrm{MgO}$ catalyst. 


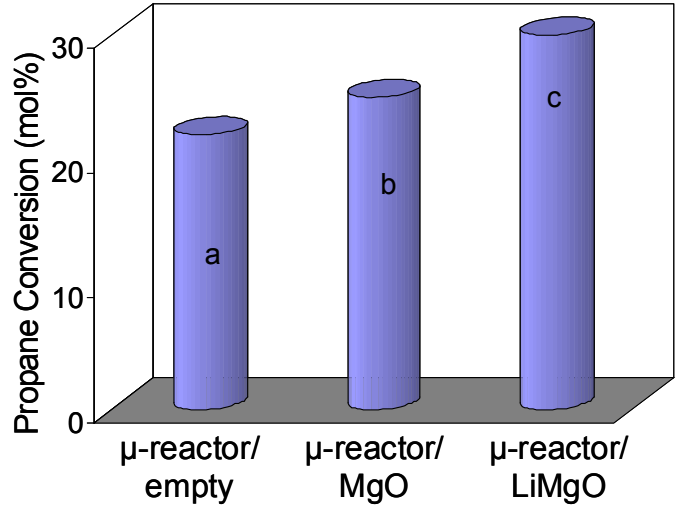

Figure 8. Propane conversion in microreactor in the presence of plasma at RT (a) empty reactor, (b) reactor containing $\mathrm{MgO}$ and (c) reactor containing $\mathrm{Li} / \mathrm{MgO}$. Conditions: flow rate $15 \mathrm{ml} / \mathrm{min}$, feed composition $10 \%$ propane and $1 \%$ oxygen in $\mathrm{He}$, power $3 \mathrm{~W}$.

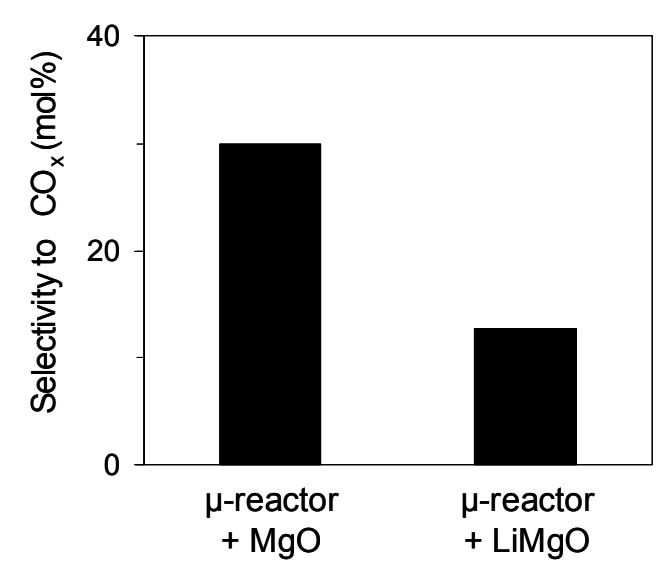

during oxidative conversion of propane in the presence of plasma in a microreactor containing (i) $\mathrm{MgO}$ and (ii) $5 \mathrm{wt} \% \mathrm{Li} / \mathrm{MgO}$. Conditions: flow rate 15 $\mathrm{ml} / \mathrm{min}$, feed composition $10 \%$ propane and $1 \%$ oxygen in $\mathrm{He}$ at RT.

These findings are similar to those we reported earlier [10] for the case of oxidative cracking of propane employing a fixed bed reactor at $600^{\circ} \mathrm{C}$, viz. on $\mathrm{MgO}$ we found a selectivity to $\mathrm{CO}_{\mathrm{x}}$ of up to $80 \%$ and this dropped to $40 \%$ in the presence of lithium. Fig. 10 shows the selectivity to olefins as a function of the oxygen partial pressure. In the explored range of oxygen partial pressures, the chip containing $\mathrm{Li} / \mathrm{MgO}$ catalyst showed constant selectivity, while it decreased in the case of $\mathrm{MgO}$. This indicates that $\mathrm{MgO}$ is much less selective towards olefins than $\mathrm{Li} / \mathrm{MgO}$. Fig. 11 shows the selectivity to all the products obtained with propane and oxygen in the presence of plasma in the $\mu$-reactor containing $5 \mathrm{wt} \% \mathrm{Li} / \mathrm{MgO}$ catalyst. To summarize, the product distributions obtained with $5 \mathrm{wt} \% \mathrm{Li} / \mathrm{MgO}$ catalyst at $600^{\circ} \mathrm{C}$ in a fixed bed reactor [10] and at $25^{\circ} \mathrm{C}$ in a $\mu$-reactor in presence of plasma are given again in Table 2. This allows an easy comparison of all the data discussed so far. 
Table 2. Catalytic performance of $\mathrm{Li} / \mathrm{MgO}$ catalysts respectively tested in (i) a fixed bed reactor at $600^{\circ} \mathrm{C}[10]$ and (ii) plasma microreactor at room temperature.

\begin{tabular}{lccccccc}
\hline & \multicolumn{6}{c}{ Selectivity (\%) } \\
\cline { 2 - 7 } & $\mathrm{C}_{3} \mathrm{H}_{6}$ & $\left(\mathrm{C}_{2} \mathrm{H}_{4}+\mathrm{C}_{2} \mathrm{H}_{6}\right)$ & $\mathrm{C}_{2} \mathrm{H}_{2}$ & $\mathrm{CH}_{4}$ & $\mathrm{CO}_{\mathrm{x}}$ & $>\mathrm{C}$ \\
\hline $\begin{array}{l}\text { Fixed Bed } l \\
\text { Li/MgO }\end{array}$ & $600^{\circ} \mathrm{C}$ & 30 & 32 & - & 4 & 34 \\
$\begin{array}{l}\text { Microchipl } \\
\text { Li/MgO }\end{array}$ & RT & 13 & 20 & 8 & 12 & 13 & : \\
\hline
\end{tabular}

Conditions: $10 \%$ propane, $1-10 \%$ oxygen in helium; conversion level of propane ca. $30 \%$ in both cases, obtained by varying the space velocity (SV); ${ }^{*} \mathrm{C}_{4}=12 \%, \mathrm{C}_{4}{ }^{+}=22 \%$.

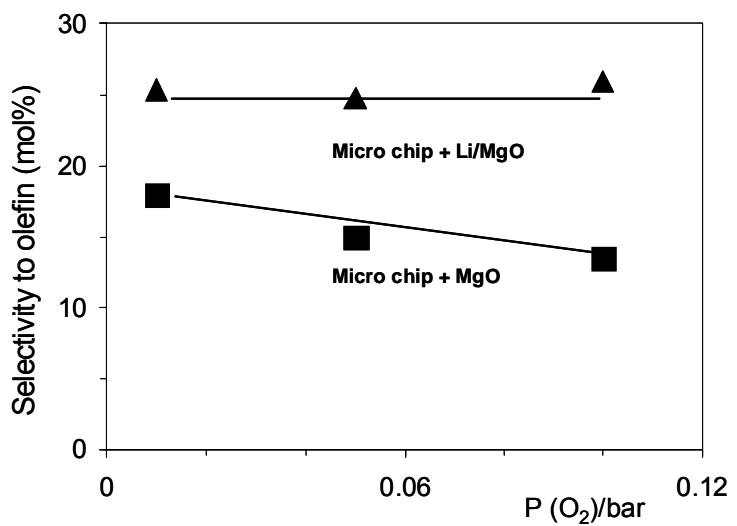

Figure 10. Influence of oxygen partial pressure on selectivity to olefins. Conditions: $10 \%$ propane, $1-10 \%$ oxygen in helium.

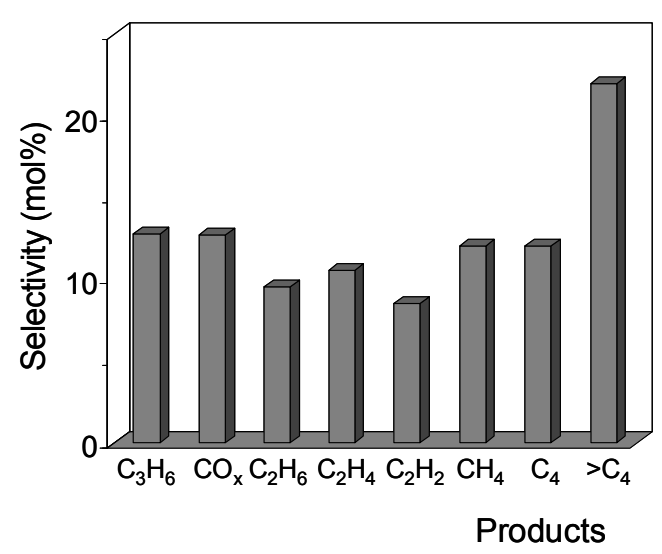

Figure 11. Selectivity to the main products for a plasma microreactor containing $5 \quad$ wt $\% \quad \mathrm{Li} / \mathrm{MgO}$ catalyst. Conditions: flow rate $15 \mathrm{ml} / \mathrm{min}$, feed composition $10 \%$ propane, $1 \%$ oxygen and balance helium at room temperature.

\section{Discussion}

It has been shown earlier $[10,30]$ that, for $\mathrm{Li} / \mathrm{MgO}$ catalysts, propane activation requires the presence of oxygen and higher temperatures $\left(\mathrm{T}>600^{\circ} \mathrm{C}\right)$. In these catalysts $\left[\mathrm{Li}^{+} \mathrm{O}^{-}\right]$type defect centers are the active sites and their formation requires the higher temperatures. The $\left[\mathrm{Li}^{+} \mathrm{O}^{-}\right]$site is claimed to have high $\mathrm{H}$-atom affinity and, at relative high temperature, is able to abstract $\mathrm{H}$. from propane molecules forming $\mathrm{n}$ - and iso-propyl radicals as primary intermediates [31,32]. These propyl radicals are formed depending on whether primary or secondary hydrogen is abstracted from propane. At the higher 
temperatures required for the reaction, endothermic decompositions are favored and the two types of radicals ( $\mathrm{E} \&$ iso) undergo different uni-molecular reaction routes in the homogeneous phase: iso-propyl can undergo $\mathrm{C}-\mathrm{H}$ bond scission at the $\alpha$-position and yields propene and a hydrogen atom, while n-propyl preferentially follows $\beta$-scission of the C-C bond, therewith forming a methyl radical and ethylene [33]. The various products formed can be accounted for by a series of radical chain reactions in the gas phase, details of which were discussed earlier [34]. It is now appropriate to discuss what happens in the presence of plasma. Non-thermal plasma generated at atmospheric pressure by DBD consists of current filaments, namely microdischarges, distributed in the space between the two electrodes (see Fig. 12). The number of microdischarges depends on (i) the voltage applied to the electrodes (ii) the distance between the electrodes (iii) the relative permittivity of the dielectric barriers and (iv) the processing gas [35]. The relative permittivity of a dielectric barrier can strongly determine the amount of charge which can be stored for a certain value of applied electric field. This parameter plays a critical role in plasma formation [36].

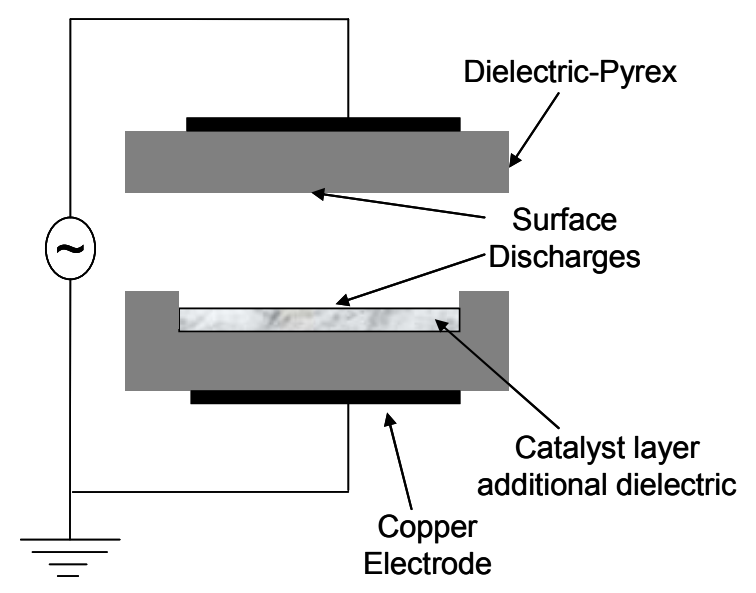

Figure 12. Sketch of the elements constituting a microplasma reactor.

In a plasma microreactor, $\mathrm{C}_{3} \mathrm{H}_{8}$ molecules are directly activated/converted via collisions with energized electrons. Activation produces radicals such as $\mathrm{C}_{3} \mathrm{H}_{7}$. due to cleavage of $\mathrm{C}-\mathrm{H}$ bonds (Eq. 3). These can initiate radical chain reactions. Thus, reaction 3 is strongly influenced by the number of charges transferred or accumulated on the dielectric surface [37] and therefore by the relative permittivity.

$$
\mathrm{C}_{3} \mathrm{H}_{8}+\mathrm{e}^{-} \rightarrow \mathrm{C}_{3} \mathrm{H}_{7}+\mathrm{H} \cdot+\mathrm{e}^{-}
$$


As shown in Fig. 8, at a fixed applied voltage, the reactivity of a microplasma towards propane is improved when a layer of $\mathrm{MgO}$ is deposited on the Pyrex surface of the chip (Fig. 12). At room temperature the permittivity $(\varepsilon)$ of $\mathrm{MgO}$ is $9.7 \mathrm{C}^{2} / \mathrm{N}^{*} \mathrm{~m}^{2}$, which is double that of Pyrex, 4.8 $\mathrm{C}^{2} / \mathrm{N}^{*} \mathrm{~m}^{2}$ [38]. Because of the higher permittivity, in the case of $\mathrm{MgO}$ a higher amount of charge can be accomodated on the surface, a situtaion for which a higher plasma reactivity is expected [39]. As proof of this, in the presence of catalyst layers we observed additional microdischarges distributed over the entire electrode area [28]. The higher charge density allows more impacts and in-elastic collisions, giving rise to excitation of a higher number of propane molecules.

In the case of the $\mathrm{Li} / \mathrm{MgO}$ catalyst layer, the reactivity is even slightly more improved than for $\mathrm{MgO}$. Though the thickness of the layers has been kept the same, in the presence of lithium the $\mathrm{MgO}$ layer is more crystalline (Fig. 4). Huang et al. [40] have shown that for the case of $\mathrm{ZrO}_{2}$ an increase of crystallinity results in an increase in permittivity. The higher crystallinity of the $\mathrm{Li} / \mathrm{MgO}$ layer can contribute to enhanced propane activation via improved permittivity, as described in the previous paragraph. The improved crystallinity for the $\mathrm{Li} / \mathrm{MgO}$ results from a ' $\mathrm{Li}$ assisted ordering' in the gel during sol-gel transformation [13].

In addition, propane activation can also occur via an indirect route, i.e. activation of gas phase oxygen by the plasma. Among the atomic processes taking place in a nonthermal plasma, the electron impact dissociation of $\mathrm{O}_{2}$ to form charged and neutral oxygen has been reported in literature and is described in reaction equations 4 and 5 [41].

$$
\begin{aligned}
& \mathrm{e}^{-}+\mathrm{O}_{2} \rightarrow 2 \mathrm{O}+\mathrm{e}^{-} \rightarrow \mathrm{O}^{-}+\mathrm{O} \\
& \mathrm{e}^{-}+\mathrm{O}_{2} \rightarrow \mathrm{O}_{2}{ }^{*}+\mathrm{e}^{-} \rightarrow \mathrm{O}+\mathrm{O}+\mathrm{e}^{-}
\end{aligned}
$$

The $\mathrm{O}^{-}$species, present in the homogeneous phase, has been reported to cause $\mathrm{C}$ $\mathrm{H}$ bond scission in alkanes e.g., methane [42], ethane [43]. In the case of propane this will result in the formation of propyl and hydroxyl radicals as shown below:

$$
\left[\mathrm{O}^{-}\right]+\mathrm{C}_{3} \mathrm{H}_{8} \rightarrow\left[\mathrm{OH}^{-}\right]+\mathrm{C}_{3} \mathrm{H}_{7}
$$

The increased propane conversion observed while co-feeding oxygen (22\%) into the $\mu$-reactor without catalyst (propane conversion was $15 \%$ in the absence of oxygen under identical conditions, results not shown here) supports the above argument 
(reaction 6). It was observed earlier [5] that by adding oxygen the number and the concentration of chain carrier radicals increased [5]. $\mathrm{C}_{3} \mathrm{H}_{7} \cdot$ radicals react fast with $\mathrm{O}_{2}$ forming hydro-peroxyl $\left(\mathrm{HO}_{2} \cdot\right)$ radicals, which can react with propane molecules to form $\mathrm{H}_{2} \mathrm{O}_{2}$. Decomposition of $\mathrm{H}_{2} \mathrm{O}_{2}$ results in hydroxyl radicals $(\mathrm{OH} \cdot)$ which become the main chain propagators.

Let us now discuss the role of $\mathrm{Li}$ on the observed selectivity. In the plasma microreactor, addition of lithium to $\mathrm{MgO}$ results in an enhanced activity and selectivity to propylene (Fig. 13) at similar levels of conversion (see Fig. 8b, c). Thus, $\mathrm{Li} / \mathrm{MgO}$ is intrinsically more selective and the better selectivity observed, may only be addressed to more selective quenching reactions taking place on the catalyst surface. In the case of $\mathrm{Li} / \mathrm{MgO}$ catalysts, as discussed earlier, $\left[\mathrm{Li}^{+} \mathrm{O}^{-}\right]$is suggested to be the active oxidation site [29] for the selective conversion of propane to olefins. Hydrogen abstraction occurs at the $\left[\mathrm{Li}^{+} \mathrm{O}^{-}\right]$site $[44,45]$, as shown in equation 1 . The propyl radicals undergo transformations in the homogeneous phase to give olefins [10, 31, 46]. It has also been shown [12] that by preparing $\mathrm{Li} / \mathrm{MgO}$ catalysts (e.g. with a sol gel method) with increased active site density allows interaction between propyl radicals and the catalyst surface via a second hydrogen abstraction step, leading to propylene (equation 2).

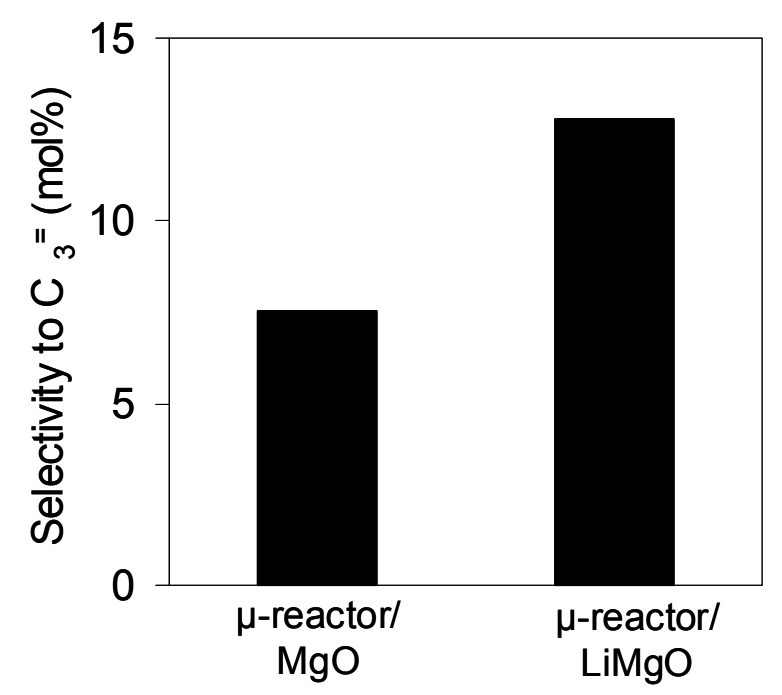

Figure 13. Selectivity to propylene for $\mathrm{MgO}$ and $\mathrm{Li} / \mathrm{MgO}$ catalysts in a microreactor in presence of plasma at RT. Comparison made at similar levels of propane conversion.

It is generally accepted that incorporation of $\mathrm{Li}$ in $\mathrm{MgO}$ occurs only at higher temperatures $\left(\mathrm{T}>500^{\circ} \mathrm{C}\right)$ and that the formation of the $\left[\mathrm{Li}^{+} \mathrm{O}^{-}\right]$site occurs via the following defect reactions 7 and 8 (Kroeger-Vink notation) [47, 48]. 


$$
\begin{aligned}
& \mathrm{Li}_{2} \mathrm{O}+2 \mathrm{Mg}_{\mathrm{Mg}}{ }^{\mathrm{x}}+\mathrm{O}_{\mathrm{O}}{ }^{\mathrm{x}} \rightarrow 2 \mathrm{Li}_{\mathrm{Mg}}{ }^{\prime}+\mathrm{V}_{\mathrm{O}}{ }^{\prime \prime}+2 \mathrm{MgO} \\
& 2 \mathrm{Li}_{\mathrm{Mg}}{ }^{\prime} \mathrm{O}_{\mathrm{O}}{ }^{\mathrm{x}}+\mathrm{V}_{\mathrm{O}}{ }^{\prime \prime}+1 / 2 \mathrm{O}_{2} \rightarrow 2 \mathrm{Li}_{\mathrm{Mg}}{ }^{\prime} \mathrm{O}_{\mathrm{o}}{ }^{\cdot}+\mathrm{O}_{\mathrm{O}}{ }^{\mathrm{x}}
\end{aligned}
$$

$\left[\mathrm{Li}^{+} \mathrm{O}^{-}\right]$sites are defect sites and their existence at lower temperatures has been investigated and confirmed, using EPR spectroscopy, by Lunsford and coworkers [49-51] In agreement with this, we propose that $\left[\mathrm{Li}^{+} \mathrm{O}^{-}\right]$defect sites may already be present at the low temperature under our conditions. Thus propyl radicals formed already at room temperature in the presence of plasma (equation 3) can interact selectively with these $\left[\mathrm{Li}^{+} \mathrm{O}^{-}\right]$sites and give improved propylene yields as suggested earlier (see equation 2).

Alternatively, the presence of plasma can also help to create other defect sites which are able to selectively terminate radicals. Detailed studies are present in literature describing emission of UV light during DBD [52]. The optical emission spectrum recorded during plasma formation (Fig. 6) shows that UV light is generated inside the microreactor. Nelson et al. [53] and later E. Knozinger et al. [54] reported, using EPR studies, that interaction between UV light and $\mathrm{MgO}$ particles can give rise to surface paramagnetic centers (trapped electrons, typically F-centers, $\left[\mathrm{V}_{\mathrm{O}}{ }^{\bullet}\right]$ ). Quantification of the UV emission power can not be done in our conditions, however, we cannot rule out UV activation. Goodman et al. suggests that an oxygen vacancy, containing one or two electrons (F-type defects), is able to activate $\mathrm{C}-\mathrm{H}$ bonds during methane oxidative coupling [55]. Bond scission occurs and the $\mathrm{H} \cdot$ is trapped at the defect site. Thus, the presence of $\left[\mathrm{V}_{\mathrm{O}}{ }^{\bullet}\right]$ type defect sites caused by the plasma, may allow $\mathrm{H} \cdot$ abstraction from propane and even propyl radicals, and in the latter case enhanced selectivity to propene can be expected.

In our experiments, we observe appreciable amounts of ethyne. Activation of methane is known to yield ethyne in the presence of plasma [56, 57]. Two routes are often suggested. Firstly, ethyne can be formed by extensive dehydrogenation of $\mathrm{C}_{2}$ species present during methane conversion [58]. We also observe $\mathrm{C}_{2}$ species during our experiments (Fig. 6). In addition, $\mathrm{CH}$ type species are formed in the presence of plasma (Fig. 6). Dimerization of such species can result in ethyne. Such a possibility is also suggested by Kado et al. during methane conversions [59]. Hydrogen redistribution during this reaction, forming dehydrogenated products as ethyne, may be the reason for the appreciable amount of methane observed. This argument can also be logically connected to the large amounts of $\mathrm{C}_{4}$ and $\mathrm{C}_{4}{ }^{+}$products that we observe. The role of 
plasma is in the activation of propane and formation of radicals at ambient temperatures as stated previously. Formation of $\mathrm{C}_{4}$ and $\mathrm{C}_{4}{ }^{+}$products from propane essentially requires $\mathrm{C}-\mathrm{C}$ bond formation, which is an exothermic process and therefore favored at lower temperatures. Coupling reactions between radicals also imply a decrease in entropy because the number of molecules/radicals is decreasing by definition. Therefore, it is not surprising to see $\mathrm{C}-\mathrm{C}$ bond formation reactions under our conditions. In the conventional fixed bed reactors, propane activation occurs at higher temperatures $\left(\mathrm{T}>600^{\circ} \mathrm{C}\right)$ in the presence of catalyst. These conditions favor the rupture of $\mathrm{C}-\mathrm{C}$ bonds, causing an increase in entropy, and therefore we see only cracking products (Table 2), i.e., with molecular weights lower than that of propane. Considering that similar amounts of $\mathrm{C}_{4}+\mathrm{C}_{4}{ }^{+}$ products are formed in the case of both the $\mu$-reactor with and without catalyst, it is suggested that the coupling of radicals occurs in the homogeneous phase predominantly.

\section{Conclusions}

Oxidative conversion of propane was carried out using a $\mu$-reactor in the presence of cold plasma. Under these conditions it is possible to oxidize propane at RT and atmospheric pressure.

A uniform layer of $\mathrm{Li} / \mathrm{MgO}$ catalyst was synthesized by a sol-gel method and deposited onto the open channel of the reactor by micropipette. Enhanced olefin selectivity in the presence of $\mathrm{Li} / \mathrm{MgO}$ catalyst indicates the possible formation of active defect sites at these mild conditions due to the influence of the plasma.

Conditions present in the investigated microplasma reactor, in particular the low temperature used during propane activation, favor the formation of $\mathrm{C}-\mathrm{C}$ bonds. $\mathrm{C}_{4}$ and $\mathrm{C}_{4}{ }^{+}$ are the major products and the coupling of the radicals occurs predominantly in the homogeneous phase. 


\section{References}

[1] Driscoll, D. J.; Campbell, K.; Lunsford, J. H. Advances in Catalysis 1987, 35, 139.

[2] Vislovskiy, V. P.; Suleimanov, T. E.; Sinev, M. Y.; Tulenin, Y. P.; Margolis, L. Y.; Cortes Corberan, V. Catalysis Today 2000, 61, 287.

[3] Buyevskaya, O. V.; Baerns, M. Catalysis Today 1998, 42, 315.

[4] Couwenberg, P. M.; Chen, Q.; Marin, G. B. Industrial \& Engineering Chemistry Research 1996, 35 (11), 3999.

[5] Leveles, L.; Seshan, K.; Lercher, J. A.; Lefferts, L. J. Catal. 2003, 218, 296.

[6] Lunsford, J. H. Langmuir 1989, 5, 12.

[7] Tevault, D. E.; Lin, M. C.; Umstead, M. E.; Smardzeqski, R. R. Int. J. Chem. Kinet. $1979,11,445$.

[8] Wang, J. X.; Lunsford, J. H. J. Phys. Chem. 1986, 90, 5883.

[9] Balint, I.; Aika, Ken-ichi J. Chem. Soc., Faraday Trans. 1997, 93 (9), 1797.

[10] Leveles, L.; Seshan, K.; Lercher, J. A.; Lefferts, L. J. Catal. 2003, 218, 307.

[11] Kondratenko, E. V.; Sinev, M. Y. Applied Catalysis A: General 2007, 325, 353.

[12] Trionfetti, C.; Babich, I. V.; Seshan, K.; Lefferts, L. Topics in Catalysis, 2006, 39 (34), 191.

[13] Trionfetti, C.; Babich, I. V.; Seshan, K.; Lefferts, L. Applied Catalysis A: Gen. 2006, $310,105$.

[14] Cavani, F.; Trifiro, F. Catalysis Today 1995, 24, 307.

[15] Kim, H. Plasma Processes and Polymers 2004, 1, 91.

[16] Kogelschatz, U. Plasma Chemistry and Plasma Processing 2003, 23 (1), 1.

[17] de Mello, A.; Wootton, R. Lab on a chip 2002, 2, 7N.

[18] Jensen, K. F. Chemical Engineering Science 2001, 56, 293.

[19] Eliasson, B.; Liu, C.; Kogelschatz, U. Ind. Eng. Chem. Res. 2000, 39, 1221.

[20] Ajmera, S. K.; Delattre, C.; Schmidt, M. A.; Jensen, K. F. J. Catal. 2002, 209, 401.

[21] Tiggelaar, R. M.; Benito-Lopez, F.; Hermes, D. C.; Rathgen, H.; Egberink, R. J. M.;

Mugele, F.; Reinhoudt, D. N.; van den Berg, A.; Verboom, W.; Gardeniers, J. G. E. Chemical Engineering Journal 2007, 131, 163.

[22] Nozaki, T.; Muto, N.; Kadio, S.; Okazaki, K. Catalysis Today 2004, 89, 67.

[23] Kogelschatz, U. Plasma Physics and Controlled Fusion 2004, 46, B63.

[24] Okumoto, M.; Kim, H. H.; Takashima, K.; Katsura, S.; Mizuno, A. IEEE Transaction on Industry Applications 2001, 37 (6), 1618.

[25] Diao, Y.; Walavender, W. P.; Sorensen, C. M.; Klabunde, K. J.; Ricker, T. Chem. 
Mater. 2002, 14, 362.

[26] Chen, H.; Bednarova, L.; Besser, R. S.; Lee, W. Y. Applied Catalysis A: General 2005, 286, 186.

[27] Agiral, A.; Trionfetti, C.; Seshan, K.; Lefferts, L.; Gardeniers, J. G. E. Abstract of papers, ICPIG Meeting, Czech Republic, July 2007.

[28] Agiral, A.; Trionfetti, C.; Seshan, K.; Lefferts, L.; Gardeniers, J. G. E. Abstract of papers, ISPC18 Meeting, Japan, August 2007.

[29] Lugue, J.; Crosley, D. R. 1999 Lifbase: Database and Spectral Simulation Program (ver.1.6) SRI International Report MP 99-009

[30] Leveles, L.; Fuchs, S.; Seshan, K.; Lercher, J. A.; Lefferts, L. Applied Catalysis A: Gen. 2002, 227, 287.

[31] Zhang, Hong Sheng; Wang, Ji Xiang; Driscoll, D. J.; Lunsford, J. H. J. Catal. 1988, 112(2), 366.

[32] Wang, D.; Xu, M.; Shi, C.; Lunsford, J. H. Catalysis Letters 1993, 18, 323.

[33] Yamauchi, N.; Miyoshi, A.; Kosaka, K.; Koshi, M.; Matsui, N. J. Phys. Chem. A 1999, 103(15), 2723.

[34] Sinev, M. Y. Res. Chem. Intermed. 2006, 32, 205.

[35] Li, R.; Yamaguchi, Y.; Yin, S.; Tang, Q.; Sato, T. Solid State Ionics 2004, 72, 235.

[36] Xu, X. Thin Solid Films 2001, 390, 237.

[37] Pons, J.; Moreau, E.; Touchard, G. J. Phys. D : Appl. Phys. 2005, 38, 3635.

[38] Lewis, T.J.; Wright, A. J. Appl. Phys. 1970, 3, 1329.

[39] Li, R.; Tang, Q.; Yin, S.; Sato, T. Fuel Processing Technol. 2006, 87, 617.

[40] Huang, A. P.; Chu, P. K.; Yan, H.; Zhu, M. K. J. Vac. Sci. Technol. B 2005, 23(2), 566.

[41] Cosby, P. C. J. Chem. Phys. 1993, 98(12), 9560.

[42] Nozaki, T.; Hattori, A.; Okazaki, K. Catalysis Today 2004, 98, 607.

[43] Zhang, X.; Zhu, A.; Li, X.; Gong, W. Catalysis Today 2004, 89, 97.

[44] Driscoll, D. J.; Martir, W.; Wang, J. X.; Lunsford, J. H. J. Am. Chem. Soc. 1985, 107, 58.

[45] Sinev, M. Y.; Bychkov, V. Y.; Korchak, V. N.; Krylov, O. V. Catalysis Today 1990, 6, 543.

[46] Sinev, M. Y. J. Catal. 2003, 216, 468.

[47] Gellings, P. J.; Bouwmeester, H. J. M. Catalysis Today 2000, 58, 1.

[48] Catlow, C. R. A.; Jackson, R. A.; Thomas, J. M. J. Phys. Chem. 1990, 94, 7889.

[49] Ito, T.; Wang, J. X.; Lin, C. H.; Lunsford, J. H. J. Am. Chem. Soc. 1985, 107, 5062. 
[50] Bothe-Almquist, C. L.; Ettireddy, R. P.; Bobst, A.; Smirniotis, P. G. J. Catal. 2000, $192,174$.

[51] Aika, Ken-ichi; Lunsford, J. H. J. Phys. Chem. 1978, 82 (16), 1794.

[52] Lu, X. ; Laroussi, M. J. Appl. Phys. 2005, 98, 23301.

[53] Nelson, R. L.; Tench, A. J. J. Chem. Phys. 1964, 40(9), 2736.

[54] Sterrer, M.; Diwald, O.; Knozinger, E.; Sushko, P. V.; Shluger, A. L. J. Phys. Chem. B 2002, 106, 12478.

[55] Wu, M. C.; Truong, C. M.; Coulter, K.; Goodman, D. W. J. Vac. Sci. Technol. A 1993, 11(4), 2174.

[56] Yang, Y. Plasma Chemistry and Plasma Processing 2003, 23(2), 327.

[57] Zhang, X.; Zhu, A.; Li, H.; Gong, W. Catalysis Today 2004, 89, 97.

[58] Kim, S. S.; Lee, H.; Na, B. K.; Song, H. K. Korean J. Chem. Eng. 2003, 20(5), 869.

[59] Kado, S.; Urasaki, K.; Sekine, Y.; Fujimoto, K.; Nozaki, T.; Okazaki, K. Fuel 2003, 82 (11), 1377. 


\section{Chapter 4}

\section{Plasma catalytic oxi-cracking of hexane for olefin synthesis at atmospheric pressure}

In this work, a plasma catalytic reactor based on a dielectric barrier discharge has been developed for oxidative cracking of hexane with $\mathrm{Li} / \mathrm{MgO}$-based catalysts at atmospheric pressure. The effect of temperature, oxygen concentration, helium flow, and $\mathrm{MgO}$ support, and the role of $\mathrm{Li} / \mathrm{MgO}$ catalysts on the conversion of hexane, and on the selectivity and yield of olefin formation are reported.

Portions of this chapter will be published in:

(In Preparation) Plasma catalytic oxi-cracking of hexane with nanoscopic oxide catalyst for olefins synthesis at atmospheric pressure, ANIL AGIRAL, CASIA BOYADJIAN, K. SESHAN, LEON LEFFERTS, J. G. E. (HAN) GARDENIERS, 


\section{Journal of Physical Chemistry C.}

\section{Introduction}

There is an enormous and increasing demand for the ethylene and propylene, which are important building blocks for chemical industry, with a predicted growth rate for the coming years of $4 \%$ [1]. For the future, it is expected that the propylene demand will grow faster than that of ethylene. The current process technology is unlikely to satisfy these high olefin demands.

Steam cracking is the major route for the production of olefins today. Light olefins are produced by cracking the hydrocarbon feedstock (ethane to naphtha) in the presence of steam at temperatures of $700-900^{\circ} \mathrm{C}$. Steam cracking is a highly endothermic reaction, requiring a substantial amount of energy input. Coke deposition on the walls of reactors which inhibits heat transfer is considered a significant issue.

One of the potential alternatives to steam cracking is catalytic oxidative cracking, which is exothermic, has minimal coke formation, while the energy required for cracking can be generated internally. Liu et al. [2] observed that during non-catalytic pyrolysis of hexane at $750^{\circ} \mathrm{C}$, in the presence of oxygen, a high conversion of hexane of $85 \mathrm{~mol} \%$ with reasonable olefin selectivities, of $59 \mathrm{~mol} \%$ for the light olefins, can be obtained. The cracking process was allowed to run in an auto-thermal way with oxygen, where exothermic combustion of product hydrogen provided the heat for cracking.

In the present study, atmospheric-pressure non-thermal plasma technology is combined with oxi-cracking of hexane to olefins in the presence of a $\mathrm{Li} / \mathrm{MgO}$ catalyst. Cold plasma with high electron temperatures generated during the cracking process can introduce efficient chemical activation routes to break thermodynamic limitations. Sol-gel synthesized $\mathrm{Li} / \mathrm{MgO}$ was shown to have a reasonable activity for oxidative cracking of hexane, with hexane conversions of $28 \%$ and an excellent selectivity to light olefins [3]. It was proposed that hexane activation occurs on the catalyst surface via $\mathrm{Li}^{+} \mathrm{O}^{-}$defect sites, where $\mathrm{O}^{-}$active sites abstract hydrogen from a secondary carbon atom, after which hexyl radicals undergo complex gas phase radical chemistry in the presence of oxygen which results in a product mixture of $\mathrm{C}_{1}-\mathrm{C}_{6}^{+}$hydrocarbons (paraffins, olefins) as well as combustion products. It is our purpose to investigate the oxidative cracking of hexane in an alternating current barrier discharge reactor in the presence of $\mathrm{Li} / \mathrm{MgO}$ catalyst to instantly produce olefins at elevated temperatures. The effect of plasma and catalyst 
parameters for conversion, product selectivity and yield will be explained on the basis of an oxidative radical mechanism.

\section{Experimental}

Fig. 1 shows a schematic representation of the plasma catalytic reactor. A discharge was generated between a high voltage wire electrode, to which a $6 \mathrm{kV}$ peak AC voltage with $50 \mathrm{kHz}$ frequency was applied, and a grounded metal foil which was positioned around a quartz tube. The output power of the supply was $10 \mathrm{~W}$. Unless stated otherwise, a total gas flow rate of $100 \mathrm{ml} / \mathrm{min}$ was used for a gas mixture containing $10 \%$ hexane and $8 \%$ oxygen in helium. The discharge gap was filled with a packed bed of nonconducting catalyst particles. The mean free path of electrons in the micropores of the particles is too small to maintain a discharge, the discharge is generated in the voids between the particles, very close to the catalyst surface. The dielectric reactor wall makes the plasma current almost independent of the gas mixture, and spark formation is inhibited. The advantage of such a packed bed plasma catalytic reactor is that it possesses the highest possible catalyst surface area to plasma volume ratio, and therefore forms the optimal combination of continuous flow plasma and catalytic technology.

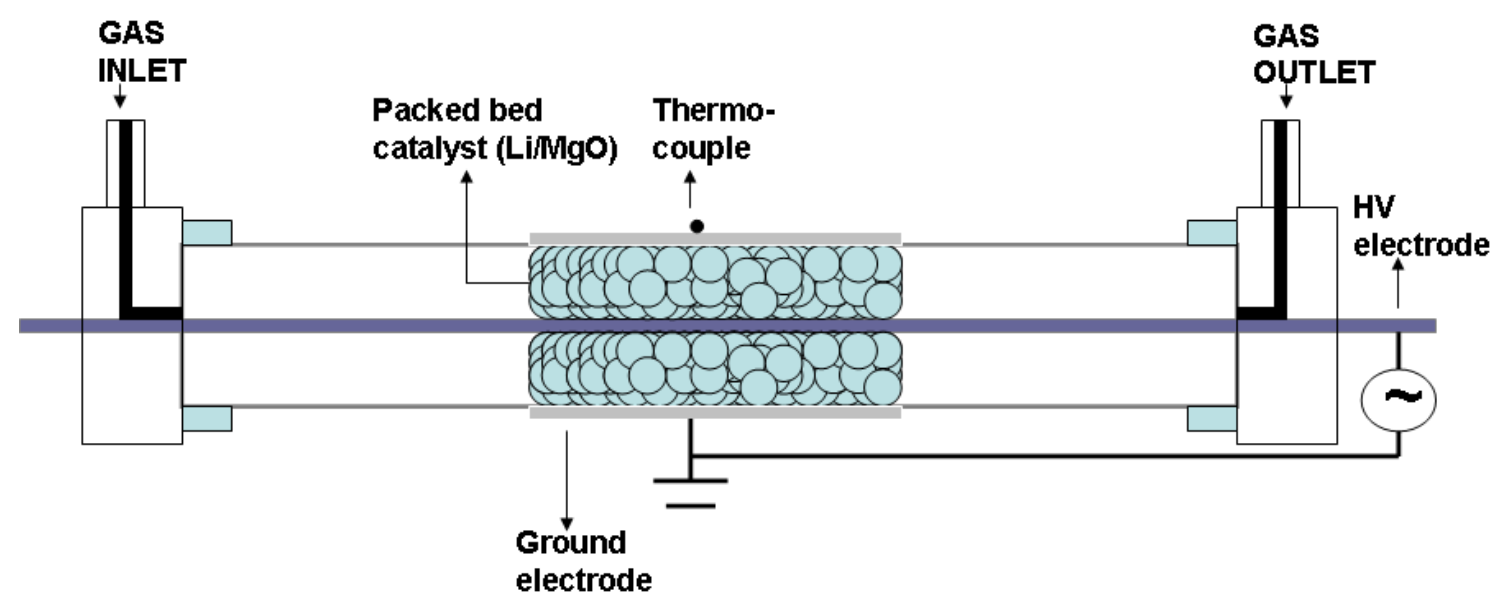

Figure 1. Plasma catalytic reactor based on dielectric barrier discharge.

A $\mathrm{Mg}\left(\mathrm{OCH}_{3}\right)_{2}$ solution (Aldrich), methanol (Merck) and $\mathrm{LiNO}_{3}$ (Aldrich) were used as catalyst precursor materials. Pure hexane (Fluka) was used for catalytic experiments. $\mathrm{Li} / \mathrm{MgO}$ catalysts were prepared by mixing a methanol solution 
containing $\mathrm{Mg}\left(\mathrm{OCH}_{3}\right)_{2}(0.4 \mathrm{M})$ and the $\mathrm{LiNO}_{3}$ amount required to obtain $1 \mathrm{wt} . \% \mathrm{Li} / \mathrm{MgO}$, with a solution of water in methanol $(0.8 \mathrm{M})$ to form a sol at room temperature. This sol mixture was allowed to stay for $24 \mathrm{~h}$ for gelation, after which the gel was dried at $50^{\circ} \mathrm{C}$ in vacuum for $7 \mathrm{hrs}$ and calcined at $500^{\circ} \mathrm{C}$ in air for $1 \mathrm{hr}$. The BET surface area of the catalyst was found to be $75 \mathrm{~m}^{2} / \mathrm{g}$. The catalytic tests were carried out in a quartz reactor of $4 \mathrm{~mm}$ internal diameter and the catalyst bed (10 mm length) was packed between two quartz-wool plugs. A thermocouple outside the quartz tube reactor was used to control the temperature of the furnace.

Mass-flow controllers (Brooks) were used to control the flow of gases. Two electrically actuated 4-port 1-position valves (Valco) were used to switch the reaction mixture to a bypass line to measure the composition of the feed. A Dionex Dual Gradient P680 HPLC pump was used to dose liquid hexane at an accurate rate. The hexane was gasified in a cylindrical gasifier operated at a temperature of $130^{\circ} \mathrm{C}$. The temperature of all lines of the setup was kept constant at $130^{\circ} \mathrm{C}$ to avoid condensation of hexane.

An elaborate micro-GC system was applied for full analysis of $\mathrm{C}_{1}-\mathrm{C}_{8}$ hydrocarbons, including paraffins and olefins. The online analysis system consisted of two micro GCs (Varian CP4900). The first micro GC is a quad system consisting of four channels with four different columns: Column 1 is a Molsieve 5A Plot (He carrier gas) for the separation of $\mathrm{O}_{2}, \mathrm{~N}_{2}, \mathrm{CH}_{4}$ and $\mathrm{CO}$, column 2 a PoraPlot Q column for the separation of $\mathrm{CO}_{2}, \mathrm{C}_{2} \mathrm{H}_{6}, \mathrm{C}_{2} \mathrm{H}_{4}, \mathrm{H}_{2} \mathrm{O}$, column 3 an Alumina $\mathrm{KCl}$ Plot at $\mathrm{T}=80{ }^{\circ} \mathrm{C}$ for the separation of $\mathrm{C}_{3}$ and $\mathrm{C}_{4}$ hydrocarbons (paraffins and olefins), and column 4 an Alumina $\mathrm{KCl}$ Plot at $\mathrm{T}=160{ }^{\circ} \mathrm{C}$ for the separation of $\mathrm{C}_{5}$ hydrocarbons (paraffins and olefins). The second Micro GC is a dual system consisting of two channels of two different columns: Column 1 is a Molsieve 5A Plot (Ar carrier gas) for the separation of $\mathrm{He}$ and $\mathrm{H}_{2}$, and column 2 a CP-SIL 5CB to separate $\mathrm{C}_{6}-\mathrm{C}_{8}$ hydrocarbons (paraffins and olefins). All channels contain TCD detectors.

A gas mixture of known concentration of $\mathrm{C}_{1}-\mathrm{C}_{6}$ hydrocarbons (paraffins, olefins) was used for the calibration of the micro GCs. Hexane conversion was calculated on a carbon mol basis i.e., $100 \% \cdot\left(6 \cdot \mathrm{C}_{6}\right.$ moles in $-6 \cdot \mathrm{C}_{6}$ moles out $) /\left(6 \cdot \mathrm{C}_{6}\right.$ moles in $)$. The selectivity to individual products was calculated based on the number of moles of carbon contained in a specific product, divided by the total number of moles of carbon in the product mixture (i.e. excluding unconverted feed). 


\section{Results and discussion}

\section{Plasma conversion of hexane without catalyst.}

Effect of temperature. Fig. 2 shows how the conversion of hexane and oxygen changes when the temperature increases from $400^{\circ} \mathrm{C}$ to $600^{\circ} \mathrm{C}$ in a plasma reactor without catalyst particles. The conversion results obtained without a plasma are also shown. The conversion of hexane increases from $27 \%$ to $33 \%$ when the temperature increases. The main reactions responsible for hexane cracking are electron impact dissociation of hexane and oxidative cracking with highly excited oxygen radicals.

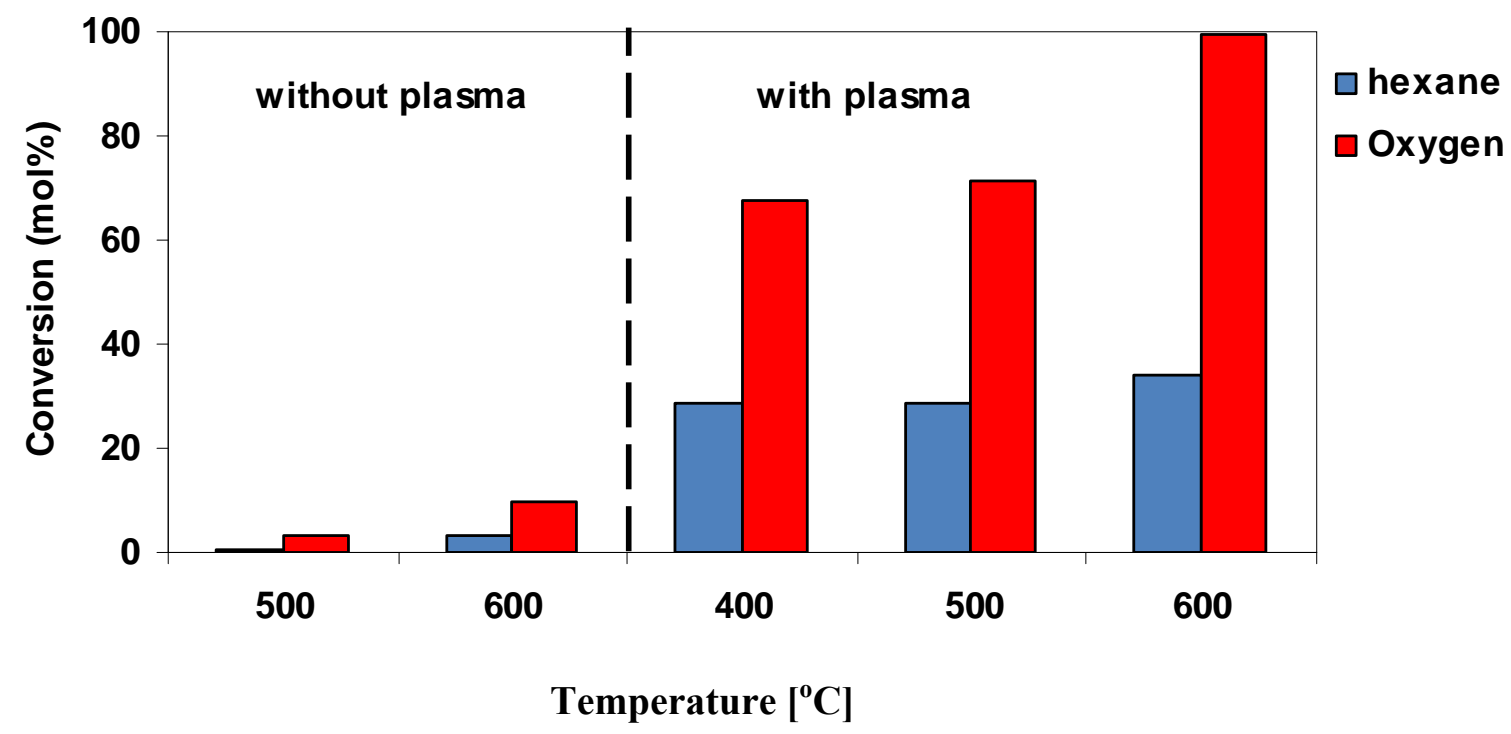

Figure 2. Results of oxidative conversion of hexane with and without the presence of plasma at the temperature range, 400 to $600^{\circ} \mathrm{C}$.

The electron impact dissociation of hexane is an extremely complex process, many dissociation modes occur simultaneously to produce hydrocarbon and oxygen radicals. It is believed that the initial reactions involved in the plasma dissociation of hexane are dissociative excitation with energetic electrons, energy transfer from metastable helium species, and processes involving excited oxygen radicals leading to hexyl radicals $\left(\mathrm{C}_{6} \mathrm{H}_{13}\right)$, hydrogen molecules $\left(\mathrm{H}_{2}\right)$ and methyl radicals $\left(\mathrm{CH}_{3}\right)$, since these are the direct products from cracking $\mathrm{C}-\mathrm{C}$ and $\mathrm{C}-\mathrm{H}$ bonds. The hexyl radicals that fragment during the initial dissociation process are believed to follow dissociation 
patterns which form olefins. Dissociation of oxygen by high-energy electron impact can yield atomic oxygen, $\mathrm{O}\left({ }^{3} \mathrm{P}\right)$ and $\mathrm{O}\left({ }^{1} \mathrm{D}\right)$ by the following reactions [4]:

$$
\begin{aligned}
& \mathrm{O}_{2}+\mathrm{e} \rightarrow 2 \mathrm{O}\left({ }^{3} \mathrm{P}\right)+\mathrm{e} \\
& \mathrm{O}_{2}+\mathrm{e} \rightarrow 2 \mathrm{O}\left({ }^{3} \mathrm{P}\right)+\mathrm{O}\left({ }^{1} \mathrm{D}\right)+\mathrm{e}
\end{aligned}
$$

It can be seen from Fig. 2 that plasma conversion of hexane is independent of temperature, the slight increase at $600^{\circ} \mathrm{C}$ is attributed to the fact that at this temperature oxygen conversion reaches $100 \%$. During the course of these experiments, a steel wire acting as a high-voltage electrode was in contact with processing gas. This wire may have acted as a hot catalytic surface that increases oxygen conversion.

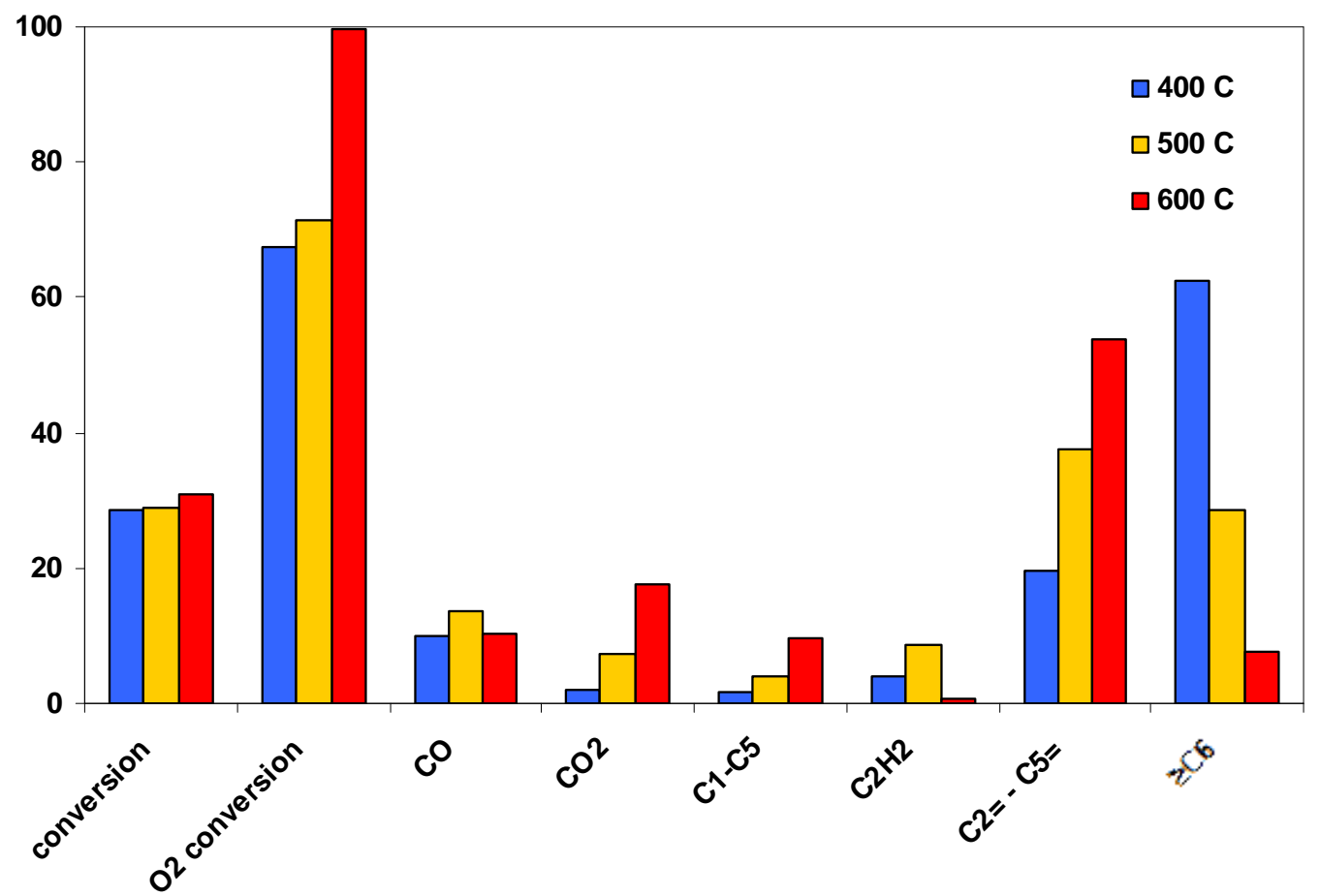

Figure 3. Effect of temperature on product selectivity.

Fig. 3 shows the corresponding selectivity values for temperatures between 400 and $600^{\circ} \mathrm{C}$. The temperature influences the product distribution significantly: At the lower temperature of $400{ }^{\circ} \mathrm{C}$ we observed a considerable formation of $\mathrm{C}_{6}+(62 \%$ selectivity $)$ and less formation of $\mathrm{C}_{2}-\mathrm{C}_{5}$ olefins ( $19 \%$ ) which shows that a lower temperature favors the coupling of radicals to produce higher hydrocarbons in the homogeneous gas phase. Free radical addition and electrophilic addition onto carbon-carbon bonds are highly possible pathways for the formation of higher hydrocarbons under plasma conditions. C- 
C bond formation is exothermic, which is why it is favored at lower temperatures. Similarly, during oxidative conversion of propane in the presence of plasma at room temperature, coupling reactions and formation of $\geq \mathrm{C}_{4}$ products were observed [5]. At the higher temperature of $600^{\circ} \mathrm{C}$ dissociation reactions, running via $\mathrm{C}-\mathrm{C}$ and $\mathrm{C}-\mathrm{H}$ bond cleavage, as well as deep oxidation reactions are favored, which explains the higher selectivity to $\mathrm{C}_{2}-\mathrm{C}_{5}$ olefins and $\mathrm{CO}_{2}$. Formation of ethyne is due to extensive dehydrogenation of $\mathrm{C}_{2}$ species in the discharge, as well as to dimerization of $\mathrm{CH}$ species.

\section{Effect of $\mathrm{O}_{2} / \mathrm{C}_{6}$ on hexane and oxygen conversion.}

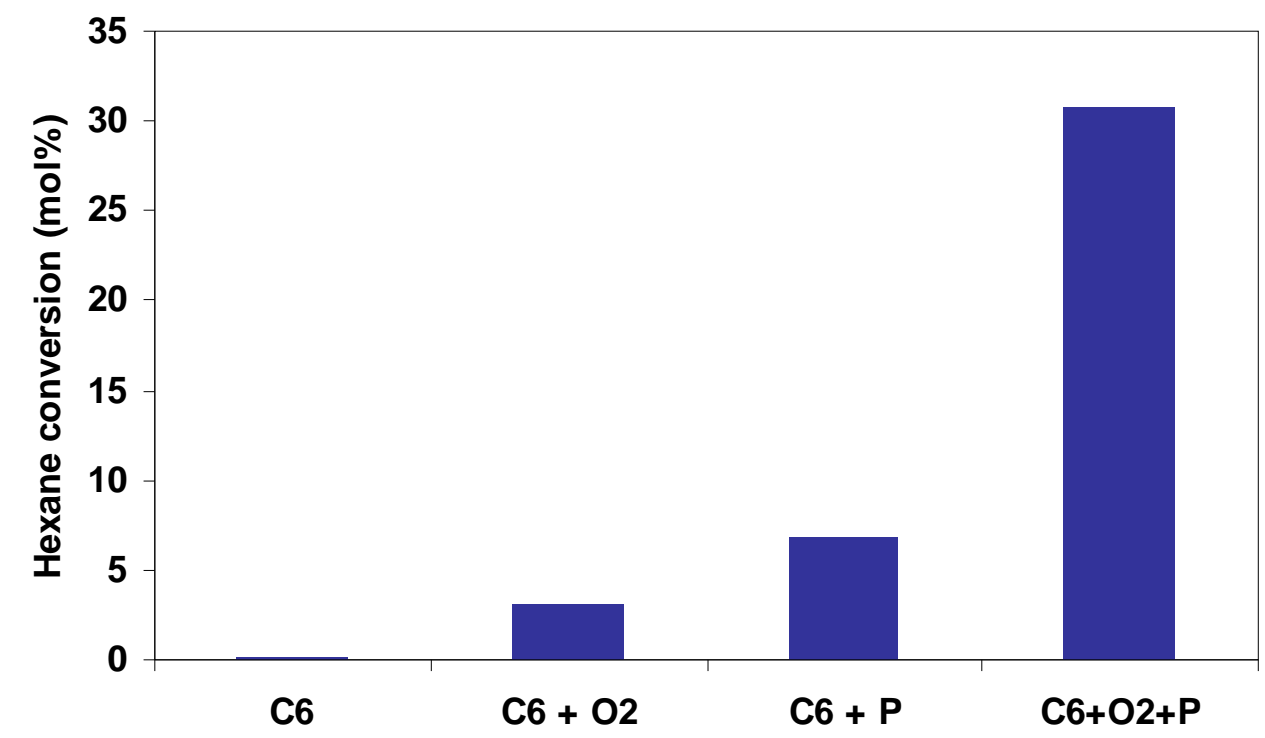

Figure 4. Effect of $\mathrm{O}_{2}$ on hexane conversion (C6: hexane, O2: oxygen, P: plasma).

Fig. 4 shows that under the experimental conditions reported here, in the absence of plasma the presence of oxygen in the feed enhances hexane conversion, and this is the essence of oxidative conversion, viz. oxygen in the gas phase can activate hexyl radicals according to eq. 3 :

$$
\mathrm{C}_{6} \mathrm{H}_{14}+\mathrm{O}_{2} \rightarrow \mathrm{C}_{6} \mathrm{H}_{12} \cdot+\mathrm{HO}_{2} .
$$

The addition of a plasma to the hexane/oxygen system results in a dramatic increase in hexane conversion. The results clearly indicate the existence of a new route for hexane conversion involving activation of gas phase oxygen by plasma.

Fig. 5 shows that as the oxygen/hexane ratio increases, a significantly higher conversion of hexane is found, which is due to the fact that during plasma cracking the 
amount of oxygen radicals increases. The primary event in the plasma oxidative cracking of hexane is the electron impact excitation of molecular oxygen yielding atomic oxygen in the ground $\mathrm{O}\left({ }^{3} \mathrm{P}\right)$ and excited $\mathrm{O}\left({ }^{1} \mathrm{D}\right)$ states. In the presence of hexane, excited atomic oxygen can open new cracking pathways. It has been reported earlier [5] that during oxidative conversion of propane, the oxygen concentration influences the concentration and type of chain carrier radicals. $\mathrm{C}_{3} \mathrm{H}_{7}$. radicals react fast with $\mathrm{O}_{2}$ forming hydro-peroxyl

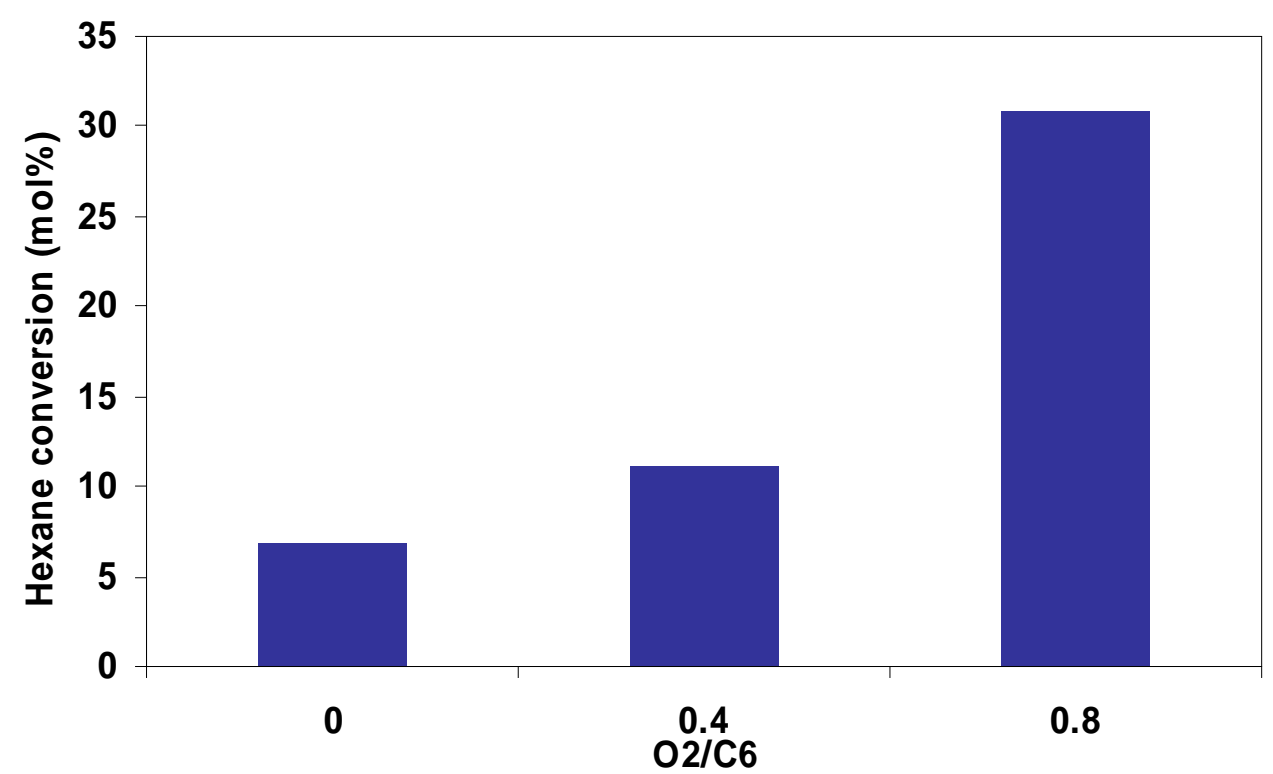

Figure 5. Effect of $\mathrm{O}_{2} / \mathrm{C}_{6}$ ratio on hexane and oxygen conversion.

$\left(\mathrm{HO}_{2} \cdot\right)$ radicals which react fast with propane to form $\mathrm{H}_{2} \mathrm{O}_{2}$. Decomposition of $\mathrm{H}_{2} \mathrm{O}_{2}$ results in hydroxyl radicals $(\mathrm{OH} \cdot)$ which become the main chain propagators. In plasma oxidative conversion, oxygen thus has two significant roles: (i) introducing new routes for hexane activation, (ii) and accelerating the radical chemistry. However, the oxygen concentration needs to be tuned carefully, since high concentrations of oxygen would compromise the selectivity to olefins.

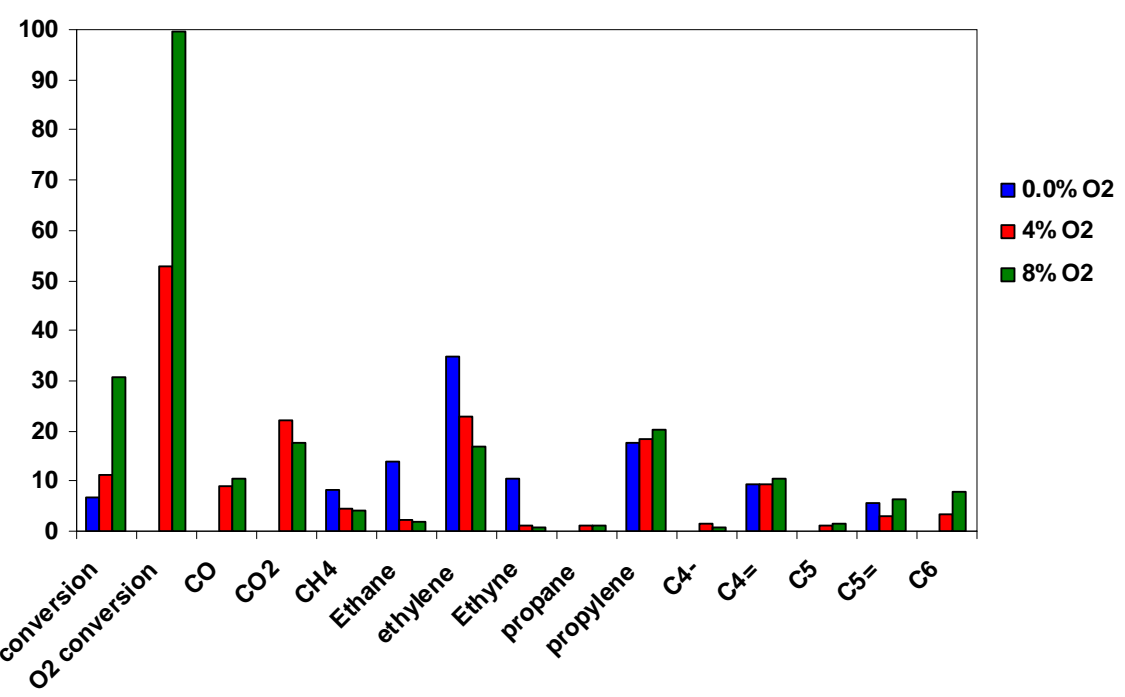


Figure 6. Effect of $\mathrm{O}_{2}$ concentration on product selectivity.

Fig. 6 shows the effect of different oxygen concentrations on product selectivity. Formation of oxygenates was not observed due to the high temperature of $600^{\circ} \mathrm{C}$.

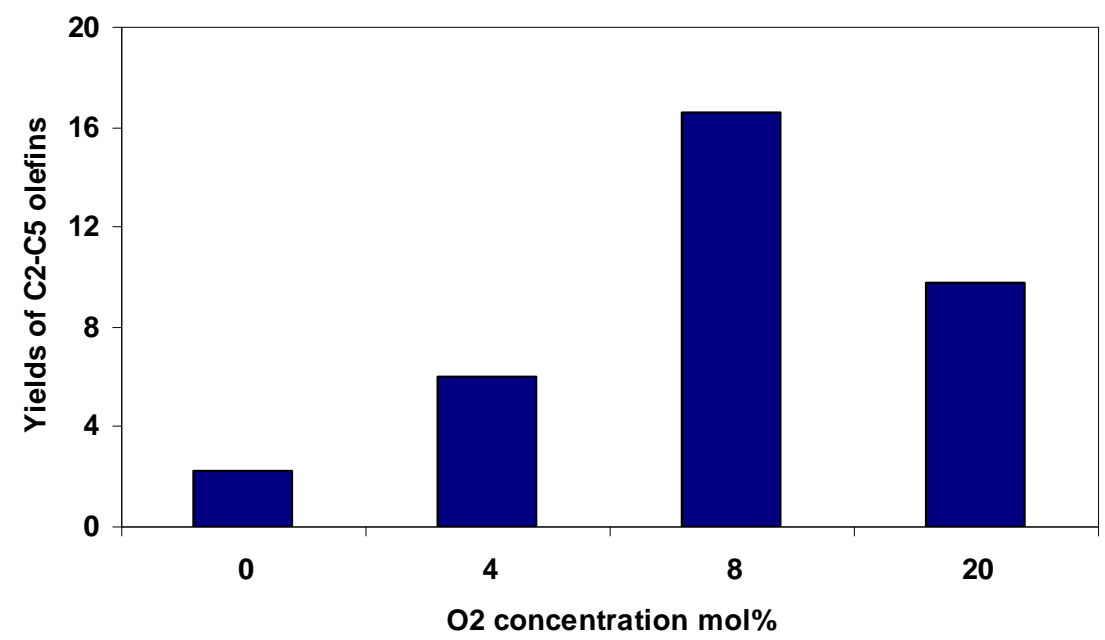

Figure 7. Yields of $\mathrm{C}_{2}-\mathrm{C}_{5}$ olefins as function of $\mathrm{O}_{2}$ concentration in the feed.

As the conversion increased, the total selectivity to olefins decreased, however the overall yield increased (Fig. 7). With the increase in $\mathrm{O}_{2}$ concentration, we observe an increased formation of combustion products $\left(\mathrm{CO}, \mathrm{CO}_{2}\right)$ and a decreased formation of methane, ethane, ethylene and ethyne. Fig. 7 shows that optimum yields of $\mathrm{C}_{2}-\mathrm{C}_{5}$ olefins were achieved at an oxygen concentration of $8 \%$.

\section{Effect of helium flow rate on hexane conversion.}

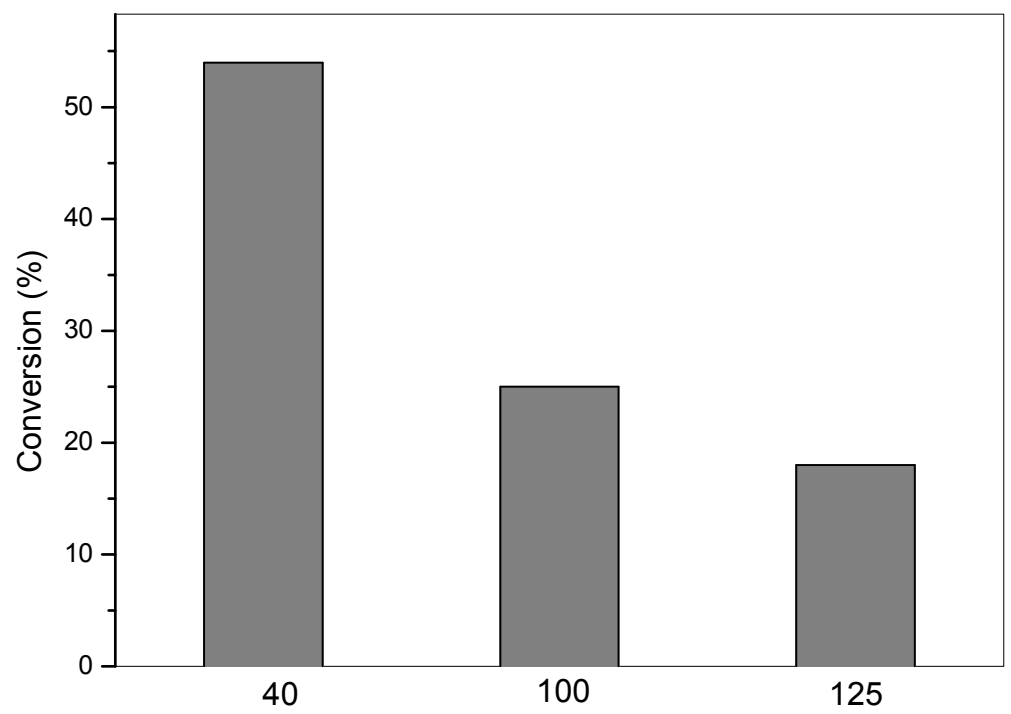


Figure 8. Effect of helium flow rate on hexane conversion.

Fig. 8 shows the effect of helium flow rate on product selectivity for non-catalytic plasma hexane conversion. Helium was used as a diluent gas, and has 2 significant effects: The most important one is that it changes the residence time of the process gas in the plasma region, a secondary effect is that it helps to activate the hexane molecule through energy exchange with highly excited helium species. Increasing the helium flow rate decreased the residence time of hexane in the plasma reactor and therefore conversion decreased considerably. Fig. 9 shows the corresponding selectivity values. A lower selectivity to olefins is observed when the helium flow rate decreases, which can be explained by the fact that although the conversion decreased with increasing flow rate, the increasing number of excited helium species may lead to an acceleration of combustion reactions due to energy transfer to the oxygen and hydrocarbon radicals. This can be concluded from the increased selectivity to $\mathrm{CO}_{\mathrm{x}}$ products. However, since the ratio of energy spent on hexane conversion decreases with increasing helium content, the conversion decreases. A maximum olefin yield of $26 \%$ can be observed at $40 \mathrm{ml} / \mathrm{min}$ helium flow.

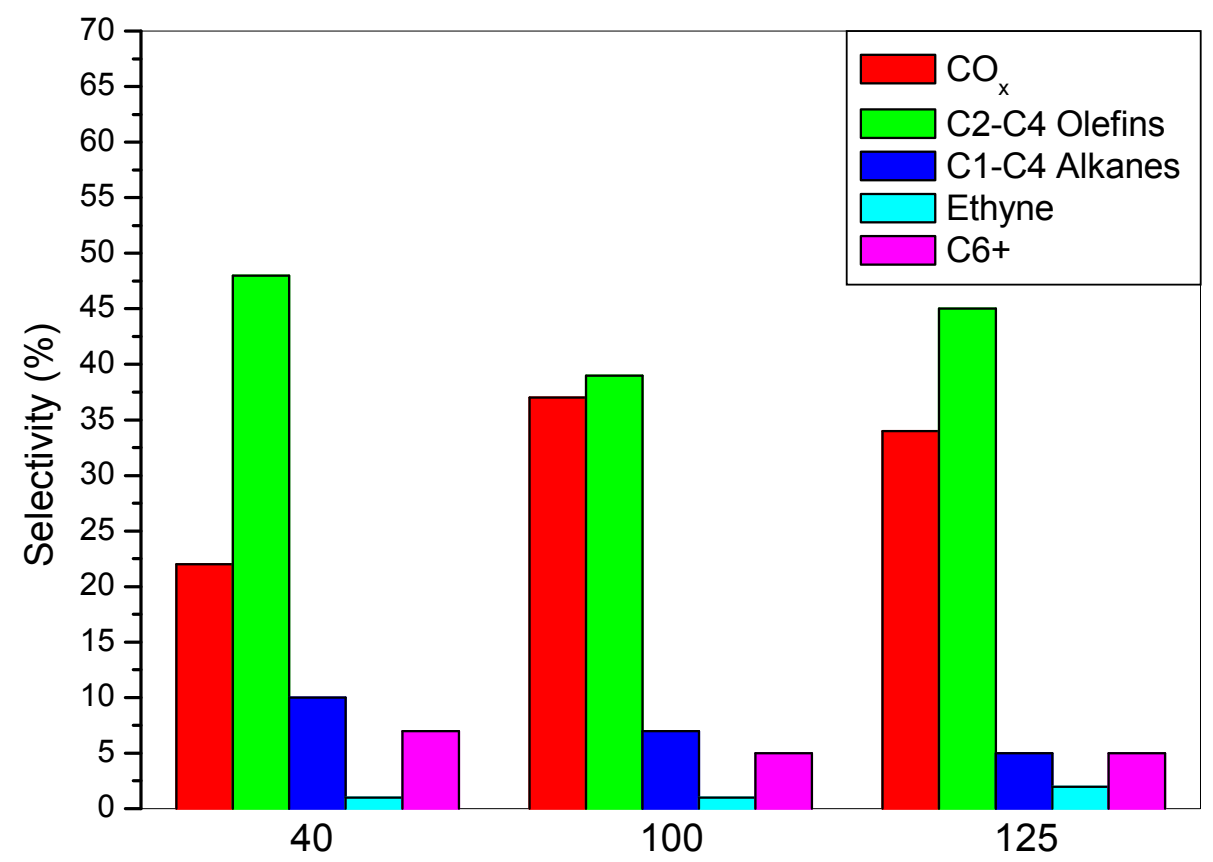

Figure 9. Effect of helium flow rate on product selectivity. 
3. 2 Plasma enhanced catalytic process. $\mathrm{MgO}$ is a basic oxide support for the $\mathrm{Li} / \mathrm{MgO}$ catalyst. To be able to compare and understand the Li effect, we carried out plasma conversion experiments in the presence of a $\mathrm{MgO}$ support. $\mathrm{MgO}$ particles were filled in the plasma region and conversion, selectivity and yield values were compared for the cases of: plasma alone, $\mathrm{MgO}$ alone, and plasma $+\mathrm{MgO}$. Pure plasma conversion experiments were carried out in the presence of $\mathrm{SiO}_{2}$ particles, under the assumption that $\mathrm{SiO}_{2}$ does not have catalytic activity and represents the same geometric structure in the reactor as with the catalyst particles. Fig. 10 shows the conversion for the 3 different cases. Plasma $+\mathrm{MgO}$ gave the highest conversion because of the electron impact dissociation processes during discharge. The difference in conversion between plasma + $\mathrm{MgO}$ and plasma $+\mathrm{SiO}_{2}$ can be due to the difference in permittivity of the two dielectrics: A different permittivity may slightly change the accumulation of charge in the plasma before breakdown, so that more streamers can be formed at the contact point of particles. Fig. 11 shows the selectivity values. If we calculate the olefin yield (around $14 \%$ ), it shows no difference with the plasma and the plasma $+\mathrm{MgO}$ cases, which leads us to the conclusion that there is no synergistic effect of plasma catalysis with the $\mathrm{MgO}$ support in these experiments.

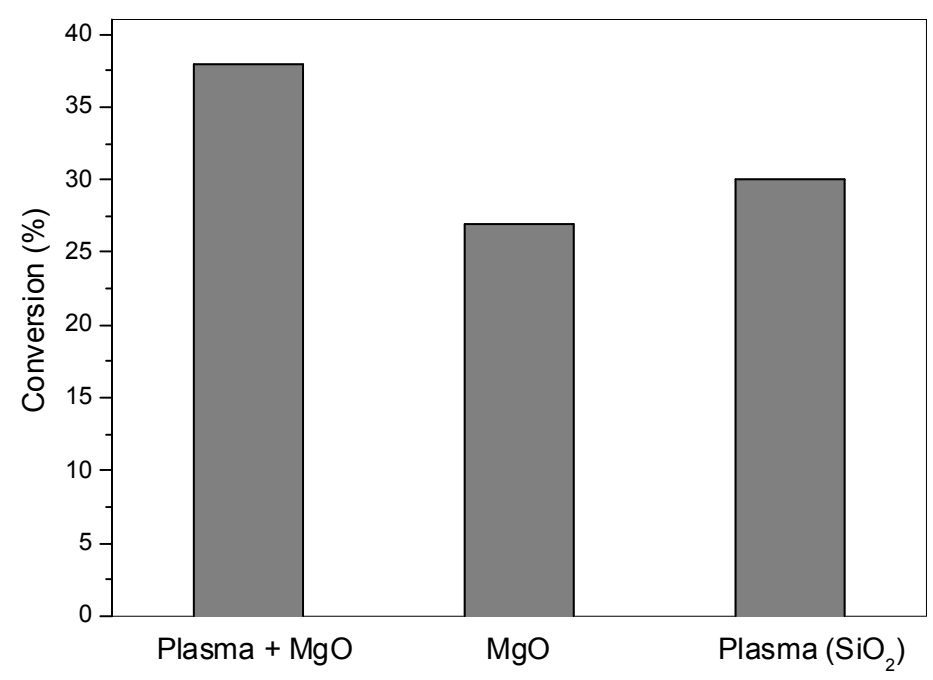

Figure 10. Effect of $\mathrm{MgO}$ on conversion of hexane..

Fig. 12 shows the role of the catalyst $\mathrm{Li} / \mathrm{MgO}$ in enhancing the total yield of $\mathrm{C}_{2}$ $\mathrm{C}_{5}$ olefins during oxidative conversion of hexane, both in absence and presence of plasma. In the absence of plasma, the catalytic system gives higher yields of olefins, and this 
enhancement is more significant at $600^{\circ} \mathrm{C}$. The presence of $\mathrm{Li} / \mathrm{MgO}$ is crucial to induce hexane activation at a relatively low temperature of $600^{\circ} \mathrm{C}$. It is believed that $\mathrm{Li}^{+} \mathrm{O}^{-}$defect sites are responsible for the catalytic activity [3], $\mathrm{Li}^{+} \mathrm{O}^{-}$defect sites have been

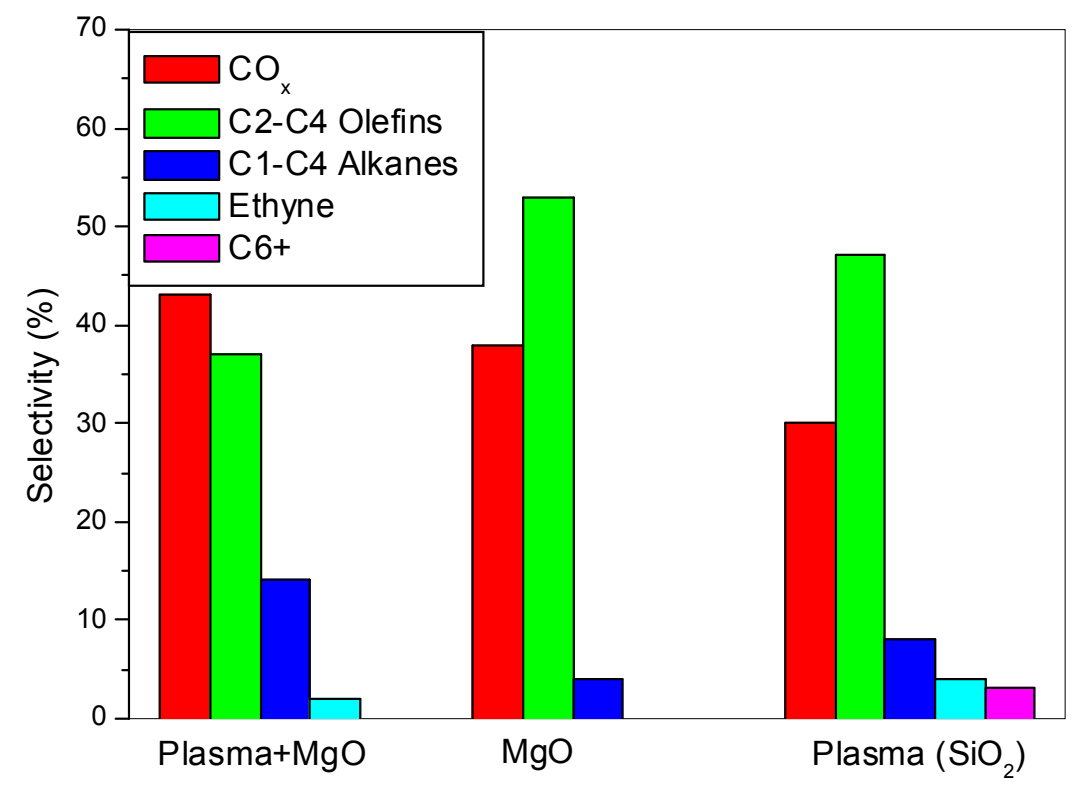

Figure 11. Effect of $\mathrm{MgO}$ on the product selectivities.

reported to cause scission of $\mathrm{H}$ atoms from alkanes [3]. In the case of hexane, we propose the same pathway for activation of hexane over $\mathrm{Li} / \mathrm{MgO}$, which is via homolytic scission of a $\mathrm{C}-\mathrm{H}$ bond, leading to the formation of a hexyl radical:

$\mathrm{C}_{6} \mathrm{H}_{14}+\mathrm{Li}^{+} \mathrm{O}^{-} \rightarrow \mathrm{C}_{6} \mathrm{H}_{13} \cdot+\mathrm{Li}^{+} \mathrm{OH}^{-}$

For the plasma system we observed an improved olefin yield, which suggests a new selective pathway for hexane activation.

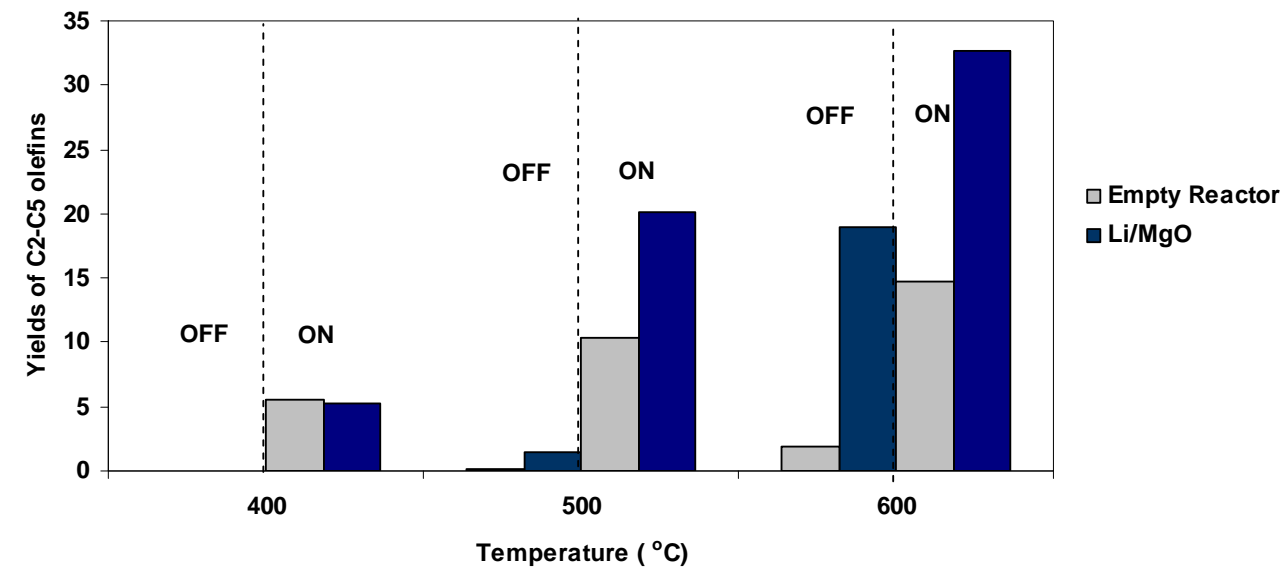


Figure 12. Yield of olefins with two systems. (i) empty reactor, and (ii) $\mathrm{Li} / \mathrm{MgO}$ with $(\mathrm{ON})$ or without plasma $(\mathrm{OFF})$. (6.5 $\mathrm{cm}$ of reactor bed was packed with $\mathrm{Li} / \mathrm{MgO})$

In order to investigate the synergistic effect between plasma and $\mathrm{Li} / \mathrm{MgO}$ catalyst, the following three systems were investigated in the temperature range $400-600^{\circ} \mathrm{C}$ : (i) $\mathrm{Li} / \mathrm{MgO}$, (ii) inert quartz particles + plasma and (iii) $\mathrm{Li} / \mathrm{MgO}+$ plasma. Fig. 13 shows both hexane and oxygen conversions for these three systems at three different temperatures. The system with plasma and $\mathrm{Li} / \mathrm{MgO}$ shows a beneficial result only at $\mathrm{T}>400^{\circ} \mathrm{C}$, at $400^{\circ} \mathrm{C}$ the hexane conversion for this system is very similar to that achieved for the plasma with inert particles, which is mainly due to the low reaction temperature and insufficient energy for $\mathrm{C}-\mathrm{H}$ bond cleavage via active sites of the catalyst. At $400^{\circ} \mathrm{C}$ the $\mathrm{Li} / \mathrm{MgO}-$ alone system shows a conversion of only $2 \%$.

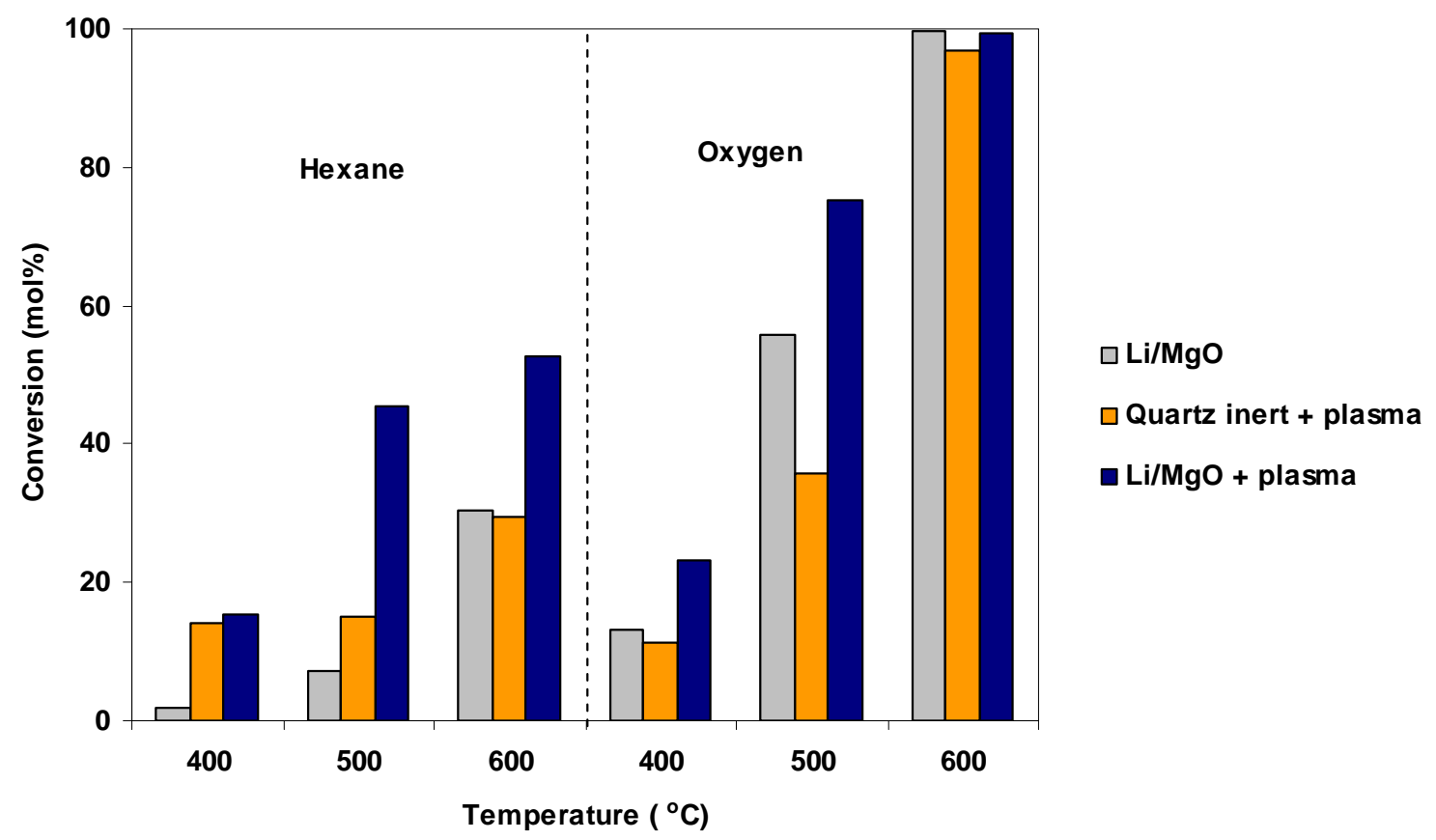

Figure 13. Hexane and oxygen conversions. (i) $\mathrm{Li} / \mathrm{MgO}$, (ii) inert quartz + plasma, and (iii) $\mathrm{Li} / \mathrm{MgO}+$ plasma.

Fig. 14 shows the product distribution at $500^{\circ} \mathrm{C}$, again for the three different systems mentioned above. $\mathrm{Li} / \mathrm{MgO}$ shows a high selectivity to combustion products (75 $\%$ ) and gives only $22 \%$ of total olefins $\left(\mathrm{C}_{2}-\mathrm{C}_{5}=\right)$. At these low reaction temperatures deep oxidation reactions over the catalyst surface are favored. Intermediate radical species, specifically $\mathrm{CH} \cdot \mathrm{CH}_{3}$ and $\mathrm{C}_{2} \mathrm{H}_{5}$ interact with unselective oxygen sites on the catalyst 
surface and form alkoxide species as precursors for $\mathrm{CO}_{\mathrm{x}}$. This explains the low selectivity to $\mathrm{C}_{1}-\mathrm{C}_{5}$ alkanes and ethylene in the case of the $\mathrm{Li} / \mathrm{MgO}$ system. However, applying a plasma changes the product distribution by increasing the selectivity to total olefins to 43 $\%$ and decreasing the selectivity to $\mathrm{CO}_{\mathrm{x}}$ to $30 \%$. Unlike it is the case in an empty reactor at comparable temperatures, with inert or catalyst particles only traces of $\geq \mathrm{C}_{6}$ products were formed. In the plasma- $\mathrm{Li} / \mathrm{MgO}$ system at $500^{\circ} \mathrm{C}$ a similar product distribution was observed. This indicates that oxygen in the plasma- $\mathrm{Li} / \mathrm{MgO}$ system was selectively involved in the activation of hexane molecules in the gas phase. Therefore, in a plasma + $\mathrm{Li} / \mathrm{MgO}$ system, there are three pathways for hexane activation: (i) $\mathrm{C}-\mathrm{H}$ bond scission by $\mathrm{Li}^{+} \mathrm{O}^{-}$active sites, (ii) $\mathrm{C}-\mathrm{H}$ bond scission by electron-impact excitation and (iii) $\mathrm{C}-\mathrm{H}$ bond scission by activated $\mathrm{O}$ radicals.

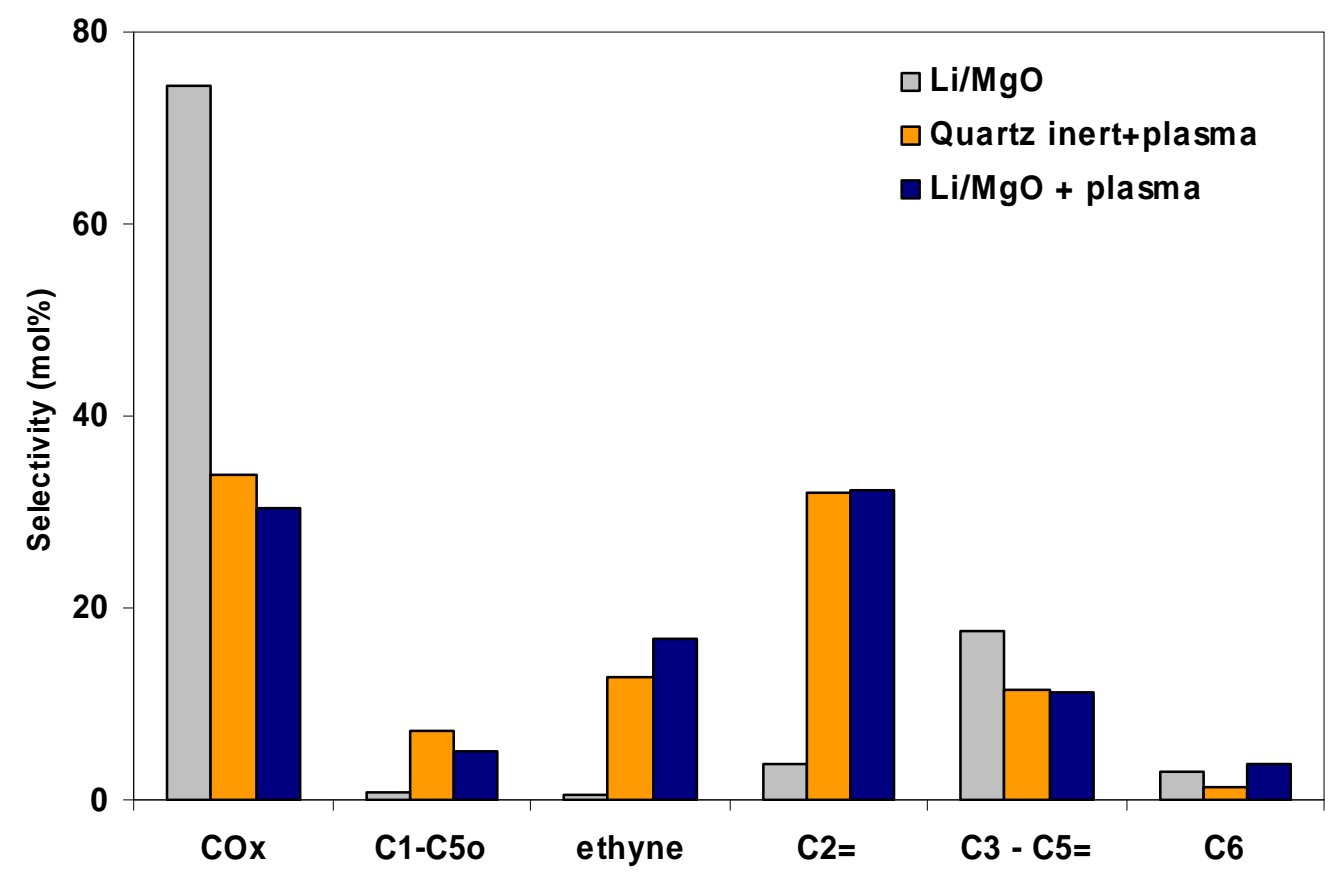

Figure 14. Product distribution at $500{ }^{\circ} \mathrm{C}$ for three different systems; i) $\mathrm{Li} / \mathrm{MgO}$, (ii) inert quartz + plasma, and (iii) $\mathrm{Li} / \mathrm{MgO}+$ plasma.

Fig. 14 also shows that the product distribution for the plasma $+\mathrm{Li} / \mathrm{MgO}$ system is very similar to that for the inert particles + plasma system. In both systems we observed substantial formation of ethyne and ethylene and less formation of $\mathrm{C}_{3}-\mathrm{C}_{5}$ olefins or combustion products. The presence of ethyne is evidence for the plasma chemistry described earlier. The results imply a lower contribution from the catalyst in the 
activation of hexane and initiation of hexyl radicals. At this low reaction temperature, plasma chemistry seems to be more dominant.

At $600^{\circ} \mathrm{C}$ (Fig. 15), the product distribution from the plasma $+\mathrm{Li} / \mathrm{MgO}$ system seems to be more similar to that of $\mathrm{Li} / \mathrm{MgO}$ in the absence of plasma. We observed more formation of $\mathrm{C}_{3}-\mathrm{C}_{5}$ olefins with a higher $\left(\mathrm{C}_{3}{ }^{=}-\mathrm{C}_{5}{ }^{=}\right) / \mathrm{C}_{2}{ }^{=}$ratio. We speculate that the catalyst has a higher contribution to hexane activation at $600^{\circ} \mathrm{C}$. In the case of $\mathrm{Li} / \mathrm{MgO}$, the increased formation of $\mathrm{C}_{3}-\mathrm{C}_{5}$ olefins indicates an involvement of the catalyst in the process by hydrogen abstraction. Typically, in a cracking sequence primary hydrocarbon radicals will yield $\mathrm{C}_{2}$ fragments and secondary radicals will yield $>\mathrm{C}_{2}$ fragments.

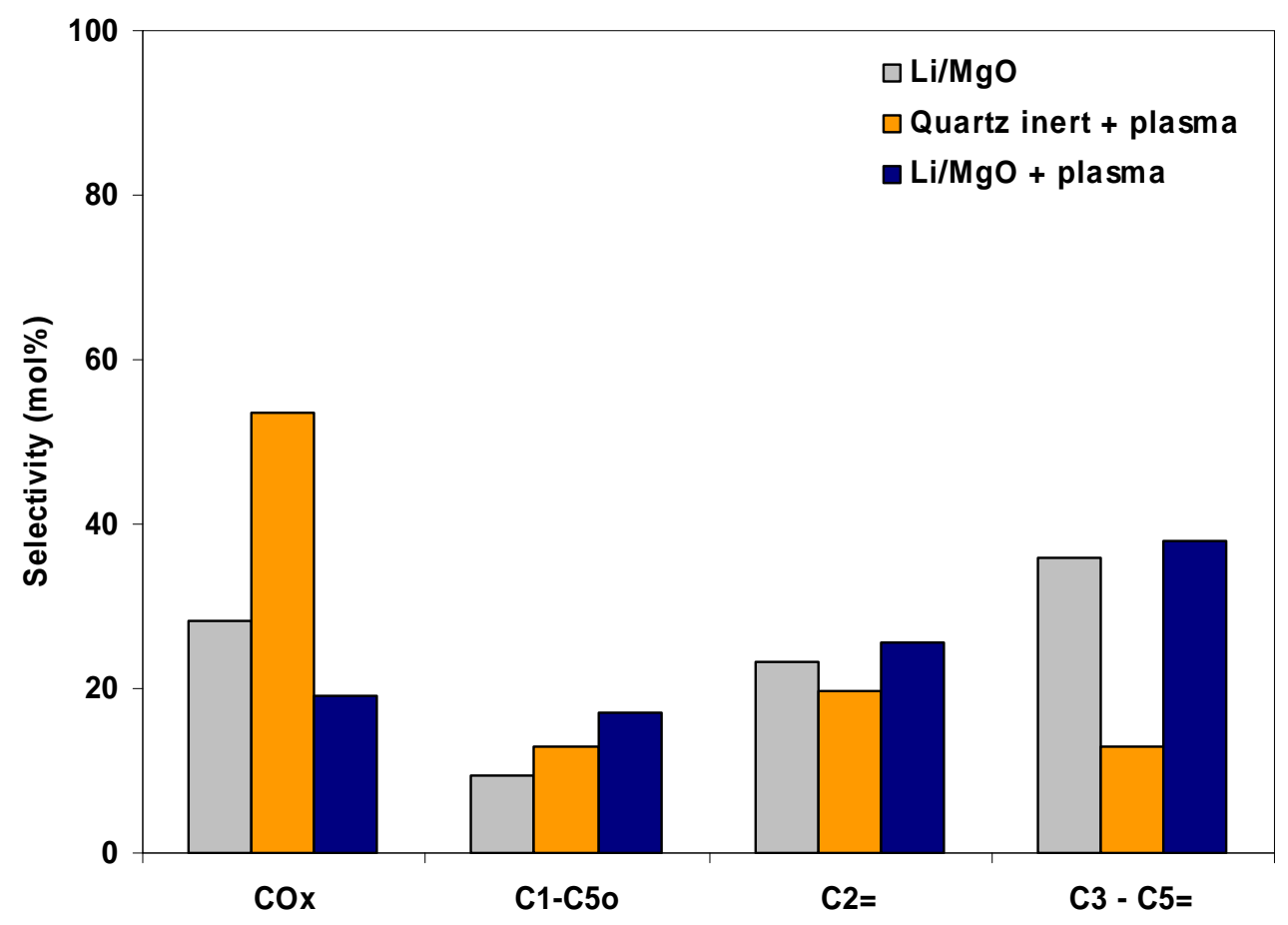

Figure 15. Product distribution at $600{ }^{\circ} \mathrm{C}$ for three different systems; i) $\mathrm{Li} / \mathrm{MgO}$, (ii) inert quartz + plasma, and (iii) $\mathrm{Li} / \mathrm{MgO}+$ plasma

\section{Conclusion}

In the gas phase oxidative conversion of hexane the application of plasma induces hexane activation via electron-impact excitation, which enhances hexane conversions at temperatures as low as $400^{\circ} \mathrm{C}$. The product distribution is mainly controlled by the temperature, at a temperature of $600^{\circ} \mathrm{C} \mathrm{C}-\mathrm{C}$ and $\mathrm{C}-\mathrm{H}$ cleavage leads to cracking products, while at low temperatures, as is also reported in literature, coupling reactions of 
intermediate radicals become more significant.

Compared to a non-catalytic plasma system, a system with both plasma and a catalyst gives a dramatic improvement in the yield of olefins $\left(\mathrm{C}_{2}{ }^{-}-\mathrm{C}_{5}{ }^{-}\right)$at the relatively low temperatures of 500 and $600{ }^{\circ} \mathrm{C}$. In this system, hexane activation takes place via three main routes; (i) $\mathrm{C}-\mathrm{H}$ bond scission by $\mathrm{Li}^{+} \mathrm{O}^{-}$active sites, (ii) by electron-impact excitation and (iii) $\mathrm{C}-\mathrm{H}$ bond scission by oxygen radicals.

The nature of the hexyl radicals, primary or secondary, will determine the faith of these radicals in the gas phase. In the gas phase in the presence of a plasma these radicals will undergo a series of electron collisions and dissociation reactions via $\mathrm{C}-\mathrm{C}$ and $\mathrm{C}-\mathrm{H}$ bond scission leading to the final products. At a temperature of $500{ }^{\circ} \mathrm{C}$ in a plasma + $\mathrm{LiMgO}$ system, we speculate that the catalyst contributes less to hexane activation, which results in a product distribution very similar to that in a system with plasma on inert particles. At the higher temperature of $600^{\circ} \mathrm{C}$ the catalytic contribution becomes more relevant, resulting in a product distribution very similar to that of $\mathrm{Li} / \mathrm{MgO}$ in absence of plasma.

\section{Acknowledgements}

We thank the Technology Foundation STW, applied science division of NWO and the technology programme of the Ministry of Economic Affairs, The Netherlands for financial support (project number 06626). Part of this research was supported by the CW/NWO, The Netherlands (project number 700.50.005). 


\section{References}

(1) Ren, T.; Patel, M.; Blok, K. Olefins from conventional and heavy feedstocks: Energy use in steam cracking and alternative processes. Energy 2006, 31, 425 - 451

(2) Liu, X.; Li, W.; Xu, H.; Chen, Y. Production of light alkenes with low $\mathrm{CO}_{2}$ emission from gas phase oxidative cracking (GOC) of hexane. React. Kinet. Catal. Lett, 2004, Vol. 81. No.2, 203-209

(3) Trionfetti, C.; Babich, I.V.; Seshan, K.; Lefferts, L. Formation of high surface area $\mathrm{Li} / \mathrm{MgO}$ - Efficient catalyst for the oxidative dehydrogenation/cracking of propane. Appl. Catal. A: General , 2006, 310, 105-113

[4] Kudryashov, S. V.; Shchegoleva G. S.; Ryabov A. Yu.; Sirotkina E. E. Simulation of the kinetics of cyclohexane oxidation in a barrier discharge reactor. High Energy Chemistry, 2002, 36, 5, 349-353.

[5] Agiral, A.; Trioneftti, C.; Seshan, K.; Gardeniers, J. G. E. Propane conversion at ambient temperatures $\mathrm{C}-\mathrm{C}$ and $\mathrm{C}-\mathrm{H}$ bond activation using cold plasma in a microreactor. Chem. Eng. \& Tech., 2008, 31, 8, 1116 - 1123. 


\section{Chapter 5}

\section{Direct methane conversion to liquid oxygenates using a multi-phase flow, non-thermal plasma microreactor}

Direct synthesis of liquid oxygenates from partial oxidation of methane has been studied in a multi-phase flow, non-equilibrium plasma microreactor near $0^{\circ} \mathrm{C}$ at atmospheric pressure. A method for liquid-water injection into the microreactor was introduced in order to remove incomplete oxidation products such as methanol, which prevents further oxidation with excited species originating from the microplasma. Unlike in the conventional methane oxidation at high-temperature, in the microplasma reactor at low-temperature a significant amount of hydrogen peroxide $\left(\mathrm{H}_{2} \mathrm{O}_{2}\right)$ was produced, which accelerates the rate-determining step in methane partial oxidation: hydroxyl radicals $(\mathrm{OH})$ derived from $\mathrm{H}_{2} \mathrm{O}_{2}$ efficiently abstract hydrogen from methane. As a result of the synergistic oxidizing effects of $\mathrm{H}_{2} \mathrm{O}_{2}$ and $\mathrm{O}_{2}$, a one-pass yield of liquid oxygenates of $10 \%$ was demonstrated .

Portions of this chapter published in:

Japanese Patent - Patent No. 09T026, Tokyo Institute of Technology: "Method for oxidation of hydrocarbons and oxidation reactor" TOMOHIRO NOZAKI, 
MASAHIKO NAKASE, ANIL AGIRAL, KEN OKAZAKI, 2009-147043.

(In preparation) Direct methane conversion to liquid oxygenates using multiphase flow, non-thermal plasma microreactor, $\underline{\text { Chemical Communications }}$

\section{Introduction}

The direct synthesis of liquid oxygenates by partial oxidation of methane is an attractive alternative process which reduces capital and operating costs of high temperature, energy intensive, multi-step processes that run via the production of synthesis gas $\left(\mathrm{H}_{2}+\mathrm{CO}\right)$. Although a tremendous effort has been made in direct methane conversion to liquid oxygenates by homogeneous gas phase reactions and over solid catalysts, the product yield in most studied cases led to the conclusion that such processes are not economically feasible [1]. More recently, atmospheric pressure non-thermal plasma processes have been highlighted as viable synthesis methods because the high energy electron impact involved in these processes activates the strong $\mathrm{C}-\mathrm{H}$ bond of methane even at room temperature. Although this enables better process control compared to conventional thermochemical methods, an economically interesting yield of liquid oxygenates has not been achieved yet [2]. A reason for this is that liquid products like methanol are much more reactive than methane, and such products are already oxidized in the active plasma region before a sufficient amount of methane is activated. To overcome this problem, Nozaki et al. utilized a nonthermal plasma generated in a microreactor [3]. Performing plasma process in a microreactor enables better control over process parameters, and can enhance the selectivity of desirable products because of unconventional thermochemical conditions [4].

In the present study a microreactor is described which applies an atmospheric pressure non-thermal plasma for methane partial oxidation to achieve the direct synthesis of liquid oxygenates. To prevent further oxidation of liquid products, the reactor was combined with a pulsed liquid water injection method. This method, as well as the addition of a small amount of hydrogen peroxide $\left(\mathrm{H}_{2} \mathrm{O}_{2}\right)$ into the liquid water, which dramatically increased both methane conversion and liquid product selectivity, will be discussed in detail i this chapter.

\section{Experimental}

Fig. 1 shows the experimental setup for partial oxidation of methane in a plasma microreactor. The microreactor consists of a quartz glass tube (i.d. $1.5 \mathrm{~mm}$ and wall 
thickness of $1.5 \mathrm{~mm})$ with a twisted metallic wire $(0.5 \mathrm{~mm}$, stainless steel) inside it (see Fig. 2). In all experiments, a reaction gas mixture of methane $\left(20 \mathrm{~cm}^{3 /} \mathrm{min}\right)$ and oxygen $\left(20 \mathrm{~cm}^{3 /} \mathrm{min}\right)$ with a residence time in the microplasma region of $132 \mathrm{~ms}$ was used at atmospheric pressure.

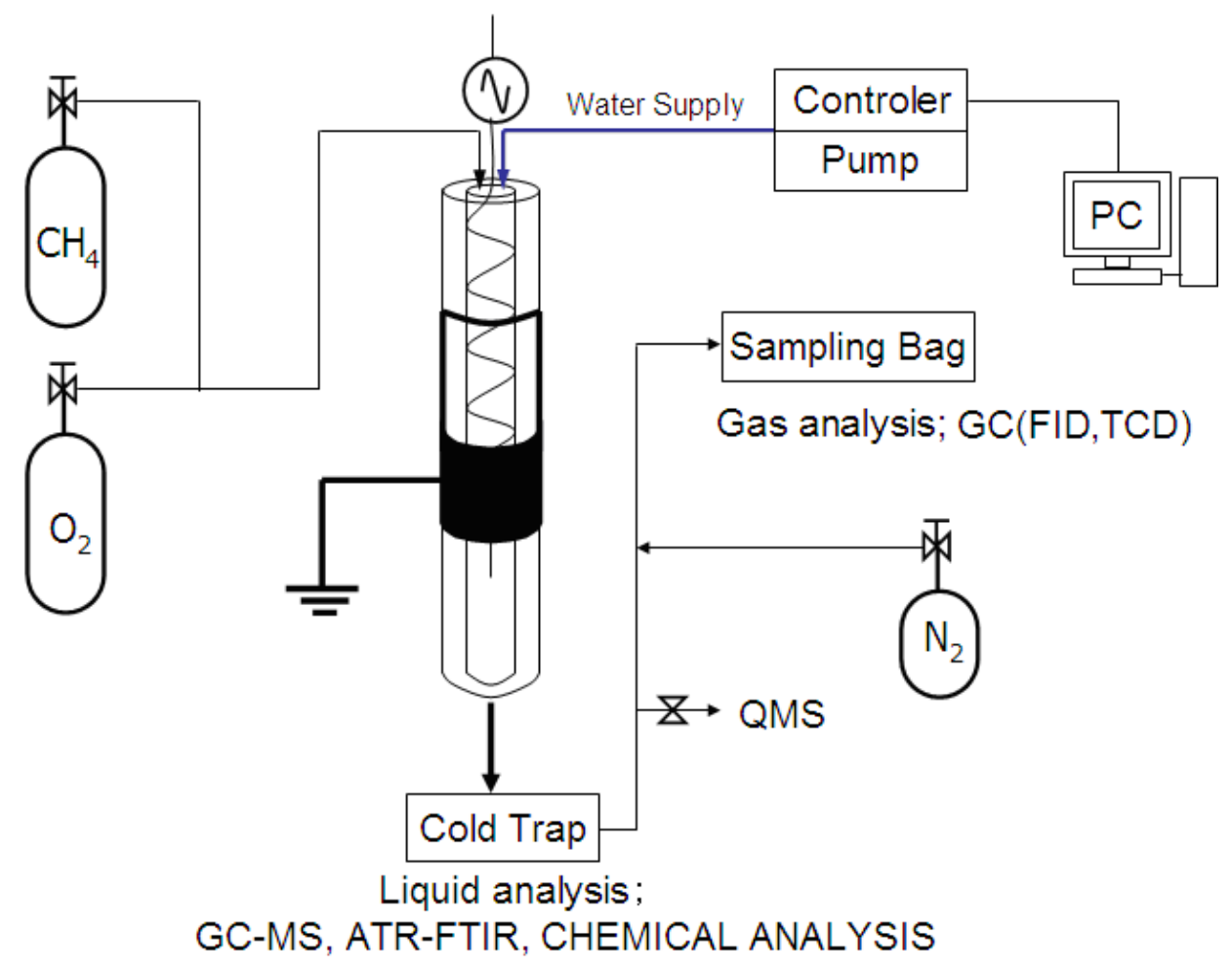

Figure 1. Experimental setup with the plasma microreactor system for the synthesis of liquid oxygenates by partial oxidation of methane.

The reactor is placed in an ice-water bath to keep the temperature near $0^{\circ} \mathrm{C}$. A pulsed high-voltage at $10 \mathrm{kHz}$ was applied between the twisted metallic wire and a grounded aluminum foil electrode wrapped around the glass tube, as shown in Fig. 2b. The principle of plasma generation is similar to a dielectric barrier discharge (DBD), which can be characterized by a large number of nanosecond filamentary streamers [5], which prevents excess gas heating. High energy electrons enable the direct activation of $\mathrm{CH}_{4}$ and $\mathrm{O}_{2}$ without increase in reaction temperature. A microreactor configuration enhances heat removal from the reaction zone, maintaining precise control of the reaction temperature near $0{ }^{\circ} \mathrm{C}$. Under these conditions, liquid components are condensed first on ions and then on charged droplets to form aerosol drops [6] which eventually precipitate on the cooled microreactor wall. Pulsed water injection (see Fig. 3) was applied to remove liquid oxygenates from the active plasma region before the oxidize further to 
oxygenates. When the water enters the microreactor, the discharge was temporarily extinguished because the liquid water completely covers the thin wire electrode. To take this into account, the experiment time was set to $30 \mathrm{~min}$.

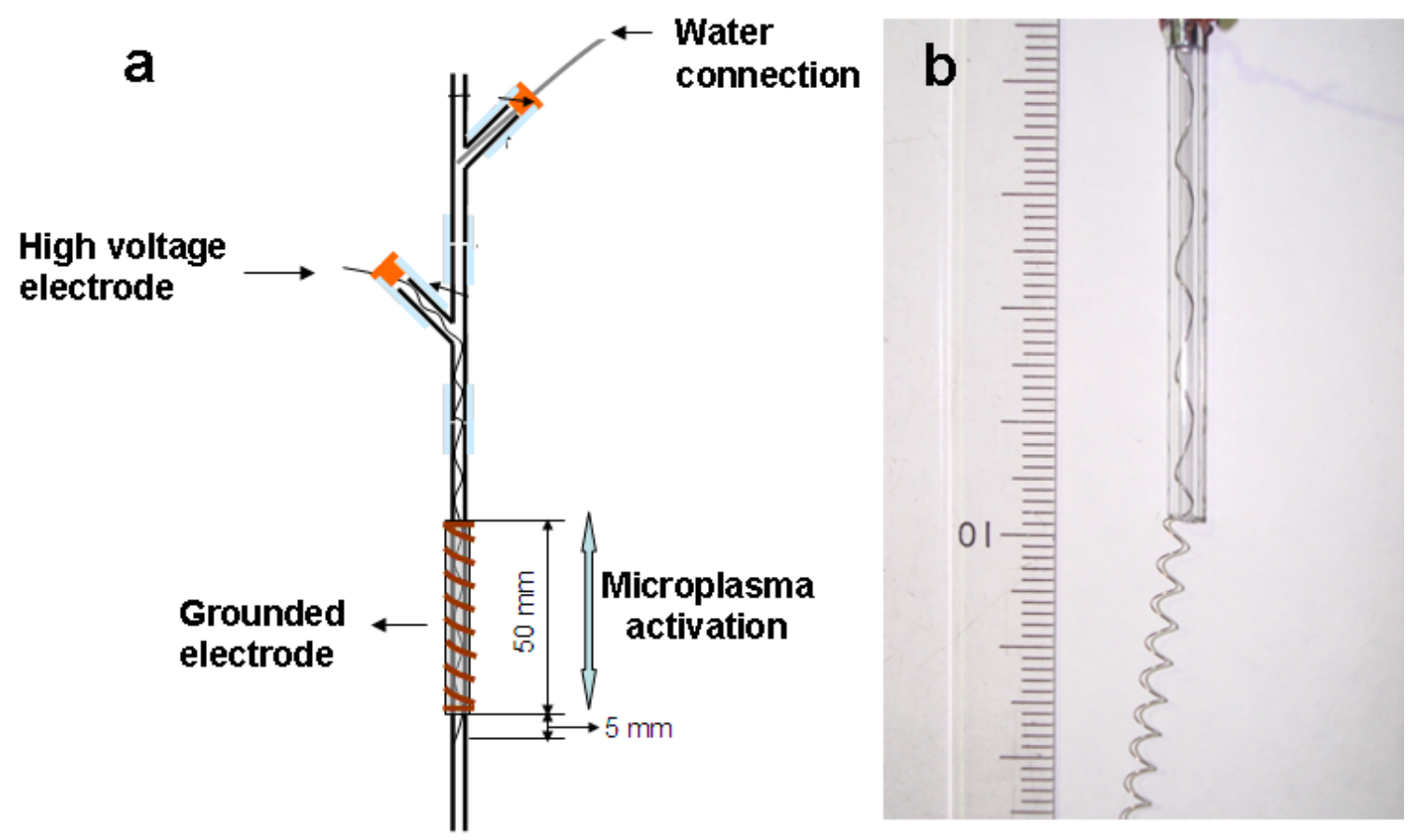

Figure 2. (a) Schematic diagram of plasma microreactor and (b) insertion of high voltage electrode (twisted metal wire) into the quartz tube.

Liquid products are collected in a cold trap $\left(0^{\circ} \mathrm{C}\right)$ and analyzed quantitatively by gas chromatography / mass spectrometry (SHIMADZU, QP2010Plus), gas products are analyzed with gas chromatography (SHIMADZU, GC-8A) with TCD and FID detectors. An on-line quadrupole mass spectrometer (Pfeiffer, Prisma QMS100) is also used for the qualitative analysis of gas phase products. The concentration of $\mathrm{H}_{2} \mathrm{O}_{2}$ was determined by iodometric titration, which is based on the oxidation of iodide by $\mathrm{H}_{2} \mathrm{O}_{2}$ to iodine in the presence of acid and molybdate catalyst. The iodine formed can be titrated with thiosulfate solution, incorporating a starch indicator. 


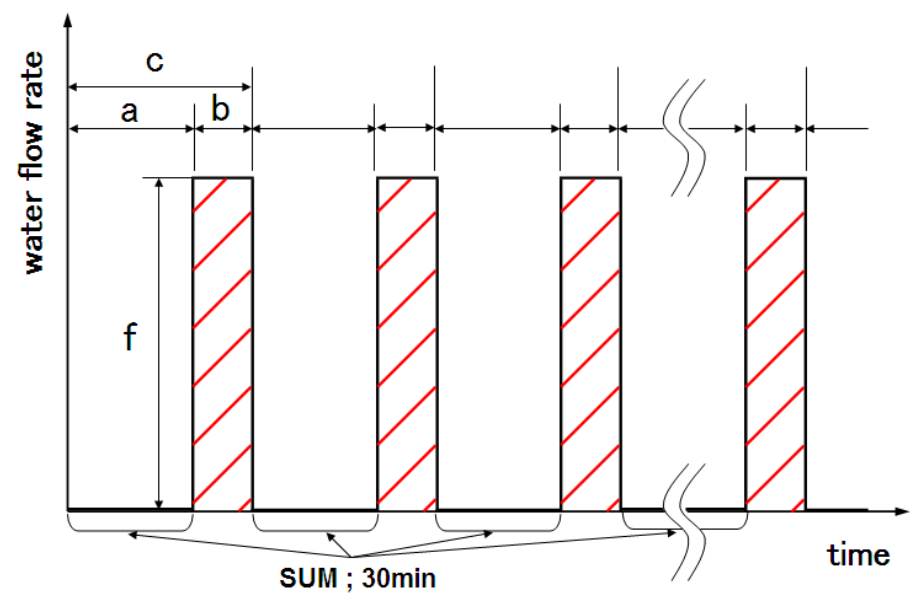

$\begin{array}{ccccc}\begin{array}{c}\mathrm{a} \\ (\mathrm{min})\end{array} & \begin{array}{c}\mathrm{b} \\ (\mathrm{sec})\end{array} & \begin{array}{c}\mathrm{f} \\ \left(\mathrm{cm}^{3} / \mathrm{min}\right)\end{array} & \begin{array}{c}\text { Synthesis } \\ \text { time }(\mathrm{min})\end{array} & \begin{array}{c}\text { Inj. water } \\ \left(\mathrm{cm}^{3}\right)\end{array} \\ 1 & 10 & 0.6 & 35.1 & 3.06 \\ 2 & 10 & 1.2 & 32.6 & 3.06 \\ 3 & 10 & 1.8 & 31.7 & 3.06 \\ 5 & 10 & 3.0 & 31.0 & 3.06\end{array}$

Figure 3. Scheme of pulsed water injection during plasma process in microreactor.

\section{Results and discussion}

\section{Effect of pulsed injection of liquid-water.}

Fig. 4 shows methane conversion for different time intervals between pulsed water injections, and for the case of no water injection. In the experiments without water injection, the carbon balance was $70 \%$ due to polymerization and oxidation of liquid products exposed to the discharge; these products deposit or condense on the reactor wall. Due to the uncontrolled reaction time for condensed products, the repeatability of the experiments was low. On the other hand, pulsed water injection removes the oxygenates efficiently before further oxidation takes place, and in these cases the carbon balance increased over $90 \%$. This is due to the fact that mechanical removal of liquid oxygenates by pulsed water injection improves the controllability of the reaction time for condensed liquid products. An other effect of liquid water injection may be that excess heat generated by methane partial oxidation is efficiently removed. However, methane conversion decreased as the time interval decreased, i.e. too frequent water injection has a negative effect on methane conversion. This phenomenon will be discussed later in relation to $\mathrm{H}_{2} \mathrm{O}_{2}$ formation. 


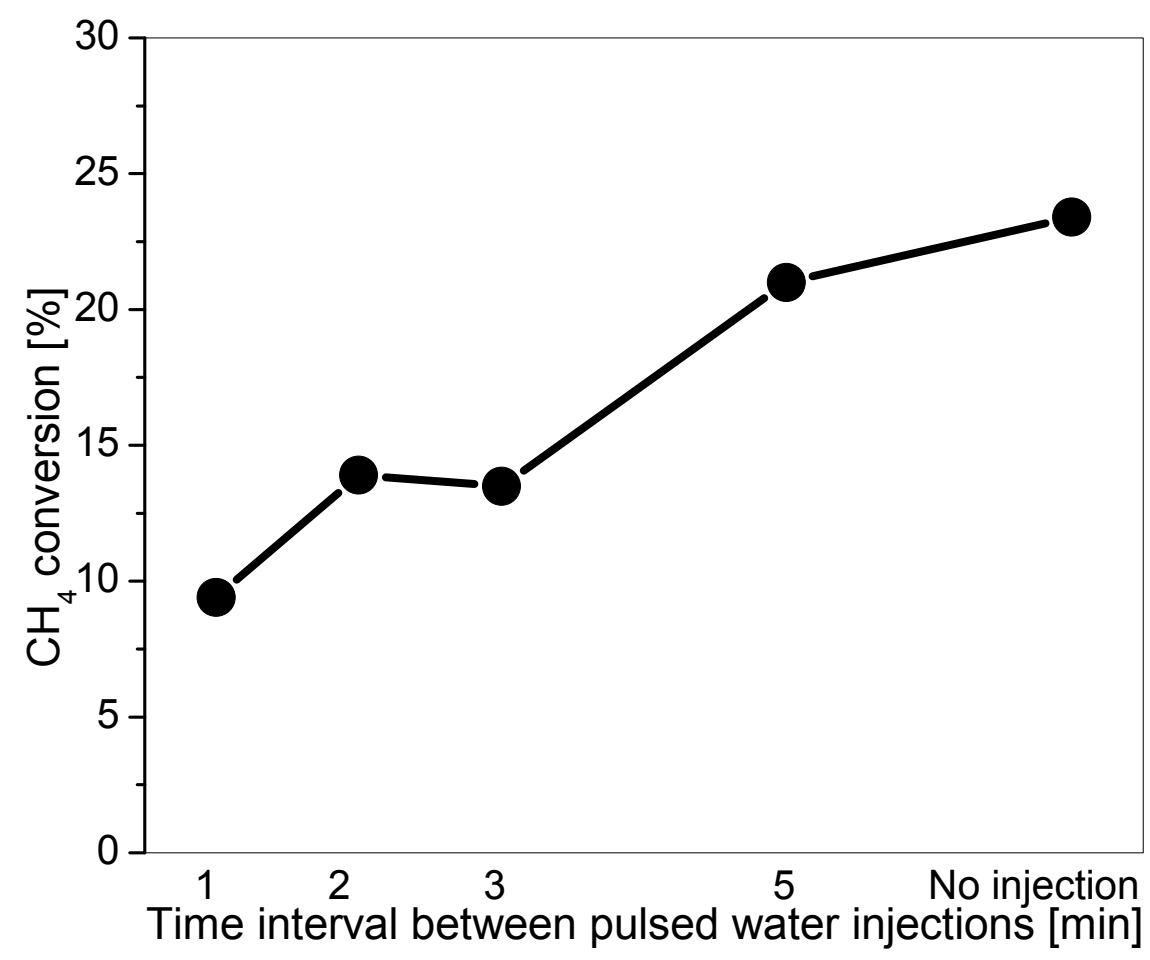

Figure 4. Effect of time interval between pulsed water injections on methane conversion.

Table I shows the total oxygenate yield and the fractions of methanol $\left(\mathrm{CH}_{3} \mathrm{OH}\right)$, formaldehyde $(\mathrm{HCHO})$, and formic acid $(\mathrm{HCOOH})$ formed in these experiments. The $\mathrm{HCOOH}$ yield significantly increased with increasing time interval. Methane oxidation by liquid $\mathrm{D}_{2} \mathrm{O}$ injection showed no major incorporation of deuterium (D) into the oxygenates, as follows from reactions (1)-(2):

$\mathrm{D}_{2} \mathrm{O}+\mathrm{e} \rightarrow \mathrm{DO}+\mathrm{D}+\mathrm{e}$

$\mathrm{OD}+\mathrm{CH}_{3}+\mathrm{M} \rightarrow \mathrm{CH}_{3} \mathrm{OD}+\mathrm{M}$

Here, $\mathrm{M}$ refers to a third collision partner such as $\mathrm{CH}_{4}$ and $\mathrm{O}_{2}$. On the basis of the isotopic trace experiment, it is assumed that the hydrogen present in the oxygenates stems from methane. Direct methanol synthesis by a simple recombination of methyl and hydroxyl radicals originating from liquid water is very unlikely.

Analysis of post-discharge liquid products indicates the formation of $\mathrm{H}_{2} \mathrm{O}_{2}(2$ $\mathrm{wt} \%$ in the reaction products). It has been found that the concentration of $\mathrm{H}_{2} \mathrm{O}_{2}$, $\mathrm{CH}_{3} \mathrm{OH}$, and $\mathrm{HCHO}$ at room temperature decreased over time, whereas the $\mathrm{HCOOH}$ concentration increased. This is the result of oxidation of liquid oxygenates due to the 
presence of $\mathrm{H}_{2} \mathrm{O}_{2}$. Unlike conventional methane oxidation under high temperature conditions, at a low temperature the formation of $\mathrm{H}_{2} \mathrm{O}_{2}$ and its reactivity has great impact on both methane conversion and oxygenate selectivity. As discussed before, liquid water injection is an important process to wash out liquid oxygenates condensed on the microreactor wall. The negative effect on methane conversion that liquid water injection has, is because $\mathrm{H}_{2} \mathrm{O}_{2}$ is also eliminated by the water pulses, leading to a subsequent decrease in the production of $\mathrm{OH}$, which is normally the result of plasma-induced decomposition of $\mathrm{H}_{2} \mathrm{O}_{2}$.

Table 1 Total liquid yield and fractions of liquid oxygenates in pulsed water injection experiments.

$\begin{array}{ccccc}\begin{array}{c}\text { Time interval } \\ \text { of } \mathrm{H}_{2} \mathrm{O} \\ \text { injection } \\ {[\text { min] }}\end{array} & \begin{array}{c}\text { Liquid sum } \\ {[\%]}\end{array} & \begin{array}{c}\mathrm{CH}_{3} \mathrm{OH} \\ \text { yield [\%] }\end{array} & \begin{array}{c}\mathrm{HCHO} \\ \text { yield [\%] }\end{array} & \begin{array}{c}\mathrm{HCOOH} \\ \text { yield [\%] }\end{array} \\ 1 & 1.9 & 0.7 & 1 & 0.3 \\ 2 & 3.0 & 1.1 & 1.1 & 0.8 \\ 3 & 3.6 & 1.1 & 1.7 & 0.9 \\ 5 & 4.3 & 1.2 & 1.9 & 1.3 \\ \text { No water } & 4.0 & 1.3 & 1.6 & 1.1\end{array}$

\section{$\mathrm{H}_{2} \mathrm{O}_{2}$ as a reaction promoter: synergy between $\mathrm{H}_{2} \mathrm{O}_{2}$ and $\mathrm{O}_{2}$.}

$\mathrm{H}_{2} \mathrm{O}_{2}$ has strong oxidizing properties. It is used in advanced oxidation processes using the discharge of water, because it can enhance the decomposition efficiency of organic pollutants in contaminated water [7]. The enhanced decomposition ability is attributed to reactions of $\mathrm{OH}$ formed by plasma-induced dissociation of $\mathrm{H}_{2} \mathrm{O}_{2}$. It must be mentioned that our experiments with pure oxygen and liquid-water injection do not produce $\mathrm{H}_{2} \mathrm{O}_{2}$, indicating that $\mathrm{H}_{2} \mathrm{O}_{2}$ is produced during methane partial oxidation. We hypothesize that $\mathrm{H}_{2} \mathrm{O}_{2}$ formation through reactions (3) and (4) is very unlikely: 
$\mathrm{O}_{2}+\mathrm{e} \rightarrow \mathrm{O}+\mathrm{O}+\mathrm{e}$

$\mathrm{H}_{2} \mathrm{O}+\mathrm{O} \rightarrow \mathrm{H}_{2} \mathrm{O}_{2}$

In order to clarify the reaction mechanism involving $\mathrm{H}_{2} \mathrm{O}_{2}$, solutions with different concentrations of $\mathrm{H}_{2} \mathrm{O}_{2}$ were injected into the discharge with 3 min time intervals. Fig. 5 shows the effect on methane conversion. The conversion increased from $13 \%$ in the case of pure water injection to $24 \%$ for a $2 \mathrm{wt} \% \mathrm{H}_{2} \mathrm{O}_{2}$ solution injected. Analysis of the $\mathrm{H}_{2} \mathrm{O}_{2}$ concentration before and after the plasma treatment showed that $0.2-0.3 \mathrm{wt} \%$ of $\mathrm{H}_{2} \mathrm{O}_{2}$ (based on total liquid) was consumed during plasma treatment.

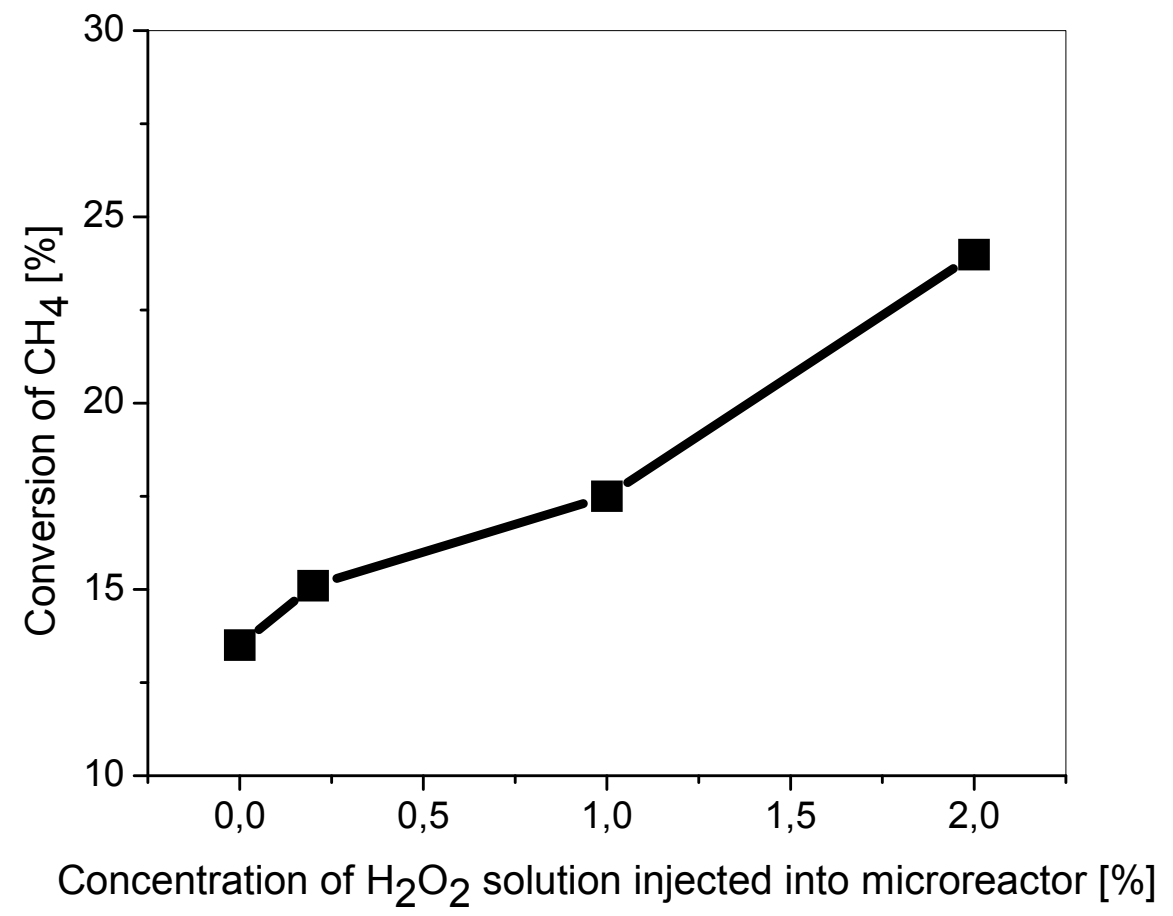

Figure 5. Effect of concentration of injected $\mathrm{H}_{2} \mathrm{O}_{2}$ on methane conversion in plasma microreactor.

Fig. 6 shows the effect of the $\mathrm{H}_{2} \mathrm{O}_{2}$ concentration on liquid product selectivity. The total liquid selectivity increased with increasing $\mathrm{H}_{2} \mathrm{O}_{2}$ concentration and the highest selectivity achieved was $56 \%$ at a methane conversion of $18 \%$. It is assumed that plasma-generated reactive species interact with $\mathrm{H}_{2} \mathrm{O}_{2}$ in solution at the gas-liquid interface and that the generation of $\mathrm{OH}$ through $\mathrm{H}_{2} \mathrm{O}_{2}$ decomposition triggers the activity to shift the selectivity to oxygenates. In order to clarify the major role of $\mathrm{H}_{2} \mathrm{O}_{2}, 1 \mathrm{wt} \%$ $\mathrm{D}_{2} \mathrm{O}_{2}$ solution was injected into the plasma microreactor. The same methane conversion 
was obtained as with the $1 \mathrm{wt} \% \mathrm{H}_{2} \mathrm{O}_{2}$ injection experiments, whereas no major incorporation of deuterium (D) into the oxygenates was found by mass spectrometry. As discussed previously, a simple recombination of $\mathrm{CH}_{3}$ and $\mathrm{OH}$ derived from $\mathrm{H}_{2} \mathrm{O}_{2}$ decomposition, is unlikely. Therefore we speculate that the major role of $\mathrm{H}_{2} \mathrm{O}_{2}$-induced $\mathrm{OH}$ is hydrogen abstraction from methane as shown in reaction (5). This scheme implies that the methane conversion increases with $\mathrm{H}_{2} \mathrm{O}_{2}$ while deuterium is not incorporated into liquid oxygenate products.

$\mathrm{CH}_{4}+\mathrm{OD} \rightarrow \mathrm{CH}_{3}+\mathrm{ODH}$

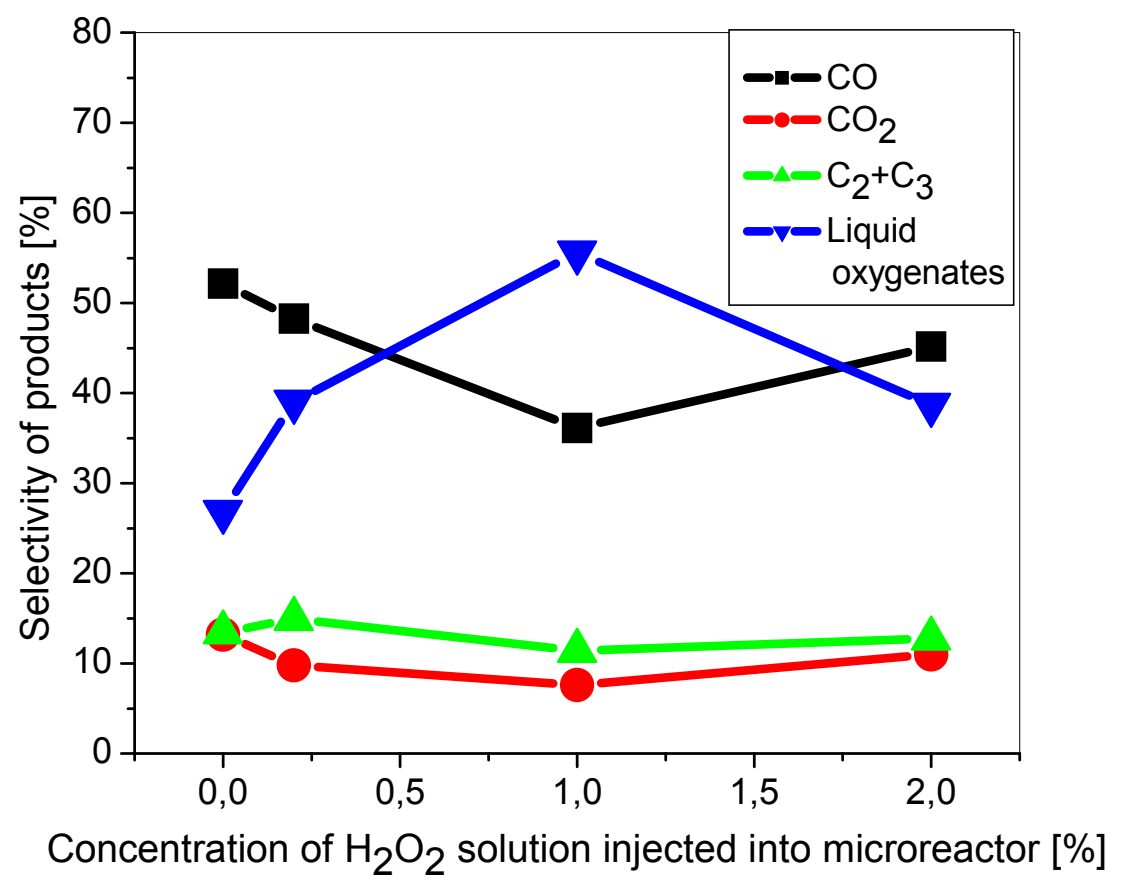

Figure 6. Effect of concentration of $\mathrm{H}_{2} \mathrm{O}_{2}$ solution injected into microplasma reactor on product selectivity.

Table II shows the total liquid yield and the formed fractions of $\mathrm{CH}_{3} \mathrm{OH}, \mathrm{HCHO}$, and $\mathrm{HCOOH}$, for different $\mathrm{H}_{2} \mathrm{O}_{2}$ concentration. The maximum oxygenate yield was around $10 \%$ which is almost 3 times higher than in the pure water injection experiments. Note that in the experiment with $1 \mathrm{wt} \% \mathrm{H}_{2} \mathrm{O}_{2}$ solution in the absence of $\mathrm{O}_{2}$ only a minor methane conversion (1-2\%) is found, and that the selectivity for liquid oxygenates was negligibly small. Therefore, it is suggested that $\mathrm{H}_{2} \mathrm{O}_{2}$ is the main promotor in methane conversion, while $\mathrm{O}_{2}$ works as the main oxidant, which converts $\mathrm{CH}_{4}$-derived species to 
various oxygenates.

Table II. Total liquid yield and fractions of $\mathrm{CH}_{3} \mathrm{OH}, \mathrm{HCHO}$, and $\mathrm{HCOOH}$ in pulsed $\mathrm{H}_{2} \mathrm{O}_{2}$ solution injection experiments.

$\begin{array}{ccccc}\begin{array}{c}\mathrm{H}_{2} \mathrm{O}_{2} \\ {[\%]}\end{array} & \begin{array}{c}\text { Liquid } \\ \text { sum [\%] }\end{array} & \begin{array}{c}\mathrm{CH}_{3} \mathrm{OH} \\ \text { yield [\%] }\end{array} & \begin{array}{c}\mathrm{HCHO} . \\ \text { yield [\%] }\end{array} & \begin{array}{c}\mathrm{HCOOH} \\ \text { yield [\%] }\end{array} \\ 0 & 3.6 & 1.1 & 1.6 & 0.9 \\ 0.2 & 5.9 & 1.2 & 3.1 & 1.6 \\ 1 & 9,7 & 1.4 & 4.4 & 3.9 \\ 2 & 9.3 & 1.4 & 5.7 & 2.2\end{array}$

It is important to note that not only liquid oxygenates, but also synthesis gas $\left(\mathrm{H}_{2}+\mathrm{CO}\right)$ was directly formed near $0{ }^{\circ} \mathrm{C}$ and atmospheric pressure. A product mixture with $36 \% \mathrm{CO}$ selectivity at $18 \%$ methane conversion, with a $\mathrm{H}_{2} / \mathrm{CO}$ ratio of approximately unity, can be converted into liquid hydrocarbons under moderate conditions using a conventional catalytic process. Eventually, the total liquid yield could amount to $16.5 \%$ (which is very close to the commercial target at the same conversion) with the following estimation:

Liquid yield $(10 \%)+$ Syn-gas sel. $(36 \%) \times \mathrm{CH}_{4}$ conv. $(0.18)=16.5 \%$.

\section{Conclusion}

In conclusion, the direct synthesis of liquid oxygenates by methane partial oxidation was demonstrated, with a one pass yield of $10 \%$, using an atmospheric pressure, multi-phase flow, non-thermal plasma microreactor. A pulsed liquid water injection method was developed to prevent excessive oxidation of liquid products and therewith increase the yield of desired products. Hydrogen peroxide $\left(\mathrm{H}_{2} \mathrm{O}_{2}\right)$ is found to be a key component, which increases both methane conversion as well as liquid oxygenate selectivity. The maximum oxygenate yield was $10 \%$ and found for the case where the $\mathrm{H}_{2} \mathrm{O}_{2}$ solution was injected into the microplasma. $\mathrm{O}_{2}$ was used as a major oxidant of $\mathrm{CH}_{4-}$ 
derived species. Liquid water injection removed not only liquid oxygenates, but also $\mathrm{H}_{2} \mathrm{O}_{2}$ from the microreactor. The latter has a negative effect on methane conversion because it decreases the concentration of $\mathrm{OH}$ produced by plasma-induced decomposition of $\mathrm{H}_{2} \mathrm{O}_{2}$. Therefore pulsed water injection must be carefully optimized to further increase liquid product yield.

\section{Acknowledgment}

This research was supported by the Grant-in-Aid for Exploratory Research (20656038), MEXT, Japan and foundation STW, applied science division of NWO and the technology program of the Ministry of Economic Affairs, The Netherlands, and project number 06626. A.A. was supported in part by the Global COE program, "Multidisciplinary Education and Research Center for Energy Science", MEXT, Japan. 


\section{References}

1 P. S. Casey, T. McAllister and K. Foger, Ind. Eng. Chem. Res., 1994, 33, 1120.

2 (a) A. Indarto, IEEE Trans. on Dielectrics and Electrical Insulation, 2008, 15, 1038; (b) A. Indarto, D. R. Yang, J. Palgunadi, J.-W. Choi, H. Lee and H. K. Song, Chem. Eng. Proc., 2008, 47, 780 .

3 (a) T. Nozaki, A. Hattori and K. Okazaki, Catal. Today, 2004, 98, 607; (b) T. Nozaki, S. Kado, A. Hattori and K. Okazaki, Studies in Surf. Sci and Catal., 2004, 147, 505.

4 C. Trionfetti, A. Agiral, J. G. E. Gardeniers, L. Lefferts and K. Seshan, ChemPhysChem, 2008, 9, 533; (b) C. Trionfetti, A. Agiral, J. G. E. Gardeniers, L. Lefferts and K. Seshan, J. Phys. Chem. C, 2008, 112, 4267; (c) A. Agiral, C. Trionfetti, L. Lefferts, K. Seshan and J. G. E. Gardeniers, Chem. Eng. Technol., 2008, 31, 1116; (d) A. Agiral, A. W. Groenland, J. K. Chinthaginjala, K. Seshan, L. Lefferts and J. G. E. Gardeniers, J. Phys. D.: Appl. Phys., 2008, 41, 194009.

5 U. Kogelschatz, Plasma Chem. Plasma Proc., 2003, 23, 1.

6 S. P. Bugaev, A. V. Kozyrev, V. A. Kushinov, N. S. Sochugov and P. A. Khryapov, Plas. Chem. Plas. Proc., 1998, 18, 247.

7 A. T. Sugiarto, T. Ohshima and M. Sato, Thin Solid Films, 2002, 407, 174. 


\section{Chapter 6}

\section{Microplasma activation of catalyst for CNF synthesis in a microreactor}

An in-situ CVD method was developed in order to grow CNFs on Ni/alumina and nickel thin film catalyst coated inside a closed channel fused silica microreactor. By directly flowing reactant gases over a catalytic coating inside the capillaries, a mechanically stable and porous CNF-alumina composite was formed with high surface area $\left(160 \mathrm{~m}^{2} / \mathrm{g}\right)$. Effects of growth time, growth temperature and $\mathrm{H}_{2}$ addition during pretreatment and deposition steps on the composite thickness and nanofibers diameter were investigated. Hydrogen addition increases the deposition rate and helps in producing a mechanically stable support in the capillary. In the second part of this chapter, a method for microplasma activation of catalyst for CNFs synthesis in the microreactor will be described. A dielectric barrier discharge is generated by flowing helium and hydrogen through a microreactor capillary which contains the coating of Ni-alumina catalyst to activate carbon nanofiber (CNF) synthesis. Cold plasma operation for $15 \mathrm{~min}$ is simple and audio-visual and increases the CNF yield significantly compared to non-activated samples and can compete with a high temperature treatment at $973 \mathrm{~K}$ for $2 \mathrm{~h}$.

Portions of this chapter were published in:

Catalyst Activation with Microplasma for Carbon Nanofibers Synthesis in Microreactor, ANIL AGIRAL, LEON LEFFERTS, J. G. E. (HAN) GARDENIERS, IEEE Transactions on Plasma Science, Special Issue on Atmospheric Pressure Plasmas: Science and Applications, 37(6) 2009 985-992, ISSN: 0093-3813 doi:10.1109/TPS.2009.2019981.

In-situ CVD of Carbon Nanofibers in a Microreactor, ANIL AGIRAL, LEON 
LEFFERTS, J. G. E. (HAN) GARDENIERS, Catalysis Today, Special Issue on Carbon for Catalysis, June (2009), doi:10.1016/j.cattod.2009.04.023.

\section{Introduction}

Carbon nanofibers (CNFs) are graphite materials which can be used as nanostructured catalyst supports in gas and liquid phase applications [1]. They form aggregates that have high porosity (macroporous structure) with minimized tortuosity so that mass transfer rates will be maximized in the liquid phase [2]. CNFs can be catalytically grown over transition metal surfaces such as (alloys of) iron, cobalt, nickel; chromium, vanadium and molybdenum, employing methane, carbon monoxide, synthesis gas $\left(\mathrm{H}_{2} / \mathrm{CO}\right)$, ethylene and ethane as the carbon source in the temperature range $700-$ $1200 \mathrm{~K}[2,3]$. The main difficulties in using powder CNFs are agglomeration and filtration in slurry phase operations, and high pressure drops when they are applied in fixed-bed reactors [4]. It is important to immobilize CNFs on structured supports, not only to avoid these difficulties but also to provide effective contact with reactants and create functionalized sites on the support. For this purpose, thin layers of CNFs were grown on structured supports such as ceramic monolith [5] and metal foams [6] with the aim of achieving a new catalyst support with excellent properties for applications in liquid phase.

Recently, there has been great interest in microreactors with fast heat and mass transfer characteristics for applications in chemical synthesis [7], kinetic analysis [8] and catalyst development [9]. As-grown carbon nanostructures in a microreactor give a significant increase in surface-to-volume ratio and favor the contact surface between reactants. Moreover, decreasing the dimensions into the nanoscopic regime leads to significantly higher heat-transfer coefficients and improved mass transport, therewith enabling a better control of chemical process parameters. Examples are the work of Ago et al. [10] who incorporated Pt-modified carbon nanotubes (CNTs) into a microreactor, and that of Schneider et al. [11], who developed a monolithic porous carbon nanotube structure as a chemical reactor.

In our work we have developed an in-situ CVD method to grow mechanically stable CNFs on Ni/alumina catalyst inside a fused silica microreactor. The method provides a facile bottom-up way to increase surface-to-volume ratio of microreactors and opens opportunities for new high-surface-area nanoscopic catalyst supports and new catalysts themselves in microreaction technology. In the second part of this chapter, we will 
describe a method for simple and controlled activation of catalyst coatings in capillaries by performing an atmospheric pressure cold plasma process with excited species already formed at ambient temperatures.

It has been found that an important step for growth of CNFs is a high temperature treatment of the metal catalyst with reducing gases such as hydrogen or ammonia. By this step, the oxidized metal is reduced and segregates into discrete nano-islands which act as a catalyst for the growth process $[2,12]$. The thermal activation procedure increases nanofiber yield significantly.

As a low temperature activation alternative to thermal activation, an atmospheric pressure plasma chemical treatment, in which chemically active species in the plasma react at the catalyst surface [13], may be used. Plasma technology for the preparation and treatment of various catalysts has been reported by several authors [14-23], and the utilization of reactive plasmas for nanofabrication and surface manipulation to create nanoassembly patterns has been reviewed by Ostrikov et al. [24]. Recently, direct contact of non-equilibrium plasmas with the surface has been found to improve nanoarray arrangement through electric charge-related effects [25, 26]. Combinatorial and numerical studies have revealed the use of non-equilibrium plasma systems to improve ordering and size uniformity in nickel nanodot arrays on silicon surfaces [25] and to form linear carbon connections between silver nanoparticles by electric field-driven diffusion fluxes on plasma exposed surfaces [26]. Moreover, chemical reduction methods with hydrogen plasma to prepare metal-loaded catalysts [27] and nanoparticles in aqueous solutions [28] have been demonstrated as a quick and efficient treatment at ambient temperatures.

This chapter will present the characterization of a continuous flow low-power microplasma capillary reactor which is based on a dielectric barrier discharge. In-situ activation at room temperature and atmospheric pressure of $\mathrm{Ni} /$ alumina catalyst coated on the walls of a fused silica microreactor is performed by forming a helium-hydrogen plasma mixture inside the capillary. To the best of our knowledge, this is the first report on catalyst activation in a microreactor by an atmospheric pressure plasma process. The microplasma treatment increases the yield of CNFs synthesis significantly, as is concluded from a comparison of the properties of CNFs grown on Ni/alumina catalyst pre-treated with the microplasma with those untreated or prepared by thermal treatment.

\section{Experimental}


In-situ CVD of CNFs Synthesis. Fig. 1 shows the applied sample preparation scheme. The microreactor is a commercial fused silica capillary (HP-porous-layer open-tubular $\mathrm{Al}_{2} \mathrm{O}_{3}$ column, "S" deactivated) with an inner diameter of $0.53 \mathrm{~mm}$ and coated with $\mathrm{Al}_{2} \mathrm{O}_{3}$. The capillary was flushed continuously for 1 hour with distilled water to dissolve the deactivating agent $\left(\mathrm{Na}_{2} \mathrm{SO}_{4}\right)$, free liquid was removed and the samples were dried at 373 $\mathrm{K}$ for $1 \mathrm{hr}$, followed by heating in flowing air $(5 \mathrm{~K} / \mathrm{min})$ at $923 \mathrm{~K}$ to remove the polyimide coating on the outside of the capillary. Nickel was deposited on the alumina coating by adsorption from a pH-neutral nickel solution $(0.1 \mathrm{M})$. The solution containing $29 \mathrm{~g}$ of $\mathrm{Ni}\left(\mathrm{NO}_{3}\right)_{2} \cdot 6 \mathrm{H}_{2} \mathrm{O}, 80 \mathrm{~g} \mathrm{NH} \mathrm{NO}_{3}$ and $4 \mathrm{ml}$ of ammonia solution $(25 \mathrm{wt} . \%)$ per liter was flushed through the capillary for 2 hrs. Excess liquid was removed by air flow, and the capillary was dried overnight at room temperature and then heated to $373 \mathrm{~K}$ for $2 \mathrm{hrs}$, followed by reduction in a flow of $20 \%$ hydrogen in nitrogen $(5 \mathrm{~K} / \mathrm{min})$ at $923 \mathrm{~K}$ for $2 \mathrm{hrs}$. An attempt was also made to deposit a nickel thin film inside a capillary microreactor with in-situ atmospheric pressure chemical vapor deposition using nickel acetylacetonate as the source material. This was done by sublimation of nickel acetyl acetonate at $493 \mathrm{~K}$ and flowing the formed vapor through the microreactor with helium as carrier gas (10 $\mathrm{ml} / \mathrm{min})$ and hydrogen as reducing gas $(10 \mathrm{ml} / \mathrm{min})$. During growth of the nickel film, the microreactor was heated to $573 \mathrm{~K}$. The microreactor was fitted in a metal block heated with a cartridge heater capable of supplying $100 \mathrm{~W}$ and type $\mathrm{K}$ thermocouples were put next to the capillary to measure the temperature. CNF growth was carried out in-situ by flowing reactant gases through the capillary. As pre-treatment step, the catalyst was reduced with $50 \%$ hydrogen in helium at $973 \mathrm{~K}$ for $120 \mathrm{~min}$ (total flow rate $8 \mathrm{ml} / \mathrm{min}$ ). Next, the temperature was ramped at $5 \mathrm{~K} / \mathrm{min}$ to the CNF growth temperature. When the desired temperature was reached, the gas mixture was switched to $50 \%$ ethylene and 10 $\%$ hydrogen in helium (total flow rate $10 \mathrm{ml} / \mathrm{min}$ ). The amount of carbon deposited in the microreactor was determined from the capillary weight before and after deposition. The nickel loading on the alumina coating was measured with a Philips X-ray fluorescence spectrometer (PW 1480). The morphology of the CNFs was studied with scanning electron microscopy (SEM) (LEO 1550 FEG SEM) equipped with EDX analysis, and high resolution transmission electron microscopy (HRTEM, Philips CM300ST-FEG microscope). HRTEM analyses were performed by mounting the samples on a carbon supported copper grid. The BET surface area, pore volume and pore size distribution were measured by $\mathrm{N}_{2}$ adsorption-desorption at $77 \mathrm{~K}$ using an ASAP 2400 (Micromeritics) instrument. The error margin in the surface area measurement is around $10 \%$ due to the low amounts of CNFs used in the analysis. 


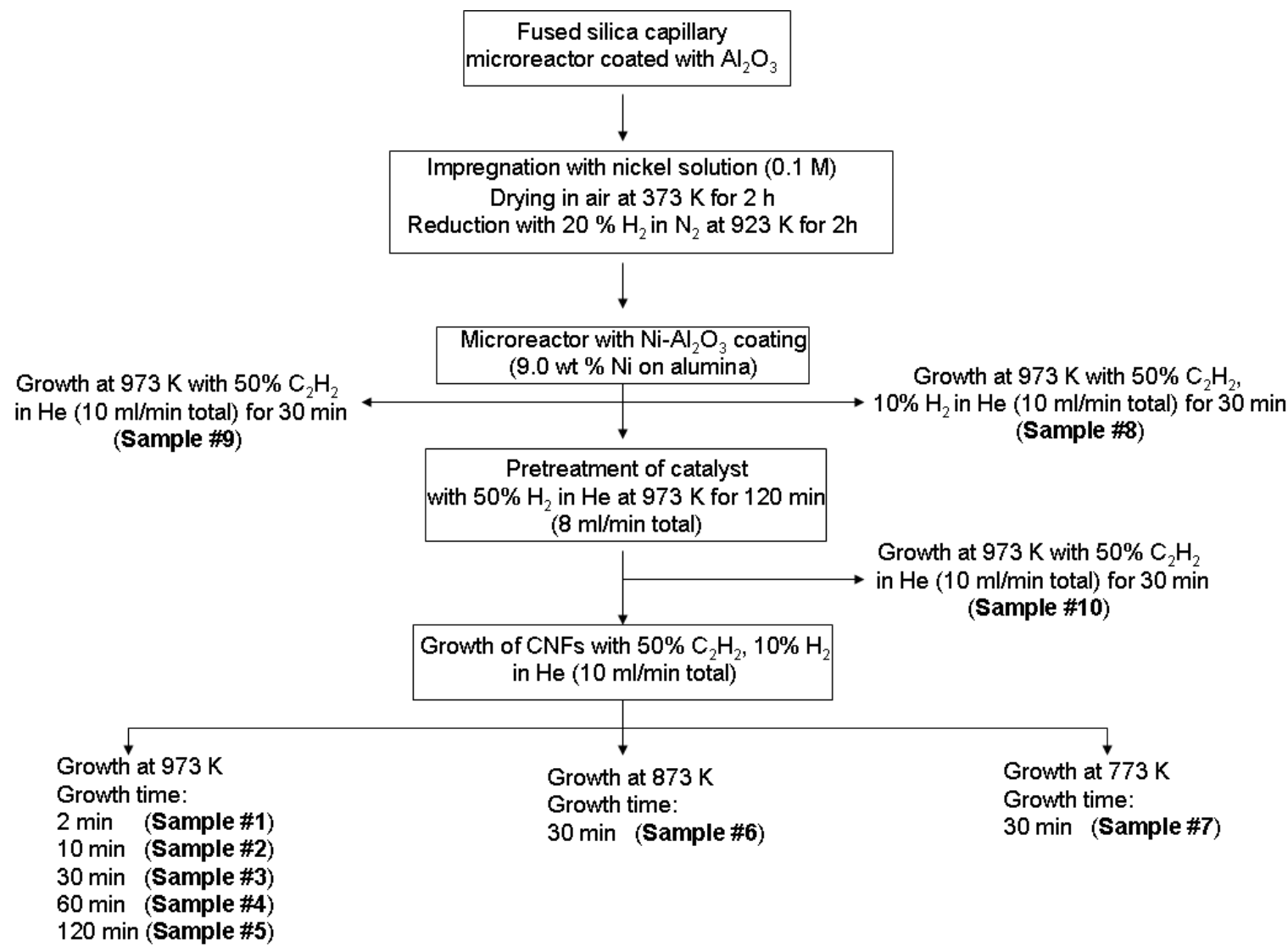

Figure 1. Sample preparation scheme.

Catalyst activation with microplasma. Thermal (973 K) and microplasma (300 K) activation of the $\mathrm{Ni} /$ alumina catalyst with hydrogen $(5 \mathrm{ml} / \mathrm{min})$ and helium $(150 \mathrm{ml} / \mathrm{min})$ was carried out for $120 \mathrm{~min}$ and $15 \mathrm{~min}$, respectively. After activation, the temperature was increased to $973 \mathrm{~K}$ at a rate of $5 \mathrm{~K} / \mathrm{min}$, next the gas mixture was switched to $50 \%$ ethylene and $10 \%$ hydrogen in helium (total flow rate $10 \mathrm{ml} / \mathrm{min}$ ) and nanofiber growth was carried out for $30 \mathrm{~min}$.

A schematic diagram of the plasma set-up is shown in Fig. 2. The fused silica capillary microreactor $(500 \mu \mathrm{m}$ ID, $550 \mu \mathrm{m}$ OD) with an internal $\mathrm{Ni}$ /alumina catalyst coating is connected to the gas supply through a steel connector and a graphite ferrule that is also used as a cylindrical high-voltage electrode. A metal block touching the capillary at the end and in contact with the gas serves as the ground electrode, without which it is not possible to ignite the plasma. The pressure drop over the capillary reactor during the activation treatment is 0.05 bar, measured with a pressure sensor mounted at the gas connection. The high-voltage electrode is connected to a power supply with a peak voltage of $6 \mathrm{kV}$ at a sinusoidal frequency of $50 \mathrm{kHz}$. Energy is capacitively coupled into 
the microplasma reactor; therefore no arcing and sputtering on the electrodes will occur. There is no need for impedance matching due to the low frequency power.

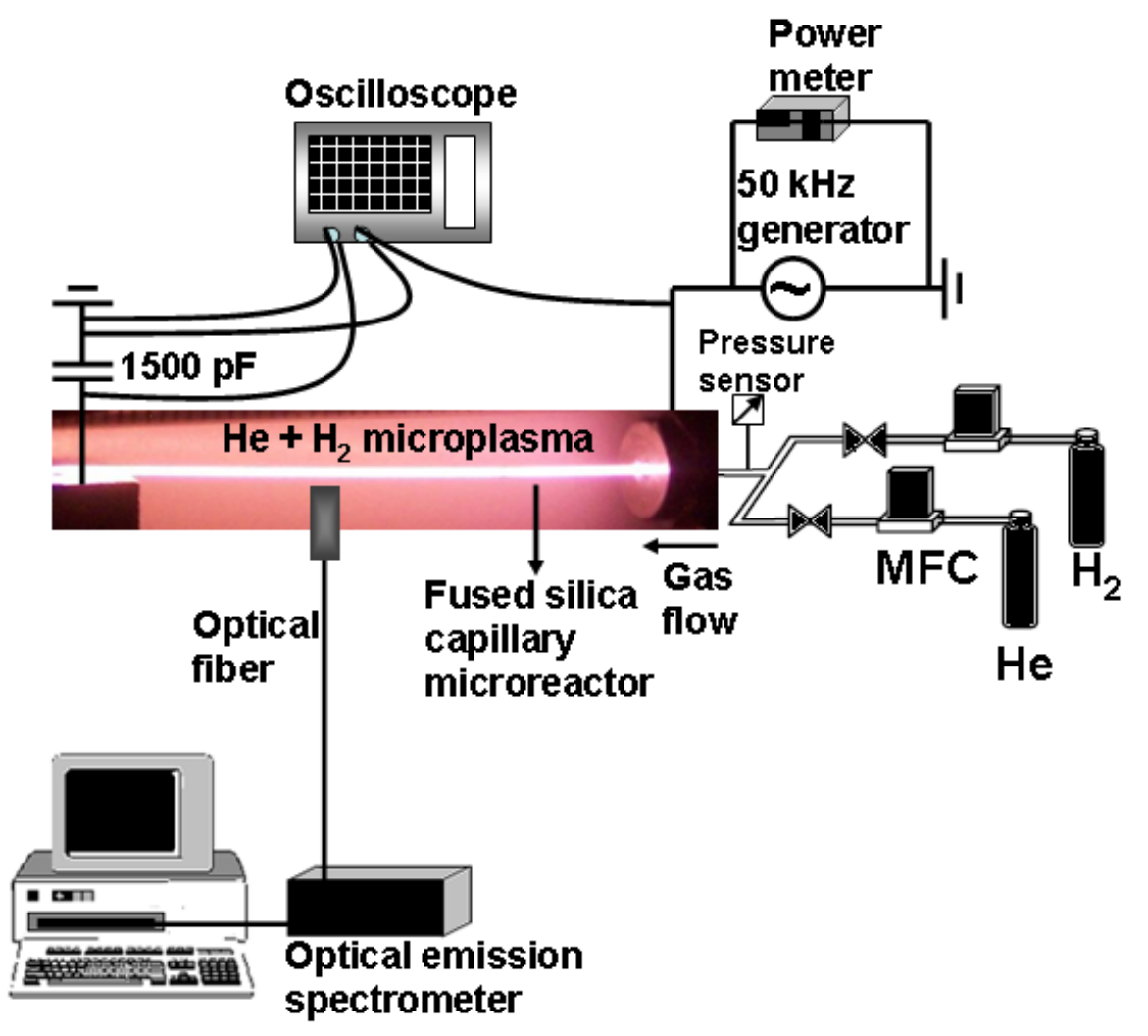

Figure 2. Schematic diagram of the microplasma activation set-up.

Plasma activation of the catalyst is done at $300 \mathrm{~K}$ with a flow of hydrogen ( 5 $\mathrm{ml} / \mathrm{min})$ and helium $(150 \mathrm{ml} / \mathrm{min})$ for $15 \mathrm{~min}$. Since the plasma cannot fill the whole volume of the capillary tube at lower flow rates, it is believed that active transport of ionized species by gas flow to the grounded electrode is essential for a uniform treatment. The plug-in power of the plasma source is measured with a power meter (HAMEG HM8115-2). A high-voltage probe (Tektronix P6015A, 1000X) and a $1500 \mathrm{pF}$ capacitor are used to measure the applied voltage and the transported charge, respectively. The current is monitored by replacing the test capacitor with a $55 \Omega$ resistor. Voltage signals are recorded with an oscilloscope (Tektronix TDS 3054, $500 \mathrm{MHz}$ ), and the power absorbed by the plasma is evaluated on the basis of Lissajous figures measured with this oscilloscope. Light emission from the discharge is collected through a collimating lens in a $90^{\circ}$ angle to the outside capillary where the catalyst was selectively removed. An optical fiber transmits the light into an optical emission spectrometer (HR 4000, Ocean Optics) which is connected to a PC for analysis of the spectra. 


\section{Results and discussion}

In-situ CVD of carbon nanofibers in a microreactor. Fig. 3a shows fused silica capillaries coated with $\mathrm{Al}_{2} \mathrm{O}_{3}$ and Ni-loaded $\mathrm{Al}_{2} \mathrm{O}_{3}\left(\mathrm{Ni}_{-}-\mathrm{Al}_{2} \mathrm{O}_{3}\right)$. Alumina has been commercially used as a stationary phase in Gas Chromatography of hydrocarbons and other organic molecules. Here the alumina coating is applied as an amorphous and porous support for nickel as catalyst for $\mathrm{CNF}$ deposition. The ca. $8 \mu \mathrm{m}$ thick $\mathrm{Ni}-\mathrm{Al}_{2} \mathrm{O}_{3}$ layer after calcination is shown in Fig. 3b. According to XRF analysis, the nickel concentration in alumina was found to be constant within $3 \%$ along the capillary.
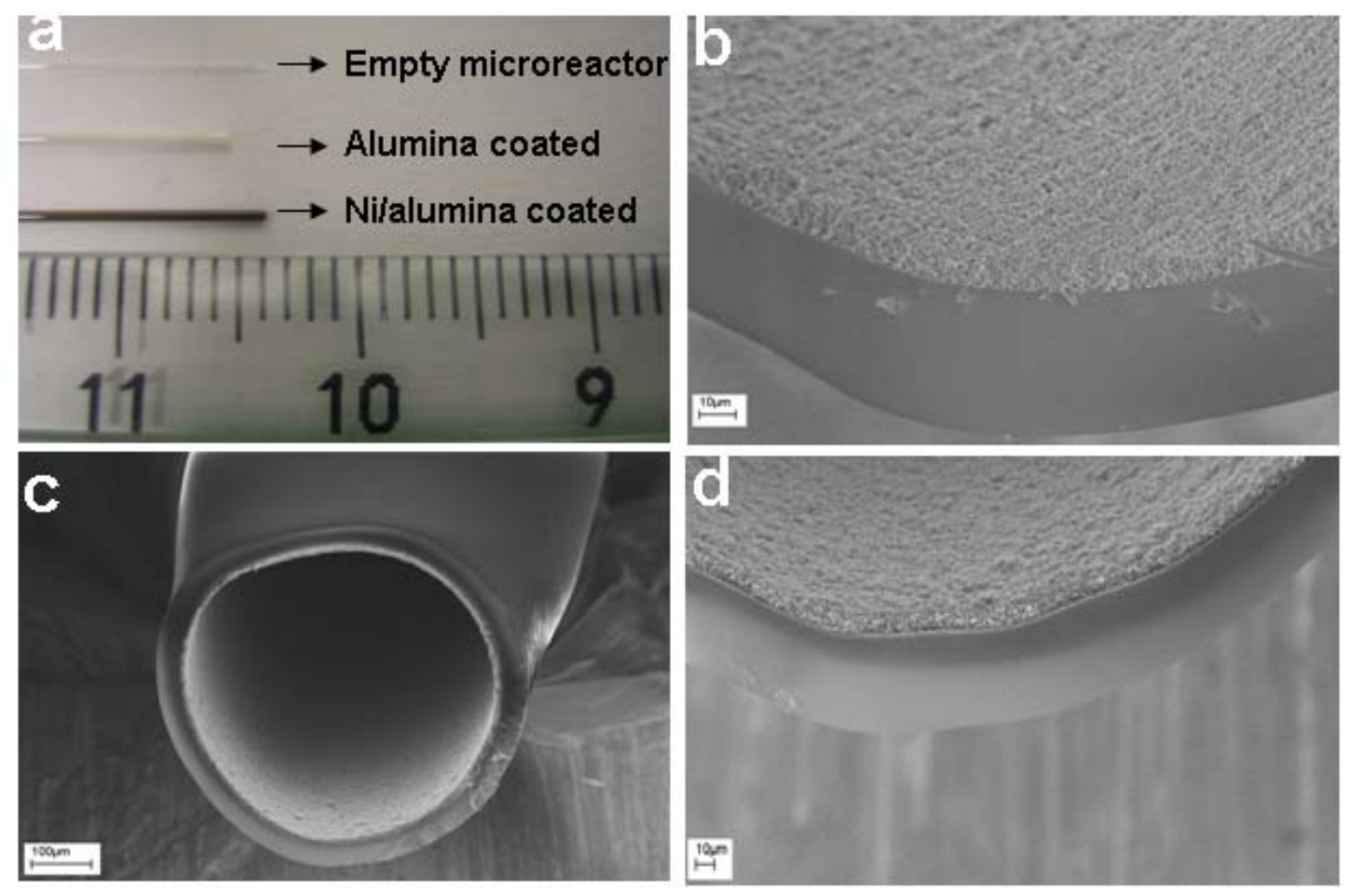

Figure 3. (a) Fused silica capillaries coated with $\mathrm{Al}_{2} \mathrm{O}_{3}$ and $\mathrm{Ni}$ loaded $\mathrm{Al}_{2} \mathrm{O}_{3}\left(\mathrm{Ni}^{-} \mathrm{Al}_{2} \mathrm{O}_{3}\right)$, (b) SEM image of cross section of Ni- $\mathrm{Al}_{2} \mathrm{O}_{3}$ layer, (c) and (d) SEM cross sections of capillaries after in-situ growth of CNF at $973 \mathrm{~K}$ for $120 \mathrm{~min}$.

SEM-EDX analysis of the $\mathrm{Ni}$ concentration at a cross section of the $\mathrm{Ni}-\mathrm{Al}_{2} \mathrm{O}_{3}$ layer (Figure $3 \mathrm{~b}$ ) indicates that $\mathrm{Ni}$ is evenly distributed in the alumina layer. The Ni loading on alumina is found to be $9.0 \mathrm{wt} \%$. The specific surface area of the catalyst layer is around $310 \mathrm{~m}^{2} / \mathrm{g}$ and the total pore volume $0.29 \mathrm{~cm}^{3} / \mathrm{g}$ with an average pore size of $37.3 \mathrm{~nm}$. Figs. $3 \mathrm{c}$ and $3 \mathrm{~d}$ show SEM cross sections of capillaries after in-situ growth of CNF at $973 \mathrm{~K}$ for $120 \mathrm{~min}$. The CNFs grown on the porous $\mathrm{Ni}-\mathrm{Al}_{2} \mathrm{O}_{3}$ layer have a uniform thickness of 9.5 $\mu \mathrm{m}$ along the capillary wall. A highly dense, homogenous and porous CNF-alumina 
composite was formed with a thin layer of CNFs at its outside (Fig. 3d). It is observed that the apparent thickness of the Ni-alumina layer increased due to high fragmentation and expansion during CNF deposition. The BET surface area of the composite is found to be $160 \mathrm{~m}^{2} / \mathrm{g}$ and the pore volume is $0.17 \mathrm{~cm}^{3} / \mathrm{g}$ with an average pore size of $42.5 \mathrm{~nm}$. It can be seen from Fig. 3d that a bulk nanofiber layer filled the voids and covered the alumina fragments. The decrease in pore volume shows that part of the mesopores in the alumina is filled or even destroyed by fragmentation.

Table 1. Characterization of CNF coating in the microreactor at different conditions.

\begin{tabular}{rlrllll}
\hline $\begin{array}{l}\text { Sample } \\
\text { number }\end{array}$ & $\begin{array}{l}\text { Growth } \\
\text { temperature } \\
(\mathrm{K})\end{array}$ & $\begin{array}{l}\text { Growth } \\
\text { time } \\
(\mathrm{min})\end{array}$ & $\begin{array}{l}\mathrm{H}_{2} \text { flow } \\
\text { in deposition } \\
(\mathrm{sccm})\end{array}$ & $\begin{array}{l}\mathrm{H}_{2} \text { flow } \\
\text { in pretreatment } \\
(\mathrm{sccm})\end{array}$ & $\begin{array}{l}\text { Composite } \\
\text { thickness } \\
(\mu \mathrm{m})\end{array}$ & $\begin{array}{l}\text { Nanofiber } \\
\text { diameter } \\
(\mathrm{nm})\end{array}$ \\
\hline & & & & & & \\
1 & 973 & 2 & 1 & 4 & 7.7 & $10-20$ \\
2 & 973 & 10 & 1 & 4 & 7.7 & $10-30$ \\
3 & 973 & 30 & 1 & 4 & 7.7 & $10-30$ \\
4 & 973 & 60 & 1 & 4 & 9.4 & $10-30$ \\
5 & 973 & 120 & 1 & 4 & 9.5 & $10-60$ \\
6 & 873 & 30 & 1 & 4 & 8.1 & $10-30$ \\
7 & 773 & 30 & 1 & 4 & 7.5 & $10-20$ \\
8 & 973 & 30 & 1 & 0 & 7.4 & $10-20$ \\
9 & 973 & 30 & 0 & 0 & 6.6 & $10-20$ \\
10 & 973 & 30 & 0 & 4 & 7.7 & $10-20$ \\
\hline
\end{tabular}

The incluence of growth time and temperature, $\mathrm{H}_{2}$ flow and pre-treatment on $\mathrm{CNF}$ growth were analyzed. Table 1 presents the average composite thickness and the nanofiber diameter range as a function of the conditions during synthesis. It is seen that the thickness of the CNF-alumina composite and the diameter of the fibers along the capillary increased with increasing deposition time (Samples 1-4). Carbon deposition led to fragmentation of the alumina layer and as the CNFs continued to grow, the total composite thickness increased. It is known that [2, 29-31] larger Ni particles cause slow formation of CNFs and this fact explains the observation of thicker nanofibers in the composite with longer deposition times. To study the influence of temperature on the deposition, CNFs were also grown at $873 \mathrm{~K}$ and $773 \mathrm{~K}$ (Sample 6-7). Thinner nanofibers were grown on alumina at $773 \mathrm{~K}$ compared to the fibers grown at $973 \mathrm{~K}$. The reason for this is that at lower temperatures agglomeration and surface migration of Ni nanocrystal particles is reduced and the resulting smaller Ni particles lead to thinner nanofibers. The 
critical role of hydrogen during pretreatment and deposition is evident: hydrogen increased the yield and thickness of the CNF composite (Table 1, Samples 8,9,10).
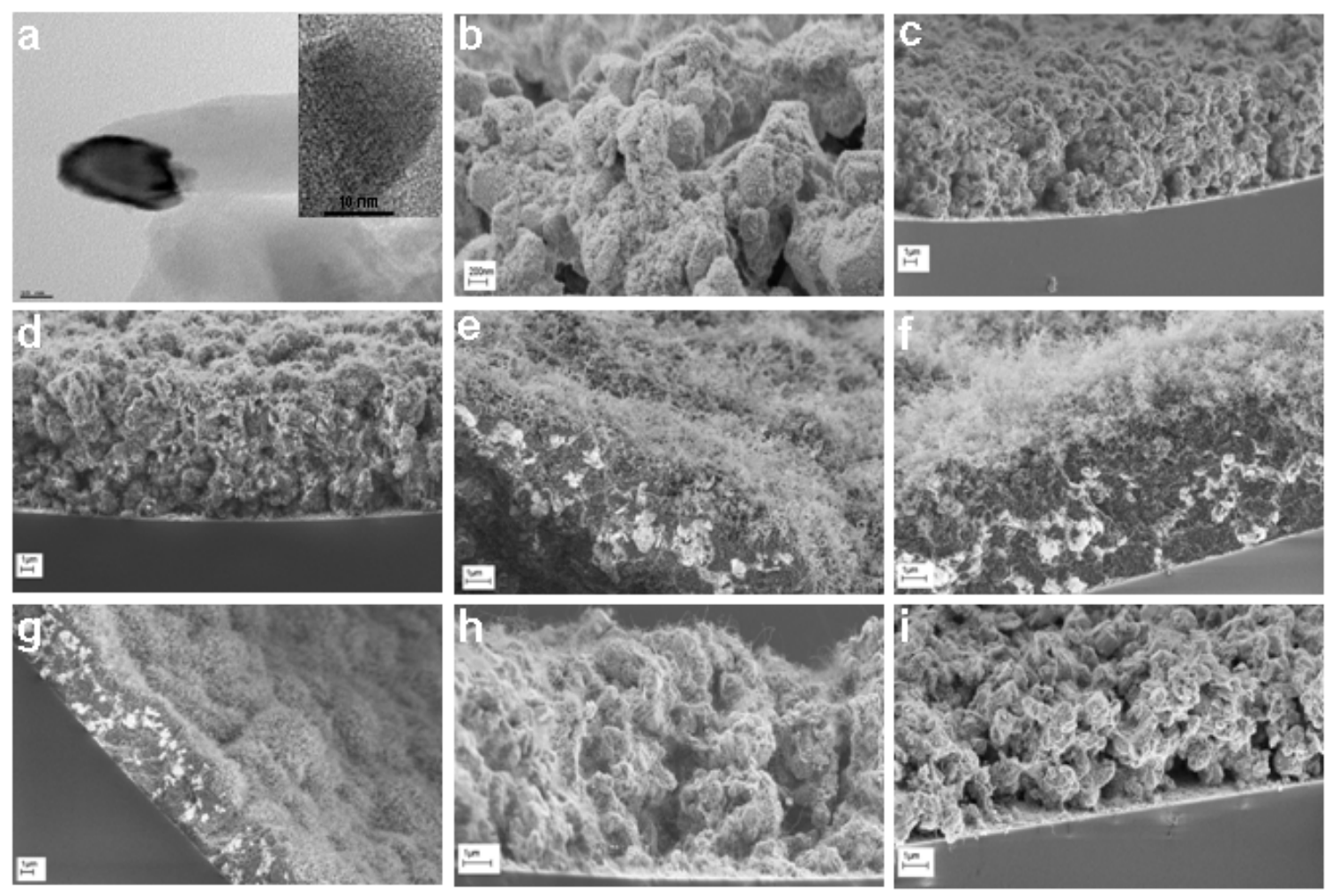

Figure 4. (a) TEM micrograph of Ni catalytic nanoparticle at the tip of a single nanofiber with a diameter of $30 \mathrm{~nm}$, taken from Sample 5. The inset shows the interplanar spacing of a Ni nanoparticle, which is $2.8 \AA$, (b) surface of Ni/alumina catalyst after $5 \mathrm{sec}$ of deposition at $973 \mathrm{~K}$, (c) after $2 \mathrm{~min}$, (d) after $10 \mathrm{~min}$, (e) after $2 \mathrm{hrs,} \mathrm{(f)} 30 \mathrm{~min}$ deposition at $873 \mathrm{~K},(\mathrm{~g}) 30 \mathrm{~min}$ deposition at $773 \mathrm{~K}$, (h) CNF layer grown at $973 \mathrm{~K}$ for 30 min without hydrogen pretreatment and (i) without hydrogen during deposition.

HRTEM analysis shows that the primary structure of all CNFs is fishbone-type (data not shown). Fig. 4a is a typical TEM micrograph, taken from Sample 5, of a Ni catalytic nanoparticle at the tip of a single nanofiber with a diameter of $30 \mathrm{~nm}$. Th inset of Fig. $4 \mathrm{a}$ shows that the interplanar spacing of the Ni particle is $2.8 \AA$, which corresponds to that between (111) planes of the cubic unit cell [32].

The time evolution of CNF growth on alumina in the microreactor was studied and is shown in Fig. $4 b-4$ e. Fig. $4 b$ shows the surface of the Ni/alumina catalyst after $5 \mathrm{sec}$ of deposition at $973 \mathrm{~K}$. This is the initial growth stage with many nano-islands as nucleation sites which are considered to play an important role in nanofiber formation. Catalyst particles were reported to have hemispherical geometry with a finite contact area with 
the substrate surface [33]. As graphite layers precipitated out of the catalyst nanoparticles, graphite nano-islands were formed as shown in Fig. 4b. The final range in nanofiber diameters depends on this initial stage with varying Ni nanoparticle size. After 2 minutes (Fig. 4c), a thin layer of CNFs was formed, which consists of nanofibers rapidly grown from small $\mathrm{Ni}$ particles. The CNF-alumina composite thickness and nanofiber diameter increased after $10 \mathrm{~min}$ of deposition, as shown in Fig. 4d. It turns out that fragmentation of the support layer had already started due to the fact that some of the thicker nanofibers fill the pores of the alumina. Fig. $4 \mathrm{e}$ shows the CNF-alumina composite layer formation after 2 hrs of deposition. The alumina layer was completely fragmented and a dense carbon layer filled the voids of the fragments. A homogeneous and thin layer of CNFs can be seen at the outside of the composite. The composite is mechanically stable showing no cracks or detachment from the glass capillary wall. Similarly, a densely packed nanofiber deposit under the loosely grown surface CNFs can be seen in Fig. 4e. Fig. 4f and 4g show the composite layers grown at $873 \mathrm{~K}$ and $773 \mathrm{~K}$, respectively. Similar to what happens at $973 \mathrm{~K}, \mathrm{CNF}$ grown at these temperatures produce stable and dense layers. Fig. 4h and $4 \mathrm{i}$ show the CNF layer grown without hydrogen pretreatment and without hydrogen during deposition, respectively. Growth yield and composite thickness decreased in both cases. The composite layer showed some detachment from the capillary walls and remained mechanically unstable after deposition. This indicates that hydrogen addition during pretreatment and deposition increases the rate of $\mathrm{CNF}$ formation so that a stable composite layer can be obtained. The $\mathrm{CNF}$ growth rate on $\mathrm{Ni}-\mathrm{Al}_{2} \mathrm{O}_{3}$ in the microreactor was determined from the weight increase. Deactivation of the catalyst resulted in a decrease in the formation rate and complete deactivation was observed after $2 \mathrm{hrs}$, as can be seen in Fig. 5. Deactivation occurs when carbon encapsulates the surface of nickel particles [34]. 


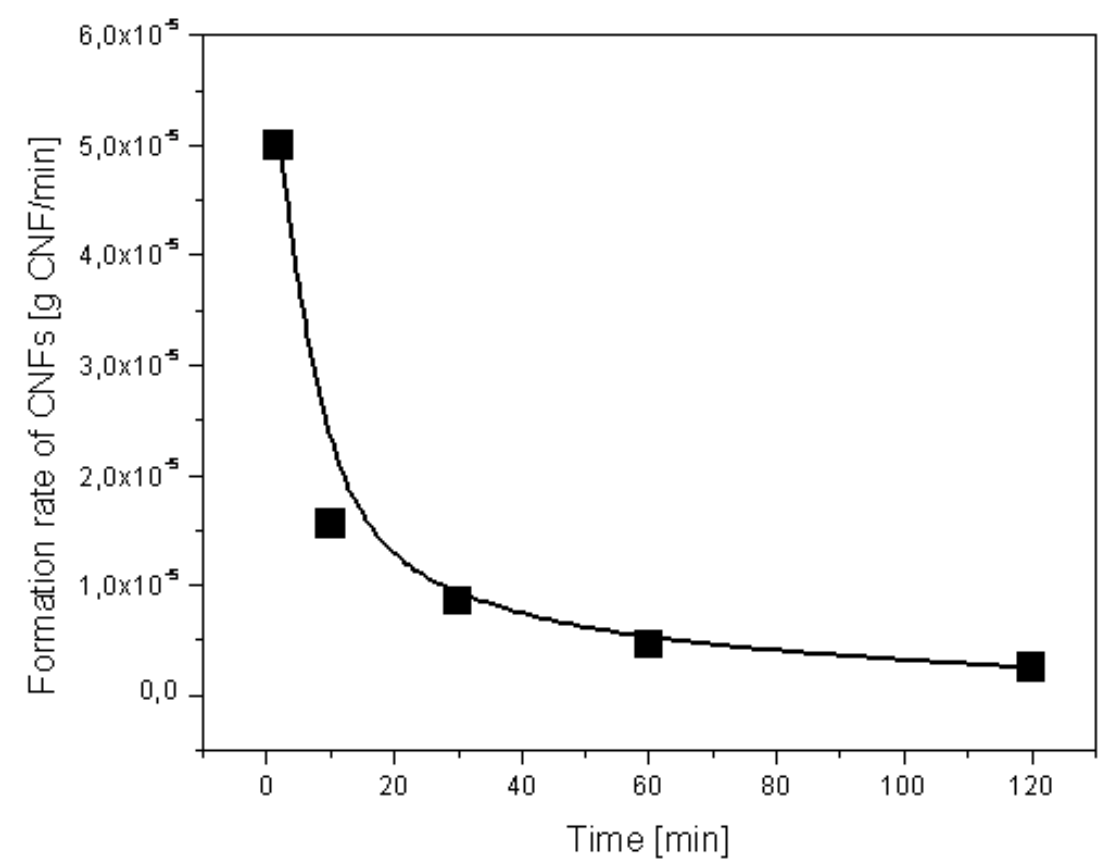

Figure 5. Change of CNF formation rate with time.
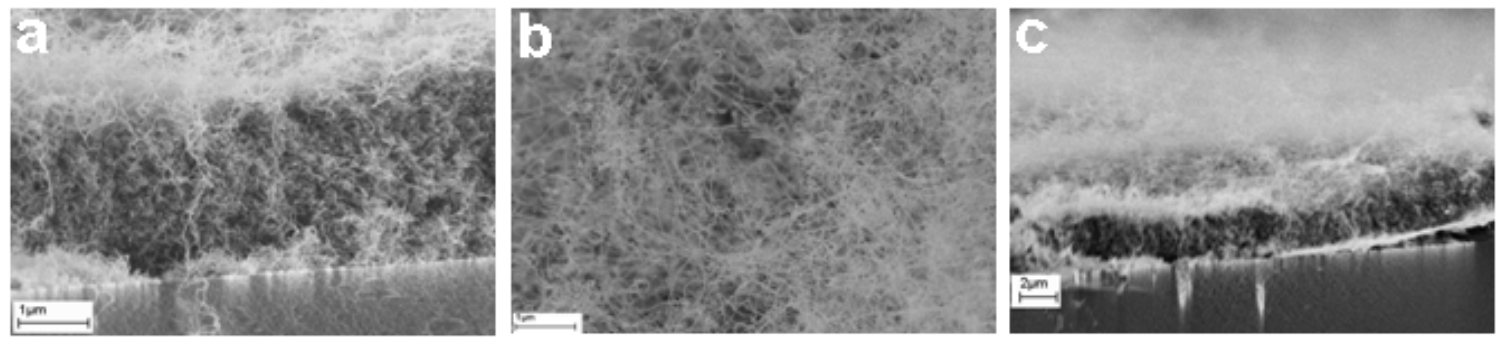

Figure 6. CNF growth on a nickel thin film inside the microreactor, at $973 \mathrm{~K}$ for $30 \mathrm{~min}$.

As an alternative approach to high-surface-area Ni-loaded alumina, a Ni thin film was applied as a catalyst for CNF synthesis. Maruyama et al. [35] obtained polycrystalline nickel films by hydrogen reduction of a precursor by low-temperature atmospheric pressure chemical vapor deposition. Using a similar method, a nickel film was grown by hydrogen reduction of nickel acetylacetonate in the microreactor. The 25 $\mathrm{nm}$ thick film was transparent with a mirror-like surface. Figs. 6a-c show a $2 \mu \mathrm{m}$ thick CNF film, deposited at $973 \mathrm{~K}$ for 30 min on a nickel thin film, which completely covers the inner surface of the capillary. Unfortunately the in-situ CVD process led to detachment of nickel, due to thermal stress, as is shown in Fig. 6c. To solve this delamination problem, an adhesion layer such as tantalum may be applied. 


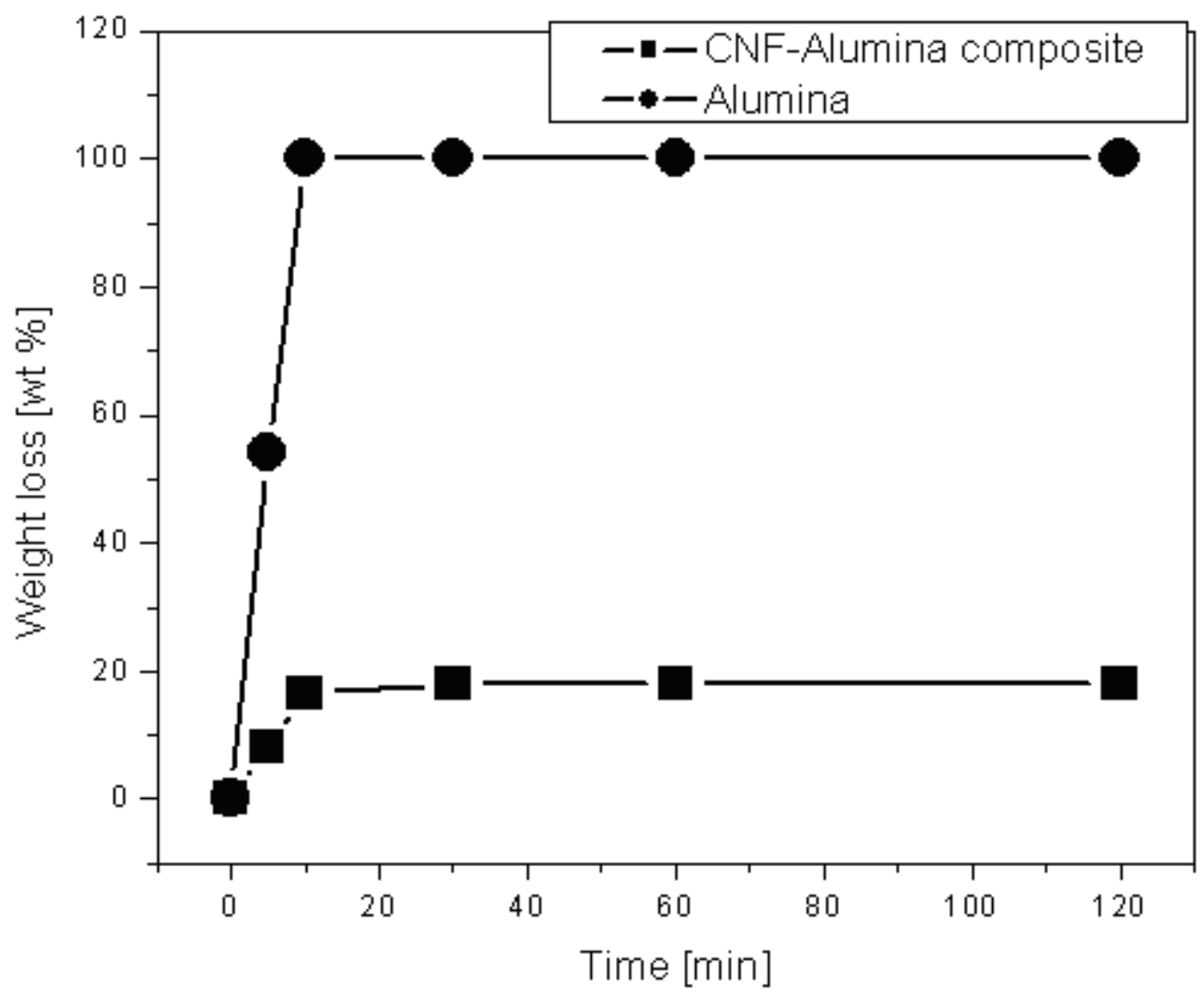

Figure 7. Mechanical stability test based on weight loss of alumina and CNF-alumina composite coating in the microreactor during sample maltreatment with $40 \mathrm{kHz}$ ultrasound in pure water.

The stability and attachment of the CNF-alumina composite was compared with an alumina layer on the surface of the capillary wall by determining the weight loss during maltreatment of the sample with $40 \mathrm{kHz}$ ultrasound in pure water. Fig. 7 indicates that the alumina layer was completely removed after 10 minutes, but of the CNF-alumina composite only $18 \%$ was removed. The latter layer remained stable after 2 hours, showing that CNF incorporation resulted in enhanced mechanical stability.

In summary, in-situ CVD of CNFs was carried out by flowing reactant gases through a Ni/alumina coated fused silica capillary microreactor. A homogeneous and thin layer of highly porous and mechanically stable CNF-alumina composite was formed with high surface area $\left(160 \mathrm{~m}^{2} / \mathrm{g}\right)$. The thickness of CNF-alumina composite and the average diameter of the fibers increases with increasing deposition time. Hydrogen addition during pretreatment and deposition is important to increase growth yield and to produce a mechanically stable composite support in the capillary. 


\section{Carbon nanofiber synthesis on a catalyst activated by a microplasma in a microreactor.}

Discharge Characteristics. Voltage and current waveforms measured for helium (150 $\mathrm{ml} / \mathrm{min}$ ) and hydrogen $(5 \mathrm{ml} / \mathrm{min})$ mixtures are shown in Figs. $8 \mathrm{a}$ and $8 \mathrm{~b}$, respectively. Two current peaks per cycle of applied voltage can be observed, which are typical for atmospheric pressure glow discharges (APG) [36]. Three requirements for the development of a stable APG between parallel plate dielectric electrodes were suggested [37]: (i) a source with frequency higher than $1 \mathrm{kHz}$, (ii) a dielectric material on one of the electrodes, and (iii) helium as dilution gas.
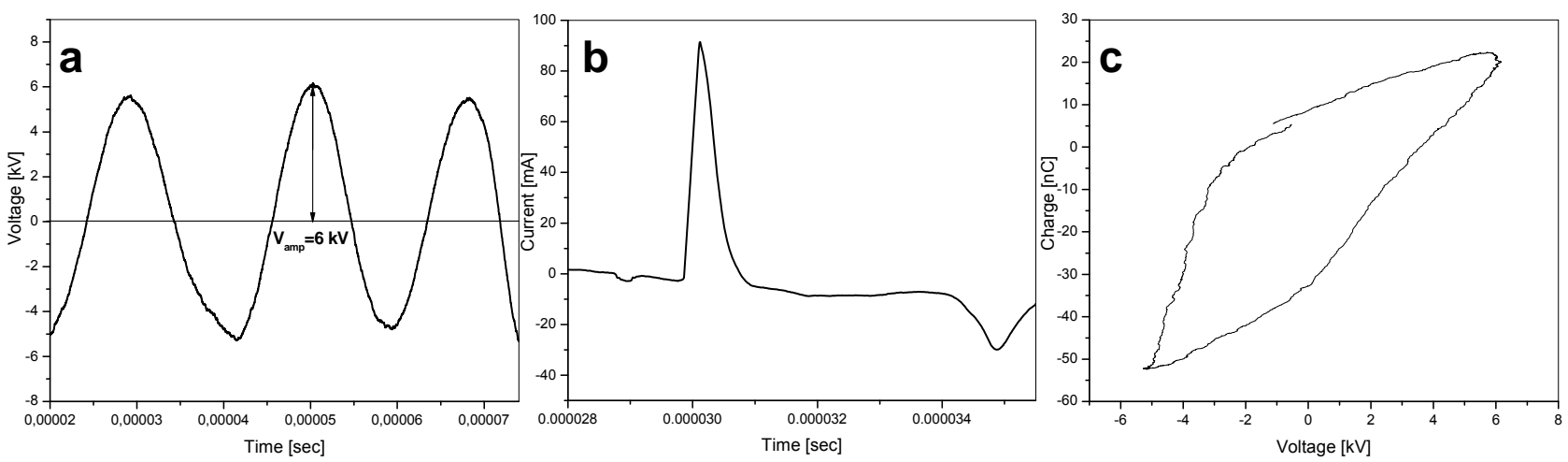

Figure 8. (a) Waveforms of the applied voltage, (b) transferred current. (c) Measured Lissajous figure for the DBD in helium $(150 \mathrm{ml} / \mathrm{min})$ and hydrogen $(5 \mathrm{ml} / \mathrm{min})$.

In our experiments in a continuous-flow capillary system we observe similar behavior. Increasing the hydrogen flow rate to $20 \mathrm{ml} / \mathrm{min}$ resulted in a filamentary discharge which is revealed by the multi-peak character of the discharge current. Diluting $\mathrm{H}_{2}$ in $\mathrm{He}$ under our experimental conditions is essential to create a glow discharge with radial homogeneity, which is important for a homogeneous activation treatment of the catalyst. It was not possible to fill the whole capillary volume with a discharge at helium flow rates lower than $40 \mathrm{ml} / \mathrm{min}$, which suggests that flow of formed charged and excited species towards the surface of the grounded electrode is essential for self-sustaining the discharge in the capillary. Lissajous figures, i.e. a plot of charge as a function of the applied voltage through one period, as shown in Fig. 8c, can be used to determine the power dissipation in the microplasma reactor. The power dissipated per voltage cycle can be expressed as: 
$P=\frac{W}{T}=\frac{\int_{t 0-T / 2}^{t 0+T / 2} V(t) d Q(t)}{T}$

where $V(t)$ is the applied voltage, $Q(t)$ is the charge moved through the discharge cell, and $T$ is the period of applied voltage. The average plasma power is calculated to be $8 \mathrm{~W}$, which corresponds to a power density of $680 \mathrm{~W} / \mathrm{cm}^{3}$ in the microreactor. This stable high power density atmospheric pressure plasma is in the glow discharge range where uniform and effective surface treatment can be expected.

For reference, Fig. 9a shows the emission spectrum of a helium discharge (150 $\mathrm{ml} / \mathrm{min}$ ) in the capillary. Various transitions of $\mathrm{O}, \mathrm{N}_{2}, \mathrm{~N}_{2}{ }^{+}, \mathrm{He}$ and $\mathrm{OH}$ are observed. It has to be mentioned that the sensitivity of the used spectrometer drops for wavelengths above $800 \mathrm{~nm}$. The measured spectrum is dominated by He I excitation lines at $388.9 \mathrm{~nm}$ $\left(2^{3} \mathrm{~S}-3^{3} \mathrm{P}^{0}\right), 447.2 \mathrm{~nm}\left(2^{3} \mathrm{P}^{0}-4^{3} \mathrm{D}\right), 471.3 \mathrm{~nm}\left(2^{3} \mathrm{P}^{0}-4^{3} \mathrm{~S}\right), 492.2 \mathrm{~nm}\left(2^{1} \mathrm{P}^{0}-4^{1} \mathrm{D}\right), 501.6 \mathrm{~nm}$ $\left(2^{1} \mathrm{~S}-3^{1} \mathrm{P}^{0}\right), 587.6 \mathrm{~nm}\left(2^{3} \mathrm{P}^{0}-3^{3} \mathrm{D}\right), 667.8 \mathrm{~nm}\left(2^{1} \mathrm{P}^{0}-3^{1} \mathrm{D}\right), 706.5 \mathrm{~nm}\left(2^{3} \mathrm{P}^{0}-3^{3} \mathrm{~S}\right)$ and $728.1 \mathrm{~nm}$ $\left(2^{1} \mathrm{P}^{0}-3^{1} \mathrm{~S}\right)$ [38]. A large number of metastable helium atoms exists in the discharge. Helium metastable species can be created by direct electron impact $\left(\mathrm{E}_{\text {threshold }}=19.82 \mathrm{eV}\right)$, transitions from higher states, and dissociative recombination between molecular helium ions and low energy electrons [39]. The $\mathrm{OH}$ line $\left(\mathrm{A}^{2} \Sigma^{+}-\mathrm{X}^{2} \Pi\right.$ transition) at $306.4 \mathrm{~nm}$, an oxygen line at $777.3 \mathrm{~nm}$, a second positive electronic transition of $\mathrm{N}_{2}\left(\mathrm{C}^{3} \Pi_{\mathrm{u}}-\mathrm{B}^{3} \Pi_{\mathrm{g}}\right)$ and its vibrational sub-transitions at $337 \mathrm{~nm}(0-0), 315.6 \mathrm{~nm}(1-0), 357.5 \mathrm{~nm}(0-1), 353.3 \mathrm{~nm}$ (12), $313.4 \mathrm{~nm}(2-1), 394.2 \mathrm{~nm}(2-5), 380.2 \mathrm{~nm}(0-2), 375.3 \mathrm{~nm}(1-3), 414 \mathrm{~nm}(3-7), 296.1$ $\mathrm{nm}(3-1), 297.5 \mathrm{~nm}(2-0)$ and $311.5(3-2)$, the first negative $\mathrm{N}_{2}^{+}$of $\mathrm{N}_{2}^{+}\left(\mathrm{B}^{2} \Sigma_{\mathrm{u}^{-}}^{+} \mathrm{X}^{2} \Sigma_{\mathrm{g}}^{+}\right)$ transitions at $391.2 \mathrm{~nm}(0-0), 356.1 \mathrm{~nm}(2-1)$ and $427.8 \mathrm{~nm}(0-1)$, the NO lines from the $\mathrm{NO}\left(\mathrm{A}^{2} \Sigma^{+}, v^{\mathrm{I}}-\mathrm{X}, v^{\mathrm{II}}\right)$ at $236.3 \mathrm{~nm}(0-1)$ and $247.1 \mathrm{~nm}(0-2)$ and the $\mathrm{H}_{\beta}$ and $\mathrm{H}_{\alpha}$ lines at 486 $\mathrm{nm}$ and $656 \mathrm{~nm}$ are also found due to the presence of residual water and air, caused by the fact that the microreactor is open to air. The main channels that produce $\mathrm{N}_{2}{ }^{+}$and $\mathrm{OH}$ emissions are thought to be Penning ionization and charge transfer reactions with metastable species and molecular ions of helium, respectively [40, 41]. 

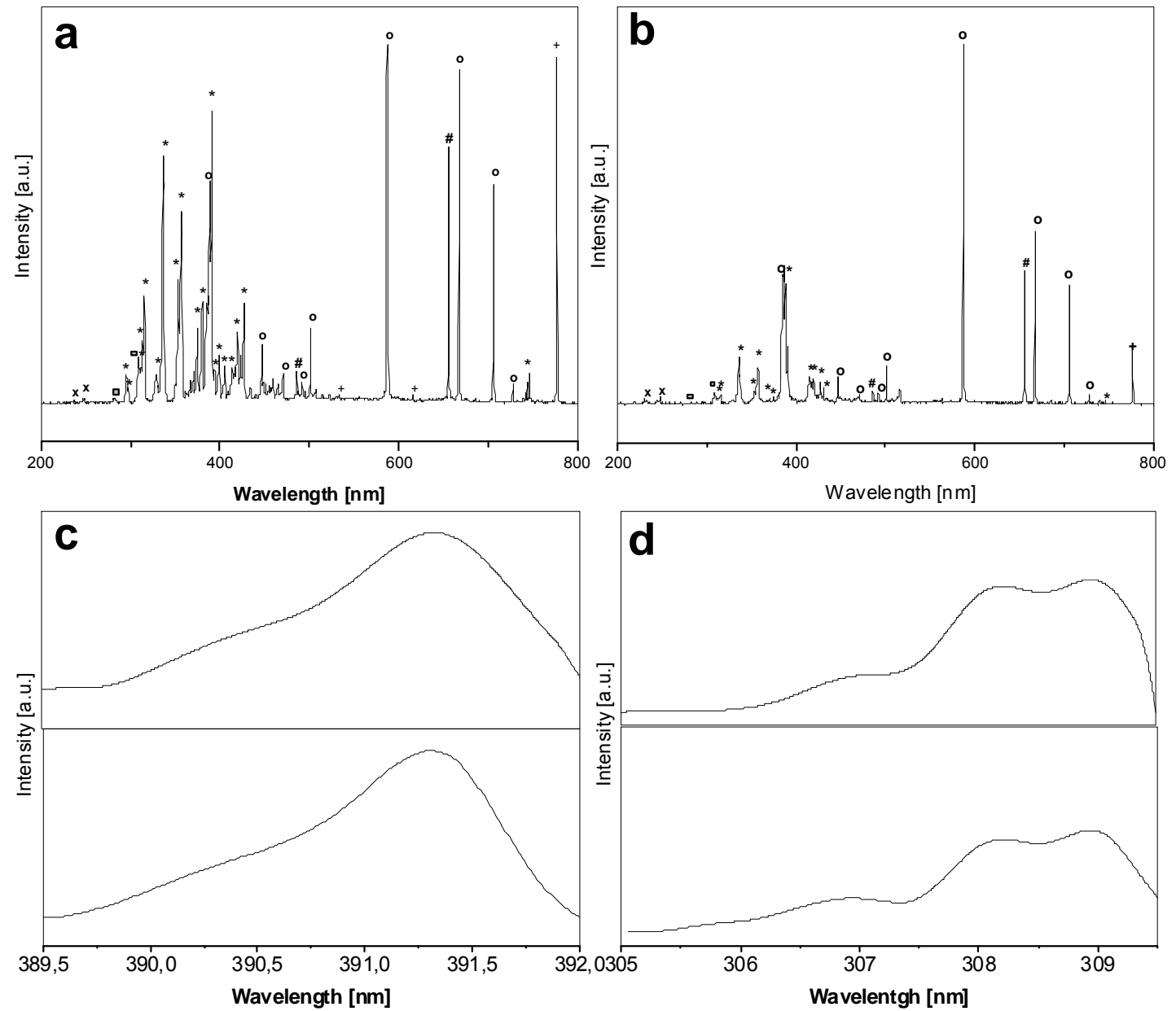

Figure 9. (a) Emission spectra for helium plasma. (b) Helium + hydrogen plasma [(*) nitrogen, $\left({ }^{\circ}\right)$ helium, (\#) hydrogen, $(x)$ nitrogen oxide, $(+)$ oxygen, $(\square)$ hydroxyl lines]. (c) The experimental molecular spectrum (lower bands) with synthetic spectrum (upper bands) of $\mathrm{N}_{2}{ }^{+}$first negative system $(388-392 \mathrm{~nm})$ and (d) $\mathrm{OH}$ band $(306-310 \mathrm{~nm})$.

In an atmospheric pressure helium plasma, determination of the electron temperature is not possible just by using emission lines, due to the overpopulation of the lower atomic states with respect to the Saha balance in a non-equilibrium state [42]. Due to the fact that helium is the lightest noble gas with high ionization potential, the discharge has generally high average electron temperature and low electron density. At atmospheric pressure, a typical average electron temperature of $2 \mathrm{eV}$ has been found in helium plasma's $[43,44]$. It is possible to calculate the atomic excitation temperature $\left(\mathrm{T}_{\mathrm{exc}}\right)$ which describes the population of atomic excited sates, under the assumption that they follow a Boltzmann distribution. The excitation temperature should be high enough to enable the excitation of hydrogen and $\mathrm{Ni}$ /alumina catalyst to the energy levels needed for 
activation. Using the helium line intensities from the observed optical emission spectrum and the spectroscopic data (wavelengths, energies, statistical weights and transition probabilities), the $T_{\text {exc }}$ values are ca. $1700 \mathrm{~K}$ indicating a low electronic-temperature plasma. Fig. $9 \mathrm{~b}$ shows the emission spectrum for a helium $(150 \mathrm{ml} / \mathrm{min})+$ hydrogen ( $5 \mathrm{ml} / \mathrm{min}$ ) discharge used for activating the Ni/alumina catalyst for CNFs growth in the capillary. Hydrogen addition results in the decrease of the intensity of the emission bands in the spectrum. Increasing the flow rate of hydrogen to $20 \mathrm{ml} / \mathrm{min}$ causes a larger decrease in the intensity of the helium lines and a further increase in flow rate leads to termination of the plasma, indicating the importance of helium metastable species in sustaining the discharge. $\mathrm{T}_{\text {exc }}$ decreases to $1600 \mathrm{~K}$ with hydrogen addition since electrons loose their energy through excitation and dissociation reactions with hydrogen molecules. Another parameter which is important in the plasma activation treatment is the gas temperature in the discharge. By measuring rotational temperatures of diatomic molecules in the discharge ( $\mathrm{OH}$ and $\left.\mathrm{N}_{2}^{+}\right)$, a gas temperature can be derived, based on the fact that rotational-translational relaxation is fast enough to equilibrate rotational temperature and gas temperature [45, 46]. Fig. 9c and Fig. 9d compare the experimental molecular spectrum (lower bands) and the synthetic spectrum of the $\mathrm{N}_{2}{ }^{+}$first negative system (388$392 \mathrm{~nm})$ and the $\mathrm{OH}$ band $(306-310 \mathrm{~nm})$, respectively. Since resolution of the spectrometer is not high enough to resolve rotational lines in order to obtain a Boltzmann plot for the determination of rotational temperature, the experimental band is compared with a synthetic spectrum calculated by LIFBASE software [47]. A gas temperature of $350 \pm 50 \mathrm{~K}$ is obtained. Additionally, a micro thermocouple inserted into the capillary during discharge indicates a $40 \mathrm{~K}$ increase after $15 \mathrm{~min}$ operation. These results suggest that low temperature activation of the catalyst is performed with the plasma species in the microreactor at atmospheric pressure.

Catalyst Characterization and CNFs Synthesis. Fig. 10a shows a SEM picture of a fused silica capillary coated with Ni/alumina. The alumina layer, which after calcination has a layer thickness of $8 \mu \mathrm{m}$, is shown in Fig. $10 \mathrm{~b}$. 

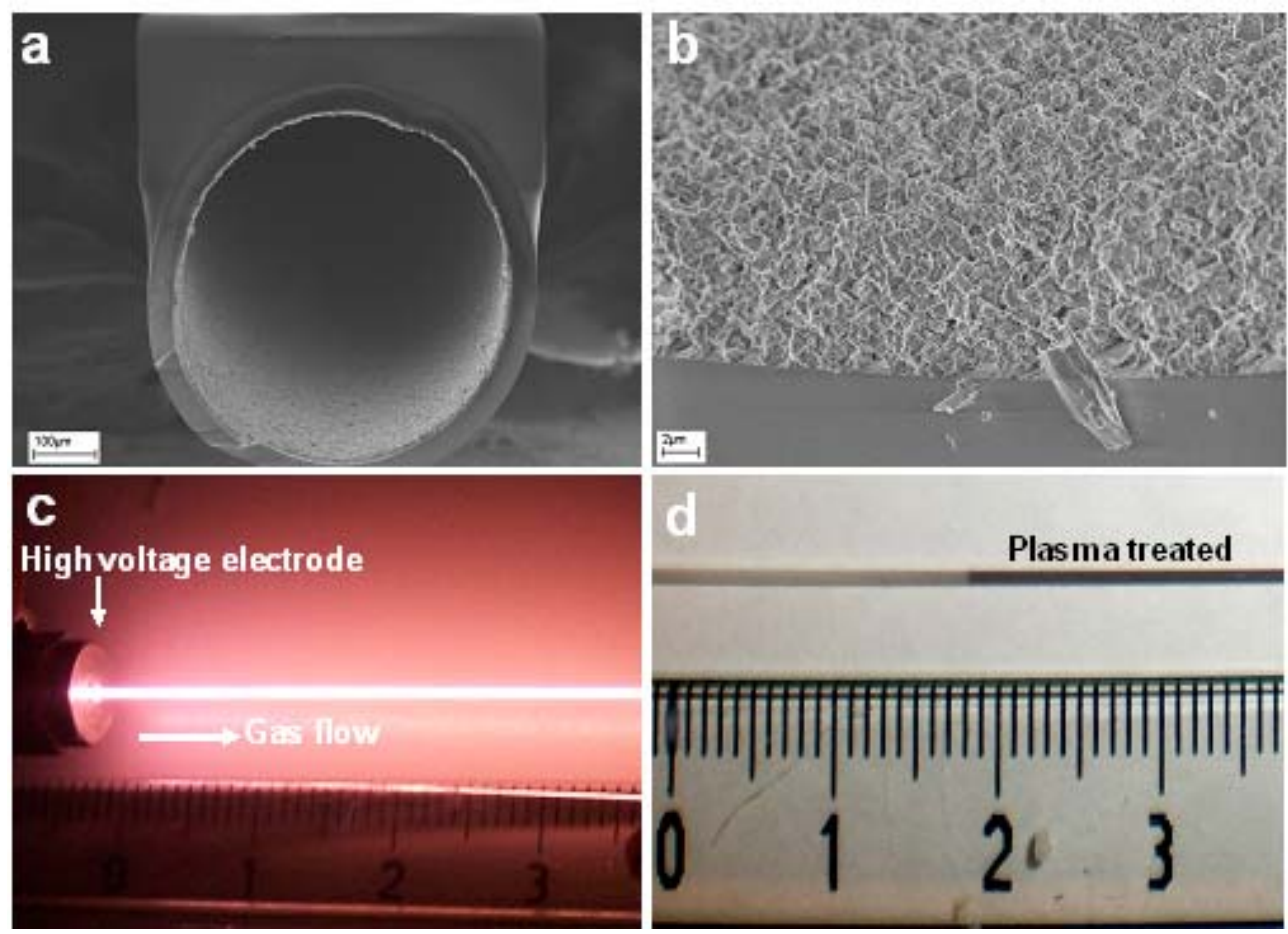

Figure 10. (a) SEM picture of a fused silica capillary coated with Ni/alumina. (b) The catalyst layer after calcination. (c) Helium $(150 \mathrm{ml} / \mathrm{min})+$ hydrogen $(5 \mathrm{ml} / \mathrm{min})$ microplasma treatment of $\mathrm{Ni} /$ alumina coating to increase the catalytic activity for in-situ CNFs synthesis in the capillary. (d) Change in color of catalyst from light gray to dark gray after activation for 15 minutes.

According to XRF analysis, the nickel concentration in the alumina layer is 9.0 wt.\%. Nickel is distributed homogeneously according to XRF and SEM-EDX analyses performed on various parts of the microreactor. The catalyst has a high specific surface area $\left(310 \mathrm{~m}^{2} / \mathrm{g}\right)$. Fig. $10 \mathrm{c}$ shows the helium $(150 \mathrm{ml} / \mathrm{min})+$ hydrogen $(5 \mathrm{ml} / \mathrm{min})$ microplasma treatment of $\mathrm{Ni} /$ alumina coating used to increase the catalytic activity for insitu CNFs synthesis in the capillary. Activation for 15 minutes results in a change in color of the catalyst, from light gray to dark gray, as shown in Fig. 10d. This color change is due to the reductive interaction of the plasma with the surface of the supported nickel. The catalyst is also reduced using a conventional thermal method at $973 \mathrm{~K}$ for $2 \mathrm{~h}$ with the same flow rates of helium and hydrogen and this treatment also changes the color of the catalyst to dark gray. 

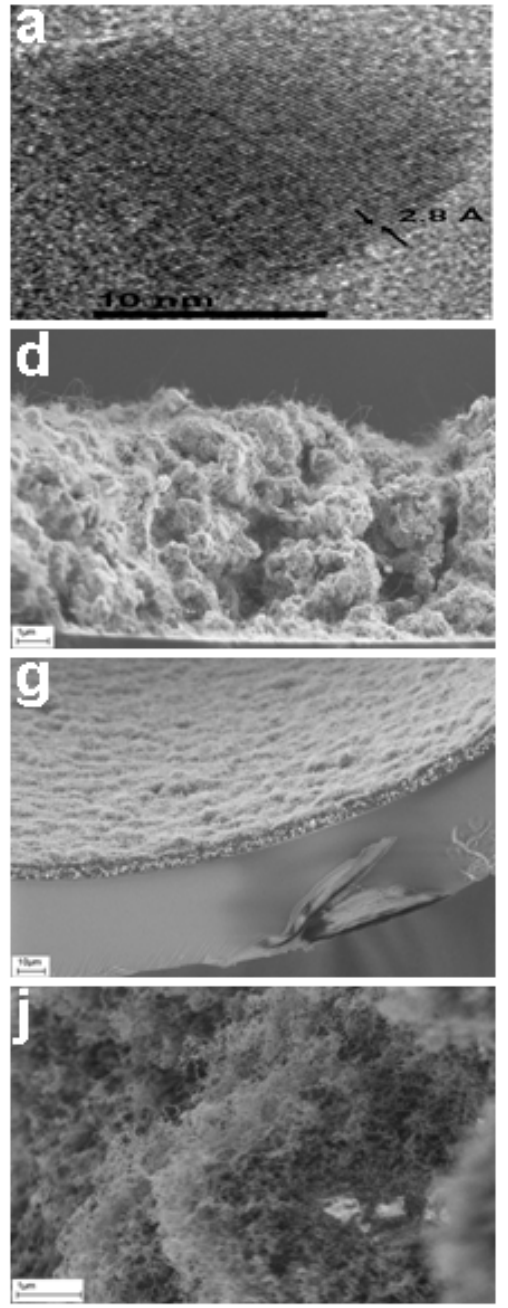
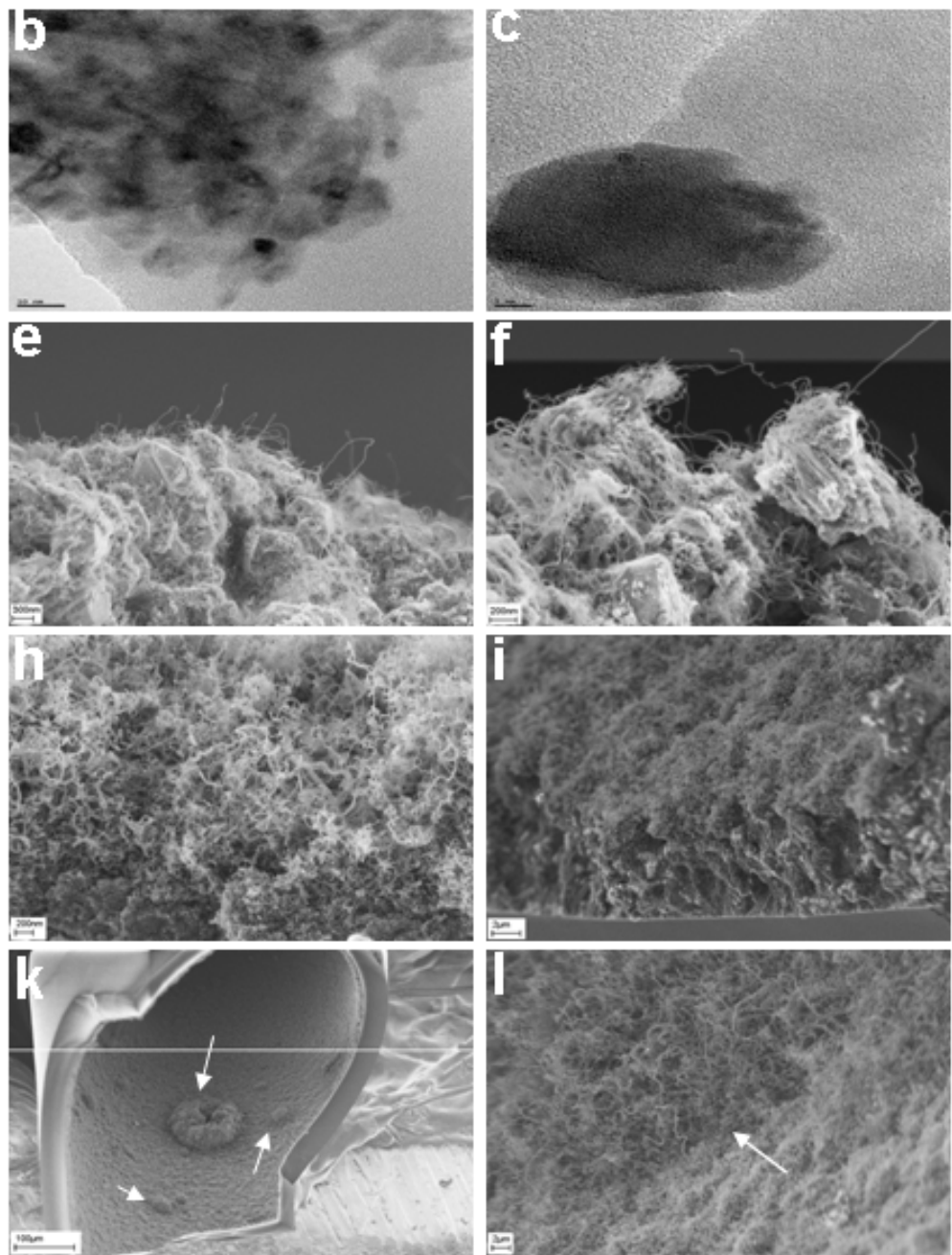
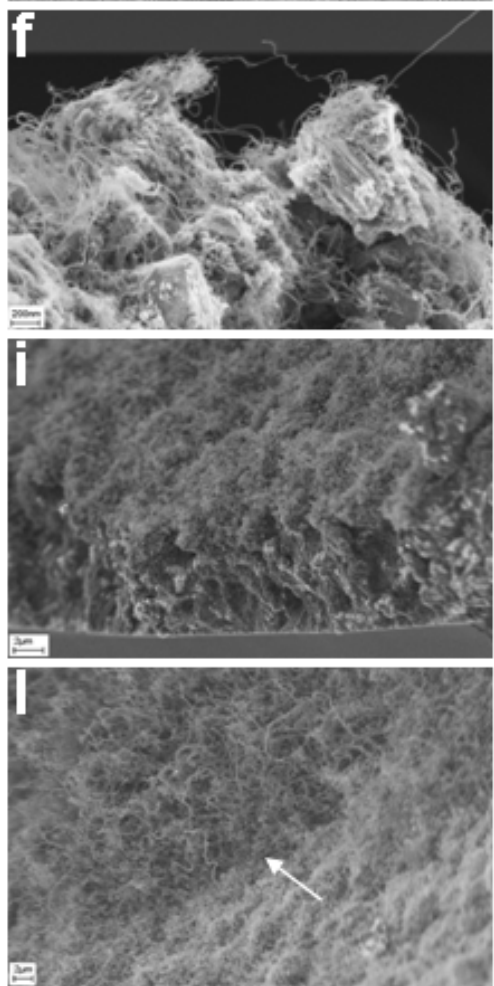

Figure 11. (a) TEM micrograph of nickel nanoparticle. (b) TEM images of nickel particles on alumina and (c) on the tip of one fiber. (d-f) SEM pictures of CNFs-alumina composite grown without any activation, ( $\mathrm{g}-\mathrm{h}$ ) after thermal activation at $973 \mathrm{~K}$ for $2 \mathrm{~h}$, (ij) after low temperature plasma activation for $15 \mathrm{~min}$ and (k-1) for $30 \mathrm{~min}$ cases. White arrows show the non-homogeneous growth of fibers in the microreactor.

The structure of the fibers after deposition was studied with SEM and HRTEM. According to TEM analysis, the primary structure of the nanofibers is fishbone-like. Fig. 11a shows a TEM micrograph of a nickel nanoparticle with $2.8 \AA$ interplanar spacing between (111) planes of the cubic unit cell. Carbon-containing gas decomposes on these nickel catalyst particles to produce carbon atoms which precipitate to form a graphite layer $[48,49]$. In the initial stage of growth, graphite layers precipitate out of the catalyst nanoparticles and graphite nano-islands are formed [33]. Since the range of nanofiber diameters depends on that initial size of nickel nanoparticles, it is essential to have a good dispersion and small particles of nickel for uniform CNFs growth. Fig. 11b and 11c are 
representative TEM images of nickel particles on alumina and on the tip of one fiber, respectively. In order to understand the effect of activation treatment, SEM pictures of CNFs-alumina composite grown after no activation [Fig. 11(d-f)], after thermal activation at $973 \mathrm{~K}$ for $2 \mathrm{~h}$ [Fig. 11(g-h)] and after low-temperature plasma activation for $15 \mathrm{~min}$ [Fig. 11(i-j)] and 30 min [Fig. 11(k-1)] are shown.

Growth of CNFs in alumina causes fragmentation and an increase in the thickness of this layer in all samples. It is believed that in the beginning of the growth process, a small amount of CNFs causes the fragmentation and expansion of the alumina layer and after that, further growth leads to filling of created open volume between the fragments [29]. Apparently, the open volumes as shown in the sample without any activation treatment [Fig. 11d] indicate that the growth yield is less than in the samples activated thermally [Fig. 11g] or with a plasma [Fig. 11i]. In activated samples, extended growth of the CNFs leads to filling of the voids in the alumina layer so that a homogeneous and dense CNFs-alumina composite layer with high surface area $\left(160 \mathrm{~m}^{2} / \mathrm{g}\right)$ containing mesopores is formed in the microreactor. The CNF formation rate increases from $5.2 * 10^{-6}$ $\mathrm{g} / \mathrm{min}$ in non-activated samples to $8.2 * 10^{-6} \mathrm{~g} / \mathrm{min}$ and $8.7^{*} 10^{-6} \mathrm{~g} / \mathrm{min}$ in plasma treated and thermally treated ones, respectively. These results prove that a short treatment of $\mathrm{Ni} /$ alumina catalyst with atmospheric pressure cold plasma is beneficial for CNFs synthesis and can compete with thermal activation. Moreover, the diameter of the nanofibers at the surface obtained from plasma activated samples is more uniform than the diameters for samples thermally activated. It is assumed that after a low temperature discharge treatment, relatively smaller and more dispersed nickel particles are formed. However, increasing the plasma treatment period to $30 \mathrm{~min}$ causes sintering of catalyst particles and this results in non-uniform growth of nanofibers in the microreactor as shown in Fig. 11(k-1). Therefore, it is important to optimize the plasma treatment period in order to have a good dispersion of catalyst and to prevent sintering.

To further clarify chemical processes during microplasma treatment of catalyst, an attempt was made to calculate reaction rates and energy deposition directed towards various collision processes (elastic, inelastic and ionization) between electrons and gas species. BOLSIG + software [50] was used to solve the Boltzmann-equation for electrons in a uniform electric field, using the classical two-term expansion. The list of processes and electron collision cross sections used for electron energy distribution function computation for a helium-hydrogen mixture were taken from the SIGLO database [51]. Elastic, ionization, rotational, vibrational and electronic excitation processes provided 24 electron impact reactions of helium and hydrogen.. Fig. 12 shows the energy fraction 
input into collision processes, versus electron energy ( $\sim 3 \%$ hydrogen in helium system).

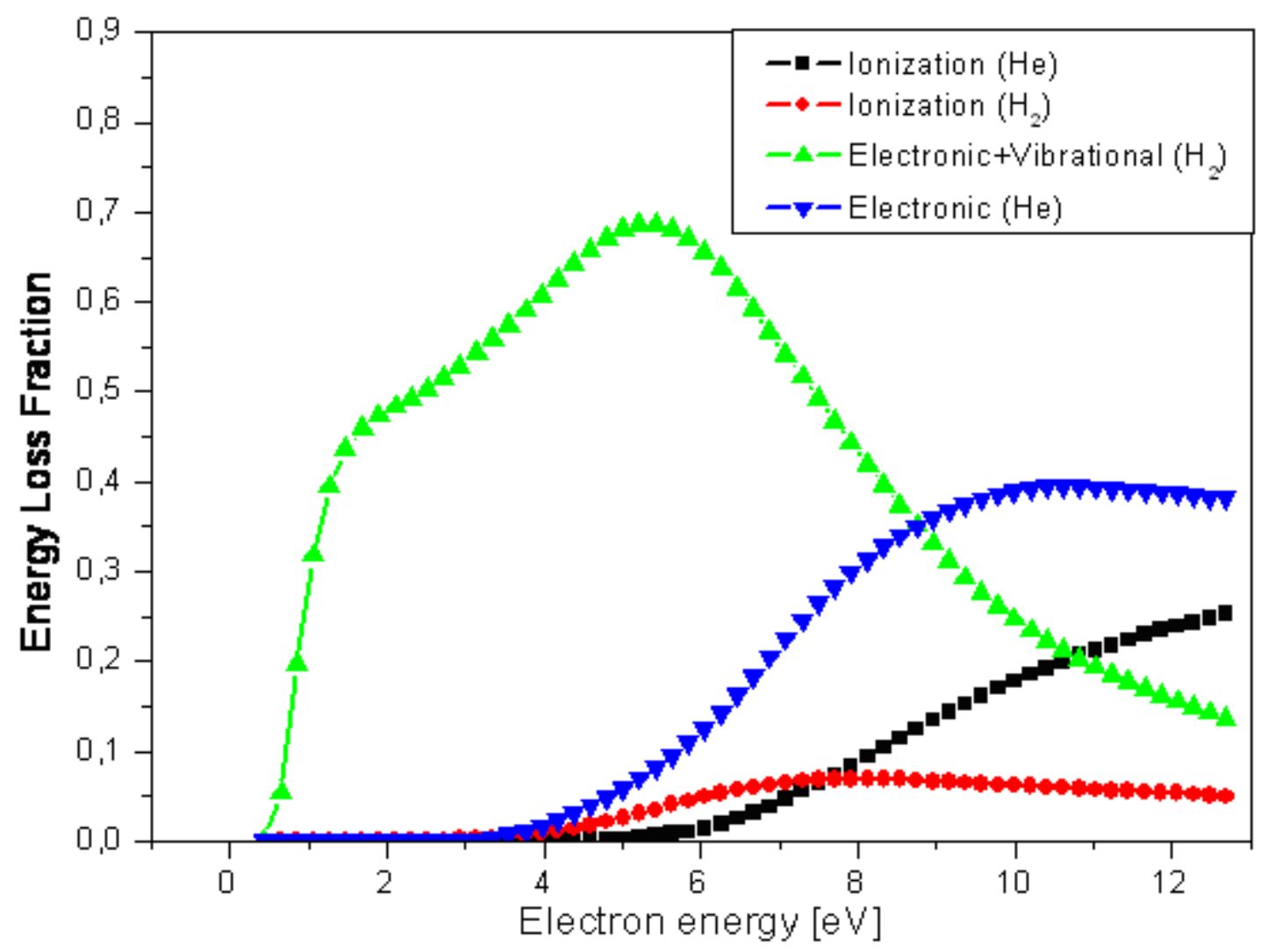

Figure 12. Energy fraction put into collision processes versus electron energy $(\sim 3 \%$ hydrogen in helium system).

In the microplasma reactor, the average electron energy is between 2 and $5 \mathrm{eV}$. In the experimental operation region, energy deposition directed electron excitation of hydrogen has the highest fraction. This means that hydrogen excitation plays an important role in the activation scheme. For the hydrogen molecule, the dissociation occurs via $\mathrm{b}^{3} \Sigma_{\mathrm{u}}{ }^{+}$and $\mathrm{a}^{3} \Sigma_{\mathrm{g}}^{+}$electronic excitation states and these reaction channels have higher rate coefficients over other channels for excitation of hydrogen molecules in the electron energy range between $2 \mathrm{eV}$ and $5 \mathrm{eV}$. Therefore, it can be concluded that excited hydrogen radicals play the most important role for surface activation of catalyst in the microreactor at atmospheric pressure. The yield of ions and metastable excited species is lower, and these species are already relaxed to their ground state before they begin to interact strongly with the surface. Another important source of hydrogen radicals is dissociation of hydrogen molecules by energy transfer from the metastable helium radicals [36]. Plasma treatment resulted in a reduction and etching of the catalyst layer by atomic hydrogen radicals. The presence of electric charges can also have an effect on the catalyst surface by arranging nanoparticles through electric charge-related effects [25]. 
After longer microplasma treatments non-uniform growth of CNFs was observed, which could be due to the fact that nanoparticles tend to agglomerate to reduce surface energy. The thermal activation treatment increases agglomeration quite severaly due to the high surface mobility at high temperatures.

\section{Conclusion}

A homogeneous and thin layer of highly porous and mechanically stable CNFalumina composite with high surface area $\left(160 \mathrm{~m}^{2} / \mathrm{g}\right)$ was formed by in-situ CVD in a fused silica capillary microreactor. A dielectric barrier discharge generated by flowing helium and hydrogen through the open air capillary microreactor has been used for activation treatment of a $\mathrm{Ni} /$ alumina catalyst coating in the microeactor, in order to enhance CNF synthesis. The DBD is characterized as uniform and stable, with high power density $\left(680 \mathrm{~W} / \mathrm{cm}^{3}\right)$ and works at ambient gas temperature. Cold plasma treatment for $15 \mathrm{~min}$ increases the CNF growth yield from $5.2 * 10^{-6} \mathrm{~g} / \mathrm{min}$ in nonactivated samples to $8.2^{*} 10^{-6} \mathrm{~g} / \mathrm{min}$ with activation. Comparison of the discharge treatment with a thermal treatment at $973 \mathrm{~K}$ for $2 \mathrm{~h}$ shows that the diameter of nanofibers is much more uniform in the former case. Longer treatment with plasma for $30 \mathrm{~min}$ results in sintering of catalyst particles, which leads to non-uniform growth of the fibers.

\section{Acknowledgements}

This research is supported by the Technology Foundation STW, applied science division of NWO and the technology program of the Ministry of Economic Affairs, The Netherlands, project number 06626. The authors thank H. Nair for assistance in the experiments, B. Geerdink for technical support, L. Vrielink for BET and XRF measurements and Mark Smithers for SEM and TEM/EDX analysis. 


\section{References}

[1] P. Serp, M. Corrias and P. Kalck, Appl. Catal. A 253 (2003) 337.

[2] K. De Jong, J. Geus, Catal. Rev. - Sci. Eng. 42 (2000) 481.

[3] N. M. Rodriguez, J. Mater. Res. 8 (1993) 3233.

[4] R. Vieira, C. Pham-Huu, N. Keller, M. J. Ledoux, Chem. Comm. (2002) 954.

[5] N. Jarrah, J. G. Van Ommen, L. Lefferts, Catal. Today 79-80 (2003) 29-33.

[6] J. K. Chinthaginjala, D.B. Thakur, K. Seshan, L. Lefferts, Carbon, 46 (2008) 16381647.

[7] C. Wille, H. -P. Gabski, T. Haller, H. Kim, L. Unverdorben, R. Winter, Chem. Eng. J. $101(2004) 179$.

[8] A. Rogue, B. Spoetzl, K. Gebauer, R. Schenk, A. Renken, Chem. Eng. Sci. 56 (2001) 1419.

[9] P. Claus, D. Honicke, T. Zech, Catal. Today 67 (2001) 319.

[10] N. Ishigami, H. Ago, Y. Motoyama, M. Takasaki, M. Shinagawa, K. Takahashi, T. Ikuta, M. Tsuji, Chem. Commun.(2007) 1626-1628.

[11] A. Popp, J. J. Schneider, Angew. Chem. Int. Ed. 47 (2008) 8958-8960.

[12] A. Agiral, H. Nair, K. Seshan, L. Lefferts, and J.G.E (Han) Gardeniers, "In-situ CVD of CNFs in a microreactor", in Carbon for Catalysis III Conf., 2008.

[13] C. J. Liu, G. P. Vissokov, and B. W. -L. Jang, Catalysis Today 72 (2002) pp. 173184.

[14] T. Peev, G. P. Vissokov, I. Czako-Nagy, and A. Vertes, Appl. Catal. 19 (1985) pp. 301-305, 1985.

[15] D. E. Halverson, and D. L. Cocke, J. Vac. Sci. Technol. A. 7 (1989) pp. 40-48.

[16] H. R. Khan, and H. Freay, J. Alloys Compounds 10 (1993) pp. 209-217.

[17] J. Blecha, J. Dudas, A. Lodes, and J. Derco, J. Catal. 116 (1989) pp. 285-290.

[18] M. B. Kizling, and S. G. Järås, Appl. Catal. 147 (1996) pp. 1-21.

[19] Y. Nariki, Y. Inoue, and K. Tanaka, J. Mater. Sci. 25 (1990) pp. 3101-3104.

[20] T. M. Maesen, H. W. Kouwenhoven, and H. V. Bekkum, J. Chem. Soc. Faraday Trans., 86 (1990) pp. 3967-3970. 
[21]. H. Uyama, T. Nakamura, and S. Tanaka, Plasma Chem. Plasma Process. 13 (1993) pp. 117-131.

[22]. K. Sugiyama, and O. Akazawa, Plasma Chem. Plasma Process, 6 (1986) pp. 179193.

[23] Y. Zhang, W. Chu, W. Cao, C. Luo, X. Wen, and K. Zhou, Plasma Chem. Plasma Process. 20 (2000) pp. 137-144.

[24] K. Ostrikov, Rev. Mod. Phys. 77 (2005) pp. 489-511.

[25] I. Levchenko, K. Ostrikov, K. Diwan, K. Winkler, D. Mariotti, Appl. Phys. Lett. 93 (2008) pp. 183102.

[26] I. Levchenko, K. Ostrikov, D. Mariotti, Carbon 47 (2008) pp. 344-347.

[27] J. -J. Zou, C. -J. Liu, Y. -P. Zhang, Langmuir 22(5) (2006) pp. 2334-2339.

[28] I. G. Koo, M. S. Lee,J. H. Shim, J. H. Ahn, W. M. Lee, J. Mater.Chem. 15 (2005) pp. $4125-4128$.

[29] N. A. Jarrah, J. G. Van Ommen, L. Lefferts, J. Mater. Chem. 14 (2004) 1590-1597.

[30] M. L. Toebes, J. H. Bitter, A. J. Van Dillen, K. P. de Jong, Catal. Today 76 (2002) $33-42$.

[31] R. T. Baker, P. S. Harris, R. B. Thomas, R. J. Waite, J. Catal. 30 (1973) 86.

[32] S. -H. Wu, D. -H. Chen, J. Colloid Interface Sci. 259 (2) (2003) 282-286.

[33] H. Cui, X. Yang, M. L. Simpson, D. H. Lowndes, M. Varela, Appl. Phys. Lett. 84 (2004) 20.

[34] H. Yang, R. T. K. Naker, J. Phys. Chem. B 108(52) (2004) 20273-20277.

[35] T. Maruyama, T. Tago, J. Mater. Sci. 28 (1993) 5345-5348.

[36] T. Yokoyama, M. Kogoma, T. Moriwaki and S. Okazaki, J. Phys. D: Appl. Phys. 23 (1990) pp. 1125-1128.

[37] S. Kanazawa, M. Kogoma, T. Moriwaki and S. Okazaki, J. Phys. D: Appl. Phys. 21 (1988) pp. 838-840.

[38] M. C. Quintero, A. Rodero, M. C. Garcia, and A. Sola, Applied Spectroscopy 51 (1997) pp. 778-784.

[39] G. Nersisyan, and W. G. Graham, Plasma Sources Sci. Technol. 13 (2004) pp. 582587. 
[40] N. K. Bibinov, A. A. Fateev, and K. Wiesemann, , J. Phys. D: Appl. Phys. 34 (2001) pp. 1819-1826.

[41] N. K. Bibinov, A. A. Fateev, and K. Wiesemann, Plasma Sources Sci. Technol. 10 (2001) pp. 579-588.

[42] J. Jonkers, Excitation and transport in small scale plasmas. $\mathrm{PhD}$ thesis, Eindhoven University of Technology, Eindhoven, 1998.

[43] I. E. Kieft, E. P. Van Der Laan, and E. Stoffels, New J. Phys. 6 (2004), pp.149-162.

[44] J. Jonkers, and J. A. M. Van der Mullen, J. Quant. Spectrosc. Radiat. Transfer 61 (1999) pp. 703-709.

[45] S. Pellerin, J. M. Cormier, F. Richard, K. Musiol, and J. Chapelle, J. Phys. D: Appl. Phys. 29 (1996) pp. 726-739.

[46] A. Czernichowski, J. Phys. D: Appl. Phys. 20 (1987) pp. 559-564.

[47] J. Luque, and D. R. Crosley - SRI International Report MP, 1999.

[48] R. T. K. Baker, M. A. Barber, R. J. Waite, P. S. Harris, and F. S. Feates, J. Catal. 26 (1972) pp. 51-62.

[49] R. T. K. Baker, Carbon 27 (1989), pp. 315-323.

[50] G. J. M. Hagelaar, L. C. Pitchford, Plasma Sources Sci. Technol. 14 (2005) pp. $722-$ 733.

[51] SIGLO Homepage, URL www.siglo-kinema.com/bolsig.htm. 


\section{Chapter 7}

\section{Charge injection from nanostructures at atmospheric pressure and on-chip microplasma reactors with integrated nanoelectrodes}

In the first part of this chapter, synthesis, characterization and atmospheric pressure field emission operation of tungsten oxide $\mathrm{W}_{18} \mathrm{O}_{49}$ nanorods will be discussed. Nanorods with diameters of 15-20 nm were grown on tungsten thin films exposed to ethene and nitrogen at $700^{\circ} \mathrm{C}$ at atmospheric pressure. Atmospheric pressure field emission measurements in air showed a turn-on field of $3.3 \mathrm{~V} / \mu \mathrm{m}$, and a stable and reproducible emission current density of $28 \mathrm{~mA} / \mathrm{cm}^{2}$. In the second part, carbon nanofibers (CNFs) and tungsten oxide nanorods have been incorporated in a continuous flow microplasma reactor to increase the reactivity and efficiency of the barrier discharge at atmospheric pressure. Field emission of electrons from the nanostructures supplies free electrons and ions during microplasma production. In comparison with planar electrodes in air at the same applied voltage, for the nanostructured electrodes a reduction in breakdown voltage, a higher number of microdischarges and a higher energy deposition were observed. It was also shown that compared to planar electrodes, $\mathrm{CO}_{2}$ consumption increased with CNFs in the microplasma reactor.

Portions of this chapter were published in:

On chip microplasma reactors using tungsten oxide nanowires and carbon nanofibers as electrodes, ANIL AGIRAL, ALFONS W. GROENLAND, J. KUMAR CHINTHAGINJALA, K. SESHAN, LEON LEFFERTS, J. G. E. (HAN) GARDENIERS, Journal of Physics D: Applied Physics, volume 41, page 194009 (2008).

Synthesis and atmospheric pressure field emission operation of $\mathrm{W}_{18} \mathrm{O}_{49}$ nanowires, ANIL AGIRAL, J. G. E. (HAN) GARDENIERS, Journal of Physical Chemistry C, volume 112(39), page 15183-15189 (2008).

(Book Chapter) On-chip tungsten oxide nanowire based electrodes for charge injection, ANIL AGIRAL, J. G. E. (HAN) GARDENIERS, will appear in "Nanowires" by IN-TECH Publishing, Vienna, Austria, January 2010, ISBN 978-9537619-X-X. 


\section{Introduction}

Transition metal oxides have been intensively investigated over the years, due to their potential applications in nanoelectronics, optoelectronics and sensor devices $[1,2]$, and recently nanostructured transition metal oxides have also received great interest [3]. Among the transition metal oxide nanostructures, tungsten oxide nanorods show good sensing and outstanding field emission (FE) properties with stable and high emission current density due to large aspect ratio, low turn-on field and stability in low vacuums of $10^{-6}-10^{-3}$ Torr $[4,5]$. Several researchers have synthesized highly crystalline tungsten oxide nanorods by heating tungsten filaments [6], foils or films in vacuum at temperatures above $1000^{\circ} \mathrm{C}[7,8]$. However, to the best of our knowledge there are no reports on the direct synthesis of tungsten oxide nanorods on tungsten thin films at atmospheric pressure and temperatures as low as $700^{\circ} \mathrm{C}$. Although $\mathrm{FE}$ properties of tungsten oxide nanorods have been reported, there are no studies on atmospheric pressure FE performance. In the first part of this chapter, the high-yield synthesis of uniform and crystalline $\mathrm{W}_{18} \mathrm{O}_{49}$ on tungsten films by thermal annealing in ethene and nitrogen will be described. The growth mechanism and atmospheric pressure FE properties of tungsten oxide nanorods are discussed.

Miniaturized plasma sources have generated considerable interest recently, owing to a number of important applications [9]. Performing the plasma process in a microreactor leads to precise control of residence time and extreme quenching conditions, enabling control over the reactants to selectively produce desirable products [10].

Carbon nanofibers and $\mathrm{W}_{18} \mathrm{O}_{49}$ nanorods have remarkable field emission characteristics $[11,12]$. Due to the high aspect ratio, local field enhancement at the apex of nanoscale tip lowers the threshold voltage for field emission and field ionization. Field electron emission and field ionization can supply free electrons and ions which can contribute to a pre-breakdown current during the initiation of a discharge. Multiplication of electrons in a series of impact ionizations can lower the breakdown voltage in microplasma devices. Eden et al. [13] demonstrated that incorporation of multiwall carbon nanotubes (CNTs) into the cathode reduces the ignition voltage and increases the radiative efficiency. From plasma catalysis point of view, field emitted electrons can vibrationally excite molecules near a surface and lower the activation energy for dissociative adsorption [14].

In the second part of the chapter, the incorporation of carbon nanofibers (CNFs) and $\mathrm{W}_{18} \mathrm{O}_{49}$ nanorods on a silicon chip electrode which is placed in a glass microreactor 
channel will be described. The characteristics of dielectric barrier discharge with $\mathrm{W}_{18} \mathrm{O}_{49}$ nanowires and $\mathrm{CO}_{2}$ conversion with CNFs will be discussed and compared with plane-toplane electrodes without nanostructures.

\section{Experimental}

\section{Synthesis of tungsten oxide nanorods and field emission measurements.}

Tungsten oxide nanorods were grown in a quartz reactor with a glass plate to support ntype Si (100) (1-10 Ohm $\mathrm{cm})$ samples, on which a $300 \mathrm{~nm}$ thick tungsten film was deposited by DC plasma sputtering from a $99.999 \%$ pure tungsten target. The sample was heated to $700^{\circ} \mathrm{C}\left(6^{\circ} \mathrm{C} / \mathrm{min}\right)$ in $\mathrm{N}_{2}(80 \mathrm{sccm})$ at atmospheric pressure and when the temperature of $700^{\circ} \mathrm{C}$ was reached, ethene $(27 \mathrm{sccm})$ was introduced into the chamber for 20 mins while the output gas composition was monitored with on-line gas chromatography (Varian GC model 3700 equipped with a 15m Q-plot column). Finally, the sample was cooled down to room temperature in $\mathrm{N}_{2}$ flow $(80 \mathrm{sccm})$. Hydrogen and nitrogen gases with purity $99.999 \%$ (INDUGAS, The Netherlands) and ethene with purity $99.995 \%$ (Hoek Loos, The Netherlands) were used.

Structural and compositional characterization of the nanorods was carried out by using scanning electron microscopy (SEM) (LEO 1550 FEG) and high resolution transmission electron microscopy (HRTEM) equipped with EDX analysis (Philips CM300ST-FEG microscope). Selected area diffraction (SAD) was also conducted during TEM experiments. X-ray Photoelectron Spectroscopy (XPS) analysis was performed in a PHI Quantera Scanning ESCA Microprobe system.

Atmospheric pressure FE measurements were carried out in a laminar air flow cabinet at room temperature. The FE device fabrication process is illustrated in Fig. 1a, 1b and 1c. Initially, n-type silicon substrates were oxidized to form $\mathrm{SiO}_{2}$ as dielectric spacer and a rectangular window, with an area of $0.7 \mathrm{~cm}^{2}$, was defined by photolithography. After wetetching of $\mathrm{SiO}_{2}$ in $\mathrm{HF}$ solution, a tungsten film was sputtered into the window. Following nanorod growth on the cathode, a silicon substrate with a $10 \mathrm{~nm}$ gold layer as extractor electrode was clamped to the cathode to ensure a $2-\mu \mathrm{m}$ electrode distance in a diode structure. The cross section of the diode structure before nanorod growth is shown in Fig. 1d. Cathode surfaces before and after nanorod growth are shown in Fig. 1e and 1f, respectively. Voltage-current data were obtained with a Keithley 237 source meter unit. 
(a)

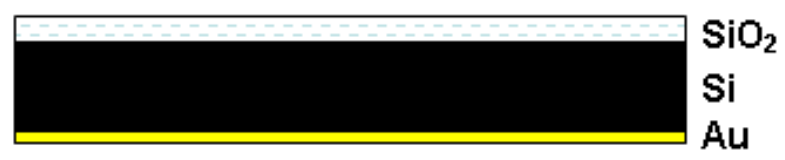

(b)

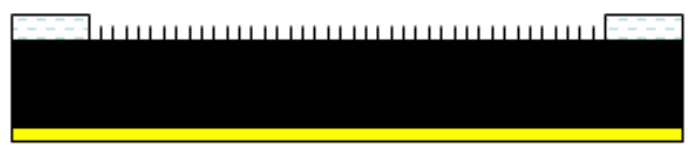

(c)

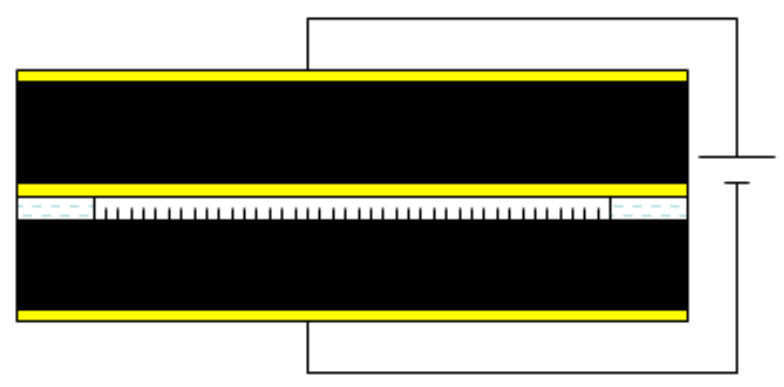

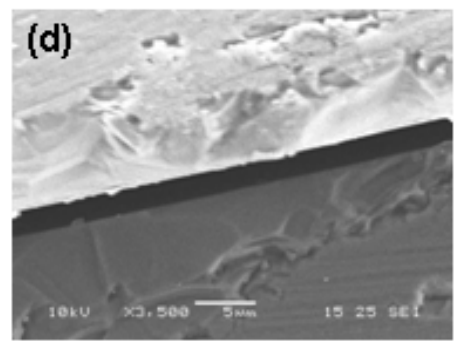

(e)
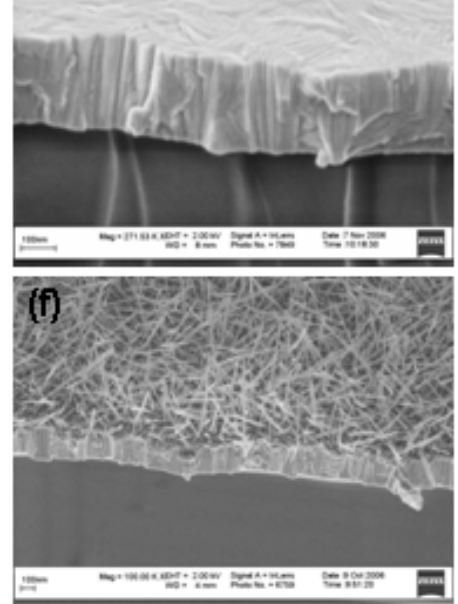

Figure 1. FE device fabrication process (a) oxidation of n-type silicon substrate to form $\mathrm{SiO}_{2}$ substrate and gold deposition for back contact, (b) wet-etching of $\mathrm{SiO}_{2}$ and nanorod growth on tungsten films sputter-deposited in a rectangular window defined by photolithography and (c) clamping of gold-coated anode. SEM pictures show: Cross section of diode structure before nanorod growth (d) and cathode surfaces before (e) and after (f) nanorod growth.

\section{Incorporation of nanostructures into microplasma reactor.}

For CNFs, standard (100) n-type silicon wafers were cleaned in fuming $\mathrm{HNO}_{3}$ to remove organic and inorganic contamination. Wafers were patterned in a standard lithography process finishing with $20 \mathrm{~min} 120^{\circ} \mathrm{C}$ post bake. $10 \mathrm{~nm}$ nickel catalyst on $10 \mathrm{~nm}$ tantalum barrier layers were deposited by electron beam evaporation. Excess metal was removed by lift-off in acetone, enhanced by ultrasonic agitation. Samples with regular arrays of metal dots with 4 $\mu \mathrm{m}$ in diameter were fabricated. For $\mathrm{W}_{18} \mathrm{O}_{49}$ nanorods, $250 \mathrm{~nm}$ titanium-tungsten alloy and 50 $\mathrm{nm}$ tungsten metal layers were deposited by plasma sputtering. Silicon chips with $\mathrm{Ni}$ and $\mathrm{W}$ layers were placed in a chemical vapor deposition (CVD) setup. Tungsten oxide nanorods and CNFs were grown on tungsten and nickel thin films respectively, which were exposed to 27 sccm of $\mathrm{C}_{2} \mathrm{H}_{4}$ and $80 \mathrm{sccm}$ of $\mathrm{N}_{2}$ at $700^{\circ} \mathrm{C}$ at atmospheric pressure for 20 minutes. 
The resulting silicon chips were placed in glass microreactors with a rectangular cross section of $50 \mathrm{~mm}$ in length and $20 \mathrm{~mm}$ in width. Microchannels, inlet and outlet holes for gas flow were created by powder blasting and the glass layers were thermally bonded to seal the microchannel hermetically. Silicon chips before (light gray) and after (black) CVD process are shown in Fig. 2a, a picture of the complete device and a schematic representation of it are shown in Fig. 2b and Fig. 2c, respectively.
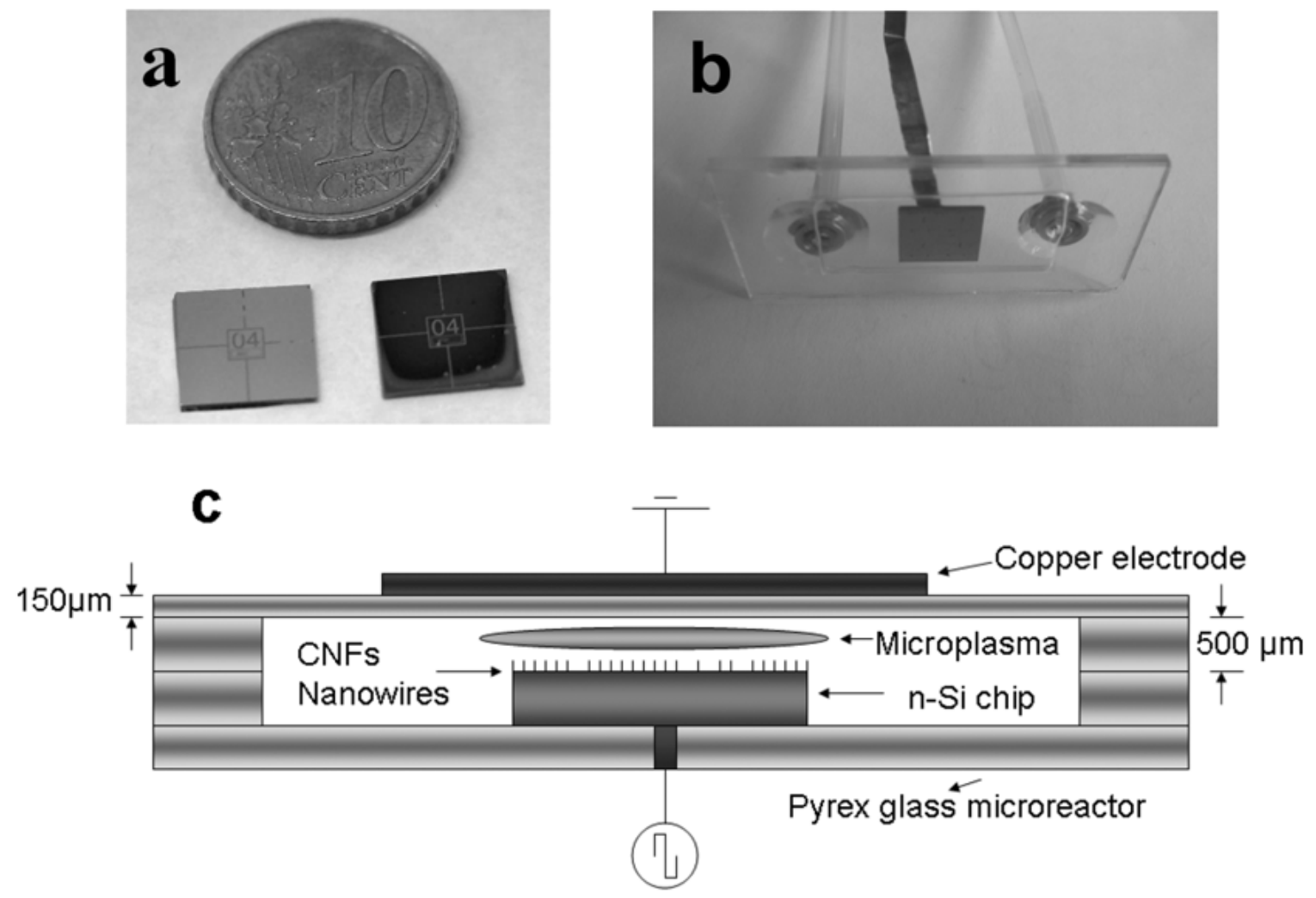

Figure 2. (a) Silicon chip before and after CVD process, (b) microplasma reactor, (c) general diagram of the device.

A combination of a high voltage amplifier (Trek 610E) and a function generator (Agilent 3322A) was used to generate a barrier discharge at $1 \mathrm{kHz}$ in the microplasma reactor. The voltage drops across a resistor and a capacitor connected in series with the reactor electrodes were used to calculate the transferred current and charge, respectively. Light emitted from the barrier discharge was collected by inserting an optical fiber into the microchannel and connecting it to an optical emission spectrometer (HR 4000, Ocean Optics). The power absorbed by the plasma was evaluated on the basis of Lissajous figures measured with an oscilloscope. 


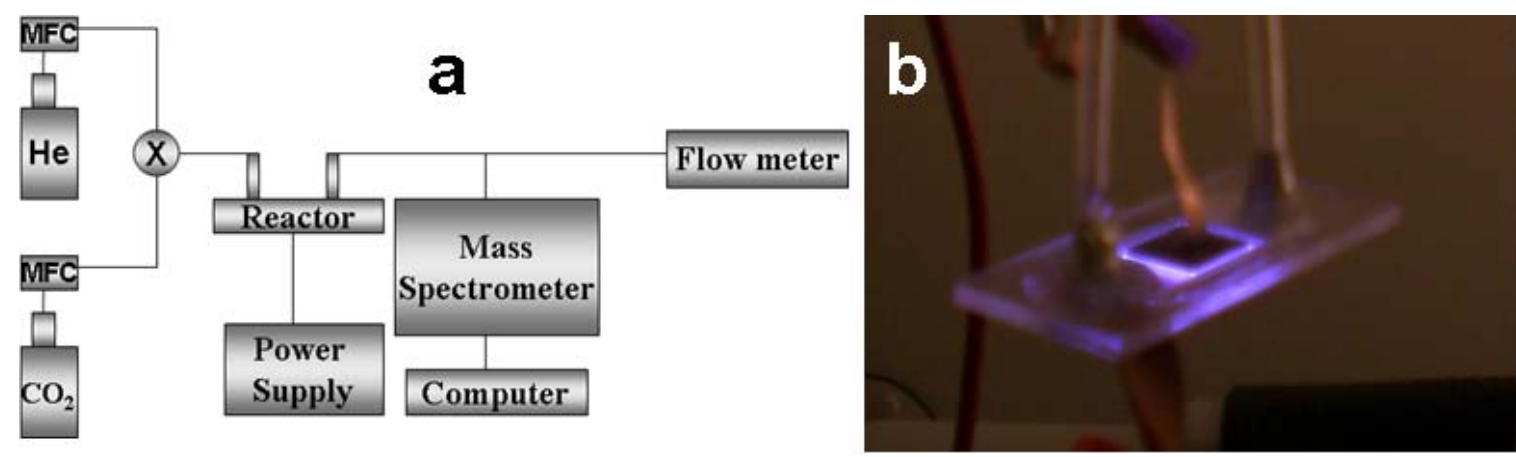

Figure 3. (a) Experimental apparatus for testing $\mathrm{CO}_{2}$ conversion in a microplasma reactor with a CNF array as electrode; (b) microplasma reactor during operation.

The experimental apparatus for testing $\mathrm{CO}_{2}$ decomposition to $\mathrm{CO}$ and $\mathrm{O}_{2}$ using CNFs as electrodes, and the microplasma reactor in operation, are shown in Fig. 3a and 3 b, respectively. Gas flow was controlled by mass flow controllers. $\mathrm{CO}_{2}$ flows through the inlet of the microreactor and is processed in the barrier discharge region between the silicon chip with nanostructures and the glass dielectric. A quadrupole ion-trap mass spectrometer (Pfeiffer QMS 422) with residual gas analyzer was used for gas analysis. Helium gas with a known flow rate was mixed with $\mathrm{CO}_{2}$ before introduction into the reactor. The mole fractions of the different gases were measured with the calibrated mass spectrometer. Conversion of $\mathrm{CO}_{2}$ was calculated on the basis of the known He flow rate $\mathrm{He}$ and the mole fraction of unreacted $\mathrm{CO}_{2}$.

\section{Results and discussion}

Synthesis and atmospheric pressure field emission operation of $\mathrm{W}_{18} \mathrm{O}_{49}$ nanowires

Synthesis and characterization of $\mathrm{W}_{18} \mathrm{O}_{49}$ nanorods. Fig. 4a shows a SEM image of tungsten oxide nanorods which were grown on tungsten thin films exposed to 27 sccm of $\mathrm{C}_{2} \mathrm{H}_{4}$ and $80 \mathrm{sccm}$ of $\mathrm{N}_{2}$ at $700^{\circ} \mathrm{C}$ at atmospheric pressure. The straight rods were grown uniformly and with high yield on the thin film, and have diameters and average length in the range of $15-20 \mathrm{~nm}$ and 50-250 $\mathrm{nm}$, respectively. 

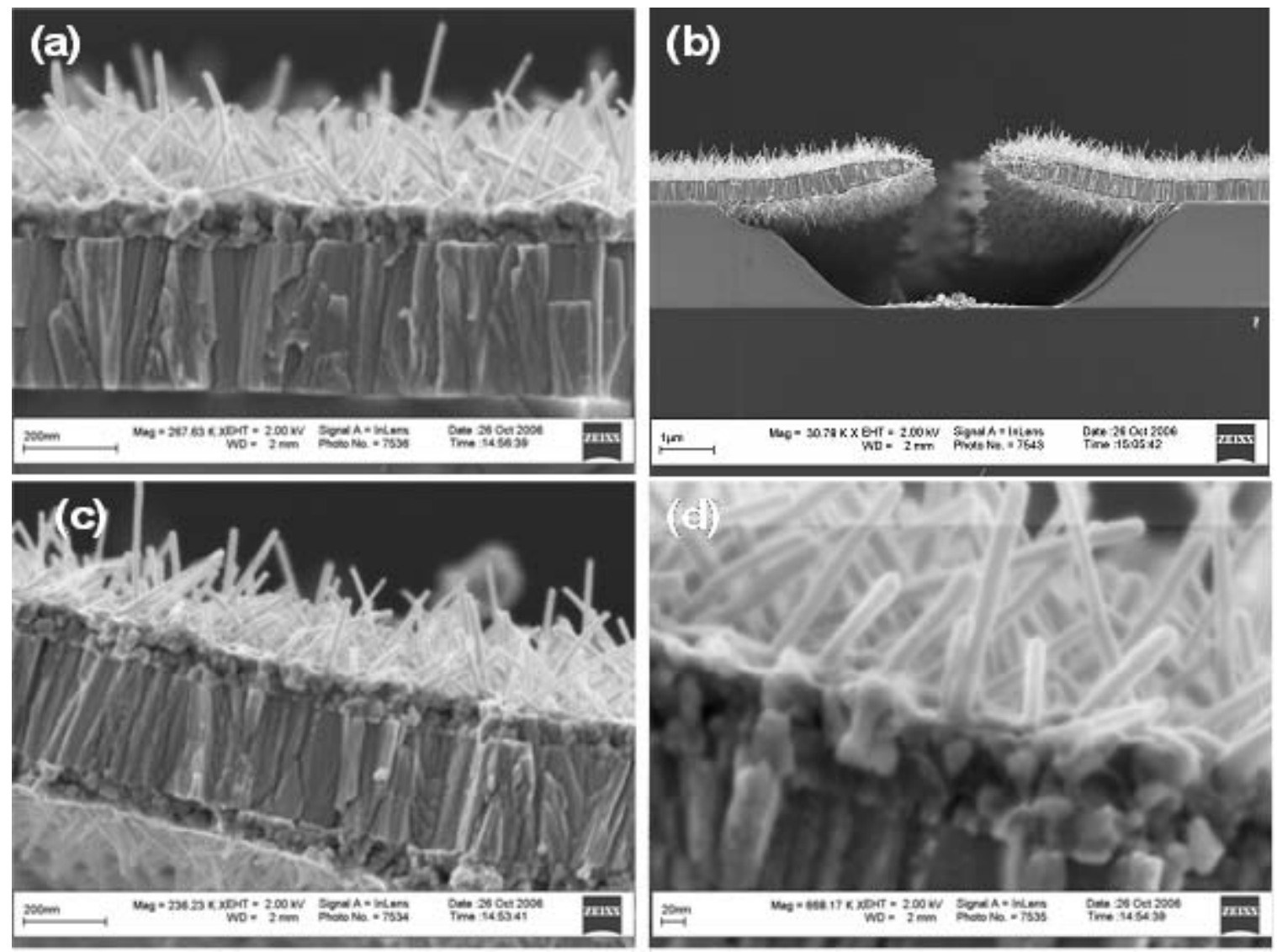

Figure 4. Cross section SEM image of tungsten oxide nanorods grown on tungsten thin films exposed to $27 \mathrm{sccm}$ of $\mathrm{C}_{2} \mathrm{H}_{4}$ and $80 \mathrm{sccm}$ of $\mathrm{N}_{2}$ at $700^{\circ} \mathrm{C}$ at atmospheric pressure (a), nanorod growth on both sides of freestanding thin films (b), high magnification images of nanorod growth (c) and (d).

To further illuminate the microstructure of as-deposited films, nanorods were grown on both sides of freestanding thin films as shown in Fig. 4b. High-magnification SEM images showed that the film has parallel ridges, which is a characteristic feature of sputtered tungsten films [15], covered with a dense nodular nanostructure at the tungsten/nanorod interface with a thickness of $40 \mathrm{~nm}$ (Fig. $4 \mathrm{~b}$ and $4 \mathrm{c}$ ). X-ray diffraction analysis on the bulk sample revealed characteristic peaks for $\mathrm{WO}_{3-\mathrm{x}}, \alpha-\mathrm{W}_{2} \mathrm{C}, \beta-\mathrm{W}, \alpha-\mathrm{W}$ and Si. Since $\mathrm{WO}_{3}$ and $\mathrm{W}_{18} \mathrm{O}_{49}$ exhibit similar peaks which are difficult to distinguish, SAD and HRTEM techniques were used to determine chemical structure and composition. From the HRTEM image in Fig. 5a it can be derived that the d-spacing along the long side of the nanorod is $3.78 \AA$, which is in agreement with the SAD analysis (Fig. 5b) and corresponds to the (010) plane of monoclinic $\mathrm{W}_{18} \mathrm{O}_{49}$ 

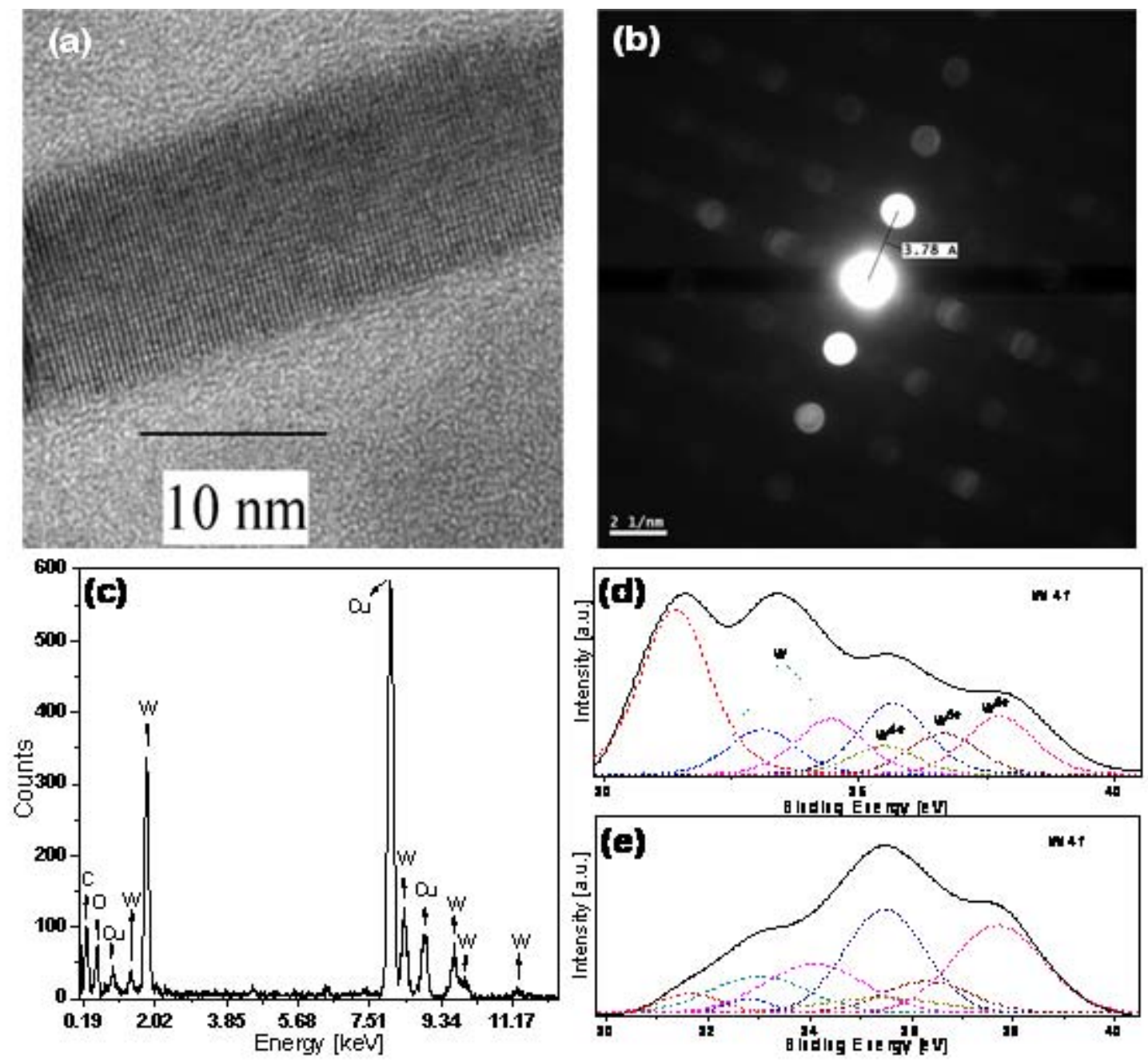

Figure 5. HRTEM image of $\mathrm{W}_{18} \mathrm{O}_{49}$ nanorods (a), $\mathrm{SAD}$ pattern corresponding to (010) plane of monoclinic $\mathrm{W}_{18} \mathrm{O}_{49}$ with d-spacing $3.78 \AA(\mathrm{b})$, EDX analysis performed on central part of nanorods (c), deconvoluted XPS spectra of tungsten film (d) and nanorod sample (e).

(JCPDS no. 36-0101). [010] is the growth direction of the nanorod due to close-packed planes of (010) of monoclinic $\mathrm{W}_{18} \mathrm{O}_{49}\left(\mathrm{WO}_{2.72}\right)$. EDX analysis performed on the central part of the area of nanorods in Fig. 5c confirmed that oxygen is in the order of 2.73 times the amount of tungsten, as evidence in addition to the findings HRTEM and SAD measurements. The derived carbon and copper concentrations are high, due to the underlying carbon-supported copper grid, and cannot be used as a measure for the composition of the film. To determine the structure of the interfacial phase between the nanorods and deposited film (Fig. $4 \mathrm{c}$ and $4 \mathrm{~d}$ ), we removed that phase and analyzed the 
diffraction pattern by SAD (not shown). Observation of the d-spacings $2.36 \AA$ and $1.36 \AA$ corresponds to the phases $\alpha-\mathrm{W}_{2} \mathrm{C}(002)$ and $\alpha-\mathrm{W}_{2} \mathrm{C}(103)$, respectively [16].

XPS was used to investigate the chemical bonding states on the surface of the tungsten thin film and the nanorods, the results are shown in Fig. 5d and 5e, respectively. In Fig. 5d, W 4f spectra were deconvoluted into Lorentzian-Gaussian peaks (dashed

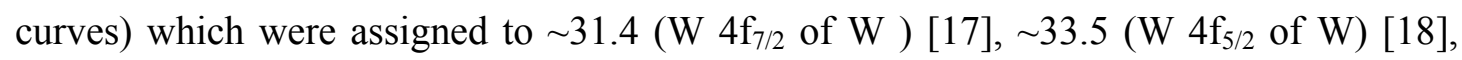

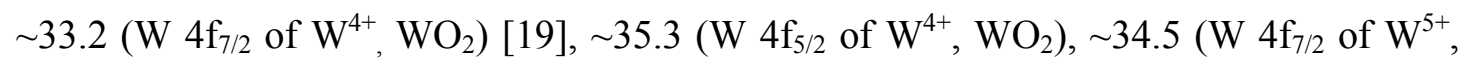
$\mathrm{WO}_{\mathrm{x}}$ ) [20], $\sim 36.6\left(\mathrm{~W} 4 \mathrm{f}_{5 / 2}\right.$ of $\left.\mathrm{W}^{5+}, \mathrm{WO}_{\mathrm{x}}\right), \sim 35.7\left(\mathrm{~W}_{4} \mathrm{f}_{7 / 2}\right.$ of $\left.\mathrm{W}^{6+}, \mathrm{WO}_{3}\right)[21], \sim 37.8(\mathrm{~W}$ $4 \mathrm{f}_{5 / 2}$ of $\left.\mathrm{W}^{6+}, \mathrm{WO}_{3}\right)$. After nanorod growth, the intensity ratio of binding states of oxidized tungsten to metallic tungsten increased, which is consistent with $\mathrm{W}_{18} \mathrm{O}_{49}$ formation (Fig. 5e). A low intense peak at about $31.7 \mathrm{eV}$ was attributed to tungsten carbide $\mathrm{W} 4 \mathrm{f}_{7 / 2}$ (Fig. 5e) which is possibly bound in the nanorod/film interface [22].

Oxygen on the tungsten thin film comes from the native oxide layer that was formed when the sample was exposed to air. Molecular oxygen in the air can dissociatively chemisorb with oxygen atoms at triply-coordinated sites [23]. To determine the effect of chemisorbed oxygen present on the tungsten surface, hydrogen was introduced at $700^{\circ} \mathrm{C}$ for $20 \mathrm{~min}$ before nanorod growth, to reduce the surface. After ethene exposure, a dramatic decrease in the number of nanorods was observed. These observations support that tungsten oxide nanorod growth results from the oxygen on the surface. To further clarify tungsten carbide phase formation during nanorod synthesis at the surface of the tungsten film, ethene conversion was determined with on-line chromatography. The carbon deposition rate was calculated from the production rate of hydrogen, which was the only product in the gas phase, Eq. (1). Table 1 shows the time evolution of hydrogen, ethene and calculated carbon deposition based on the reaction which occurs on the tungsten surface:

$$
\mathrm{C}_{2} \mathrm{H}_{4(\mathrm{~g})} \leftrightarrow 2 \mathrm{C}_{(\mathrm{s})}+2 \mathrm{H}_{2(\mathrm{~g})}
$$

The conversion of ethene was almost constant and around $5 \%$. Most likely a solid-state reaction took place between tungsten and deposited carbon, to form a tungsten carbide phase during nanorod growth:

$$
2 \mathrm{~W}_{(\mathrm{s})}+\mathrm{C}_{(\mathrm{s})} \leftrightarrow \mathrm{W}_{2} \mathrm{C}_{(\mathrm{s})}
$$


We have examined the role of the tungsten carbide phase for nanorod formation with an experiment in which only nitrogen gas was introduced, at $700^{\circ} \mathrm{C}$ for 20 min with a flow rate of $80 \mathrm{sccm}$. Some nanorods were observed; however, it turned out that without ethene gas the nanorods only grow with very low yield. Since tungsten carbide was not incorporated in the nanorods, it is assumed that it promoted their nucleation and growth. Wang et al. [24]

Table 1. Hydrogen evolution and carbon deposition during nanorod growth

Time (min) $\mathrm{H}_{2}(\mathrm{mmol} / \mathrm{min}) \mathrm{C}_{2} \mathrm{H}_{4}(\mathrm{mmol} / \mathrm{min}) \mathrm{C}(\mathrm{mmol} / \mathrm{min})$

\begin{tabular}{llll}
\hline 4 & 0.27 & 1.27 & 0.27 \\
8 & 0.27 & 1.27 & 0.27 \\
12 & 0.26 & 1.26 & 0.26 \\
16 & 0.26 & 1.26 & 0.26 \\
20 & 0.26 & 1.25 & 0.26 \\
\hline
\end{tabular}

prepared tungsten oxide nanowires from sputter-deposited $\mathrm{WC}_{\mathrm{x}}$ films using an annealing/oxidation process. They observed conversion from $\mathrm{W}_{2} \mathrm{C}$ to $\mathrm{W}_{18} \mathrm{O}_{49}$ nanowires with a chemical reaction of tungsten and oxygen inside the nanorods during the oxidation process, due to a Vapor-Solid (VS) growth mechanism. Tungsten oxide was formed due to an oxidation process with oxygen. In our case, a VS growth mechanism cannot be an explanation since nanorods were formed with most of the oxygen on the tungsten surface. The Vapor-Liquid-Solid (VLS) growth model also could not be applied since there were no nanoparticles at the end of the tungsten oxide nanorods [25]. Chen et al. [26] reported on the formation of crystalline $\mathrm{WO}_{3}$ nanowires at $650^{\circ} \mathrm{C}$ using thermal annealing of tungsten plates in a acetylene and nitrogen atmosphere at 5 Torr pressure. Their findings did not reveal any presence of tungsten carbide; however, they proposed a nucleation mechanism based on the diffusion of carbon at grain boundaries which create lattice faults acting as dislocation sources for nanowire growth. A similar enhancement of nucleation of crystalline $\mathrm{WO}_{3}$ nanowires was also observed by Klinke et al. when the oxidized tungsten films were exposed to hydrogen and methane at $900^{\circ} \mathrm{C}$ [27]. Their results 
showed that tungsten carbide formed at the $\mathrm{W} / \mathrm{WO}_{3}$ interface enhances the strain which drives whisker formation. They claimed that hydrogen pretreatment increased the yield by enhancing oxygen diffusion. In our case, hydrogen pretreatment reduced the tungsten oxide surface area, which decreased the yield. However, in-situ production of hydrogen during ethene decomposition on the surface can contribute to enhance oxygen diffusion especially through the grain boundaries. $\mathrm{W}_{18} \mathrm{O}_{49}$ nanorods can grow on dislocation sources probably originating from the defects along the grain boundaries. Tungsten carbide formation may create an interfacial strain which enhances $\mathrm{W}_{18} \mathrm{O}_{49}$ nanorod growth.

\section{Atmospheric pressure field emission measurements of $\mathrm{W}_{18} \mathrm{O}_{49}$ nanorods}

Atmospheric pressure FE properties of tungsten oxide nanorods measured in air for a contact gap close to $2 \mu \mathrm{m}$ are illustrated in Fig. 6a. The mean free path of an electron in air is approximately $2 \mu \mathrm{m}$ [28], so the probability of ionization from collisions of gas particles with FE electrons is very limited in this case, but the few collisions which develop positive ions in front of nanorods can increase current density [29]. The macroscopic current density $J_{M}\left(\mathrm{~mA} / \mathrm{cm}^{2}\right)$ was estimated to be the emission current $(I)$ divided by the surface area of the diode window ( $A_{M}=$ macroscopic film area) on the cathode $\left(0.7 \mathrm{~cm}^{2}\right)$. The macroscopic electric field $F_{M}(\mathrm{~V} / \mu \mathrm{m})$ was defined as the applied voltage divided by the gap $(\sim 2 \mu \mathrm{m})$ between the cathode and the gold coated anode. To remove the contamination and adsorbate layer on the nanorod surface, a constant bias of $10 \mathrm{~V} / \mu \mathrm{m}$ for $5 \mathrm{~min}$ was applied continuously before measurements. The FE turn-on field was defined as the electric field required to extract a current density of $10 \mu \mathrm{A} / \mathrm{cm}^{2}$. This field is ca. $3.3 \mathrm{~V} / \mu \mathrm{m}$. The $J_{M}-F_{M}$ plotted in Fig. 6a shows the FE diode characteristics for 3 consecutive sweeps (plots $a-b-c)$ of negative cathode voltage. The exponential dependence of current density on electric field suggests a FE process. A similar experiment performed using a parallel plate diode structure (tungsten surface as cathode) without nanorods did not show rectification behavior (plot d). 

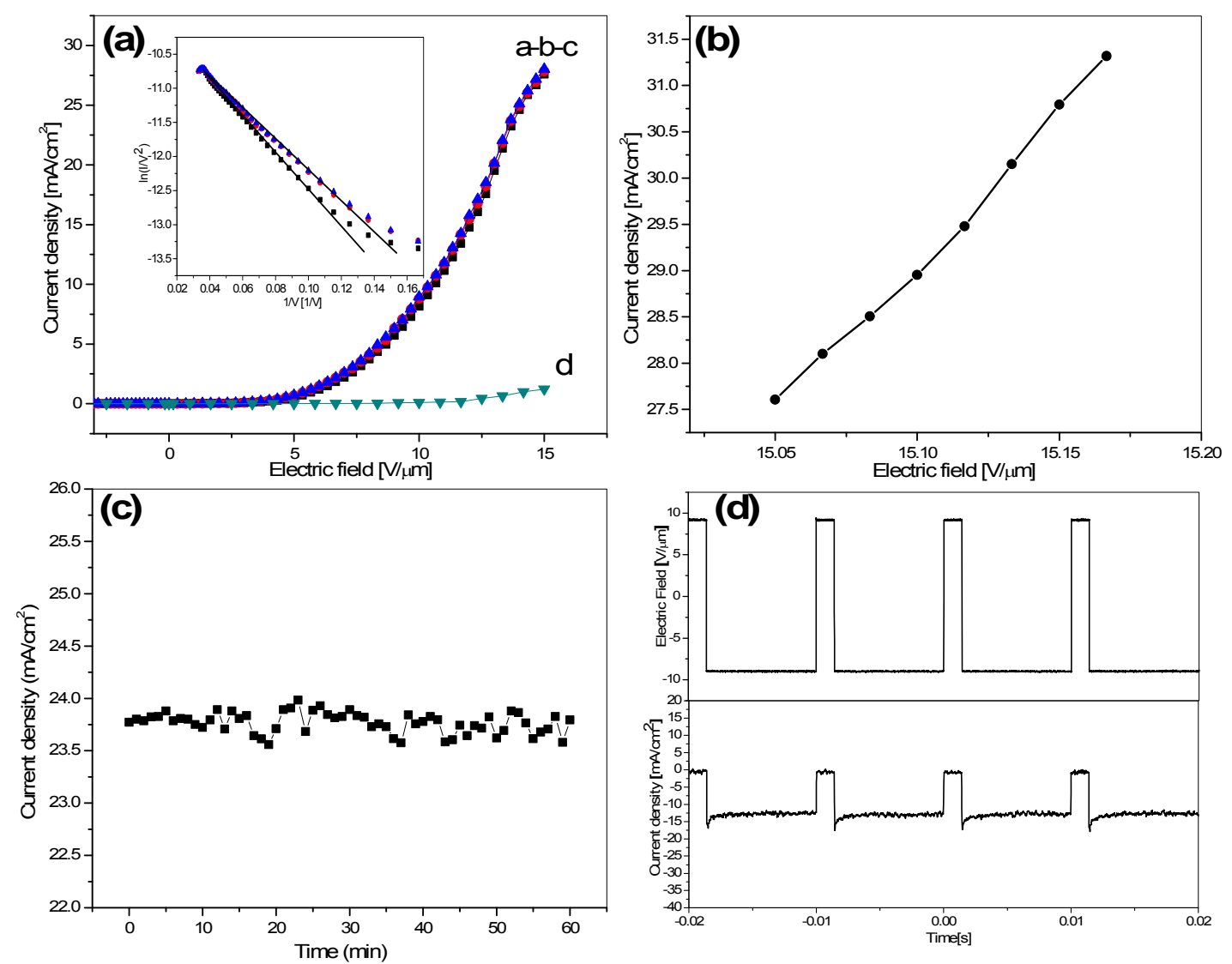

Figure 6. Atmospheric pressure FE properties of tungsten oxide nanorods measured in air for a contact gap $\sim 2 \mu \mathrm{m}$. In (a) the macroscopic current density vs. macroscopic electric field $\left(J_{M}-F_{M}\right)$ plots a-b-c correspond to 3 consecutive sweeps of negative cathode voltage with nanorods, while plot $d$ shows the results of a parallel-plate diode without nanorods (insets are the corresponding Fowler Nordheim plots); (b) $J_{M}-F_{M}$ plots at high electric field in space charge region before breakdown at $15.2 \mathrm{~V} / \mu \mathrm{m}$; (c) emission stability of the nanorods at $13.6 \mathrm{~V} / \mu \mathrm{m}$ over $1 \mathrm{hr}$; (d) pulsed electron emission when $100 \mathrm{~Hz}$ square wave voltage was applied.

The emission characteristics were analyzed by standard Fowler-Nordheim (FN) tunneling theory using the current-density equation [30]:

$$
J=\left[\tau_{F}^{-2} a \varphi^{-1} F^{2}\right] \exp \left[-v_{F} b \varphi^{3 / 2} / F\right]
$$

where the 'first Fowler-Nordheim constant' $a=e^{3} / 8 \pi h_{p}=1.541434 \times 10^{-6} \mathrm{AeVV}^{-2}$, 'second Fowler-Nordheim constant' $b=(8 \pi / 3)\left(2 m_{e}\right)^{1 / 2} / e h_{p}=6.830890 \times 10^{9} \mathrm{eV}^{-3 / 2} \mathrm{Vm}^{-1}, e$ is the elementary positive charge, $m_{e}$ is the electron mass, $h_{p}$ is Planck's constant, $J$ is 
local current density, $F$ is local field, $\varphi$ is local work function of emitting surface, $\tau_{F}$ and $v_{F}$ are the values of $\tau$ (decay rate correction factor) and $v$ (tunneling exponent correction factor) which apply to a barrier of unreduced height $h$ equal to the local work function $\varphi$. For the elementary triangular barrier, the correction factors $v$ and $\tau$ are set equal to unity. Assuming that the local work function is uniform, the emission current $I$ can be written as $I=A_{N} J$, where $\mathrm{A}_{\mathrm{N}}$ is notional emission area. This gives:

$$
I=A_{N} J=A_{N} \tau_{F}^{-2} a \varphi^{-1} F^{2} \exp \left[-v_{F} b \varphi^{3 / 2} / F\right]
$$

Geometric field enhancement may lead to the local field $F$ to be greater than $F_{M}$ by a factor $(\gamma)$ which is called the field enhancement factor:

$$
\gamma=F / F_{M}
$$

In the literature, FN plots from tungsten oxide nanowires are analyzed using FN theory for metals [20, 31]. FN plot analysis has been discussed in detail by Forbes et al. $[32,33]$. If the macroscopic electric field $F_{M}$ is used as FN variable in Eq. (4) to replace F, the formula can be written as:

$$
\ln \left[I / F_{M}^{2}\right]=\ln \left[A_{N} \tau_{F}^{-2} a \varphi^{-1} \gamma^{2}\right]-\left[v_{F} b \varphi^{3 / 2} / \gamma\right] / F_{M}
$$

The theoretical model for a FN plot is the tangent to Eq. (6), taken at some appropriate value $\mathrm{F}_{\mathrm{M} 1}$ of macroscopic field [33]:

$$
\ln \left[I / F_{M}^{2}\right]=\ln \left[A_{N} r_{l} a \varphi^{-1} \gamma^{2}\right]-\left[s_{1} b \varphi^{3 / 2} / \gamma\right] / F_{M}
$$

where $r_{l}$ and $s_{l}$ are the generalized intercept correction factor and the generalized slope correction factor, respectively, taken at field $\mathrm{F}_{\mathrm{M} 1}$ [32]. $s_{1}$ is close to 1 and therefore omitted in the interpretation of the slope of the FN plot, which then becomes equal to $b \varphi^{3 / 2} / \gamma$. Tungsten oxide is an n-type semiconductor. The FE theory for semiconductors is complex, since the emission can take place from one or more bands. A detailed discussion has been given elsewhere [33]. Assuming that the emission current comes predominantly from one band, and $\varphi$ is $5.7 \mathrm{eV}$, which is similar to $\mathrm{WO}_{3}$ [5], the field enhancement factor found from the FN plot is 7228 . 
Estimation of the apex field-enhancement factor $\gamma$ of a protrusion on a flat planar surface has been described with 'hemisphere on a post' and 'hemi-ellipsoid on a plane' models [34]. Both these geometrical models are applicable to tungsten oxide nanorods, considering their geometry. The 'hemisphere on a post' model gives the simple formula:

$$
\gamma=0.7(L / \rho)
$$

where $L$ and $\rho$ are protrusion length and base radius, respectively. In the 'hemi-ellipsoid on a plane' model $\gamma$ can be written as:

$$
\gamma=\zeta^{3} /[(v \ln (v+\zeta))-\zeta]
$$

where $L$ is the semi-major axis length, $\rho$ is the semi-minor axis length, $v(=L / \rho)$ is the ratio of $L$ to $\rho$ and $\zeta$ equals $\left(v^{2}-1\right)^{1 / 2}$. According to both formulae, $\gamma$ increases with increasing length and decreasing base radius of the protrusions. Therefore, it is reasonable to state that there is a high probability that FE takes place from longer and smaller diameter tungsten oxide nanorods. If the formula of the 'hemisphere on a post' model for a nanorod of $15 \mathrm{~nm}$ diameter and $250 \mathrm{~nm}$ length is used, $\gamma$ is calculated to be around 23 which is far below the experimental field enhancement factor. However, SEM and HRTEM analysis revealed that there are few nanorods on the sample with length and diameter of $\sim 1 \mu \mathrm{m}$ and $\sim 12 \mathrm{~nm}$, respectively. Applying the 'hemi-ellipsoid on a plane' formula, $\gamma$ can be calculated to be 5776, which is of the order of the experimental value. A small part of the sample surface may have protruding nanorods with longer length and smaller diameter than the average dimensions, but there may also be other reasons for the deviating estimation of $\gamma$. For example, at atmospheric pressure in air adsorption and desorption of molecules on the emitter surface can change $\varphi$ dynamically and activation of new emission sites on the most prominent points of nanorods can result in different slopes in FN plots as observed in the inset of Fig. 6a. The underlying surface may enhance the macroscopic field in the case of non-flat surfaces. The tungsten carbide phase formed dislocation climbs which can change the flatness of the interface, or there may be atomic-scale roughness on top of the nanorods, which all makes the models mentioned above less accurate.

At high electric fields $(>13 \mathrm{~V} / \mu \mathrm{m}), J_{M}$ diverged from the Fowler-Nordheim equation. Fig. $6 \mathrm{~b}$ shows the $J_{M}-F_{M}$ plot in the region where saturation affects were observed and eventually breakdown occurred around $15.2 \mathrm{~V} / \mu \mathrm{m}$. We also measured the 
emission stability of the nanorods at $13.6 \mathrm{~V} / \mu \mathrm{m}$ (Fig. 6c), but no significant degradation in emission current was observed over 1 hour of operation. Current fluctuations can be due to surface chemical interactions with adsorbents which can affect the tunneling state of nanorods or residual ions impacting on the surface. To demonstrate the viability of tungsten oxide nanorods as a pulsed electron source, a $100 \mathrm{~Hz}$ square wave voltage was applied to the cathode and pulsed electron emission with good repetition rate was observed (Fig. 6d).
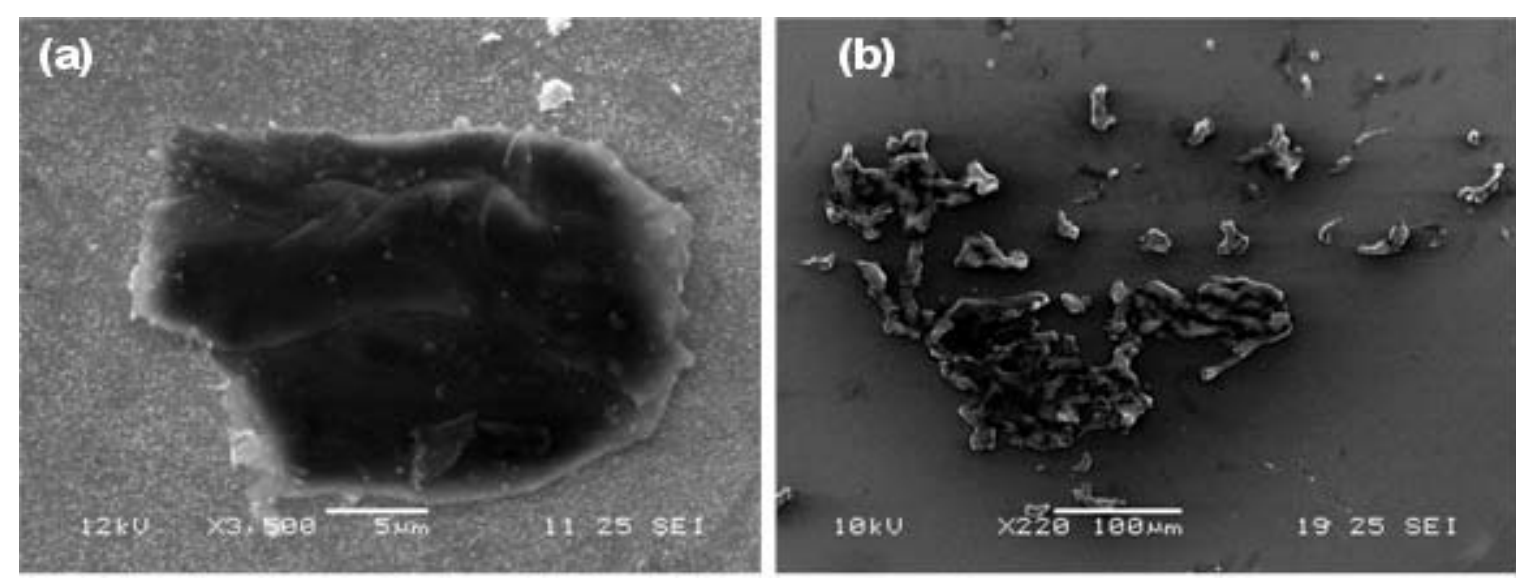

Figure 7. Crater formation on the surface of cathode (a) and melted film traces on anode surface (b) observed after breakdown.

When the $F_{M}$ reaches the value of $15.2 \mathrm{~V} / \mu \mathrm{m}$, breakdown occurred. The presence of craters on the cathode surface (Fig. 7a) and melted film traces on the anode surface (Fig. 7b) are suggestive of an explosive FE process, as it is also typically observed in the breakdown of contact gaps in vacuum [35]. Explosion of emitters can take place under overloading with high density FE currents [36]. Resistive heating and the Nottingham mechanism might have produced the increased temperature accompanying the emission process [37]. The Nottingham effect arises when the temperature inside the emitters increases faster than that of the surface, due to the energy difference between emitted electrons and their replacement in the lattice through the electrical circuit. Under these conditions, temperature rises to a critical level and a phase transition of the cathode into a dense plasma and loss of cathode material is observed. The presence of "frozen" droplets of cathode material on the anode surface (Fig. 7b) may be an indication of an explosive emission mechanism [38]. However, there are also other possible explanations for the observed effects [39]. 
On-chip microplasma reactors using carbon nanofibers and tungsten oxide nanowires as electrodes

Characterization of CNFs and tungsten oxide nanorods Fig. 8a shows arrays of dots where CNFs are successfully grown on nickel layers with a CVD process. Very dense CNFs were grown with a maximum height of 2-3 $\mu \mathrm{m}$. Higher aspect ratio structures in a random arrangement of nanofibers give a maximum probability for field emission, due to their higher field amplification factor. Fig. 8b shows a single dot with $4 \mu \mathrm{m}$ diameter. Details of the synthesis and growth mechanism of the nanorods have been described in the previous section.
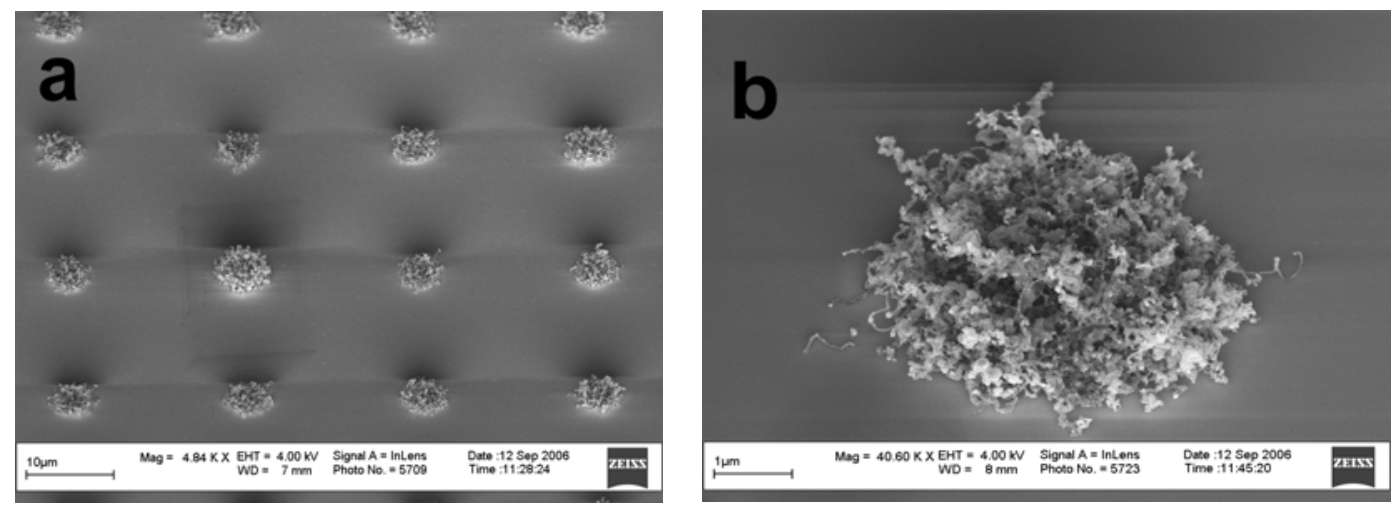

Figure 8. HR-SEM images of a $\mathrm{CNF}$ growth experiment at $700^{\circ} \mathrm{C}$ for 20 minutes showing (a) dot arrays and (b) a single dot of $4 \mu \mathrm{m}$.

\section{Tungsten oxide nanorods as microplasma electrodes at atmospheric pressure in air}

The silicon chip containing nanorods was incorporated in a glass microchannel to generate a barrier discharge between the nanorods and a copper foil electrode protected by a glass dielectric layer. The thickness of the glass was $150 \mu \mathrm{m}$ and the channel depth $500 \mu \mathrm{m}$. A square wave voltage with $1 \mathrm{kHz}$ frequency was applied to the silicon chip while the copper was grounded. 


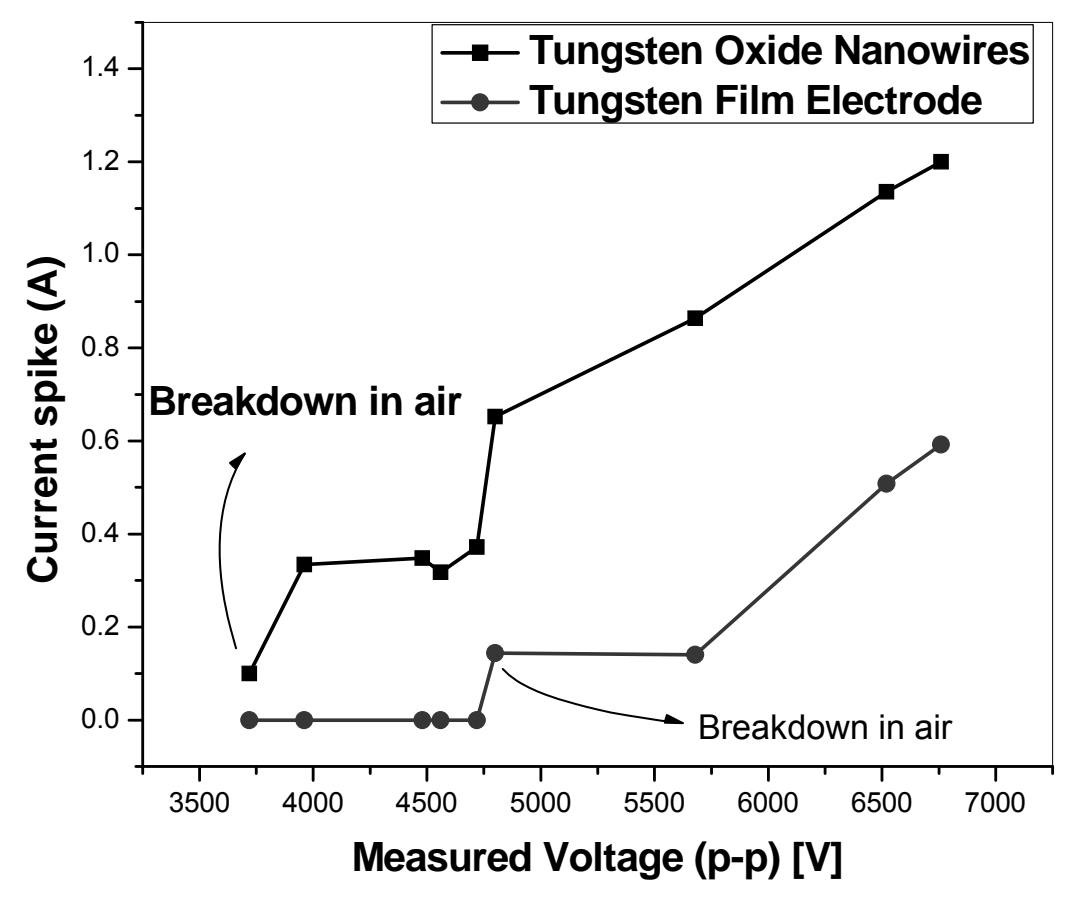

Figure 9. Comparison of discharge current spikes measured with tungsten oxide nanowires and with a planar tungsten film electrode for varying applied peak-to-peak voltage; $\mathrm{f}=1 \mathrm{kHz}$. Points show the current measured with oscilloscope at corresponding measured voltage values. Breakdown voltage is defined as voltage level at which light emission was detected by optical emission spectrometer.

Fig. 9 shows the measured discharge current spikes in air at atmospheric pressure to compare tungsten oxide nanowires and a planar tungsten film electrode. The breakdown voltage during barrier discharge generation is defined as the voltage level at which light emission was detected by an optical emission spectrometer with acquisition time of $0.1 \mathrm{sec}$. The current transferred during streamer production shows a sudden increase due to the breakdown of the gas gap. This breakdown voltage reduced from 4800 $\mathrm{V}$ to $3720 \mathrm{~V}$ in the case of nanorods. This clearly shows that microdischarges occur at a lower voltage due to electric field enhancement on nanorods. The amount of current that is transferred across the gap is also much higher in the case of the nanorod electrode. The reduction of breakdown voltage and increase in transferred current is suggestive of electric field amplification and emission of electrons on the nanorod surface. The electric field inside the microplasma reactor $(5 \mathrm{~V} / \mu \mathrm{m})$ is enough to generate field emitted electrons before breakdown. Since there is a native oxide layer of a few nanometer thickness on the tungsten film, it is believed that both electrode surfaces have similar work functions. 


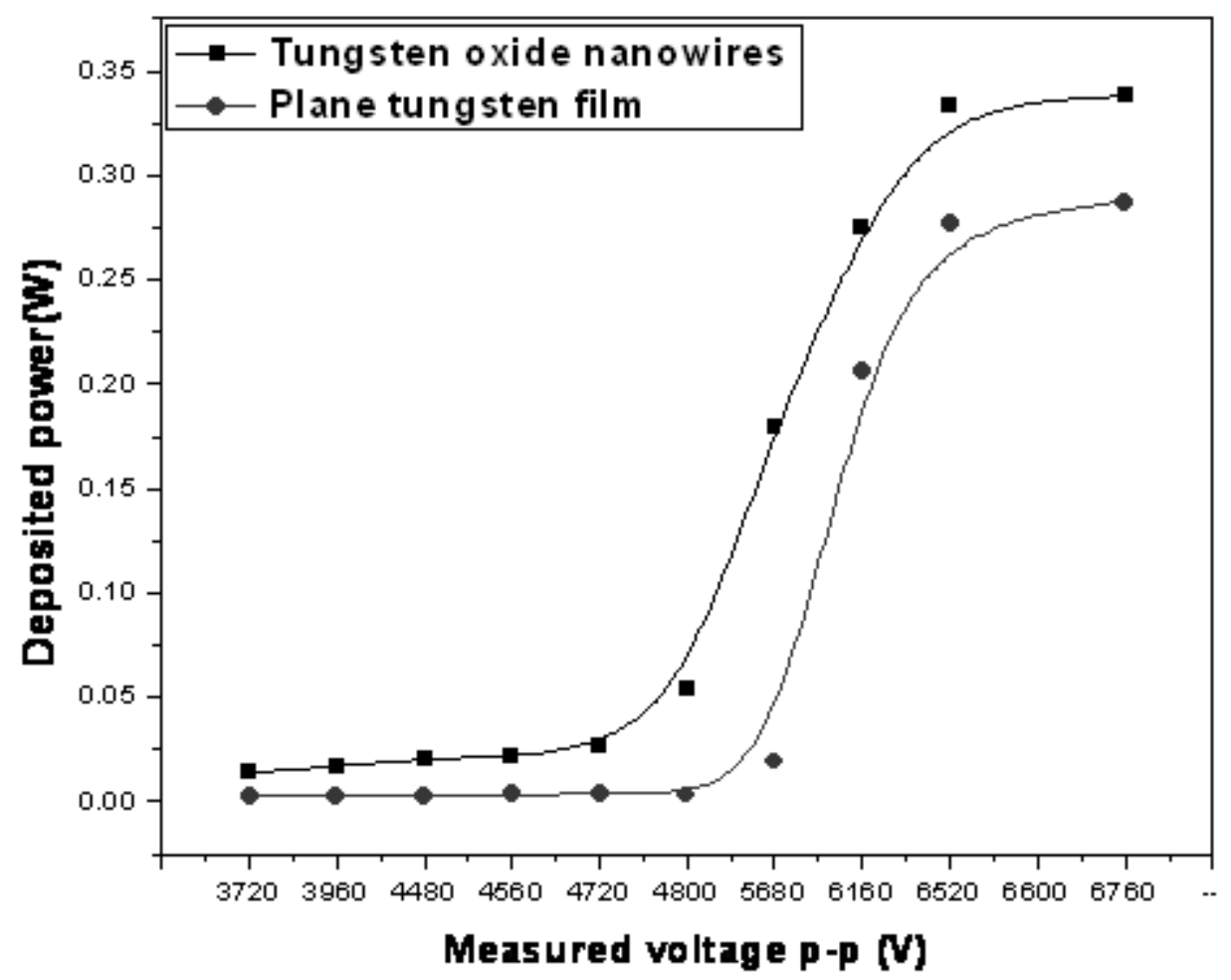

Figure 10. Comparison of power deposited into the microplasma, measured on tungsten oxide nanowires and a planar tungsten film electrode for varying applied (peak-to-peak) voltage, at $\mathrm{f}=1 \mathrm{kHz}$.

Fig. 10 shows a comparison of power deposited into the microplasma as a function of measured voltage. At the same voltage, a higher energy density microplasma was obtained with the nanorods due to the generation of a higher number of microdischarges. Local electric field enhancement on the surface helps to increase the number of microdischarges. The microplasma volume also increased since more streamers were generated and the discharge became more homogenous. An optical fiber was inserted into the microchannel to analyze light emission. The obtained spectra are shown in Fig. 11a for tungsten oxide nanorods and in Fig. 11b for planar tungsten film electrodes. In the case of nanorods, the intensity of the emission lines is much higher. Jani et al. [40] investigated the variation of electron temperature by spectroscopic measurement using the second positive system (SPS) of $\mathrm{N}_{2}(337.1 \mathrm{~nm})$ and the first negative system (FNS) of $\mathrm{N}_{2}^{+}(391.4 \mathrm{~nm})$. They showed that the ratio of the SPS to the FNS changes with electron temperature in the discharge, and the intensity ratio of the lines (FNS of $\mathrm{N}_{2}^{+} /$SPS of $\mathrm{N}_{2}$ ) increase with increasing average electron energy. The intensity ratio was calculated to be 0.061 and 0.058 for nanowires and planar electrodes, respectively, which shows no remarkable difference although the intensity of the emission 
lines is much higher for the spectrum for the nanowire electrode at the same applied voltage.

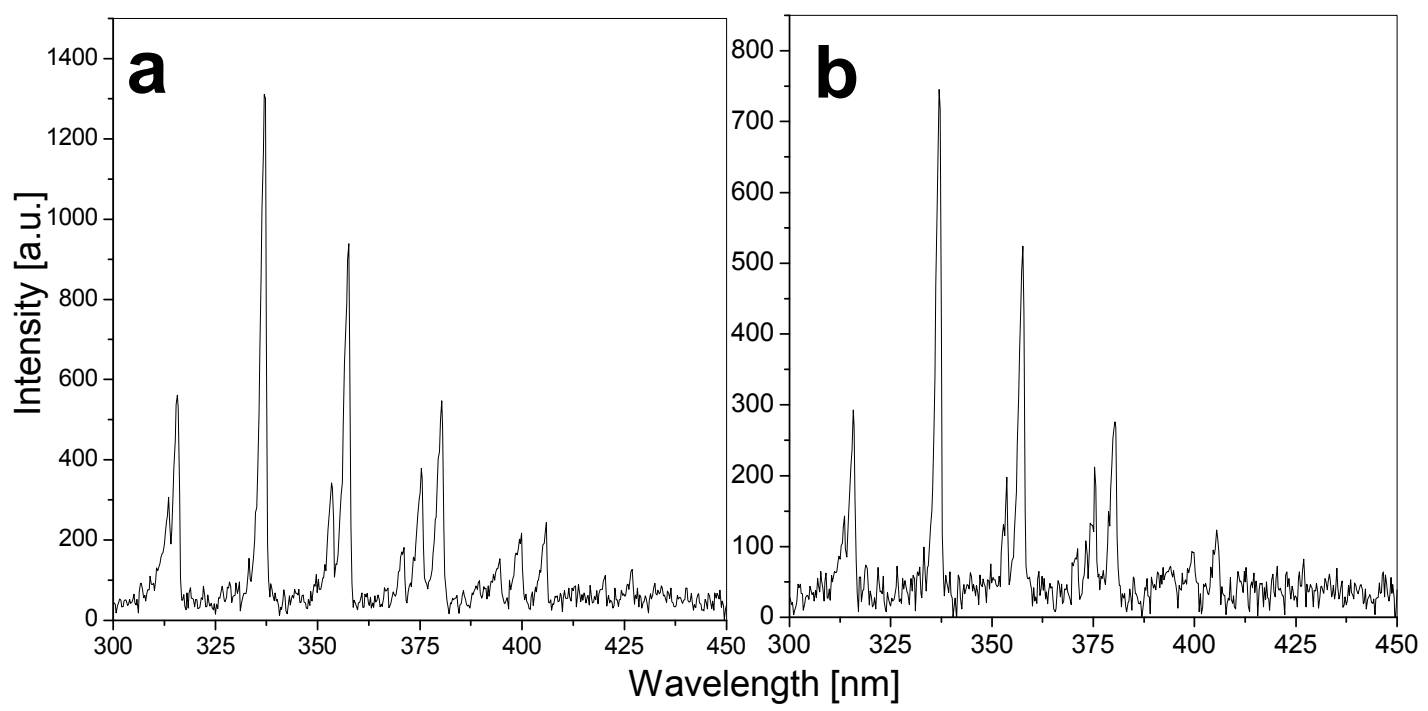

Figure 11. Emission spectrum of the microplasma generated using (a) tungsten oxide nanowires and (b) tungsten film planar electrodes at atmospheric pressure in air, V: 6770 p-p square wave voltage at $1 \mathrm{kHz}$ frequency.

\section{$\mathrm{CO}_{2}$ consumption in the microplasma reactor with CNFs as electrodes at atmospheric pressure}

Carbon dioxide conversion to carbon monoxide and oxygen is an endothermic reaction with an enthalpy of $283 \mathrm{~kJ} / \mathrm{mol}$. This reaction can be used to dispose of carbon dioxide or to produce oxygen. Arrays of CNFs grown on the silicon chip were used to compare the conversion levels with a planar electrode at the same applied potentials. Electrical characterization of the plasma showed that CNF electrodes generated more microdischarges than the planar electrodes and that the energy density deposited into the microplasma also increased. 


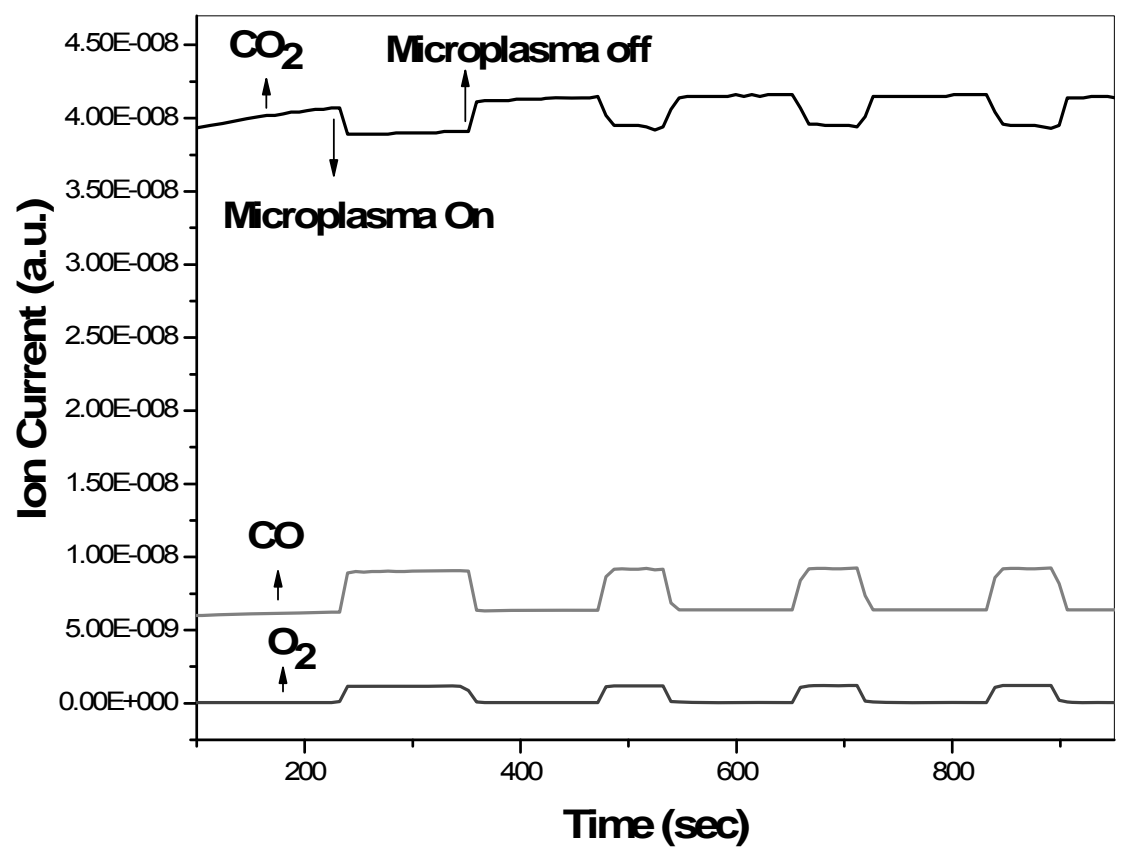

Figure 12. Mass spectrometric analysis of $\mathrm{CO}_{2}$ conversion in a microplasma reactor with CNF electrodes at $10 \mathrm{sccm}$ He flow, a measured voltage of $5.5 \mathrm{kV}(\mathrm{p}-\mathrm{p})$ and $\mathrm{f}=1 \mathrm{kHz}$, .

Helium was introduced into the reactor at a $10 \mathrm{sccm}$ flow rate. Gas mole fraction data were obtained by mass spectrometry. The conversion of $\mathrm{CO}_{2}$ was calculated based on the calibrated ion current data, which leads to a calculation of mole fractions and $\mathrm{CO}_{2}$ flow before and after the microplasma processing. As the plasma ignited, $\mathrm{O}_{2}$ and $\mathrm{CO}$ formation was observed in the spectrum, as is shown in Fig. 12. Since the gas in the microplasma is at ambient temperature, no thermal cracking takes place in the microreactor. Inelastic electron collisions, three body reactions and surface reactions are responsible for the conversion. For a better understanding of the importance of electron impact reactions in a $\mathrm{CO}_{2}$ plasma, the Boltzmann equation for electrons was solved using the BOLSIG+ code [41]. Reaction rate coefficients as a function of average electron energy are tabulated in Fig. 13. Cross-section data of 1 elastic, 8 vibrational, 2 electronic excitation, 1 ionization and 1 attachment process were used in the simulations for a pressure of 1 atm. At low electron energies $(0-4 \mathrm{eV})$ rate coefficients of vibrational excitations are much higher. A further increase in the electron energy leads to a considerable increase in the rate coefficients of the dissociative excitations which are mainly responsible for $\mathrm{CO}_{2}$ decomposition. 


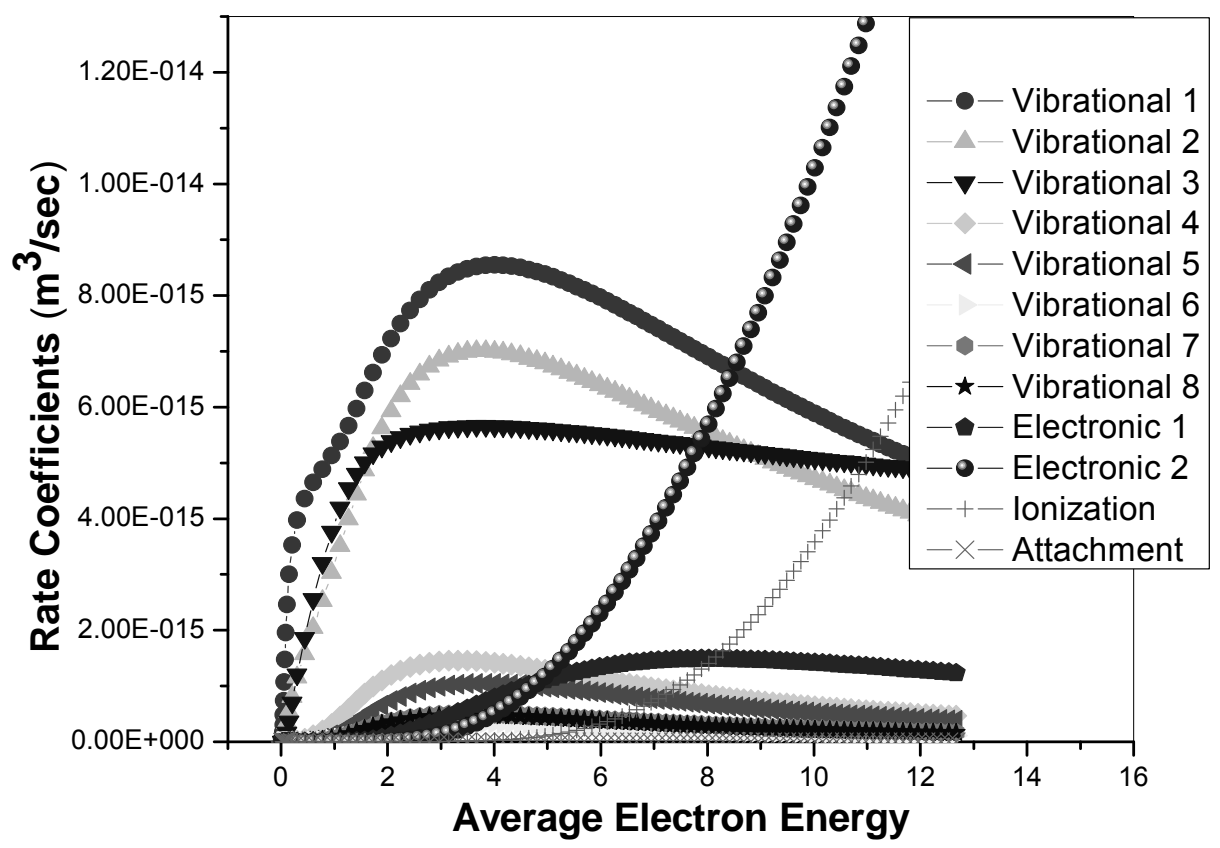

Figure 13. Rate coefficients calculated as a function of electron energy in $\mathrm{CO}_{2}$ plasma.

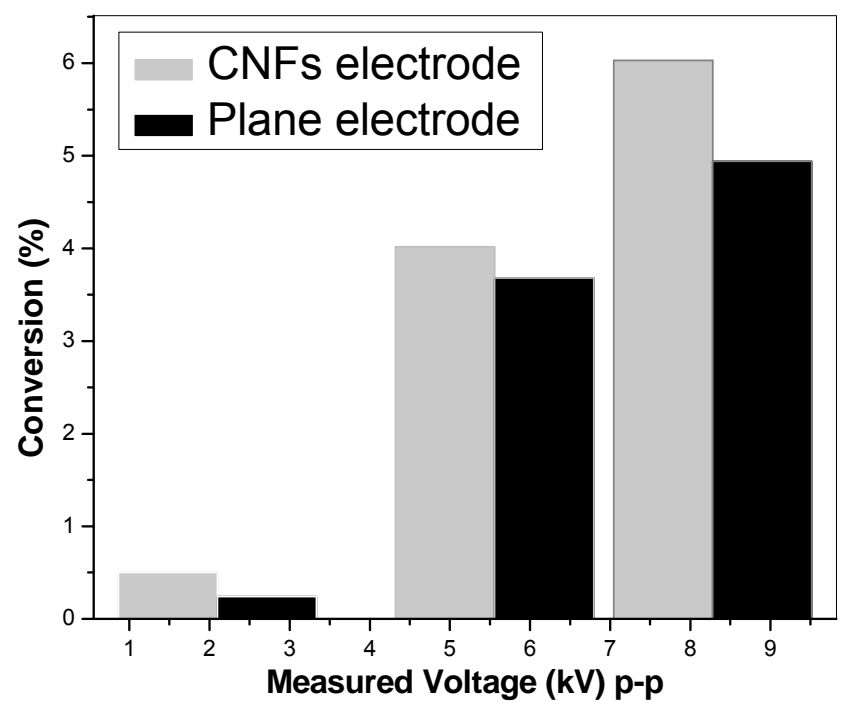

Figure 14. $\mathrm{CO}_{2}$ conversion vs. applied voltage for $\mathrm{CNF}$ and planar electrodes, $\mathrm{f}=1 \mathrm{kHz}$.

Fig. 14 shows that at the same measured voltage levels as with the planar electrodes the conversion with the CNF electrode is enhanced due to an increase in energy deposition and in the number of reactive micro-discharges. One could also say that the number of dissociative electronic excitation channels increases, because the CNFs change the surface chemistry and open new reaction routes on the surface. 


\section{CONCLUSIONS}

In summary, uniform and highly crystalline $\mathrm{W}_{18} \mathrm{O}_{49}$ nanorods were successfully grown with high yield on sputter deposited tungsten films by thermal annealing at $700^{\circ} \mathrm{C}$ in ethene and nitrogen at atmospheric pressure. Tungsten carbide $\left(\mathrm{W}_{2} \mathrm{C}\right)$ formation at the surface of the tungsten film increased the nucleation and growth of nanorods by generating dislocation sources and interfacial strain. Stable atmospheric pressure field emission and pulsed field emission took place in air at a current density up to $28 \mathrm{~mA} / \mathrm{cm}^{2}$. The field emission current obeyed the Fowler-Nordheim equation. Saturation effects were observed above $20 \mathrm{~mA} / \mathrm{cm}^{2}$ and eventually breakdown was reached.

A microplasma reactor having tungsten oxide nanorods and CNFs as electrodes were fabricated in a barrier discharge configuration. Field enhancement at the apex of the tips of nanostructures resulted in electron emission at atmospheric pressure in air. For the CNFs, a decrease in breakdown voltage during barrier discharge generation resulted in a higher number of microdischarges and a higher power deposition at the same measured potential compared to planar cathodes. Finally it was shown that the reactivity of a discharge for $\mathrm{CO}_{2}$ decomposition can be increased by using a $\mathrm{CNF}$ electrode.

\section{Acknowledgements}

This research is supported by the Technology Foundation STW, applied science division of NWO and the technology program of the Ministry of Economic Affairs, The Netherlands, project number 06626. The authors thank B. Geerdink for technical support and Mark Smithers for SEM and TEM/EDX analysis. 


\section{References}

[1] Wang, Z. L. Adv. Mater. 2003, 15, 432.

[2] Simon, I.; Bârsan, N.; Bauer, M.; Weimar, U. Sens. Actuators B 2001, 73, 1.

[3] Pan, Z. W.; Dai, Z. R.; Wang, Z. L. Science 2001, 291,1947.

[4] Kim, Y. S.; Ha, S.-C.; Kim, K.; Yang, H.; Choi, S.-Y.; Kim,Y. T.; Park, J. T.; Lee, C. H.;

Choi, J.; Paek, J.; Lee, K. Appl. Phys. Lett. 2005, 86, 213105.

[5] Seelaboyina, R.; Huang, J.; Park, J.; Kang, D. H.; Choi, W. B. Nanotechnology 2006, 17, 4840.

[6] Liu, K.; Foord, D. T.; Scipioni, L. Nanotechnology, 2005, 16, 10.

[7] Liu, Z.; Bando, Y.; Tang, C. Chem. Phys. Lett. 2003, 372, 179.

[8] Cho, M. H. et al. J. Vac. Sci. Technol. B 2004, 22, 1084.

[9] Becker K. H., Schoenbach K. H. and Eden J. G., J. Phys. D: Appl. Phys. 2006, 39, R55.

[10] Nozaki T., Hattori A. and Okazaki K., Catal. Today 2004, 98, 607.

[11] Guillorn M. A., Melechko A. V., Merkulov V. I., Ellis E. D., Britton C. L., Simpson M. L., Lowndes D. H. and Baylor L. R., Appl. Phys. Lett. 2001, 79, 3506.

[12] Zhou J., Gong L., Deng Z., Chen J., She J. C., Xu N. S., Yang R. and Wang Z. L. Appl. Phys. Lett. 2005, 87, 223108.

[13] Park S. J. and Eden J. G., Appl. Phys. Lett. 2004, 84, 4481.

[14] Tas M. A. 1995 Plasma Induced Catalysis: PhD Thesis (Technical University of Eindhoven) $\mathrm{p} 14$.

[15] Gosnet, A. M. H.; Ladan, F. R.; Mayeux, C.; Launois, H.; Jancour, M. C. J. Vac. Sci.

Technol. A 1989, 7, 1663.

[16] Wang, S. J.; Chen, C. H.; Chang, S. C.; Uang, K. M.; Juan, C. P.; Cheng, H. C. Appl.

Phys. Lett. 2004, 85, 12.

[17] Mueller, D.; Shih, A. J. Vac. Sci. Technol. A 1988, 6, 1067.

[18] Rogers, J. D.; Sundaram, V. S.; Kleiman, G. G.; Castro, C. G. C.; Douglas, R. A.; Peterlevitz, A. C. J. Phys. F. 1982, 12, 2097.

[19] Salvati, L.; Makovsky, L. E.; Stencel, J. M.; Brown, F. R.; Hercules, D. M. J. Phys. Chem. 1981, 85, 3700 .

[20] Jeon, S.; Yong, K. Nanotechnology 2007, 18, 245602.

[21] Fleisch, T. H.; Mains, G. J. J. Chem. Phys. 1982, 76, 780. 
[22] Katrib, A.; Hemming, F.; Hilaire, L.; Wehrer, P.; Maire, G. J. Electron Spectrosc.

Relat. Phenom. 1994, 68, 589-595.

[23] Feydt, J.; Elbe, A.; Egelhard, H.; Meister, G.; Goldmann, A. Surf. Sci. 1999, 440, 213.

[24] Wang, S. J.; Chen, C. H.; Ko, R. M.; Kuo, Y. C.; Wong, C. H.; Wu, C. H.; Uang, K. M.;

Chen, T. M.; Liou, B. W. Appl. Phys. Lett. 2005, 86, 263103.

[25] Wagner, R. S.; Ellis, W. C. Appl. Phys. Lett. 1964, 4, 89.

[26] Chen, G. Y.; Stolojan, V.; Cox, D. C.; Giusca, C.; Silva, S. R. P. IEEE Conf. on Emerg. Tech.-Nanoelectronics 2006, 376-378.

[27] Klinke, C.; Hannon, J. B.; Gignac, L.; Reuter, K.; Avouris, P. J. Phys. Chem. B 2005, 109, 17787-17790.

[28] Hopwood, J.; Iza, F. J. Anal. At. Spectrom. 2004, 19, 1145-1150.

[29] Schwirzke, F.; Hallal, M. P.; Maruyama, X. K. IEEE Trans. Plasma Sci. 1993, 21, 410-415.

[30] Forbes, R. G.; Deane, J. H. B. Proc. R. Soc. A 2007, 463, 2907-2927.

[31] K. Huang, et al. Physica E 2007, doi:10.1016/j.physe.2007.04.007.

[32] Forbes, R. G. J. Vac. Sci. Technol. B 1999, 17(2), 526-533.

[33] Forbes, R. G. Solid-State Electronics 2001, 45, 779-808.

[34] Forbes, R. G.; Edgcombe, C. J.; Valdré, U. Ultramicroscopy 2003, 95, 57-65.

[35] Fursey, G. N. Appl. Surf. Sci. 2003, 215, 113-114.

[36] Fursey, G. N. IEEE Trans. Electr. Insulation EI-20 1985, 4.

[37] Nottingham, W. B. Phys. Rev. 1941, 59, 907.

[38] Slade, P. G.; Taylor, E. D. Proc. 45th IEEE Holm. Conf. On Elect. Cont. 2001, 245250.

[39] High Voltage Vacuum Insulation: Basic concepts and technological practice, Latham, R. V., Ed.; Academic Press: London, 1995.

[40] Jani M. A., Takaki K. and Fujiwara T., J. Phys. D: Appl. Phys. 1999, 32, 2560.

[41] Hagelaar G. J. M. and Pitchford L. C., Plasma Sources Sci.. Technol. 2005, 14, 722. 


\section{Chapter 8}

\section{Outlook and general recommendations}

The combination of atmospheric pressure plasmas with microreaction technology opens novel process windows for hydrocarbon conversion. To study the feasibility of such a combination, the oxidative conversion of alkanes in the $\mathrm{C}_{1}-\mathrm{C}_{3}$ range was performed in a plasma micro-reactor. Due to the cold plasma, hydrocarbon activation via homolytic $\mathrm{C}-\mathrm{H}$ and $\mathrm{C}-\mathrm{C}$ bond rupture, forming radicals, occurred exclusively in the gas phase at near ambient temperatures $\left(<50^{\circ} \mathrm{C}\right)$. In contrast to the results obtained at higher temperatures $\left(\geq 550^{\circ} \mathrm{C}\right)$, in all the experiments performed in a plasma micro-reactor, mainly products that require the formation of $\mathrm{C}-\mathrm{C}$ bonds were observed. Indeed, $\mathrm{C}-\mathrm{C}$ bond formation is an exothermic process and therefore favored at lower temperatures. A chemical kinetic model helped us to better understand the radical reaction network, which suggests that depending on radical density the product selectivity can be tailored. However, further experiments with different feed compositions are recommended. In fact, the highly efficient coupling phenomena taking place under our conditions would suggest the direct utilization of alkanes such as $\mathrm{C}_{4}-\mathrm{C}_{6}$ hydrocarbons as feedstock for a gas to liquid (GTL) process, to produce fuels or high-value chemicals. Optimization of these processes is required and further developments in this direction are highly recommended.

The oxidative conversion of propane in a plasma micro-reactor was also performed in the presence of a thin layer of Li-promoted $\mathrm{MgO}$ catalyst deposited in the micro-channel where the cold plasma was ignited. Interestingly, alkyl radicals, exclusively formed by the cold plasma, can either initiate radical chain reactions in the gas phase or intensively interact with the catalyst surface due to the high surface-tovolume ratio typical of microscale reactors. Based on our results, a selective interaction between catalyst surface and radical species could be recorded under the studied conditions. Furthermore, an investigation was performed of changing the catalyst composition. Our proposition is that plasma enhances the formation of selective catalytic sites on the surface of Li-promoted $\mathrm{MgO}$ catalyst. To bring this work further, a better understanding of the phenomena taking place on catalyst surfaces under plasma 
conditions is necessary and highly recommended. The utilization of in situ spectroscopic techniques under plasma conditions i.e., ATR and EPR on a chip would be a major breakthrough. This would allow us to investigate the interaction between radical species and catalyst surface. The formation of paramagnetic centers (EPR-active on the surface of Li-promoted $\mathrm{MgO}$ catalysts) induced by the presence of a cold plasma might thus be established and characterized. Experiments at higher temperatures are suggested for a better understanding of the catalytic effect on product selectivity.

The application of an atmospheric pressure microplasma was also studied for oxidative conversion of hexane at higher temperature $\left(600^{\circ} \mathrm{C}\right)$. Similar to the results observed in propane conversion at ambient temperatures, coupling reactions of intermediate radicals were found to be more significant at lower temperatures $\left(400^{\circ} \mathrm{C}\right)$. A plasma-integrated catalytic system with $\mathrm{Li} / \mathrm{MgO}$ resulted in dramatic improvements in olefin yield. We suggest three main routes for hexane activation; (i) $\mathrm{C}-\mathrm{H}$ bond scission by $\mathrm{Li}^{+} \mathrm{O}^{-}$active sites, (ii) by electron-impact excitation and (iii) $\mathrm{C}-\mathrm{H}$ bond scission by oxygen radicals. In order to better understand the involved reaction mechanism, it is advised to characterize the catalyst and gas phase with in-situ spectroscopic methods during plasma operation. Optical emission spectroscopic analysis is suggested for the observation of the main radicals in the gas phase, in-situ FTIR, Raman and Diffuse Reflectance UV/Vis/near-IR spectroscopy for surface and catalyst structural characterization during discharge conditions can give relevant information. Chemical kinetic modeling of the plasma-enhanced hexane conversion would help to eludicate the details of the reaction network of electron-induced, surface and gas phase radical reactions.

As suggested in the first section of this chapter about the utilization of hydrocarbons as feedstock for a gas-to-liquid process to produce fuels or specialty chemicals, the direct synthesis of liquid oxygenates from the partial oxidation of methane was realized in a multi-phase flow, non-equilibrium plasma microreactor at atmospheric pressure and near $0^{\circ} \mathrm{C}$. A method of liquid-water injection into the microreactor was introduced to remove incomplete oxidation products such as methanol, in order to prevent further oxidation with excited species in the microplasma reactor. Hydrogen peroxide contributed to acceleration of the ratedetermining step of methane partial oxidation: hydroxyl radicals $(\mathrm{OH})$ derived from $\mathrm{H}_{2} \mathrm{O}_{2}$ efficiently abstract hydrogen from methane. Eventually, a one-pass yield of $10 \%$ for liquid oxygenates was demonstrated as a result of the synergistic effect of $\mathrm{H}_{2} \mathrm{O}_{2}$ and $\mathrm{O}_{2}$ oxidants. In order to increase the yield of oxygenates, parallel microplasma reactors may be utilized so that each reactor contribute to increase conversion and 
yield. Characterization of the microplasma during operation, by emission spectroscopy is suggested in order to be able to detect and roughly quantify hydroxyl radicals in this multi-flow reactor. A parametric optimization of power, frequency, water pulse rate and flow rate of reactant gases should be performed to find optimum conditions for higher yields.

In addition to activation of hydrocarbons in the microchannels, a microplasma was also used for the growth of CNFs inside a closed channel microreactor. A dielectric barrier discharge was generated by flowing helium and hydrogen through a fused silica capillary which contained a coating of Ni-alumina catalyst which was activated to form carbon nanofibers (CNFs). A cold plasma operation for $15 \mathrm{~min}$ is simple and audio-visual and increases the CNF yield significantly compared to nonactivated samples so that it can compete with a $2 \mathrm{hrs}$ high temperature treatment at 973 K. From microreaction technology point of view, CNF-coated microreactors provide a facile bottom-up way to increase surface-to-volume ratio and act as a highsurface-area nanoscopic catalyst support. It is suggested to use the CNFs as a support for active nanoparticle catalysts and use this microreactor for two phase reactions. For a better understanding of catalyst activation with an atmospheric pressure microplasma, chemical kinetic modeling including surface reactions should be performed.

The application of field emitting nanorods and nanofibers as electrodes in a microplasma reactor system was also studied. Nanorods with diameters of 15-20 nm were grown on tungsten thin films exposed to ethene and nitrogen at $700^{\circ} \mathrm{C}$ at atmospheric pressure. Atmospheric pressure field emission measurements in air showed a turn-on field of $3.3 \mathrm{~V} / \mu \mathrm{m}$ and a stable and reproducible emission current density $\left(28 \mathrm{~mA} / \mathrm{cm}^{2}\right)$. Carbon nanofibers (CNFs) and tungsten oxide nanorods were incorporated into a continuous flow microplasma reactor to increase the reactivity and efficiency of the barrier discharge at atmospheric pressure. Field emission of electrons from those nanostructures supplied free electrons and ions during microplasma production. A reduction in breakdown voltage, a higher number of microdischarges and a higher energy deposition were observed at the same applied voltage, compared to plane electrodes in air. We studied $\mathrm{CO}_{2}$ consumption as a model reaction in order to realize highly reactive conditions generated by nanostructured electrodes, and it was shown that with the $\mathrm{CNFs} \mathrm{CO}_{2}$ consumption increased compared to plane electrodes. It would be interesting to use these nanostructured electrodes as catalyst support in a plasma catalytic process 


\section{Publications}

Patents:

1. Japanese Patent - Patent No. 09T026, Tokyo Institute of Technology: "Method for oxidation of hydrocarbons and oxidation reactor" TOMOHIRO NOZAKI, MASAHIKO NAKASE, ANIL AGIRAL, KEN OKAZAKI, 2009-147043.

Book chapter:

2. Microreactors with electrical fields, ANIL AGIRAL, J. G. E. (HAN) GARDENIERS, will appear in "Micro Systems and Devices for (Bio)chemical Processes" in the Elsevier series of Advances in Chemical Engineering, July 2009.

3. On-chip tungsten oxide nanowire based electrodes for charge injection, ANIL AGIRAL, J. G. E. (HAN) GARDENIERS, will appear in "Nanowires" by IN-TECH Publishing, Vienna, Austria, January 2010, ISBN 978-953-7619-X-X.

Peer reviewed:

4. Characterization of $\mathrm{LaMnAl}_{11} \mathrm{O}_{19}$ by FT-IR spectroscopy of adsorbed NO and $\mathbf{N O} / \mathbf{O}_{2}$, MARGARITA KANTCHEVA, ANIL AGIRAL, OLGA SAMARSKAYA, M. STRANZENBACH AND B. SARUHAN, Applied Surface Science, volume 252, page 1481-1491 (2005).

5. Alkane activation at ambient temperatures-unusual selectivities, C-C, C-H bond scission vs $\mathbf{C}-\mathbf{C}$ bond coupling, CRISTIANO TRIONFETTI, ANIL AGIRAL, J. G. E. (HAN) GARDENIERS, LEON LEFFERTS, K. SESHAN, ChemPhysChem, volume 9, page 533-537 (2008).

6. Oxidative conversion of propane in a microreactor in the presence of plasma over MgO based catalysts-an experimental study, CRISTIANO TRIONFETTI, ANIL AGIRAL, J. G. E. (HAN) GARDENIERS, LEON LEFFERTS, K. SESHAN, Journal of Physical Chemistry C, volume 112(11), page 42674274 (2008).

7. On chip microplasma reactors using tungsten oxide nanowires and carbon nanofibers as electrodes, ANIL AGIRAL, ALFONS W. GROENLAND, J. KUMAR CHINTHAGINJALA, K. SESHAN, LEON LEFFERTS, J. G. E. (HAN) GARDENIERS, Journal of Physics D: Applied Physics, volume 41, page 194009 (2008).

8. Synthesis and atmospheric pressure field emission operation of $\mathbf{W}_{18} \mathbf{O}_{49}$ nanowires, ANIL AGIRAL, J. G. E. (HAN) GARDENIERS, Journal of Physical Chemistry C, volume 112(39), page 15183-15189 (2008).

9. Propane conversion at ambient temperatures $\mathrm{C}-\mathrm{C}$ and $\mathrm{C}-\mathrm{H}$ bond activation using cold plasma in a microreactor (Review), ANIL AGIRAL, CRISTIANO TRIONFETTI, K. SESHAN, LEON LEFFERTS, J. G. E. (HAN) GARDENIERS, Chemical Engineering and Technology, volume 31(8), page 1116-1123 (2008).

10. Catalyst Activation with Microplasma for Carbon Nanofibers Synthesis in Microreactor, ANIL AGIRAL, LEON LEFFERTS, J. G. E. (HAN) 
GARDENIERS, IEEE Transactions on Plasma Science, Special Issue on Atmospheric Pressure Plasmas: Science and Applications, June (2009), ISSN: 00933813 doi:10.1109/TPS.2009.2019981.

11. In-situ CVD of Carbon Nanofibers in a Microreactor, ANIL AGIRAL, LEON LEFFERTS, J. G. E. (HAN) GARDENIERS, Catalysis Today, Special Issue on Carbon for Catalysis, June (2009), doi:10.1016/j.cattod.2009.04.023.

12. (To be submitted) Electron injection into hexane from field emitting carbon nanofiber electrodes, ANIL AGIRAL, H. BURAK ERAL, FRIEDER MUGELE, J. G. E. (HAN) GARDENIERS, Journal of Physical Chemistry C.

13. (To be submitted) Direct synthesis of liquid oxygenates in a non-equilibrium plasma microreactor, ANIL AGIRAL, MASAHIKO NAKASE, TOMOHIRO NOZAKI, KEN OKAZAKI, J. G. E. (HAN) GARDENIERS, Chemical Communications.

14. (To be submitted) Plasma catalytic oxi-cracking of hexane with nanoscopic mixed oxide catalyst for olefins synthesis at atmospheric pressure, ANIL AGIRAL, CASIA BOYADJIAN, K. SESHAN, LEON LEFFERTS, J. G. E. (HAN) GARDENIERS, Journal of Physical Chemistry C.

15. (To be submitted) Chemical kinetic modeling of propane conversion in a microplasma reactor, ANIL AGIRAL, CRISTIANO TRIONFETTI, K. SESHAN, LEON LEFFERTS, J. G. E. (HAN) GARDENIERS, Journal of Physical Chemistry C.

16. (To be submitted) Plasma catalytic oxi-cracking of hexane with nanoscopic mixed oxide catalyst for olefins synthesis at atmospheric pressure, ANIL AgIRAL, CASIA BOYADJIAN, K. SESHAN, LEON LEFFERTS, J. G. E. (HAN) GARDENIERS, Journal of Physical Chemistry C.

\section{Conference Proceedings:}

17. Characterization of an atmospheric pressure nonequilibrium surface barrier discharge microplasma with liquid electrode, ANIL AGIRAL, J. G. E. (HAN) GARDENIERS, International Workshop on Microplasmas, Greifswald, Germany, May 9-11, 2006 (Poster presentation).

18. Propane conversion in a surface-discharge microplasma reactor, ANIL AGIRAL, CRISTIANO TRIONFETTI, K. SESHAN, LEON LEFFERTS, J. G. E. (HAN) GARDENIERS, $9^{\text {th }}$ International Conference on Microreaction Technology, Potsdam, Germany, September 6-8, 2006 (Poster presentation).

19. Study of dehydrogenation of propane in a microplasma reactor, ANIL AGIRAL, CRISTIANO TRIONFETTI, K. SESHAN, LEON LEFFERTS, J. G. E. (HAN) GARDENIERS, $8^{\text {th }}$ Netherlands Catalysis and Chemistry Conference, Noordwijkerhout, Netherlands, March 5-7, 2007 (Oral presentation).

20. Kinetic model analysis of $\mathbf{C}_{3} \mathbf{H}_{8}$ plasma for olefin synthesis in microplasma reactors, ANIL AGIRAL, CRISTIANO TRIONFETTI, K. SESHAN, LEON LEFFERTS, J. G. E. (HAN) GARDENIERS, $28^{\text {th }}$ International Conference on Phenomena in Ionized Gases, Prague, Czech Republic, July 15-20, 2007 (Poster presentation). 
21. Microplasma Catalysis: Selective conversion of propane into olefins in micro-DBD plasma reactor, ANIL AGIRAL, CRISTIANO TRIONFETTI, K. SESHAN, LEON LEFFERTS, J. G. E. (HAN) GARDENIERS, $18^{\text {th }}$ International Symposium on Plasma Chemistry, Kyoto, Japan, August 26-31, 2007 (Poster presentation).

22. On-chip microplasma reactors utilizing tungsten oxide nanowires and carbon nanofibers as electrodes, ANIL AGIRAL, ALFONS W. GROENLAND, J. KUMAR CHINTHAGINJALA, K. SESHAN, LEON LEFFERTS, J. G. E. (HAN) GARDENIERS, $4^{\text {th }}$ International Workshop on Microplasmas, Tainan, Taiwan, October 28-31, 2007 (Invited Lecture).

23. Selective conversion of propane into olefins in micro-DBD plasma reactor, ANIL AGIRAL, CRISTIANO TRIONFETTI, K. SESHAN, LEON LEFFERTS, J. G. E. (HAN) GARDENIERS, Netherlands Process Technology Symposium 2007, Veldhoven, Netherlands, October 28-30, 2007 (Poster presentation).

24. Microplasma reactor for oxidative conversion of propane, CRISTIANO TRIONFETTI, ANIL AGIRAL, K. SESHAN, LEON LEFFERTS, J. G. E. (HAN) GARDENIERS, Netherlands Process Technology Symposium 2007, Veldhoven, Netherlands, October 28-30, 2007 (Oral presentation).

25. On-chip microplasma reactors utilizing nanostructures, ANIL AGIRAL, K. SESHAN, LEON LEFFERTS, J. G. E. (HAN) GARDENIERS, $9^{\text {th }}$ Netherlands Catalysis and Chemistry Conference, Noordwijkerhout, Netherlands, March 3-5, 2008 (Oral presentation).

26. Alkane activation at ambient temperature - Unusual selectivities, C-C, C-H bond scission vs $\mathbf{C}-\mathbf{C}$ bond coupling, CRISTIANO TRIONFETTI, ANIL AGIRAL, K. SESHAN, LEON LEFFERTS, J. G. E. (HAN) GARDENIERS, AIChE Spring Meeting: $10^{\text {th }}$ International Conference on Microreaction Technology, New Orleans, USA, April 6-10, 2008 (Oral presentation).

27. Microplasma reactors with integrated carbon nanofibers and tungsten oxide nanowires, ANIL AGIRAL, K. SESHAN, LEON LEFFERTS, J. G. E. (HAN) GARDENIERS, AIChE Spring Meeting: $10^{\text {th }}$ International Conference on Microreaction Technology, New Orleans, USA, April 6-10, 2008 (Oral presentation).

28. Effect of surface to volume ratio in microplasma reactors, ANIL AGIRAL, K. SESHAN, LEON LEFFERTS, J. G. E. (HAN) GARDENIERS, AIChE Spring Meeting: $10^{\text {th }}$ International Conference on Microreaction Technology, New Orleans, USA, April 6-10, 2008 (Poster presentation).

29. Oxidative conversion of propane in a microreactor in the presence of plasma over MgO based catalysts - an experimental study, CRISTIANO TRIONFETTI, ANIL AGIRAL, K. SESHAN, LEON LEFFERTS, J. G. E. (HAN) GARDENIERS, ICC 14 - Pre-symposium of International Catalysis Conference, Kyoto, Japan, July 8-12, 2008 (Oral presentation).

30. Alkane activation at ambient temperatures-unusual selectivities, C-C, C-H bond scission vs $\mathbf{C}-\mathbf{C}$ bond coupling, CRISTIANO TRIONFETTI, ANIL AGIRAL, K. SESHAN, LEON LEFFERTS, J. G. E. (HAN) GARDENIERS, ICC 14 - International Catalysis Conference, Seoul, Korea, July 13-18, 2008 (Oral presentation). 
31. Atmospheric pressure field electron emission from nanostructures, ANIL AGIRAL, J. G. E. (HAN) GARDENIERS, $35^{\text {th }}$ IEEE International Conference on Plasma Science, Karlsruhe, Germany, June 15-19, 2008 (Oral presentation).

32. In-situ CVD of CNFs in a microreactor, ANIL AGIRAL, HRUDYA NAIR, K. SESHAN, LEON LEFFERTS, J. G. E. (HAN) GARDENIERS, III International Symposium on Carbon for Catalysis, Berlin, Germany, November 9-12, 2008 (Poster presentation).

33. Carbon nanofiber deposition in microreactors by atmospheric pressure microplasma, ANIL AGIRAL, HRUDYA NAIR, K. SESHAN, LEON LEFFERTS, J. G. E. (HAN) GARDENIERS, $8^{\text {th }}$ Netherlands Process Technology Symposium, Veldhoven, Netherlands, October 27-29, 2008 (Oral presentation).

34. Integrated plasma catalytic technology for hexane oxi-cracking, ANIL AGIRAL, CASIA BOYADJIYAN, K. SESHAN, LEON LEFFERTS, J. G. E. (HAN) GARDENIERS, $10^{\text {th }}$ Netherlands Catalysis and Chemistry Conference, Noordwijkerhout, Netherlands, March 2-4, 2008 (Oral presentation).

35. Plasma catalytic conversion of hexane in a dielectric barrier discharge, ANIL AGIRAL, CASIA BOYADJIYAN, K. SESHAN, LEON LEFFERTS, J. G. E. (HAN) GARDENIERS, $19^{\text {th }}$ International Symposium on Plasma Chemistry, Bochum, Germany, July 26-31, 2009 (Oral presentation).

36. Direct synthesis of liquid oxygenates in a non-equilibrium plasma microreactor, ANIL AGIRAL, MASAHIKO NAKASE, TOMOHIRO NOZAKI, KEN OKAZAKI, J. G. E. (HAN) GARDENIERS, $238^{\text {th }}$ ACS National Meeting, Fuel Chemistry Divison, Washington DC, USA, August 16-20, 2009 (Oral presentation).

37. Microplasma activation of catalyst for carbon nanofibers incorporation in a microreactor, ANIL AGIRAL, LEON LEFFERTS, J. G. E. (HAN) GARDENIERS, $29^{\text {th }}$ International Conference on Phenomena in Ionized Gases, Cancun, Mexico, July 12-17, 2009 (Oral presentation).

38. Oxidation of lower alkanes at ambient conditions in a micro reactor, $K$. SESHAN, CRISTIANO TRIONFETTI, ANIL AGIRAL, J. G. E. (HAN) GARDENIERS, LEON LEFFERTS, 6th World Congress on Oxidation Catalysis, Lille, France, July 5-10, 2009 (Keynote Lecture).

39. Direct liquid fuel synthesis at low temperature with microplasma reactor, MASAHIKO NAKASE, ANIL AGIRAL, TOMOHIRO NOZAKI, J. G. E. (HAN) GARDENIERS, KEN OKAZAKI, $41^{\text {st }}$ Autumn Meeting of Japanese Chemical Engineering Society, Higashi-Hiroshima, Japan, September 16-18, 2009 (Oral presentation).

40. Partial oxidation of methane to liquid oxygenates using atmospheric pressure non-equilibirum plasma microreactor, MASAHIKO NAKASE, ANIL AGIRAL, TOMOHIRO NOZAKI, J. G. E. (HAN) GARDENIERS, KEN OKAZAKI, $29^{\text {th }}$ International Conference on Phenomena in Ionized Gases, Cancun, Mexico, July 12-17, 2009 (Poster presentation).

41. Direct synthesis of methanol from methane in a microplasma reactor, TOMOHIRO NOZAKI, MASAHIKO NAKASE, ANIL AGIRAL, KEN OKAZAKI, $39^{\text {th }}$ Petroleum-Petrochemical Symposium of the Japanese Petroleum 
Institute, Hamamatsu, Shizuoka, Japan, October 22-24, 2009 (Oral presentation).

42. Direct conversion of methane to liquid oxygenates via controlled oxidation using microplasma reactor, TOMOHIRO NOZAKI, ANIL AGIRAL, MASAHIKO NAKASE, KEN OKAZAKI, $22^{\text {nd }}$ Symposium on Plasma Science For Materials, Tokyo, Japan, June 15 - 16, 2009 (Oral presentation).

43. Gas-to-liquid process using microreaction technology, ANIL AGIRAL, MASAHIKO NAKASE, TOMOHIRO NOZAKI, KEN OKAZAKI, J. G. E. (HAN) GARDENIERS, $9^{\text {th }}$ Netherlands Process Technology Symposium, Veldhoven, Netherlands, October 26-28, 2009 (Poster presentation).

44. (Submitted) Gas-to-liquid process in a plasma microreactor, ANIL AGIRAL, MASAHIKO NAKASE, TOMOHIRO NOZAKI, KEN OKAZAKI, J. G. E. (HAN) GARDENIERS, $11^{\text {th }}$ International Conference on Microreaction Technology, Kyoto, Japan, March 8-10, 2010 (Oral presentation).

45. Integrated plasma $\mathrm{Li} / \mathrm{MgO}$ system for the oxidative cracking of hexane, CASIA BOYADJIAN, ANIL AGIRAL, J. G. E. (HAN) GARDENIERS, K. SESHAN, LEON LEFFERTS, $\underline{9}^{\text {th }}$ Netherlands Process Technology Symposium, Veldhoven, Netherlands, October 26-28, 2009 (Oral presentation).

46. (Accepted) Charge injection from nanostructures at atmospheric pressure and on-chip microplasma reactors with integrated nanoelectrodes, ANIL AGIRAL, J. G. E. (HAN) GARDENIERS, ASME International Mechanical Engineering Congress- Micro/Nano Technology Forum, Lake Buena Vista, Florida, USA, November 13-19, 2009 (Poster presentation). 


\section{Acknowledgments}

First of all, I would like to thank my advisor, Prof. Han Gardeniers, for giving me the opportunity to work in his group, freedom to realize my ideas and his fantastic scientific and personal guidance to help to grow myself intellectually and professionally.

I would like to thank Prof. Leon Lefferts for his great assistance and supervision through our collaborations in Catalytic Processes and Materials (CPM) group.

I am very grateful to Dr. K. Seshan for his support, his enthusiasm and encouragement for our collaboration projects.

I would like to thank Dr. Tomohiro Nozaki and Prof. Ken Okazaki for giving me the opportunity to work in Energy Phenomena Laboratory in Tokyo Institute of Technology, guiding and supporting me during my stay in Tokyo.

I would like to thank my master student, Alfons W. Groenland for bringing first brilliant ideas to the project and fabrication of successful devices which I used later in my Ph.D.

In Tokyo Institute of Technology, I would like to thank my student, Masahiko Nakase for his great assistance in completing our gas-to-liquid process project.

In CPM group, Cristiano, I would like to thank you for never giving up trying our scientific ideas regardless of time and sharing hard working times together. Kumar, thank you for collaborating with me on growing CNFs with many applications I used in my thesis. Hrudya, thank you for helping me enthusiastically with realization of our ideas with nanofibers. Gacia, thank you for collaborating with me on the hexane project. We managed to finish all the experiments successfully. I would like to thank Bert for his great technical assistance, Karin and Louise for their help in measurements.

In Physics of Complex Fluids group, I would like to thank Burak for sharing his setup to carry out experiments to realize our idea of solvated electrons.

In Mesoscale Chemical Systems group, I would like to thank David for trying first experiments with me to generate solvated electrons using cavitation bubbles. Sertan, thank you for helping me in the cleanroom and giving me ideas.

In Transducer Science and Technology Group, I would like to thank Berker for sticking with our micro hollow cathode project.

In Memrane Technology group, I would like to thank Can for never giving up trying our project "Multi-phase flow plasma catalytic membrane microreactors". Thank you Hakan for our trial of integrated microreactor-fuel cell system. 
I would like to thank all my office mates for their support, MCS, CPM and old BIOS members for little things that make life and work easier in our department: Liza, Sreenath, Wojciech, Wim, Roald, Manon, Vincent, Stefan, Maciek, Nikolay, Piotr, Bilge, Engin, Regina, Svetlana, Otto, Berta, Sergio, Davide, Mariana, Son, Dennis, Inga, Igor, Barbara, Arie, Albert, Jan, Severine, Wouter, Floor, Egbert, Wouter, Lingling, Johan, Paul, Jan, Daniel, Hermine, Georgette, Iris and Ana.

Our secretary, Jacqueline, thank you so much for your help in everyday matters.

I would like to thank all my Turkish friends in Enschede for their support.

I would like to thank Engin and Janet for agreeing to be my paranymphs.

I would like to thank my committee members, Prof. van de Sanden from Enidhoven University of Technology, Dr. T. Nozaki from Tokyo Institute of Technology, Prof. J. A. M. Kuipers, Prof. L. Lefferts, Dr. K. Seshan and Prof. M. Wessling in Twente University.

Bütün aileme, sevgili kardeşim Betüş’e, anneme, babama, canım anneanneme, babanname, Nazım ve Mehmet dedelerime, teyzelerim, halalarim, Hollanda'daki yakınlarım ve herkese, Nero’ya, Nevin'e, Kıymet, Nürvet, Hülya’ya ve sevgili Rozi’ye bana sonsuz sevgi ve destek verdikleri için teşekkür ediyorum. 


\title{
Curriculum Vitae
}

\author{
Anil Agiral, Ph.D. \\ a.agiral@utwente.nl (+31 53489 2631) \\ Mesoscale Chemical Systems, MESA+ Institute for Nanotechnology, University \\ of Twente, Enschede, The Netherlands
}

Background

Current job:

Ph.D. in Physical Chemistry/Microreaction Technology/Nanotechnology (graduation date: $6^{\text {th }}$ of November 2009), at the MESA+ Institute for Nanotechnology, University of Twente, Enschede, The Netherlands since September 2005. Supervised by Prof. J. G. E. (Han) Gardeniers. Thesis title: "Electron driven chemistry in microreactors".

\section{Education:}

M.Sc. in Physical Chemistry, at Bilkent University, Ankara, Turkey was conferred in July 2005. Supervised by Prof. Margarita Kantcheva. Thesis title: "In-situ FT-IR Spectroscopic Investigation of $\mathrm{NO}_{x}+\mathrm{CH}_{4}$ Surface Reactions on Palladium Promoted $\mathrm{WO}_{3} / \mathrm{TiO}_{2}-\mathrm{ZrO}_{2}$ Mixed Oxides".

B.Sc. in Chemistry, at Bilkent University, Ankara, Turkey was awarded in June 2003. Thesis title: "Preparation and Characterization of Tetragonal Sulfated Zirconia Promoted with Iron(III) and Manganese(II)".

\section{Awards \& Honors}

Honors, Scholarships and Medals

2009: Fellowship of GCOE program for visiting researcher, Tokyo Institute of Technology, Tokyo, Japan.

2005-2009: NWO (Netherlands Organization for Scientific Research) Ph.D. Fellowship under VICI program (Innovational Research Incentives Scheme), University of Twente, the Netherlands.

2003: Fellowship of Max Planck Society for visiting researcher, Fritz Haber Institute, Berlin, Germany.

2003-2005: Full Graduate Scholarship (around 25,000 \$ annually), including tuition, monthly stipend and accommodation, Department of Chemistry, Bilkent University, Ankara, Turkey.

1999-2003: BANSIAD's University scholarship for undergraduates, Bandirma, Turkey.

1998-2003: Full Undergraduate Scholarship (around 25,000 \$ annually), including tuition, monthly stipend and accommodation, Department of Chemistry, Bilkent University, Ankara, Turkey. 
1996-1998: Ministry of Education's Scholarship, Turkey (Ranked $6^{\text {th }}$ among about 80,000).

\section{Experience}

Working:

2009: Researcher, Energy Phenomena Laboratory, Department of Mechanical and Control Engineering, Tokyo Institute of Technology, Tokyo, Japan. Researched on "Gas to liquid process in plasma microreactors" under supervision of Prof. Ken Okazaki and Dr. Tomohiro Nozaki.

2005-2009: Teaching and research assistant, MESA+ Institute for Nanotechnology, University of Twente, Enschede, the Netherlands.

2003-2005: Teaching and research assistant, Laboratory for Advanced Functional Materials, Institute of Materials Science and Nanotechnology, Bilkent University, Ankara, Turkey.

2003: Researcher, Department of Inorganic Chemistry, Fritz Haber Institute of Max Planck Society, Berlin, Germany. Researched on "Preparation and characterization of $\mathrm{Fe}$ and $\mathrm{Mn}$ promoted sulfated zirconia catalyst for n-butane isomerization" under supervision of Prof. Robert Schlögl and Dr. Friederike Jentoft.

2002: Intern, D.Y.O Paint and Varnish Co., Izmir, Turkey. Worked in Quality control and research and development departments for car paints.

Teaching:

2007: MESA+ Institute for Nanotechnology, Enschede, The Netherlands, Teaching Assistant "AIO network Analytical Chemistry Courses". Demonstrated experiments on microreactors and microfluidic devices.

2006-2008: Department of Advanced Technology, University of Twente, Enschede, The Netherlands, Teaching Assistant "Lab-on-a-Chip Project". Developed and oversaw microfluidic experiments, and graded lab reports.

2003-2005: Department of Chemistry, Bilkent University, Ankara, Turkey, Teaching Assistant - CHEM 342 "Inorganic Chemistry Laboratory II ORGANOMETALLICS". Lectured students, graded lab reports, developed and oversaw experiments.

2003-2005: Department of Chemistry, Bilkent University, Ankara, Turkey, Teaching Assistant - CHEM 341 "Inorganic Chemistry Laboratory I - SOLID STATE CHEMISTRY". Lectured students, graded lab reports, developed and oversaw experiments.

\section{Personal}


Membership:

2009 - present: Member, American Chemical Society (ACS)

2008 - present: Member, IEEE Nuclear and Plasma Sciences,

2007 - present: Member, International Plasma Chemistry Society

Instruments:

4 years hands-on experience in class 100 cleanroom facilities of MESA+ Institute for Nanotechnology:

4-point resistive measurement, Wet oxidation, Bosch etching, anodic bonding, deposition of thin films by e-gun evaporation, plasma sputtering, electrochemical plating, photolithography, wet etching of glass and silicon, PDMS micromolding, surface profile measurement with Dektak and Ellipsometry, dicing wafers, EDX (Energy dispersive X-Ray) analysis, HR-SEM (Scanning electron microscopy) and TEM (transmission electron microscopy) analyses, KOH etching, XRD diffractometry, $\mathrm{XRF}$ analysis, etching with powder blasting, microfluidic interface and connections.

6 years hands-on-experience on catalyst characterization and process analytics:

FT-IR Spectroscopy, XRF spectroscopy, XRD of powder and thin films, BET surface analysis and porosimetry, UV-Visible Spectrometry, GC (Gas chromatography), GCMS (Gas chromatography and mass spectrometry), MS (Mass spectrometry), OES (Optical Emission Spectrometry), Raman spectroscopy, TPR and TPD (Temperature programmed reaction and desorption) techniques, TG-DSC analyses (Thermogravimetry and differential scanning calorimetry)

\section{Professional Courses:}

Summer School on Surface Reactivity and Catalysis, 2006, Aarhus, University of Aarhus, Denmark.

Winter School on Fundamentals of Nanotechnology, 2006, Enschede, University of Twente, the Netherlands.

Summer School on Bionanotechnology, 2006, Munster, University of Munster, Germany.

Summer School on Plasma Physics, 2006, Bad Honnef, Germany.

Summer School on Plasma Chemistry for Materials Processing, 2007, Kyoto, University of Kyoto, Japan.

Concepts of Chemical Engineering for Chemists, 2007, London, University College of London, England.

Course on Intellectual Property and Valorisation, 2007, Nijmegen, the Netherlands.

Course on Microplasmas: Basics and Applications, 2007, Tainan City, Taiwan.

\section{Languages:}

Native in Turkish, proficient in English, basic in German, Dutch and Japanese. 


\section{Computer:}

JAVA, Matlab, CHEMKIN, CFD-ACE+, HTML, Microsoft Office 2003, Adobe 7.0, Corel Suite 11, Chemdraw 7.0, Origin 6.1.

Sports \& Arts:

Soccer, basketball, swimming, water polo, reading, movies, travelling.

\section{REFERENCES}

Dr. J. G. E. (Han) Gardeniers, Professor in Faculty of Science and Technology (TNW), MESA+ Institute for Nanotechnology, University of Twente, Enschede, the Netherlands, j.g.e.gardeniers@utwente.nl, +31-(0)53-489 4356 (Ph.D. supervisor)

Dr. Leon Lefferts, Professor in Faculty of Science and Technology (TNW), MESA+ Institute for Nanotechnology, University of Twente, Enschede, the Netherlands, 1.lefferts@utwente.nl, +31-(0)53-489 2858 (Chemical engineering collaborator).

Dr. Ken Okazaki, Dean of Engineering Faculty, Professor in Department of Mechanical and Control Engineering, Tokyo Institute of Technology, Tokyo, Japan, okazakik@mech.titech.ac.jp.

Dr. Sefik Suzer, Head of Chemistry Department, Professor, Bilkent University, Ankara, Turkey, suzer@ffen.bilkent.edu.tr.

Students I Supervised:

1. Alfons W. Groenland, a.w.groenland@utwente.nl, +31 53489 2645, (now a Ph.D. Candidate at the University of Twente, Enschede, The Netherlands).

M.Sc. Thesis (cum laude) title: Hot tips for chemistry: development of a carbon nanotube based field emitter array for plasma chemistry on a chip.

2. Masahiko Nakase, (now a M.Sc. in Nuclear Energy Technology department of Tokyo Institute of Technology, Tokyo, Japan).

B.Sc. Thesis title: Development of gas to liquid process for partial oxidation of methane in plasma microreactors. 